\title{
An Archaeological Survey of the Radium Springs Area, Southern New Mexico
}

Thomas R. Hester

Center for Archaeological Research

Follow this and additional works at: https://scholarworks.sfasu.edu/ita

Part of the American Material Culture Commons, Archaeological Anthropology Commons, Environmental Studies Commons, Other American Studies Commons, Other Arts and Humanities Commons, Other History of Art, Architecture, and Archaeology Commons, and the United States History Commons

Tell us how this article helped you.

This Article is brought to you for free and open access by the Center for Regional Heritage Research at SFA ScholarWorks. It has been accepted for inclusion in Index of Texas Archaeology: Open Access Gray Literature from the Lone Star State by an authorized editor of SFA ScholarWorks. For more information, please contact cdsscholarworks@sfasu.edu. 


\section{An Archaeological Survey of the Radium Springs Area, Southern New Mexico \\ Creative Commons License \\ (c) (i) (8)}

This work is licensed under a Creative Commons Attribution-NonCommercial 4.0 International License 


\title{
AN ARCHAEOLOGICAL SURVEY \\ OF THE RADIUM SPRINGS AREA, SOUTHERN NEW MEXICO
}

\author{
edited by \\ Thomas R. Hester \\ with contributions by \\ Stephen L. Black, Joe] D. Gunn, Thomas R. Hester, James E. Ivey, \\ Paul R. Katz, Thomas C. Kelly and Erwin Roemer, Jr.
}

Center for Archaeological Research

The University of Texas at San Antonio

Archaeological Survey Report, No. 26 



\section{TABLE OF CONTENTS}

$$
\text { Page }
$$

List of Figures $\quad$ ii

List of Tables iv

Acknowledgements $\quad v$

I. Introduction 1

II. Research Design and Field Procedures 5

III. Environmental Setting 11

$\begin{array}{ll}\text { IV. Archaeological Background } & 19\end{array}$

V. Site Descriptions 29

VI. The Artifacts 47

VII. Interpretations, Predictive Mode1s and Recommendations 113

VIII. Appendices $\quad 135$

Appendix I--Notes on the Site Survey Coding Format, Radium Springs Survey 137

Appendix II---The High Lonesome Bead Cache 141

Appendix III--Trace Element Analysis of Obsidian Artifacts from the Radium Springs Area 173

IX. References 175 



\section{LIST OF FIGURES}

Figure

Page

1. The Radium Springs Survey Area 3

2. Views of Survey Procedures 9

3. Topography and Vegetation in Radium Springs Survey Area 12

4. Panoramic Views of Two Sites in Survey Area 32

5. Archaeological Site AR097 34

6. Views of Two Archaeological Sites in Radium Springs Area 38

7. Archaeological Sites in Radium Sprinģs Survey Area 41

8. Bifacial Artifacts 50

9. Projectile Points from Radium Springs Survey Area 52

10. Projectile Points from Radium Springs Survey Area 53

11. Cores and Driliss 56

12. Unifacial Artifacts 59

13. Miscellaneous Chipped Stone Artifacts 62

14. Ground Stone Artifact 64

15. Ground Stone Artifact 65

16. Ground Stone Artifact 66

17. Ground Stone Artifact 67

18. Ground Stone Artifact 68

19. Hammerstone and Mica-Schist Artifacts 70

20. Mica-Schist Artifact 71

21. Photomicrograph of Dri11 Tip from AR002 74

22. ET Paso Brownware Rim Sherds and Modified Sherds 83

23. Vessel Fragment 86 

Figure

24. Pottery Fragments

25. Textured Pottery 90

26. Mimbres BTack-on-White Boldface Sherds 92

27. Mimbres Black-on-White Pottery 94

28. Pottery Fragments. from AR072 and AR092 100

29. Pottery Intrusives in the Radium Springs Area 108

30. Physiographic Transect and Related Variables 126

31. Recursive Interaction Between Environment and Culture and Factors As Yet Unknown

32. Non-recursive Interaction 127

33. Ceramics and Flake Artifacts Recovered from AR095 143

34. Calcite and Shell Beads from AR095 144

35. Large Marine Pelecypod Beads from AR095 147

36. She11 Pendants and Tubular Beads from AR095 149

37. Shell Ornaments from AR095 151

38. Bead Cache from AR095 152

39. Partially Excavated Bead Cache 155

40. Cache Vessel Under Laboratory Excavation 156

41. Shell and Calcite Beads 157

42. Experimental Reconstruction of High Lonesome Beads 160

43. Strand Connector from AR095 161

44. Bead Frequency by Diameter and Thickness 165

45. Bead Frequency by Weight, Perforation Diameter, and Type
of Perforation

46. She11 and Stone Pendants from AR095 167 

LIST OF TABLES

Table

Page

1. Radium Springs Archaeological Survey

2. Types of Sites Found During the Radium Springs Survey

3. 1976 Radium Springs Survey Site Descriptions

4. Mean Areas of Certain Site Categories

5. Provenience of Lithic Artifacts, Radium Springs Survey

6. Radium Springs Ceramic Site Surface Densities

110

7. Pottery Type Temporal Spans and Archaeological Culture Phases

111

8. Distributional Analysis of Sites Found During Radium Springs Survey

9. Optimal Utilization Model

10. Site Density, Radium Springs Area

11. Cramer $V$ for Various Models

119

12. Rotated Principal Components Matrix for Environmental and Cultural Relationships in the Radium Springs Survey Area

13. Rotated Principal Components Results for Post-Laboratory Analys is

14. Rotated Principal Components Results for Post-Laboratory Analys is

15. Data on Pendants from AR095

16. Data for Bead Collection, ARO95 



\section{ERRATA}

Page 15. Third paragraph, line 2: "such" should be "some".

Page 21. Fourth paragraph, Tine 8: "hugh" should be "huge".

Pages 21 and 22 should be reversed.

Page 26. Third paragraph, 1ine 4: "1800" should be "1800s".

Fourth paragraph, Tine 3: "Espedjo" should be "Espejo".

Page 37 should begin with the following:

"Lithic Scatters

During the 1976 survey, eight lithic scatters were recorded (Table 2). The"

Page 55. Third paragraph, line 3: "weights" should be "weighs".

Page 86. Caption for Figure 23: "RX029" should be "RSO29".

Page 119. Line 9: "Table II" should be "Table 11".

Page 130. Under XIV in Table: "Tm" should be "T $n$ ".

Page 140. Line 2: "menbers" should be "members".

Line 5: "qreas" should be "areas".

Page 150. First line under Turquoise Bead Pendants:

"(Fig. 29)" should be "(Fig. 39)".

Page 158. First paragraph, 1ine 7: "baed" should be "bead".

Page 163. Fourth paragraph, line 4: "or" should be "of". 



\section{ACKNOWLEDGEMENTS}

Many people contributed to the success of the Radium Springs Archaeological Survey. Mr. Daniel C. B. Rathbun, District Manager, and Ms. Karen L. Way, District Archaeologist, of the Las Cruces District Bureau of Land Management (BLM), were most helpful in the orientation phase of the project. They provided written introduction to the ranchers in the survey area and a variety of useful literary source material, and made available to us BLM publications, maps, and their own special knowledge of the local geology, ecology, and archaeology. The help of Mr. Richard Meninger, contracting officer in the Bureau of Land Management's Denver office, in the administration of this project is greatly appreciated.

Mr. Stanley Adams of Salem, New Mexico, aided the project to completion through his vast knowledge of the survey area, and his invaluable contribution in the search for and the staking out of the survey sections. He also graciously provided camping facilities for the survey team at his San Andres ranch. Mrs. Vicki Adams' cooking boosted the morale of the survey team. Mr. Jack Harkey and his wife, Chris, of Carrizozo, New Mexico, contributed to our efforts by providing many miles of four-wheel-drive transportation.

Field director for the project was Col. Thomas C. Kelly, Research Associate of the Center for Archaeological Research.

The survey crew, all graduate-level archaeologists, consisted of crew chiefs Stephen Black and Erwin Roemer, and crew members Michele Nicklow, Roger Filson, Robert Wilkerson and Steve Vol1mer. They walked more than 1600 miles in 26 days over terrain that varied from bad to impossible with the weather ranging from burning heat to snow.

Dr. Joel D. Gunn, James Ivey, and Lynn Highley handled the computer programs. Thomas Kelly, Stephen Black and Erwin Roemer conducted the laboratory analysis, microwear studies, and photography, and helped prepare many sections of the report. Editing of chapter drafts and overal1 supervision of the project were handled by Dr. Thomas R. Hester, Dr. Joel D. Gunn and Dr. Paul R. Katz.

Kathy McCauley, the secretary of the Center for Archaeological Research, deserves special recognition for her outstanding support of the survey crew in the field. She acted as logistics officer, communications center and paymaster. Jack D. Eaton, Center Research Associate, also devoted many hours to logistical and administrative tasks.

We also extend our thanks to Dr. Michael Whalen (The University of Texas at El Paso) for sharing his knowledge of the regional ceramic traditions with us.

Among the staff and administrative units at The University of Texas at San Antonio, we are grateful to: William Stern (Budget Officer), Everitt M. Mahon 


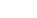


(Vice-President for Business Affairs) and Joe Powe11 (Director of Accounting) for their aid in handling the budgetary aspects of this project; Barbara Johnson and Gregory Milliger (Purchasing Division), Bob Smith (Printing Division), David Barrera, Nancy Reid and John Poindexter (Office of Instructional Services), the Computer Center staff, Dr. Richard McGehee (geologist, Division of Earth and Physical Sciences), and the University administrative officials who, in a variety of ways, supported this research (Dr. Peter T. Flawn, President; Dr. R. E. W. Adams, Dean of the College of Humanities and Social Sciences; and Dr. Thomas C. Greaves, Director of the Division of Social Sciences).

Finally, we are very appreciative of the typing staff who prepared this report: Jeanette Burch, Diana Netardus, Janette Schott, Margie Pyka, Rowena Archer and Margie Benke, administrative assistant to Dean R. E. W. Adams. Proofreaders for this report were Wanda Kaufman, Lynn Highley and Margarita A. Vazquez. 



\section{INTRODUCTION}

Thomas R. Hester

During October and November 1976, the Center for Archaeological Research of The University of Texas at San Antonio carried out an archaeological survey of the Radium Springs area in southern New Mexico (Fig. 1). This survey was conducted under the terms of a contract (YA-512-RFP6-80) between the Center and the Bureau of Land Management (BLM). Dr. Thomas R. Hester, Director of the Center, was Project Administrator, and Dr. Joel D. Gunn and Dr. Paul R. Katz served as Principal Investigators. Fieldwork was under the supervision of $\mathrm{Dr}$. Gunn, with direct field responsibilities handled by Col. Thomas C. Kelly, Research Associate of the Center. Contract Officer for the BLM was Richard Meninger (Denver), and the Contract Officer's Authorized Representative was Karen L. Way (Las Cruces).

The Radium Springs survey was initiated because the BLM desired information on the cultural resources of the region for inclusion in the "Radium Springs Geothermal Leasing Environmental Analysis Record." Thus, the survey was designed to provide an assessment of cultural resources within selected areas owned by the government. A major objective of the fieldwork was to provide the BLM with a statistically valid estimate of cultural resource densities within various environmental zones in the project area.

The Center prepared, and submitted for BLM approval, a technical proposal outlining the goals of the archaeological survey (this was sent to Mr. Meninger on September 15, 1976). The research and sampling design outlined in that proposal (see Section II of this report) followed closely the specifications set forth in Section $F$ of YA-512-RFP6-80, pages 22-25. In genera 1, the specifications called for an intensive survey of a minimum of 32 squaremile sections of land controlled by the BLM. The sample units were to be drawn by a stratified random sampling procedure, designed at a $10 \%$ level, with regional applicability in southern New Mexico. In addition, a thorough literature review was also required. Specific field survey requirements were set forth by the BLM, and a set of criteria was provided for the documentation of sites.

The Center's efforts were, we believe, successful in achieving those objectives set forth by the BLM. In actuality, we were able not only to accomplish the required survey goals, but also to survey intensively one additional squaremile section and to record a series of six important sites lying outside the boundaries of the sampling units specifically chosen for field study. Our literature survey involved not only published materials but also the study of unpublished notes and manuscripts on file at the Las Cruces BLM office, The University of Texas at El Paso, and other institutions. If it was felt that certain published or unpublished items would be useful to future researchers working in this region, even if we did not specifically cite them in the text of this report, they were included (and appropriately marked) in the bibliography (see Section IX).

This report contains the results of the Radium Springs archaeological survey. It represents a collaborative effort, in both the fieldwork and analys is 
phases, involving many of the staff members of the Center. Some research initiated during this project, such as trace element analysis of obsidian artifacts (see Appendix III) and further studies of she11 species found at one site, are not yet complete; however, they should represent substantial contributions to the archaeology of the region when published at a later date.

The reader will note that we have not included detailed site locations or site maps for the Radium Springs area (Fig. 1 provides an outline of the area in which sample sections are located). This has been done to prevent, as far as possible, the acceleration of relic-collecting and pothunting in the area. Many of the sites had been extensively surface-collected prior to the visit of the survey team, who noted potholes and other evidence of uncontrolled excavation at some of the larger sites. Archaeologists working in southern New Mexico will find site survey forms, USGS maps, a table of UTM coordinates for sites, and other locational information on file at the Museum of New Mexico (Santa Fe); duplicates are also retained at the Center for Archaeological Research. This arrangement for the deposit of detailed site locational data has been worked out with the BLM Las Cruces office (Danie1 C. Rathbun, letter to Thomas R. Hester, January 3, 1977). 


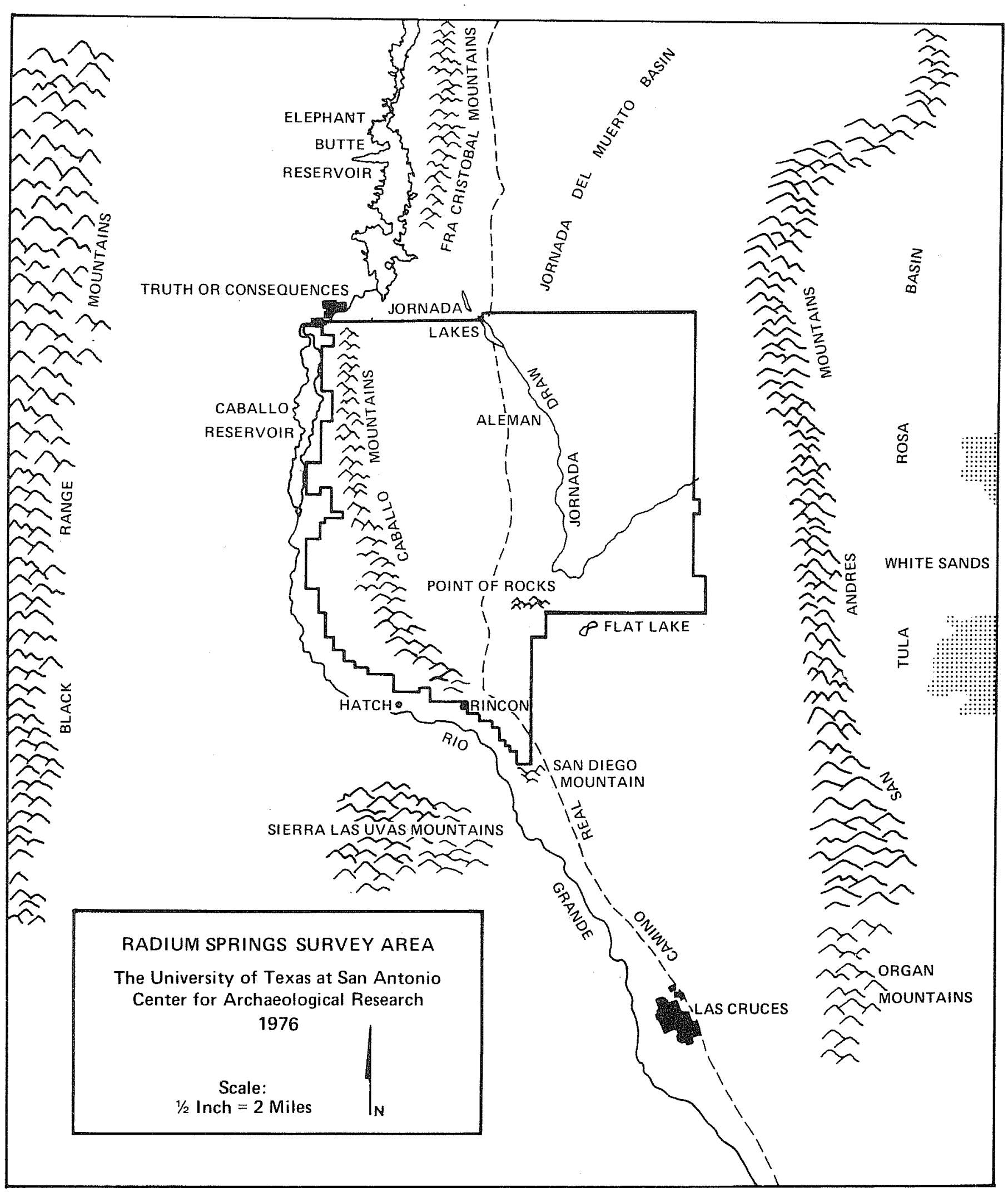

Figure 1. The Radium Springs Survey Area. Approximate boundaries of the survey area indicated by bold black lines. 



\section{RESEARCH DESIGN AND FIELD PROCEDURES}

Joel D. Gunn, James E. Ivey and Thomas C. Kelly

Sampling and Survey Technique

Bureau of Land Management specifications (YA-512-RFP6-80) called for the drawing of a $10 \%$ stratified random sample from which $5 \%$ would be surveyed within the 640 BLM-controlled sections in the Radium Springs project area (BLM Las Cruces District 3). These specifications were successfully met, with only some minor alterations as discussed later in this chapter.

Stratification of the samples was based on two models of the study area. The first is an ecological-physiographic zonation based on topographic and vegetation maps. The second is locally held knowledge of the distribution of cultural materials in the study area derived from resident informants. The ecological-physiographic data are most important to the sampling distribution and will be discussed first. Adjustments in the sampling distribution on cultural considerations are a secondary level of stratification and involve minor alterations in the pre-established zone concept.

The sampling method employed during the project was a "disproportionate stratified random sample" (Mueller 1974:32). In addition to utilizing this sampling strategy, the field crew conducted its fieldwork in accordance with the "Field Survey Requirements" outlined on pages 23-25 of Section F of YA-512RFP6-80. To facilitate research and sampling design, and to speed the processing of the field data, the crew used a specially developed form designed for computer coding (Appendix I).

After a preliminary literature review, and a review of physiographic and ecological criteria for the study area, we divided the area into four environmental zones:

Zone I: Zone I is defined by the 5003-foot contour line above sea level. Within Zone I the land starts to rise eastward toward the San Andres Mountains. Vegetation begins to grade toward broadleaf deciduous woodland.

Zone II: Zone II is defined on the east by the 5003-foot contour line and on the west by the foothills of the Caballo Mountains. It is an intermontane valley called the Jornada del Muerto. The vegetation is primarily grama grass with shrubs and dwarf shrub forms. Some areas of the valley floor are over $50 \%$ sand.

Zone III: Zone III is the foothil1s and highlands of the Cabal1o Mountains. It is bordered on the west by the Rio Grande Valley. The vegetation is sub-humid grassland, primarily grama grass with some broadleaf evergreen.

Zone IV: Zone IV is in the Rio Grande Valley west of the Caballo Mountains. Vegetation is bunchgrass-oak in the northern section, grading to broadleaf evergreens and shrub forms in the south.

Drawing a sample of 33 square miles ( 32 square miles were required by the BLM contract) from the study area was complicated by the interspersion of privately- 
owned land into the midst of the predominantly BLM-owned 1ands. The following procedure was used. A map was traced from the one supplied in YA-512-RFP6-80 showing the boundaries of the area and the privately-owned lands within that area. To this map the boundaries of the four environmental zones as defined above were added. Next the survey units of one square mile each were numbered sequentially within each zone. Table 1 shows how the number of survey units to be surveyed were apportioned among the zones.

Once the survey units were apportioned, the units to be surveyed were selected using a table of random numbers. Before drawing the sections to be surveyed the design was altered slightly to tailor it to expected field conditions. While the adjustments are small, it was considered by the BLM and project archaeologists to be in the interest of cultural research to disproportion the sample in favor of areas of known cultural intensity. To assure scientific control those areas thought to contain fewer cultural materials were systematically sampled but on a less intensive scale.

Our model for disproportioning the sample was developed from the experience of local informants. Discussions with inhabitants of the project area revealed that they classify sites on the basis of size and age. About a half dozen sites in the Jornada del Muerto are considered to be large and are recognized on an individual basis. Small sites are not recognized as discrete entities but are known in clusters or concentrated areas of occupation. At our request, big sites were marked by local informants on maps with $x$ 's roughly commensurate with the size of the site. Concentrations were outlined as large areas.

In the local typology, the age of sites was judged on the basis of the presence or absence of ceramics. 01der, non-ceramic sites were believed to be close to the playas and lakes at the center of the Jornada. Younger ceramic sites, some with pithouses, were on the San Andres slopes.

Construction of the maps showed that most of the sites and concentrations of sites occur in Zone I and II with a notable concentration toward the south end of the San Andres Mountains, and outside the project area. In fact, most of the large sites are immediately adjacent to the study area to the south. To accommodate this pattern the sample was first disproportioned downward $10 \%$ in the Caballos and West Cabal10 Slopes zones and upward 10\% in the Jornada del Muerto and west San Andres Slopes. Table 1 displays the draws made for the various zones.

The amount of disproportioning is exactly quantifiable as either a negative or positive number of sections. The probability of a given section in the project area being selected for survey is modified to the extent that it is $10 \%$ less probable it will be selected in the western zones and 10\% more probable it will be selected in the east.

Since only $5 \%$ of the $10 \%$ sample was to be surveyed, selection of draws to be surveyed was done with the knowledgeable advice of our local informants. In the interplay between the table of random numbers, the archaeologists, and the informants, with the table guarded against a totally biased selection, the archaeologist advocated as wide a coverage as possible in the confines of the random sample, and each local informant advocated use of his or her experience as to site distributions. 


\section{TABLE 1}

RADIUM SPRINGS ARCHAEOLOGICAL SURVEY

Random Samples Stratified by Zones and Disproportioned Toward the East

Underscored numbers were surveyed.

Zone 1. 71 Sections, $11 \%$ Total, 7.04 Section +.704 Sections (+10\% Disproportion) $=7.744=8 \mathrm{Sec}$.

8 Random \#'s between 1 and 71 inclusive, wi thout replacement

$12 \underline{61} \quad 59 \quad 63 \quad \underline{50} \quad \underline{42} \quad \underline{15} \quad 62$

Zone 2. 332 Sections, $52 \%$ Total, 34.32 Sect. $+3.432(+10 \%$ Disproportion $)=$ $37.752=38$ Sections

38 Random \#'s between 1 and 332 inclusive, without replacement

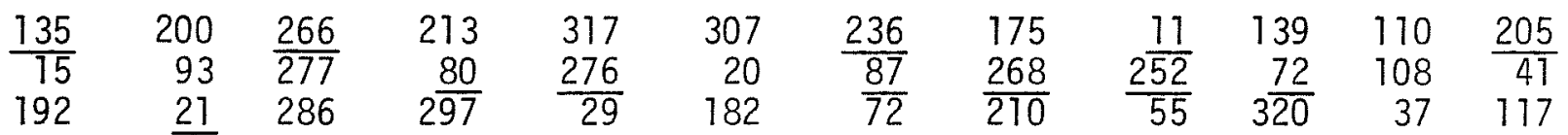

$\frac{82}{22} \quad \underline{217} \quad \underline{186} \quad 284$

$\overline{22}$ substituted for $\overline{20}$ which is partially private property

$\underline{259}$ substituted for 277

Zone 3. 190 Sections, 30\% Tota $1,19.8$ Sections $-1.98(-10 \%$ Disproportion $)=$ $17.82=18$ Sections

18 Random \#'s between 1 and 190 inclusive, without replacement

$\begin{array}{rrrrrrrrr}156 & 137 & 91 & 86 & 122 & 190 & 71 & 187 & \frac{51}{3} \\ \frac{58}{85} & 139 & \frac{64}{64} & 93 & 102 & 121 & 160 & \underline{114}\end{array}$

$\overline{85}$ substituted for 86 which was sheer shale mountain

$\underline{115}$ mistaken for 175 Zone II

Zone 4. 48 Sections, 7\% Total, 4.62 Sections - .462 (.10\% Disproportion) $=$ $4.158=4$ Sections

4 Random \#'s between 1 and 48 inclusive, without replacement

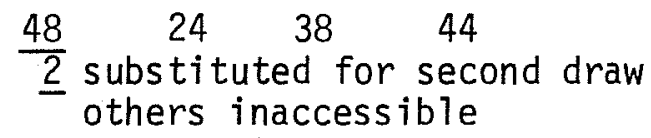


Some biasing factors lay beyond our control. The privately-owned property in the Jornada del Muerto is the better watered and more fertile land. Prehistoric inhabitants probably favored these areas and any clear understanding of their habits would require a survey of these areas.

\section{Survey Procedure}

Survey procedure was guided in its most general aspect by an agreement with the BLM to walk transects every 50 meters in the sections selected for survey. Funding was provided for 26 days of survey with a crew of nine persons.

Survey of each section was initiated by determining its location. While considerable difficulty was encountered in locating them, 30 of the 33 sections were located through the use of USGS section markers, two were tied to markers within one mile, and one at Apache Gap was laid out from map study and triangulation. Flags were placed every 0.2 mile around the section to guide the survey crew, usually by counting paces and following a Silva compass.

These flagging devices were fashioned from cane poles with plastic tap streamers or triangular flags (Fig. 2,a). Orange was found to be the best color. Blue streamers were added to corner and half-mile markers to insure their identification.

Once the section was laid out, the survey crew was lined up along a side of the section at 50 meter intervals. Each individual carried a cane pole with streamers, a police whistle, paper bags and site survey coding forms on a clipboard. Two persons carried CB radio transceivers. These were invaluable for communication relative to keeping the survey line straight and instrumental in the method adopted for site location recording.

The persons carrying the radio transceivers were located in the next-tolast position at each end of the line. One person on the end of the line carried a Brunton compass and informed the nearby transceiver bearer of the course of the line and the bearing of its length. Since the line was the instrument of measurement it was imperative that it be aligned with the relevant cardinal direction. The progress of the line was under the control of the line supervisor, who carried one of the radio transceivers and a section survey map.

As the line moved into a sweep the line supervisor was advised as to the status of the line by the compass person'and commanded the necessary corrections to maintain course by means of the transceiver. If an individual artifact was found the finder informed the line supervisor as to the transect, or tract, it was on and the nature of the artifact by calling out or by relay through the other transceiver. The line supervisor would then respond with a sweep sequence number and record it on the section survey map, at the point and row which the finder was reporting. The finder collected the artifact and if it was of an interesting nature, such as a projectile point, filled out a site survey coding form on it. If a form was to be filled out the finder blew the whistle twice and the line stopped for two minutes. At the end of two minutes the timekeeper would initiate the resumption of the survey. 


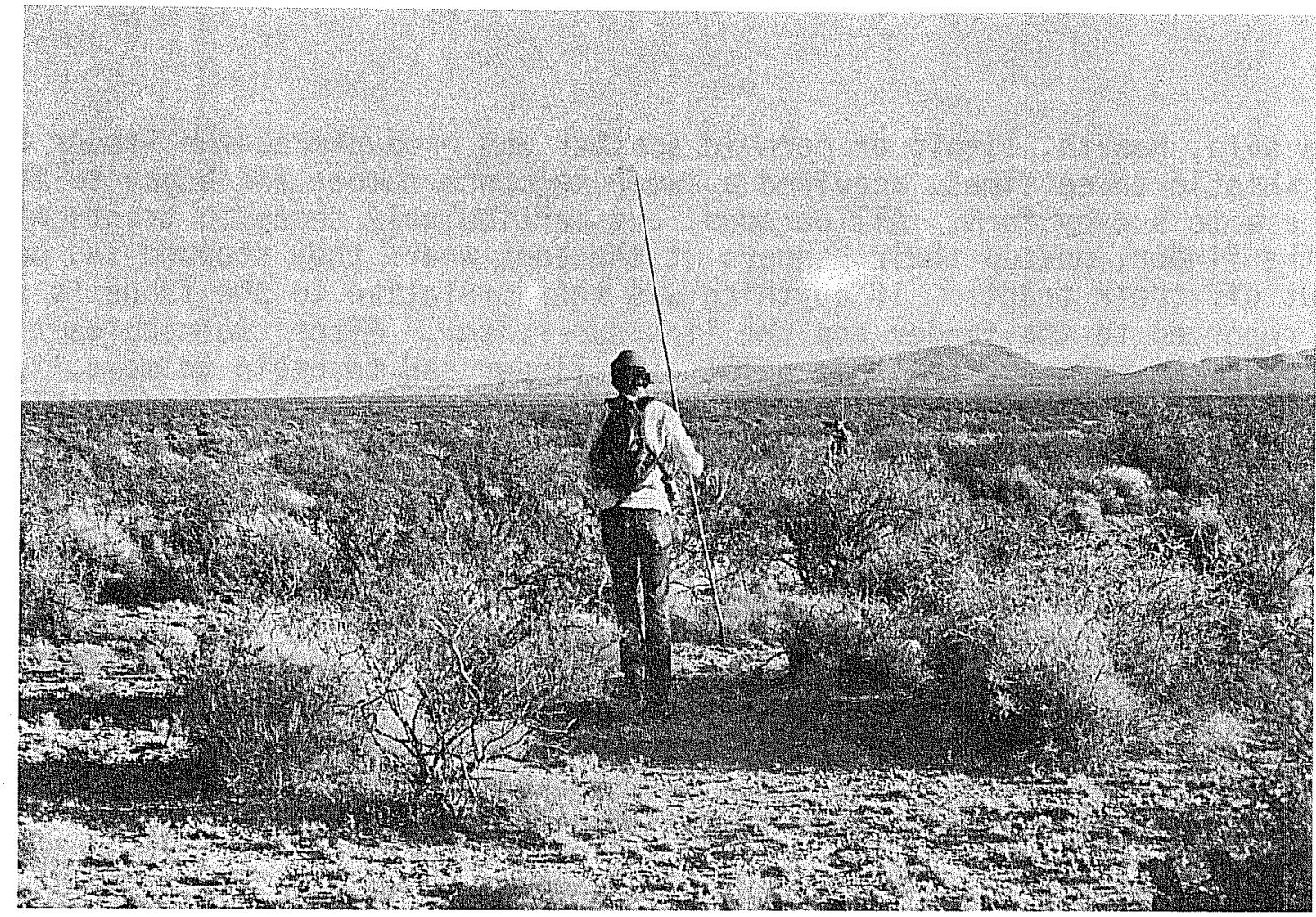

a

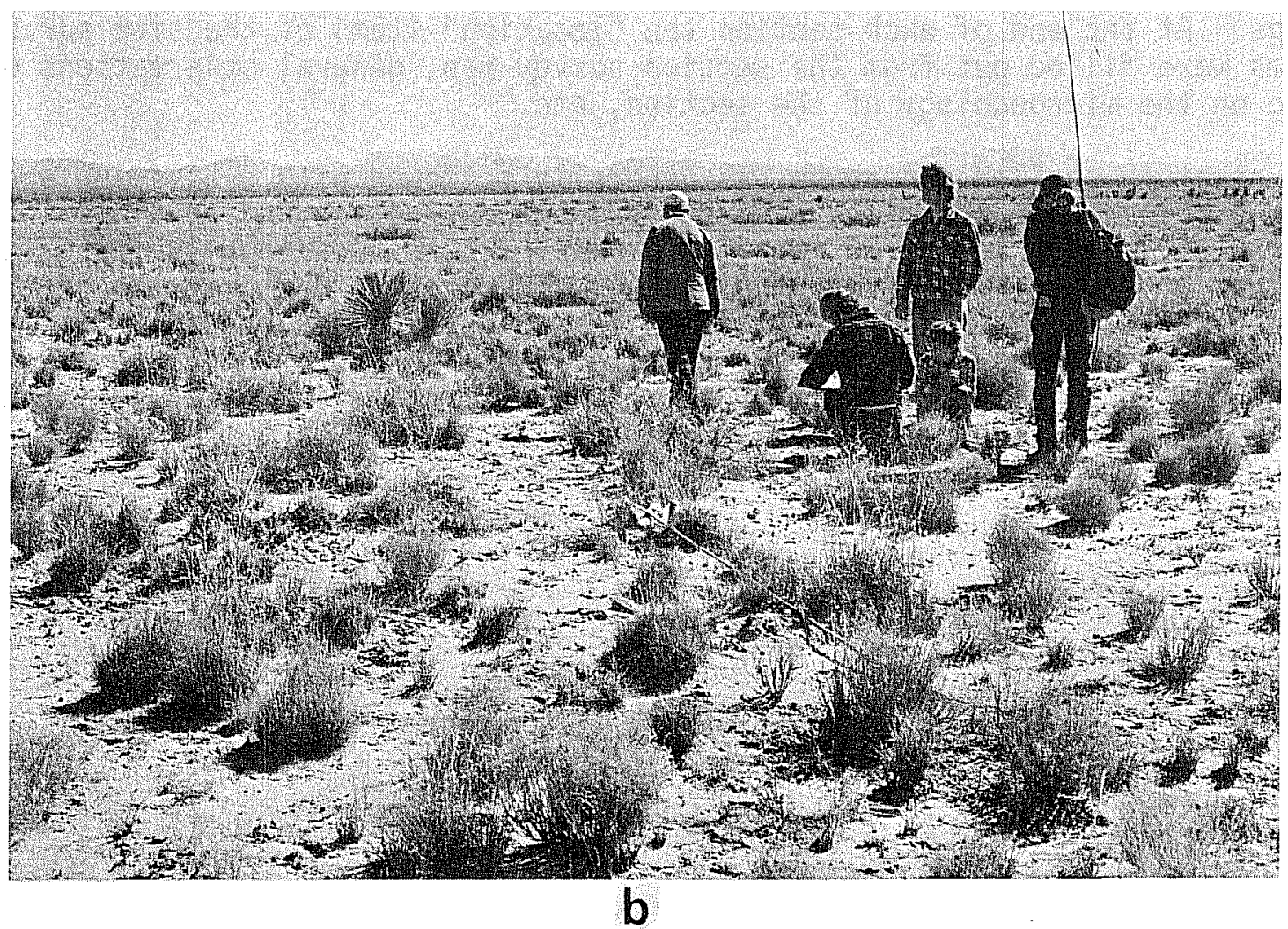

Figure 2. Views of Survey Procedures. a, survey crew in Jornada del Muerto (note walking flags and scrub brush vegetation); b, group consultation (looking east toward San Andres Mountains). 
If a site, hearth, lithic or ceramic scatter was encountered the finder blew the whistle three times, acquired a sweep sequence number and began to fill out a site survey form. All persons, but particularly those in tracts adjacent to the finder, posted their banners at the spot where they stopped and began to scout off their tracts. If anything was noted relative to the finder's site it was reported to the finder and the line supervisor. After two minutes the line was urged to move on. At this point, the finder had to begin to move, to record and to collect simultaneously. This was a challenging but not impossible task which usually became unnecessary as experience facilitated recording efficiency.

Some sites were larger than 50 meters. In this case a different mode of recording was used. The person on whose tract the site was first encountered would maintain the site survey form. All reporting of artifacts, artifact concentrations, hearths and so on were subsequently reported to the line supervisor who recorded locations on the section survey map with a standard set of symbols. No stops were made after the first site survey form was filled out. In this way the location and content recording of large sites was accomplished rapidly and systematically. Topography of larger sites was obtained later by overlaying site survey maps with enlargements of topographic sections.

At the end of each sweep the line supervisor called in the sweep sequence numbers in order of their issue, checked site survey forms for completeness, labeled bags, assigned trinomial site numbers and discussed the results of the sweep (Fig. 2,b). After five minutes the timekeeper informed the crew of the passage of time and the new tracts were stepped off, keyed to the preset .2-mile flags. At the end of each section the "location" items of the site survey forms were filled out from the section survey map, general observations were made on the microecology of the section, etc.

The strategy spelled out above was generally followed with gratifying success. Some problems were sometimes encountered with navigation and coverage. For instance, strong, localized magnetic anomalies were occasionally found to deflect Brunton compasses as much as $30^{\circ}$. On occasion the progress of the line was broken by dense vegetation which would not allow passage. Normally, however, the terrain was passable and the vegetation open enough to allow the required coverage. Checks by the field supervisor indicated that few, if any, sites were missed by these procedures. 


\section{ENVIRONMENTAL SETTING \\ Stephen L. Black}

Topography and Geology

The Radium Springs Project survey area is in the Southwestern United States Basin and Range physiographic province. The survey area borders or includes four major physiographic features: the Rio Grande Valley, the Cabal10 Mountains, the Jornada del Muerto basin or plain, and the San Andres Mountains. These four physiographic features or major environmental gradients run roughly north to south. They have long played an important role in man's occupation of the area. Fig. 3 provides two views of the area.

The Rio Grande is the major drainage system for much of the state of New Mexico. Prior to construction of dams along its course, the Rio Grande Valley was subject to periodic flooding which deposited and reworked silt, sand, and gravel enriching the valley soils. Today much of the valley is under intensive cultivation and irrigation. The valley produces large quantities of fruits, nuts, vegetables, and cotton. Caballo Reservoir forms the western boundary of the northern half of the survey area. The Caba110 Mountains rise abruptly on the east side of the Rio Grande, preventing the formation of a wide floodplain on the east side of the valley. The Caballos also served to route the river, creating a long bend.

The Caballo Mountains lie almost entirely within the survey boundaries. The Caballos (also known as the Sierra Caballos, the Spanish Mountains, and the Horse Mountains) range from four to 10 miles wide and run north to south for approximately 35 miles. Elevations range from 4400 to 7554 feet. The Caballos are very rugged; the lack of heavy vegetation has left the Caballos severely eroded and covered with many deep arroyos and steep slopes. A series of peaks range from Caba110 Cone (6091 feet) in the northern end of the range to Brushy or Timber Mountain (7554 feet) at the southern end. The Caballos can be divided into a northern and southern ridge by Palomas Gap (4760 feet). Palomas Gap was a major historical route (undoubtedly of importance in prehistoric times as we11) crossing the Rio Grande and providing access to Jornada del Muerto prior to construction of Caballo Reservoir.

Structurally the Caballo Mountains are a tilted fault block with a gentle east slope bisected by many small arroyos and a steep western face which drops to the Rio Grande. Most of the range consists of various limestone and shale formations. Precambrian formations are exposed at the base of the western face. The Caballos are not minerally rich; however, small deposits of gold, lead, copper, and vanadium have been mined. Fluorspar mines active in recent decades are located in the northern end of the range.

The foothills of the San Andres Mountains form the eastern boundary of the survey area. The San Andres Mountains are six to 18 miles wide and 


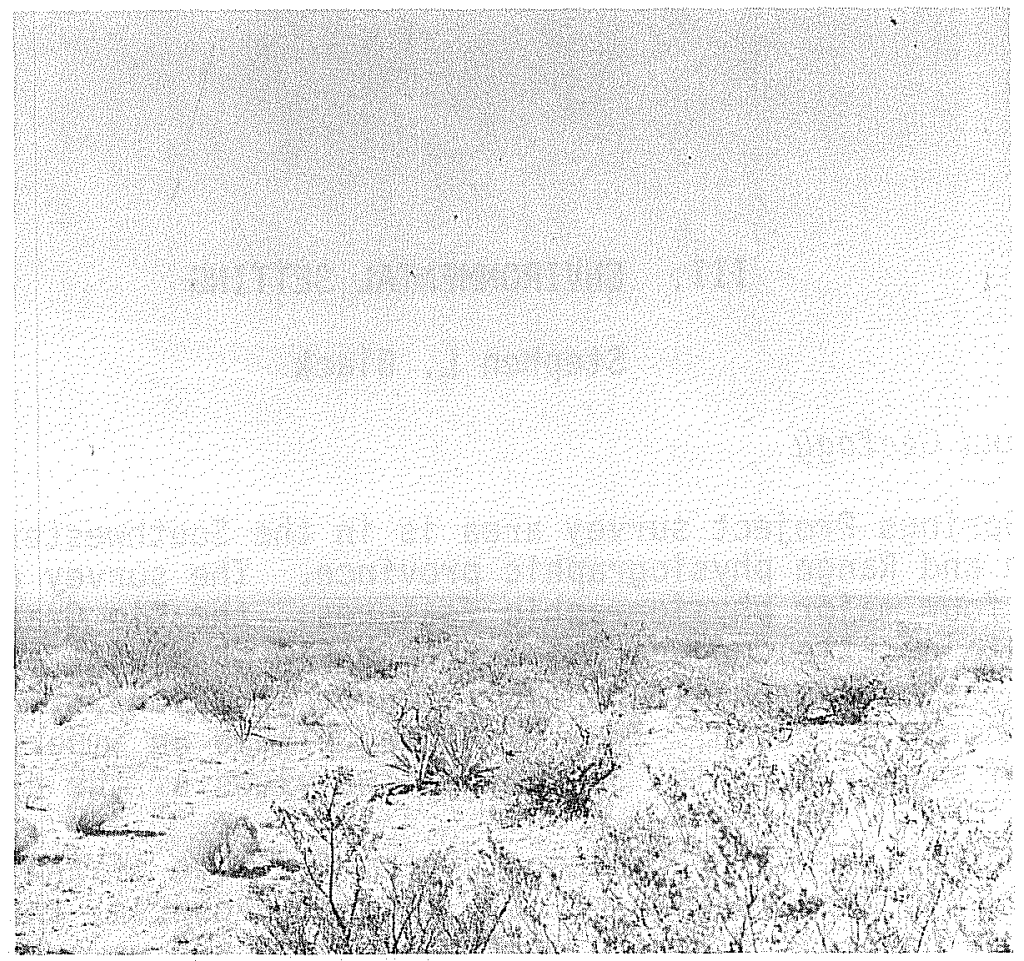

a

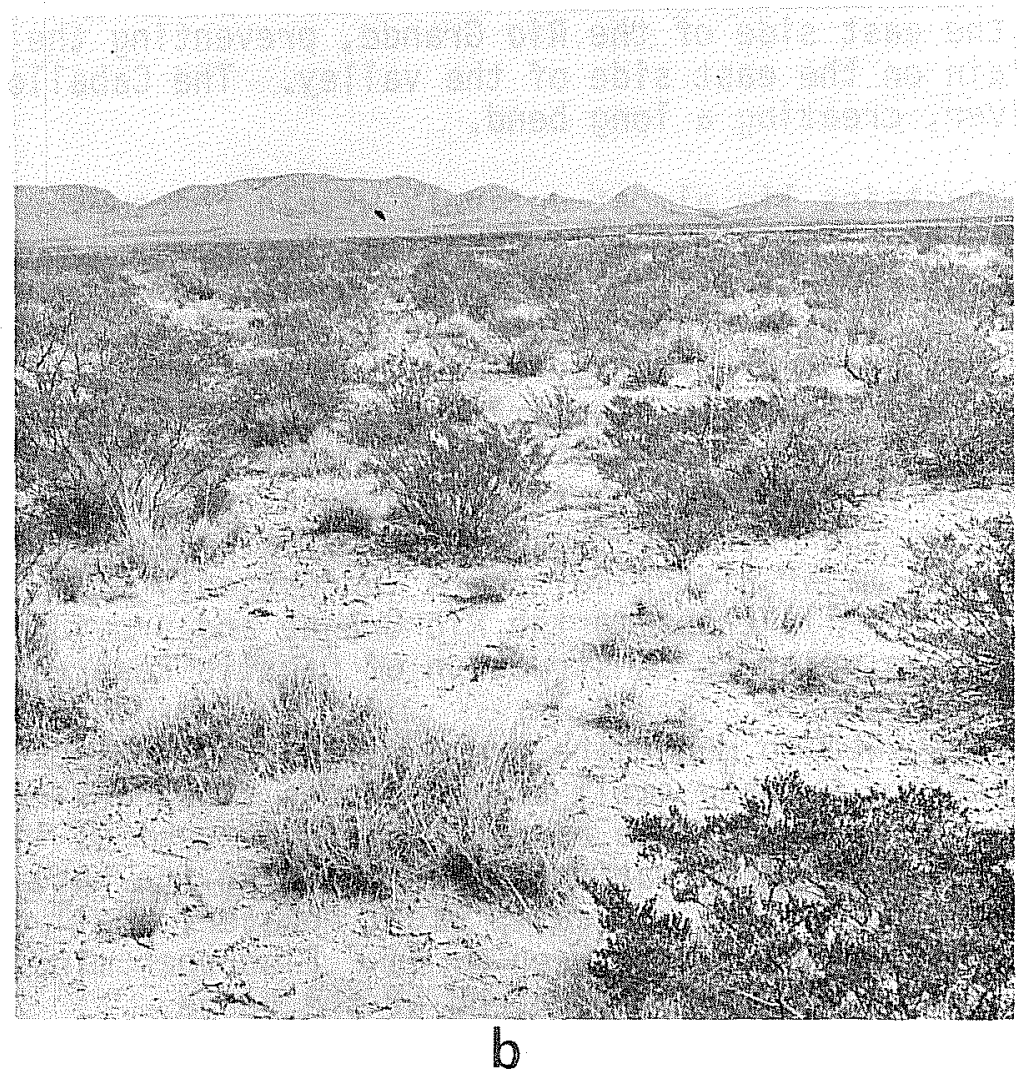

Figure 3. Topography and Vegetation in Radium Springs Survey Area. a, Facing west across Jornada del Muerto Basin from foothills of the San Andres Mountains (note creosote vegetation, grasses, yucca and rabbit bush); b, AR095, High Lonesome Windmill site. Beads scattered on surface in foreground. 
extend for approximately 80 miles. The San Andres range is a westward tilted fault block made up largely of sedimentary formations which dip westward under the Jornada Plain. The range has a gradual western slope and an abrupt eastern face, and divides the Jornada del Muerto Basin or plain on the west and the vast Tularosa Basin or valley on the east. The drainage divide falls close to the western edge of the range. This results in the majority of precipitation on the San Andres draining into the Tularosa Basin. Many smal1 arroyos dissect the west side of the range and empty into the Jornada Basin.

The San Andres Mountains range in elevation from 4600 to 8958 feet and offer more of a barrier to human travel than do the Caballos. Three peaks in the San Andres rise to more than 8000 feet: Greer Peak (8005), Salinas Peak (8958) and San Andres Peak (8239). The San Andres have more vegetation than the Cabal1os, but it is still rather sparse and erosion gives the mountains a rugged appearance. Human travel across the mountains would have been through one of the many passes at the heads of the major canyons. Major passes adjacent to the survey area from north to south are Cottonwood Canyon (6310 feet), Sulphur Canyon (5920 feet), Hembri110 Pass (5790 feet), Deadman Canyon (5740 feet) and San Andres Canyon (5350 feet).

The majority of the survey area lies between the Caballo Mountains on the west and the San Andres Mountains on the east in the large basin known as the Jornada del Muerto. The Jornada extends north to south 140 miles from the Bosque de Apache Grant (near Socorro) to the Dona Ana Mountains (near Las Cruces). It varies in width from 15 to 30 miles and in elevation from 4000 to 5000 feet. The Jornada de1 Muerto Basin is often referred to as a plain because of its flat character. The Jornada Basin actually has interior drainage with few small relief drainages into the Rio Grande at the southern and northern ends. In geologic terms the Jornada is "an asymmetrical syncline with the deepest part on the west side and with a southward plunge" (Kottlowski et al. 1956:74). This syncline has been filled with unconsolidated detritus eroding from the San Andres and Caballo Mountains which reaches a depth of over 300 feet (thickness). This alluvial fill grades from very coarse near the mountains to very fine near the center of the basin. Aeolian sand and clay deposits derived largely from the Rio Grande have contributed to the basin fill. The prevailing southwestward winds have deposited these aeolian sediments along the eastern side of the Jornada Basin, often taking the form of large sand dune ridges that have a distinct red hue.

Minor topographic features within the survey area include Point of Rocks, San Diego Mountains and several smaller hills all of which are volcanic or igneous plugs or intrusions.

water Resources

The Jornada del Muerto is quite renowned for its "waterless" character. Permanent water sources in the survey area are 1imited to the Rio Grande and a few springs, with the former undoubtedly the most reliable water source in the surrounding area. Heavy prehistoric and historic occupation 
along the Rio Grande Valley bears witness to this fact. Many writers have characterized the Jornada del Muerto as being completely without surface water, and while today this is generally true, it has not always been so. Along the center of the basin is a low drainage labeled Jornada Draw on modern maps. Jornada Draw is actually a series of depressions some of which are playas. During times of excessive rainfall these depressions fill up and become shallow lakes. Major playas in the survey area are Flat Lake and Jornada Lake or Laguna del Muerto. These large, essentially extinct playas have been known to hold water for several months of the year, a fact noted as recently as the 1920s. Evidence suggests that during cooler, wetter periods of the Pleistocene these playas were large lakes which held water year-round. These cooler-wetter intervals last occurred 8,000-13,000 B.P. and would have provided early inhabitants of the area with sufficient water resources (cf. Wendorf and Hester 1975). In addition to playas and the Rio Grande, several springs are known to have been active in the Caballo Mountains. McRae Canyon at the extreme northern end of the Caballos was the largest and most reliable of these springs and often attracted travelers. Occasional springs can be found in the San Andres Mountains in the large canyons which drain into the Tularosa Basin. Water or the lack of it must, of course, have played an extemely important role in prehistoric land utilization patterns within the survey area.

\section{Climate}

The climate of the survey area is typical of the Chihuahuan Desert: extremely variable precipitation, low humidity, high evaporation, extreme temperature ranges between day and night, and abundant sunshine. Precipitation averages eight to 10 inches annually within the survey area but varies locally and annually. A majority of the annual rainfall occurs during July-September in the form of localized torrential thunderstorms which cause a rapid runoff on sloping terrain and ponding in flat terrain and small depressions. Annual rainfal1 records kept at the Jornada Experimental Range, just south of the survey area, indicate an annual precipitation average (1915-1972) of 8.93 inches (Ares 1974). Annual averages range from 17.74 inches in 1941 to 3.03 inches in 1952. It is of interest to note that less than one-third of the annual averages fall within one inch of the 58-year mean. An average of $52 \%$ of annual rain falls during the July-September period. Periodic droughts, often lasting for several years, are well documented. During the 1951-1956 drought, annual rainfall averaged only 5-1/2 inches, of which only 2.8 inches fell during the critical July-September period. In short, rainfall in the survey area is sparse, localized and extremely variable.

Daily temperature ranges generally exceed $30^{\circ}$. Mean maximum temperature for July ranges from $80^{\circ}$ in the San Andres Mountains to $95^{\circ}$ in the Jornada Basin. Mean minimum January temperatures range from $22^{\circ}$ in the basin and San Andres Mountains to $28^{\circ}$ along the Rio Grande. Sunshine occurs $75-80 \%$ of the total possible hours. Relative humidity is usually very low, averaging $30 \%$ or 1 ess annually and ranging from $40-50 \%$ in the early morning hours to $15-30 \%$ during the afternoon. Winds are usually light but vary seasonally. The combined effect of low humidity, high afternoon temperature, and abundant sunshine results in an annual evaporation average of 89.45 inches, $80 \%$ of which occurs during the frost-free season. The average annual number of frost-free days ranges from 
200 to 220. Frost-free days cannot be interpreted as a growing season, as Buffington and Herbel (1965:142) point out, since "moisture conditions are such that normally growth occurs only from 90 to 100 days."

Considerable seasonal variation in climate is noted for the area. Winters are sunny with cool to warm days and cold nights. Snow occasionally falls in the area but normally melts on contact with the ground. Late winter and spring are normally the windiest with strong winds and gusts up to 25-35 miles per hour. When these winds occur the Jornada Basin is hazy with windblown loess. Summer brings hot afternoons and cool nights, very high evaporation rates and localized thunderstorms.

Prehistoric climatic conditions in the immediate area have not been carefully documented. However, such inferences can be drawn from surrounding areas. Wimberly and Eidenbach (1972) suggest that the climate in the adjacent Tularosa Valley has remained essentially the same for the past 4000 years. Climatic inferences prior to 4000 B.P. are not available in adjacent areas. Judge (1973), after reviewing a number of sources on paleoenvironments, concludes that the central Rio Grande area (approximately 100 miles north of the survey area) during Paleo-Indian occupation was cooler and wetter. It may be inferred that during Paleo-Indian times (ca. 8,000-13,000 B.P.) many of today's extinct playas in the survey area contained water.

Soils*

Detailed soil maps of the survey area do not exist. The soils of the Jornada Experimental Range have been mapped and provide the closest comparisons. Buffington and Herbel (1965) include a review of the Soil Conservation Service soil survey of the range and include 30 soil types, many of which have a very spotty distribution. Major types present on the range and occurring in the survey area include: Verhalen clay, Russler loam, Dona Ana complex soils, Banbar soils, Coppice duneland sands, Goldenberg sands, and Cacique loamy fine sand. Of interest, Goldenberg sands were extensively occupied by peoples who Buffington and Herbel refer to as "Pueblo Indians." Goldenberg sands are aeolian sands which take the form of large sand dunes and were deposited over piedmont soils. Goldenberg sand formations occur in the northeastern. part of the range which is adjacent to the San Andres Mountains. Similar sand formations occur within the survey area. In general, soils of the survey area range from rocky silty loams on alluvial fans adjacent to mountains to fin sands such as the Goldenberg and Coppice duneland sands which frequently form small to large dunes and ridges. Clays occur on and around playas, along the Jornada Draw, and are visible underlying sands in the cutbanks of many arroyos.

* Since this section was written, Gile (1977) has published additional data on the soils of southern New Mexico, just south of the study area. 
Fauna

Detailed studies of the survey area fauna are apparently lacking. The following partial list of common names includes fauna observed during the 1976 survey and serves only to indicate most common species present today: mule deer, antelope, jackrabbit, cottontail rabbit, badger, skunk, hawk, owl, quail, duck, dove, buzzard, roadrunner, rattlesnake, lizard, coyote and kangaroo rat. Fauna not observed but reported to us as being present in the area include: eagle, grey fox, bobcat, mountain lion (occasionally) and porcupine. Prairie dog towns were once quite extensive on the Jornada Plain, according to early travelers and surveyors. Desert bighorn sheep can be found just southeast of the survey area in the San Andres National Wildlife Refuge. Numerous aquatic species as well as migratory birds frequent the Rio Grande. Prehistoric fauna, especially during the Pleistocene, must have included many species no longer present in the area and many now-extinct forms. Bishop Cap Cave located 10 miles southeast of Las Cruces was the site of a questionable association of human bones with extinct Pleistocene fauna reported in 1929 (Davis 1969). Among species identified in cave deposits were extinct bison, sloth, horse, camel, cave bear and others dating prior to 8000 B.P. When cooler and wetter climatic conditions prevailed.

\section{Flora}

The vegetation of the survey area is typical of the lower and upper Sonoran biotic zones defined for the area by Bailey (1913). The Caballos and most of the Jornada Basin are characterized as lower Sonoran. The Point of Rocks and San Andres Mountains are typically upper Sonoran. The vegetation is generally sparse except along drainages and along the Rio Grande. Typical vegetation today consists primarily of desert scrubs (mesquite and creosote), cacti, yucca and short grasses. Considerable evidence suggests that domination of mesquite and creosote has primarily occurred within the last 100 years. Similar mesquite and thorny brush "invasions" have been noted in Texas, southern Arizona, and the Plains (cf. Bogusch 1952; Harris 1966; Reeves 1973). Early travelers generally described the Jornada Basin as a dry, grassy plain, but their descriptions of it varied considerably due to seasonal variations, frame of mind, and actual experience in the area, as the following selected quotes illustrate.

On August 1, 1840, Wislizeuus (quoted in Buffington and Herbel 1965:140) reported:

In the rainy season there is generally plenty of water on the Jornada.. a high plain in the elevation of from 4,000 to 5,000 feet above the seas, with dry, hard soil, tolerable grasses and an abundance of mesquite and palmillas [Yucca elata]. They later grow to a height of 10 to 12 feet.

Susan E. Wallace in 1888 (quoted in Little and Campbe11 1943) described the Jornada del Muerto with no small degree of poetic license: 
The portion I speak of appears to have served its time, worn out, been dispeopled and forgotten. The grass is low and mossy, with a perishing look--the shrubs, soapweed, and bony cactus withering like some grisly skeleton; the very stones are like the scoria of a furrace. You vainly look for the flight of a bird... no bee nor fly hums in the empty air; and save the lizard (the genius of desolation) and horn frog, there is no breath of Tiving things.

Stacy in 1857 traveled through the Jornada after rain had been falling, and his description (see Buffington and Herbel 1965:141) contrasts sharpiy with that of Mrs. Wallace:

Nothing could exceed the beauty of the country we traveled over this morning. The whole extent, as far as vision reached ahead, was a level plain, covered thickly with the most luxurious grass, and filled with beautiful flowers . . containing the greatest abundance of the finest grass in the world, and the richest soil here lying vacant, looked upon by the traveller with dread, because of its want of water.

Present-day vegetation of the survey area varies considerabiy, largely based on the availability of moisture. Vegetation along the Rio Grande is often dense with stands of cottonwood and willow trees. The adjacent Caballo Mountains with their steep rocky slopes are mostly sparse; creosote bush is the dominant species. Vegetation is somewhat thicker in and around the arroyos, small canyons and valleys of the Caballos and includes some thick grasses, tarbush, cacti, yucca, acacia and some mesquite. Mesquite is more common on sand dunes piled up against the western side of the Caballos. Similar vegetation is found on the steep lower slopes of the San Andres foothills. Canyons and valleys tend to be larger in the San Andres and they, as well as higher peaks, have a wider range of vegetation more typical of upper Sonoran. These include grasses, pinyon, juniper, willow, hackberry, mulberry, agave, mountain mahogany, sotol, oak and acacia. The Jornada del Muerto is no longer a grassy plain. Mesquite is the dominant, ever-increasing plant species. Vegetation patterns in the Jornada Basin include (1) mesquite sand dunes with Yucca elata, snakeweed and a few grasses in between; (2) low drainage areas, often quite broad, densely vegetated with thick tobosa grasses, black grama grass, tarbush, mesquite, acacia, allthorn, sumac, yucca and various cacti; and (3) playas and Jornada Draw, having black grama grass flats sparsely vegetated with Yucca elata and some tarbush. In general, mesquite increases in sand locales, especially sand dunes, creosote increases with slope, and grasses and vegetational variety increase in low drainages.

Excellent documentation of the relatively rapid change from grass to scrub bush occurring in the Jornada Basin as well as much of southern New Mexico is provided by two sources, Buffington and Herbel (1965) and York and DickPeddie (1969). Buffington and Herbel studied vegetation changes on the Jornada Experimental Range that have occurred since 1858. Comparison of vegetation patterns in 1858 to modern vegetation patterns is possible through the use of records made by the original Land Office Survey of 1858 which divided 
the land into sections. In 1858, good grass (black grama and tobosa) was present on an estimated $90 \%$ of the range. In 1963 good grass was present on less than 25\% of the range. From 1858 to 1963 the mesquite-dominated area increased tenfold. During the same time, creosote increased 18-fold. Tarbush increased until 1928, since which time creosote has invaded tarbush areas. It should be noted that while creosote and mesquite quickly and effectively eliminate grass cover, tarbush invades much more slowly and never completely chokes out grass. York and Dick-Peddie used similar methods (comparing land survey records to modern data) but on a much larger area--smal1 plots on transects across southern New Mexico. Their findings are much the same. Grass cover has been rapidly lost by invasion of mesquite and creosote. The question arises: how did it happen?

The possible factors discussed as causes of rapid scrub brush invasion are: overgrazing of cattle, climatic change, periodic droughts, suppression of grassland fires (cf. Reeves 1973) and seed dispersal caused by livestock (see Wells 1970 for further discussion). While many believe that during the Indian occupation of the Jornada del Muerto Basin the prairie was periodically burned (killing shrubs and allowing grass to take over), this has not been reported by any early travelers in the area and is considered an unlikely factor. Little climatic change has occurred in the area in the last several thousand years, much less in the last 100 years. Buffington and Herbel (1965:163) conclude that "seed dispersal, accompanied by heavy grazing and periodic droughts, appeared to be the major factor affecting the rapid increase of scrubs." York and Dick-Peddie offer a slightly different conclusion which is of direct archaeological significance. They observed the association of mesquite pockets noted in 1858 with "Indian campsites." They conclude: "The speed of recent occupation by mesquite may be attributed to the effects of cattle in the presence of ideal source pockets of mesquite around old Indian campsites" (ibid.:165). Buffington and Herbel (1965:162) also stated that "Indian activity contributed to the early formation of mesquite dunes before domestic livestock grazed on that area." Both studies ambiguously refer to "Indians" or "Pueblo Indians" without specifying the exact nature of sites but one suspects they refer to the easily recognized Mogolion ceramic sites in the area. York and Dick-Peddie (1969) and Buffington and Herbel (1965) suggest that mesquite dispersal may have been prompted by prehistoric use of mesquite as a source of food and firewood. 


\section{ARCHAEOLOGICAL BACKGROUND}

Stephen L. Black

\section{Previous Archaeological Investigations}

The archaeological resources of the survey area have not been carefully studied up to the time of the 1976 fieldwork. Although many sites have been recorded along the Rio Grande River within and adjacent to the survey area, only one site description (of a petroglyph site) has been published (Davis 1976); no sites have been excavated. Several Mogollon villages have been partially excavated in the general vicinity (Lehmer's work at Las Tules 1948, the Rincon Village dug by Hammack 1962, and the Hatch Site excavated by Schaafsma 1974). A brief description of these excavations wil1 be provided; for a more detailed summary see Marshall (1973). A search of the literature and files of the Museum of New Mexico revealed that no sites had been previously excavated and reported in the survey area. Available published and unpublished accounts of archaeological resources are very spotty and generally inconclusive. The following descriptions of work done in the area indicate that much remains to be done before the area will be understood archaeologically.

Lehmer set up a base camp in Las Cruces in 1940 and spent two years surveying and excavating sites while defining what he termed the Jornada Branch of the Mogolion (Lehmer 1948). He spent six weeks surveying "the Las Cruces district and the lower Tularosa Basin, with a few casts over a wider area" (Lehmer 1948:9).

Lehmer (1948:71) noted "Mimbres villages occasionally occur in and to the east of the Rio Grande Valley between Hatch and Caballo. In these, Mimbres black-on-white wares dominate decorated wares, and these are house mounds, typical ruins of Mimbres Phase Pueblos."

Lehmer did excavate a Mesilla Phase village at Las Tules which is located on the Rio Grande terrace above the floodplain near Las Cruces. He found two types of pithouses at Las Tules--rectangular pithouses with entrance ramps and circular pithouses with no visible entryways. One structure, house 5, was larger than other circular pithouses and had a $45-\mathrm{cm}$ bench around the walls with two central postholes. Lehmer suggested that the house could have been a ceremonial structure. In addition, two smaller structures were interpreted as a possible storage pit and a sweathouse. Four recognizable storage pits were uncovered. El Paso Brown was the dominant $(>85 \%)$ ceramic type found at the site. The remaining sherds were Mimbres Blackon-White, Mimbres Corrugated, San Francisco Red and Alma Plain which Lehmer says are "all native to the Mimbres Phase." Both Mimbres Boldface and Mimbres Classic were present in the collection. Few artifacts other than potsherds were found at Las Tules. These include sherd scrapers, clay pipes, Olivella beads, Glycymeris bracelets, a bone ring, finely chipped small projectile points, scrapers, one biface, oval and trough metates, manos, pestles and polishing pebbles. Lehmer (1948:13) states that Las Tules "is a typical Mesilla Phase site." Lehmer also tested a cave (La Cueva) in the Organ Mountains in which he found ceramics to a 
depth of several meters in the talus slope. Due to the disturbed nature of the cave his results were inconclusive.

In 1962 Hammack excavated a pithouse village near Rincon as part of the highway salvage work along Interstate 25. The Rincon village, LA 5599, was situated on a flat, mesquite-covered mesa overlooking the Rio Grande Valley approximately one mile east of San Diego Mountain, just outside the southern boundaries of the Radium Springs survey. Hammack uncovered six pithouse structures of which he thoroughly excavated four. LA 5599, like Las Tules, had both rectangular and circular pithouses. Structure \#4 was a relatively large (18.3 feet in diameter) circular pithouse which Hammack said was probably a communal structure. One small structure may have been a sweathouse. Other features at the site included three trash pits and one storage pit. Of the ceramics recovered, $88 \%$ were El Paso Brownware. The remaining ceramic types (in order of declining frequency) were Mimbres Boldface, Mimbres Classic, Three Circles Red-on-White, Starkweather Smudged Decorated, Jornada Brown and San Francisco Red. Other artifacts found included projectile points, bifaces, scrapers, a drill, flake tools, gravers, choppers, paint-grinding palettes, abraders, hammerstones, cores, metates, manos, pestles, discoidal beads, a piece of worked turquoise, an olivella bead and a Glycymeris pendant. Hammack interprets LA 5594 as a Capitan Phase site based on its location. All other criteria--ceramics, architecture, and artifact assemblage--indicate that LA 5599 is very similar to Las Tules. In our evaluation, LA 5599 is most likely a Mesilla Phase village. Of interest, Hammack found a cache of metal arrow points on the surface of the site which can probably be attributed to the presence of Apache in the area.

In 1964 Schaafsma (1974) excavated another pithouse site known as the Hatch site (LA 3135). The site was excavated as part of salvage work along Interstate 25. The Hatch site is situated on the east side of the Rio Grande on a gravel terrace opposite Hatch, New Mexico. It is Schaafsma's opinion that the Hatch site has three components: an Archaic or "Cochise" component, a Mesilla Phase Jornada Mogollon component and a Dona Ana Phase Jornada Mogollon component. The Mesilla Phase houses were grouped at the north end of the site and the Dona Ana Phase houses at the southern end. Despite noting these distinct groupings, Schaafsma (1974:5) states that "the structures are unrelated to each other in a formal pattern, and are all scattered in such a manner as to indicate there was no village or house organization." Marshall's (1973) summary (based on an uncompleted manuscript contains much information not available in the 1974 report. The difficulties encountered when 10 years elapsed between excavation and analysis are apparent. The Archaic component of the site consists of scattered lithics collected on the surface and includes a heavy dart point. The Mesilla Phase component at the site consists of three circular pithouses which were excavated and apparently 14 other pithouses of which only two were tested. Ceramics from the Mesilla Phase component are as follows: Alma Plain (93\%), Alma Scored (1.5\%), San Francisco Red $(1.6 \%)$, Jornada Brown $(2.7 \%)$, El Paso Brown (.2\%) and E1 Paso Polychrome (1.0\%). 
them to Jornada Mogollon and Apache cultures. The CRMD reports are not widely distributed but they do contain adequate descriptions of work done and are available in the CRMD office.

John Davis (1976) recorded a rock art site just north of Rincon which is within the survey area. The Rincon petroglyph site is located in a small canyon at the extreme southern tip of the Caballo Mountains. Davis mentions two small rockshelters in the canyon which have associated occupational debris. A variety of motifs are present, including geometric figures, corn stalks, circles, handprints, birds, anthropomorphic figures and various unrecognizable symbols. The most profuse motif is what Davis calls "bugeyed Kachinas"--these are large pairs of eyes which appear all over the site. Davis notes the similarities of the Rincon petroglyph site with those at Three Rivers, New Mexico, and Hueco Tanks, Texas, and suggests they can be attributed to Mogolion artists. Several miles south of this site on the north side of San Diego Mountains is another petroglyph site known to locals and mentioned by Trost (1970) but which has not been previously recorded. A description of the Jornada rock art style of the "Desert Mogolion" of southern New Mexico can be found in Schaafsma (7972).

Almost all sites recorded in the vicinity of the survey area are along the Rio Grande Valley, evidencing heavy occupation along this permanent water source. Archaeological resources in the interior of the Jornada del Muerto are very poorly understood, as indicated by Kelly (1966:31): "Insofar as we know now, the interior [Jornada del Muerto] has attracted only transients, such permanent sites as are reported are in ecologically more favorable localities on the edges of the basin." Professionally, the Jornada del Muerto is almost unknown; local collectors have been far more active.

Ares (1974:57) mentions: "Frequently parties hunting Indian artifacts in sand hills came to the Jornada." Local ranchers report it is not uncommon to see several hundred treasure hunters or "arrowhead" hunters searching the area on weekends. Access to the land managed by BLM is practically unlimited. While most collecting is confined to searching sand hills for "arrowheads," several sites have been excavated by collectors looking for pots in the floors of pithouses. Perhaps the worst example of this occurred just south of the survey area. A hugh village site (AR092) was bulldozed by a local "pothunter" who destroyed approximately 40 acres of a Mimbres pithouse village. in the process of looking for whole Mimbres bowls. The damage to archaeological sites and resources inflicted by local collectors and pothunters is severe, especially by those who do their searching in four-wheel-drive vehicles. However, experienced collectors can often offer the archaeologist useful site distribution data, as will be discussed later in this report.

The general area of south central New Mexico and the adjoining El Paso area of Texas has witnessed a phenomenal increase in archaeological investigations within the last five years. Major surveys which recently have been 
Architectural features found in the Dona Ana component at the Hatch site include a double room surface structure, four circular pithouses and a rectangular pithouse with a ventilator-entrance. Ceramics from these structures indicate wider occupation time spread and include: EI Paso Polychrome (35.4\%), Alma Plain (34.4\%), San Francisco Red (12.7\%), Chupadero Black-on-White $(6 \%)$ and Corrugated Smudged (Seco?, 5.1\%). Minor amounts of the following ceramic types were also found: Alma Scored, Alma Incised, Alma Fugitive Red, Mimbres Incised, El Paso Brown and Jornada Brown. Schaasfma's assignment of this component to the Dona Ana Phase is apparently based largely on structural evidence (i.e., pithouses plus surface structures found together). Lehmer believed Dona Ana Phase sites would have ceramic assemblages of approximately one-half EI Paso Brown and one-half El Paso Polychrome with Alma Plain as the intrusive type. Once again influence from the Mimbres area to the west is so strong that assignment of this component to the Dona Ana Phase may not be warranted.

From the three excavations described--Las Tules, Rincon Village, and the Hatch site--a pattern emerges regarding settlement along the Rio Grande valley. Pithouse villages dating from roughly A.D. 900-1100 are present along terraces and mesas overlooking the Rio Grande. Western influence from the adjacent Mimbres area is strongly present, especially at the Hatch site. The ventilator-entrance and ceramic types indicate this influence. All three sites have a mixture of architectural types: circular and rectangular pithouses with the addition of a small surface structure at the Hatch site. All three sites have pithouses which were larger or deeper than others at the sites and suggest the existence of communal structures. Of interest, Lehmer, Hammack, and Schaasfma al1 noted that structures were not easily discernible from surface indications. Extensive testing was necessary to define structures.

A comprehensive survey has never been attempted in the vicinity of the project area. During the 1960s, highway salvage surveys along Interstate 25 were carried out by the Museum of New Mexico. Unfortunately, the sites encountered along the route were generally poorly recorded and no summary report on the survey work has been written. Descriptions of sites encountered along the Rio Grande Valley were usually confined to a brief comment such as "chipping station," "factory site," "lithic, some pottery," etc. Most site forms indicate that the sites were "not worth excavation." Of the few sites marked as worthy of excavation or testing, only the Hatch site and the Rincon Village site were excavated. Cultural affiliations indicated on site forms are generally either Archaic or Mogollon; no Paleo-Indian sites were recorded. A majority of these sites were found on terrace remnant knolls on secondary terraces overlooking the Rio Grande.

The Cultural Resources Management Division (CRMD) of the New Mexico State University at Las Cruces has had several small testing and surveying contracts during the last few years in the Radium Springs project area and surrounding vicinity. Beckett (1976) recorded five sites in T162, RIW vicinity near Cox Tank and Estes Tank No. 3. These sites were small, deflated sherd and lithic scatters associated with scattered hearths. Beckett assigned 
completed or are in process of publication include McGregor Range (Beckes et al. 1977), Three Rivers Drainage (Human Systems Research 1977), and Hueco Bolson (Whalen 1977). Two smal1 surveys conducted as part of the Natural Areas Survey in Texas are Hueco Mountains (Betancourt 1977) and Frank1in Mountains (Way n.d.). Publication of these surveys should add considerable information to our knowledge of settlement patterns in the south central New Mexico-El Paso area. The El Paso Archaeological Society has been active in the area and has published many reports of sites, artifacts, and archaeology of the area. A field team from North Texas State University, under the direction of Pierre Morenon, has recently completed excavations of several pithouse sites near Hatch and the data should soon be published.

Cultural Histary

Prehistoric Occupation

The first populations to occupy the area were the Paleo-Indians of ca. 8,000-13,000 years ago. The Paleo-Indians lived in smal1 mobile groups, iricluding in their subsistence regime the hunting of large Pleistocene fauna such as mammoths, Bison antiquis, camel, wolf and horse (cf. J. J. Hester 1975). We recognize this widespread early hunting technology primarily on the bas is of distinctive lanceolate-shaped projectile points such as Clovis, Folsom, Eden, etc. No Paleo-Indian sites have been previously recorded in the survey area. Local collectors, however, have in their collections many Paleo-Indian projectile points such as Clovis, Folsom, and Angostura, all collected in the general vicinity of the Jornada del Muerto. Hammack (1962) noted that Folsom camps were present along the Rio Grande Valley near Rincon. The Mockingbird Gap site, a Clovis site mentioned by Judge (1973), is located at the extreme northern end of the Jornada del Muerto. Numerous PaleoIndian projectile points have been found in neighboring Tularosa Basin (cf. Krone 1975).

While no careful studies of Paleo-Indian sites have been done in the survey area, they can be predicted to occur. Judge (1973) analyzed data from 30 Paleo-Indian sites in the Central Rio Grande area approximately 75-150 miles north of Truth or Consequences. He found three critical factors governing the location of these sites: water, overview and hunting. "Hunting" refers to a broad open "hunting area" capable of supporting big game herds. "Water" sources utilized by Paleo-Indian hunters included playas or ephemeral ponds, permanent rivers and streams. Judge found most Paleo-Indian sites Tocated on ridges or knolls ("overviews") overlooking the hunting area and water sources. The numerous playas found along the middle of the broad, open Jornada del Muerto plain would have attracted herds of late Pleistocene big game animals during cooler, wetter years (with intermittent dry intervals; see Wendorf and Hester 1975:12) which occurred 8,000-13,000 years ago. These playas often are surrounded by distinct ridges which would offer a good overview of the surrounding terrain. The Rio Grande Valley would have undoubtedly offered al1 three environmental criteria during the late Pleistocene. Sometime around 8,000 years ago the large herbivores common in the late Pleistocene became extinct. This has been variously attributed 
to a gradual climatic change, from a cooler, wetter climate to a warmer, drier climate, or to the hunting pressure put on big game populations by Paleo-Indians (see Butzer 1971:507-512 and Martin and Plog 1973).

Whatever the reasons, approximately 8,000 years ago the Paleo-Indian tradition was replaced by a hunting and gathering lifeway referred to as the "Archaic".

The Archaic cultures present in the southern half of the American Southwest have been described by various terms including the Cochise variant of the Desert Archaic (Sayles and Antevs 1941), the Hueco Phase of the Jornada Branch of the Mogollon (Lehmer 1948) and the Picosa (Irwin-Williams 1967). Basically, all these terms refer to hunting and gathering cultures which existed from ca. 8,000 B.P. until the introduction of ceramics ca. A.D. 1-800. These Archaic peoples exploited a. wide variety of plant and animal resources with the emphasis clearly on gathering vegetal foods. These cultures are best known from rockshelter and cave deposits such as Bat Cave (Dick 1965), Tularosa Cave (Martin et al. 1952), Fresnal She1ter (Wimberly and Eidenback 1972) and the many caves in the Hueco Mountains (Cosgrove 1947). Open campsites, rock quarries and plant processing sites also occur but do not have many perishable items preserved. Corn was introduced during the Archaic at about 3,000 B.C. (Bat Cave) first as a wild plant and later as a domesticate. Squash and beans were added to the domestic plant list by 1000 B.C. The tool inventory included grinding stones, dart points, bifacial knives, scrapers, choppers, axes, hammerstones, drills, pestles, mortars, etc. Perishable items found in cave deposits include basketry, matting, cordage, cotton snares, netting, atlatls, digging sticks, fiber sandals, etc. Most research on the Archaic cultures in southern New Mexico has been concentrated on cave or shelter deposits at the expense of open sites; hence, overall settlement patterns are poorly understood.

Within the survey area, non-ceramic sites--presumed to be Archaic--have been recorded along Rio Grande terraces but no excavations have been carried out. Rockshelters and caves are rare in the survey area; a few small shelters occur in the Caballo Mountains (Davis 1976) but no large shelters or caves are known to exist. Quarry sites would be expected to occur in the Caballo and San Andres Mountains, as well as several igneous outcrops such as Point of Rocks. The most common Archaic site types which would likely occur in the project area are open campsites and plant processing or specific function sites. Archaic components are often recognized by archaeologists investigating later sites (Schaafsma 1974). Archaic open sites are most often defined on the basis of negative evidence, i.e., no ceramics. The Archaic hunting and gathering cultures are chronologically followed by the introduction of ceramics and the development of pithouse villages. In southern New Mexico peoples of this tradition are known as the Mogollon. In 1948 Donald J. Lehmer published the Jornada Branch of the Mogollon; he included most of the present survey area within the boundaries of his Jornada Branch. Lehmer proposed a series of phases for the northern and the southern Jornada cultural areas. His scheme follows: 
Jornada Branch of the Mogollon (After Lehmer 1948)*

Phase Names

Northern

San Andres

Three Rivers

Capitan

Hueco
Southern

El Paso

Dona Ana

Mesilla

Hueco
Time Range

A.D. $1200-1400$

A.D. $1100-1200$

A.D. $900-1100$

Prior to A.D. 900

Lehmer based his proposed phases on surveys and excavations carried out in 1940 and 1941 and comparative notes from previous researchers. Lehmer actually excavated only a Mesilla Phase and an El Paso Phase site. Mesilla Phase sites are characteristically pithouse villages consisting of circular pithouses without entrance ramps and rectangular pithouses with entrance ramps. The type site is Las Tules, discussed earlier. The dominant ceramics are El Paso Brown with Mimbres Boldface, Mimbres Classic, San Francisco Red and Alma Plain as intrusives. Lehmer's El Paso Phase was based on the Bradfield site and the Alamorgordo sites excavated by Bradfield and Stubbs. All were surface pueblo structures consisting of continuous room blocks in either long tiers or grouped around a central plaza. The dominant pottery type was El Paso Polychrome; intrusives were more numerous than Mesilla. Phase wares and included Chupadero Black-on-White, Three Rivers Red-on-Terracotta, Lincoln Black-on-Red, Playas Red Incised, Ramos Polychrome, St. Johns Polychrome and Heshotauthla Glaze Polychrome. Lehmer describes other traits and typical artifacts from both phases but the diagnostic criteria are architectural styles and ceramic types. Lehmer proposed the Dona Ana Phase as a transitional period between pithouses and surface pueblos and between El Paso Brownware and El Paso Polychrome. Northern phases were proposed by Lehmer on the basis of a difference in ceramics he found on surface sites in the northern half of the Jornada cultural area. Despite the rather tenuous nature of Lehmer's phase assignments, based largely on surface collections, 29 years have elapsed and no one has seriously challenged Lehmer's basic outline. Marshal1 (1973) provides a good summary of excavated sites of the Jornada Mogollon area.

Excavated sites of the Jornada Mogollon consist of pithouse villages, surface pueblos, and a few shelter deposits with ceramics in upper levels; all of these represent occupational sites. Other types of Jornada Mogollon sites known largely from surface indications include rock art sites (petroglyphs and pictographs; see Schaafsma 1972 for a discussion of the "Jornada Style" of rock art in New Mexico), temporary campsites, isolated sherd scatters and isolated caches. Petroglyphs occur at rock outcrops and in canyons. Occupational sites are usually close by but not in direct association. Temporary campsites, i.e., burned rock scatters with ceramics, are widespread and are known to occur along river valleys, on basin floors, on alluvial fans, and on top of mountains. In other words, temporary campsites

*For a more recent study of Jornada sites in the Hueco Bolson, see Whalen (1977). 
occur in practically all areas. Isolated chert scatters are again found in a variety of locations. Isolated caches usually involved ornamental artifacts associated with a ceramic vessel and have been found in many locales.* Pithouse villages are known to occur along the Rio Grande Valley terraces, along mountain stream terraces and on alluvial fans in basins near mountains. Surface pueblos frequently occur in association with extinct playas on basin floors (Brook 1971). Brook also mentions that these sites occur both near the center of large basins and near the edges of basins close to mountains. Buffington and Herbel (1965) note the occurrence of a surface pueblo in association with Goldenberg sand formations in the Jornada del Muerto Basin. The above site locations indicate the known range of site types. Site settlement patterns have not been adequately studied until very recently and will presumably be better understood with publication of a number of recent surveys.

Historic Occupation

Just above the future site of Las Cruces the Camino Real cut across a bend of the River [Rio Grande] and entered on a ninety-mile stretch of waterless desert--a short cut which saved distance but cost many lives, since the Indians could lurk in the mountains and pounce on their victims without warning. So many travelers were killed that this particular stretch was known as the Jornada del Muerto - the day's journey of the dead man (Sonnichsen 1958:49).

The Jornada del Muerto has also been interpreted as "journey of death" and "journey of the dead" and the implication is clear--this passage was a dangerous one for almost 300 years from Spanish exploration in the late 1500s until Anglo settlement in the latter half of the 1800 .

The first Europeans to explore the survey area were the Spanish who passed through the area frequently while settling the greener upper Rio Grande. The Chamuscado expedition in 1581 and the Espedjo expedition in 1583 were the first Europeans to view the survey area. Both expeditions followed the Rio Grande and did not cross the Jornada del Muerto; they did report unnamed nomads living in grass huts along the river. Oñate in 1598 led the first Spanish expedition to cross the Jornada del Muerto. Oñate mentioned that a group termed Mansos were encountered in the vicinity of Rincon. The Mansos were apparentiy a sma11 group, perhaps related to the Apache. However, Basehart (1973a:123) points out that "attempts to relate the Mansos with later peoples in this general area are difficuit." Several early Spanish accounts refer to a group of "Apaches del Perril10" present in the Jornada del Muerto. Schroeder (1973) notes that the Perri110 Apache attacked expeditions which tried to get water from a spring located in a narrow canyon west of the Jornada del Muerto (probabiy McRae Canyon). The Perri110 Apache were reported on the east bank of the Rio Grande near the Cabal10 Mountains in the 1620s. Schroeder also points out that other writers such as Opler and Opler (1950) have linked the Apache del Perrillo with the Mescalero Apache. The reported presence of the Mansos and Perrillo Apache indicates that nomadic groups were in the survey area when the early Spanish expeditions passed through. Detailed descriptions of these peoples are not available; and archaeologically, they have not been recognized. 
The Mescalero Apache, whose descendants survive today, are much better known. The term "mescalero" has been used to collectively describe many individual bands of Apaches who inhabited a vast area centered around their homeland, the Sierra Blanca region, where today the Mescalero Reservation is located. Groups of Mescalero Apache ranged north to Gran Quivira and beyond, west to the Rio Grande, south into Mexico and Texas, and east into the Staked Plains (Llano Estacado). Most historical accounts of Indians in the survey area can be attributed to the Mescalero Apache. Schroeder (1973) provides an excellent summary of historical accounts of the Mescalero in the Tularosa Basin and surrounding vicinity.

The Mescalero Apache lived in small autonomous bands which ranged widely and depended largely on hunting and wild plants for survival. When the Spanish introduced the horse in the Southwest, the Apache quickly became excellent horsemen who depended on the horse for survival. Much of the Apache culture was related to raiding. The Mescalero Apache raided the Pueblo Indians, the Spanish, the Mexicans, and finally the Anglo settlers. The raids provided the Apache with horses, metal for arrow points, blankets, guns, knives, food, etc.; in other words, raiding enabled the Apache to maintain a much higher standard of living than would have been possible by relying solely on hunting and gathering. Eventually the raiding caused the United States Army to almost destroy the Mescalero Apache. Controlling the Mescalero was a long and difficult process which was not successful until the late 1800s.

The Mescalero Apache were present in the survey area during the 18th and 19th centuries. "Lieutenant Whiting reported in 1849: 'their winter towns are extensively upon its banks [the Rio Grande], their spring and summer retreats are found in the mountains ..." (Sonnichsen 1958:17, quoting "Report to Secretary of War for 1849":239). Basehart (1973b) reports ethnographic accounts which mention that the Mescalero frequented the San Andres Mountains in search of blacktail deer, mountain sheep, pinyon nuts and yucca. Undoubtedly, the Apache utilized other resources available in the San Andres and elsewhere in the survey area. Basehart provides a good ethnographic review of Mescalero subsistence patterns.

During the 17th and 18th centuries the Spanish traveled frequently through the Jornada del Muerto. This trail was known as the Camino Real (the King's Highway). The Camino Real linked the Spanish settlements on the Upper Rio Grande (Santa Fe, Sandia, Albuquerque, etc.) with Chihuahua and Mexico City. Teams of oxen pulled wagons loaded with Spanish goods up the trail to Santa Fe and returned with loads of hides and wool to Mexico. These trains were normally large enough and sufficiently well-armed to avoid attack while traversing the broad Jornada del Muerto. The Spanish were normally attacked only when in smaller groups or when forced to seek water in narrow canyons in the mountains west of the Camino Rea1. Most travelers who journeyed through the Jornada del Muerto moved during the night, thus avoiding the hot summer temperatures which made daytime travel across the waterless plain practically unbearable.

Early accounts of Spanish travels through the Jornada del Muerto are few when compared to the many accounts of the perilous crossings during the $1800 \mathrm{~s}$. From the 1820s until the 1870s Anglo settlers, miners, soldiers and travelers were often attacked while crossing the Jornada del Muerto. The Anglos often traveled in smaller groups than the Spanish and were attacked quite frequently. 
Fort Selden near Radium Springs and Fort McRae near Truth or Consequences were established during the mid-1800s to protect travelers. The 90-mile stretch between these points continued to endanger travelers. John $\mathrm{C}$. Cremony traveled along the Camino Real during the 1850s. He described the trail as a "hard and splendid natural road which runs through four-fifths of the Jornada" (Cremony 1969:75). Cremony describes being chased some 70 miles by a band of Apaches.

Several stops along the Camino Real within the survey area were mentioned by travelers. The first stop for travelers heading south from Socorro was the Laguna del Muerto, now known as Jornada Lakes. These ephemeral playas held rainwater during certain times of the year. If the Laguna del Muerto was dry then water could be found at a spring in McRae Canyon just east of presentday Truth or Consequences. McRae Canyon is probably the narrow canyon west of the Jornada where Perrillo Apache attacked Spanish expeditions. Near the Cutter siding on the AT\&SF Railroad the small feature known as Black Hill was occasionally used as an overnight campsite. Cutter was, during the late $1800 \mathrm{~s}$, a stagecoach stop. One of the most often mentioned stops along the Camino Real was Aleman Camp. Aleman was first another rainwater playa and later the site of the first well in the Jornada del Muerto. In 1857, Jake Martin, "white chief of the Jornada," hired men to hand dig a 12-foot wide well to a depth of 180 feet. Martin maintained the well and pumped water with a force pump which apparently broke down frequently. A fee was charged to a11 travelers who desired a drink of precious water.

Fifteen miles farther down the trail was one of the most dreaded milestones along the Camino Real. As the trail passed just west of the Point of Rocks, a rugged igneous protrusion, bands of Apache frequently ambushed passers-by. Sonnichsen notes that in 1861 when Union troops were abandoning forts in New Mexico because of the Civil War, the Mescalero Apache who had been temporarily under control began raiding again. "Bands of warriors headed for sheep ranches in Pecos country, for the traditional ambush site at Point of Rocks on the Jornada del Muerto, and for exposed ranches and settlements in the Rio Grande Valley" (Sonnichsen 1958:101). From Point of Rocks the Camino Real turns east and follows the Rio Grande.

The Mescalero were finally brought under control in 1878 but not until after many years of battles and Indian campaigns by such men as Col. Edward Hatch and Kit Carson. Among the more famous Apache chiefs was Victorio, subject of a massive manhunt which ended after several years when Victorio and a handful of surviving warriors were killed in Mexico. At one point Colonel Hatch attacked Victorio in Hembrillo Canyon in the San Andres only to have him escape by riding across the Jornada del Muerto, over the Caballos at Palomas Gap, across the Rio Grande and into the Black Range. By the time the Mescalero were finally subjugated the survey area was the home of several ranchers who raised large herds of cattle on the lush grasslands. The eventual environmental impact of cattle, horse, and sheep grazing on the Jornada del Muerto was documented earlier. In 1881 the Camino Real was replaced by the AT\&SF Railroad between Albuquerque and El Paso, signalling a close to the colorful era of the Camino Real. 


\section{SITE DESCRIPTIONS}

Stephen L. Black, Thomas C. Kelly and Erwin Roemer, Jr.

This section contains the results of the Radium Springs survey. During the intensive survey conducted within the selected sampling units (sections), 90 sites were documented. In the course of locating the sample sections, six additional sites were recorded outside the selected areas.

In compliance with the BLM specifications under which we were working, certain types of data were recorded for all sites. These data have been tabulated and are presented here in Tables 2-4. As mentioned in Section I, specific site locations are not given.

We have sorted the 96 recorded sites into 10 categories (see Table 3). Some sites had been extensively eroded, exposing a variety of cultural debris; at others, a more limited range of materials was observed. Thus, we cannot, with any great degree of certainty, place each and every site within a specific functional category. In the following pages, we provide definitions of these 10 categories. These can be tested and refined during the course of future archaeological investigations in the region.

Cain Quarry site

The Cain Quarry Site (AR094) is a Tithic resource procurement area located .25 mile northwest of Lewis Cain's ranch headquarters RTWT16S, Section 10. This section is five-eighths BLM-controlled, one-eighth state land, and one-quarter deeded to Mr. Cain. We believe the site is on the BLM-controlled portion, but not enough time was available to locate a USGS section marker and verify its location.

The site is in the outwash area on the north side of a steep hill at $4525^{\prime}$ elevation. Drainage is to the north into Jornada Draw a mile away. Soil is sandy clay mixed with the detritus from the hillside and gray in color. Fist-size nodules of biuish-gray-white rock (identified as being felsitic rock of igneous origin by Dr. Richard McGehee, UTSA Associate Professor of Geology) cover an area 100 meters east-west by 150 meters north-south. The vegetation is mostly creosote bush and grama grass.

Aboriginal knappers have altered most of the felsite nodules at the site. Quarry blanks, crude bifaces, broken preforms, large modified flakes, flakes, and knapping debitage cover the area. While no controlled collection was made, the sample that was picked up had a high percentage of primary cortex flakes, a characteristic of 1ithic resource procurement areas (Ke17y and Hester 1975:20).

Quarry blanks, preforms, scrapers and utilized flakes of this material were found in AR007 four miles north; AR062, a village site five miles north, and in AR002 six miles northeast.

This was the only lithic procurement area identified in the Radium Springs survey and is of considerable archaeological importance. We believe it should be nominated to the National Register of Historic Places. 
TABLE 2

Types of Sites Found During the Radium Springs Survey*

$\begin{array}{ll}1 & \text { Quarry site } \\ 1 & \text { Petroglyph site } \\ 1 & \text { Historic cemetery } \\ 2 & \text { Bead caches } \\ 2 & \text { Ceramic scatters } \\ 5 & \text { Unassociated hearths } \\ 5 & \text { Ceramic villages } \\ 8 & \text { Lithic scatters } \\ 33 & \text { Lithic campsites }\end{array}$

38

Ceramic campsites

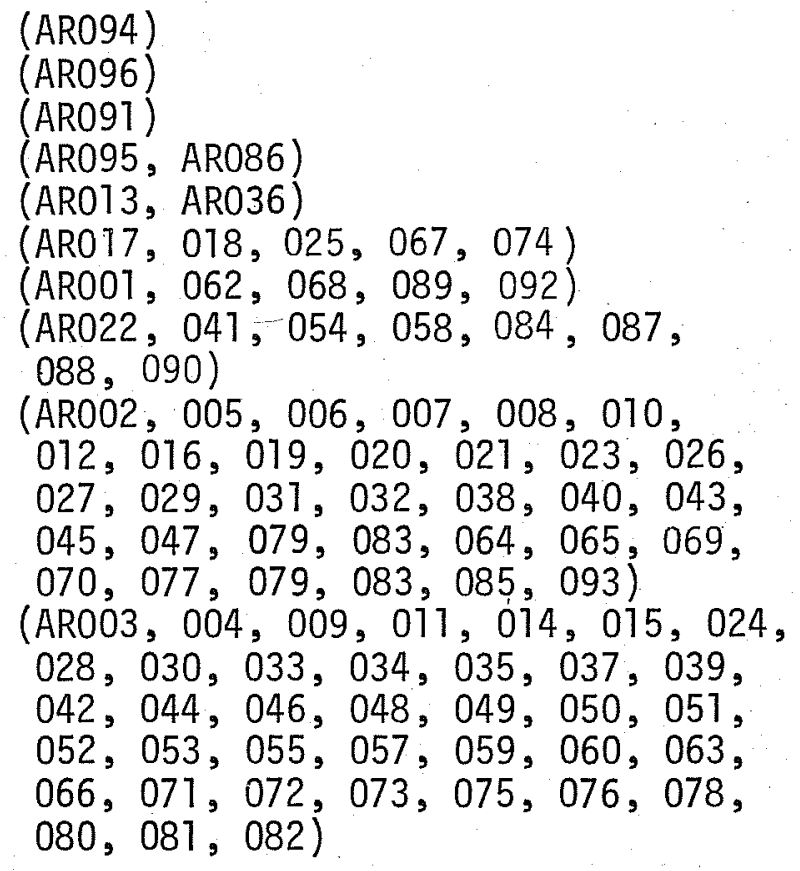

*90 sites were documented in sample sections; six others were located outside the sections. 
San Diego Mountain Petroglyph Site

The San Diego Mountain petroglyph site (AR096) is located in a narrow canyon on the north side of the mountain, just within the southern boundary of the 1976 survey area. AR096 is known to local inhabitants, local amateur archaeological groups (Trost 1970) and professionals studying rock art (Schaafsma 1972), but the site has never been fully recorded. The site was visited during off-hours by members of the Radium Springs survey crew. They took photographs (on file at the Center for Archaeological Research and the Museum of New Mexico) and recorded site data. This site is of considerable interest as a local example of Jornada Mogollon rock art.

Trost (1970) reported that an El Paso Polychrome mortuary vessel was uncovered while collecting sherds from a nearby site which he believed was related to the petroglyphs. Hammack (1962) excavated the Rincon Village site (LA5599) one mile east of San Diego Mountain. An additional nearby pithouse village was reported to us by local pothunters but we did not have time to document it. None of these sites can be directly linked to the rock art but the presence of numerous Mogollon villages within a few miles of AR096 is probably significant.

The San Diego Mountain petroglyphs were pecked on drab brown igneous boulders which are strewn along the bottom and sides of a rugged canyon. Vegetation is very sparse and consists primarily of creosote. The petroglyphs number in the hundreds, if not thousands. The dark patina of the boulders nicely contrasts the lighter-colored pecked designs. Design motifs include both anthropomorphic and geometric styles. Recognizable elements include birds, mountain goats, fish, quadrupeds, hands, legs, feet, masks, human profiles, corn plants, snakes, concentric circles and squares, step-fret motifs, checkerboard designs, parallel lines and many others. Several large boulders contain many designs which are often superimposed. Schaafsma (1972) indicates that AR096 has two distinct styles of petroglyphs: the Desert Mogolion Abstract Style and the Eastern Jornada Style. The Desert Mogollon Abstract Style is earlier and is characterized by geometric designs. The Eastern Jornada Style overlies many of the earlier designs and is characterized by anthropomorphic and realistic designs. Schaafsma states that AR096 is very similar, in stylistic terms, to a petroglyph site some 40 miles to the west in the Mimbres area. Schaafsma (1972) illustrates many photographs and drawings of the San Diego Mountain petroglyph site (AR096).

\section{Bead Caches}

Two bead caches were recorded during the 1976 survey. The High Lonesome site (AR095) is described in Appendix II of this report. AR086 (Fig. 4,b) is a large rock cairn which had been potholed. One calcite bead and a mussel shell pendent were visible on the surface. A few flakes were found in the vicinity but no ceramics were observed. Possible explanations for AR086 include a cairn burial or a bead cache. No faunal material was observed in or around the pothole. The depth and size of the pothole suggests that little of the original feature would be uncovered by testing. 


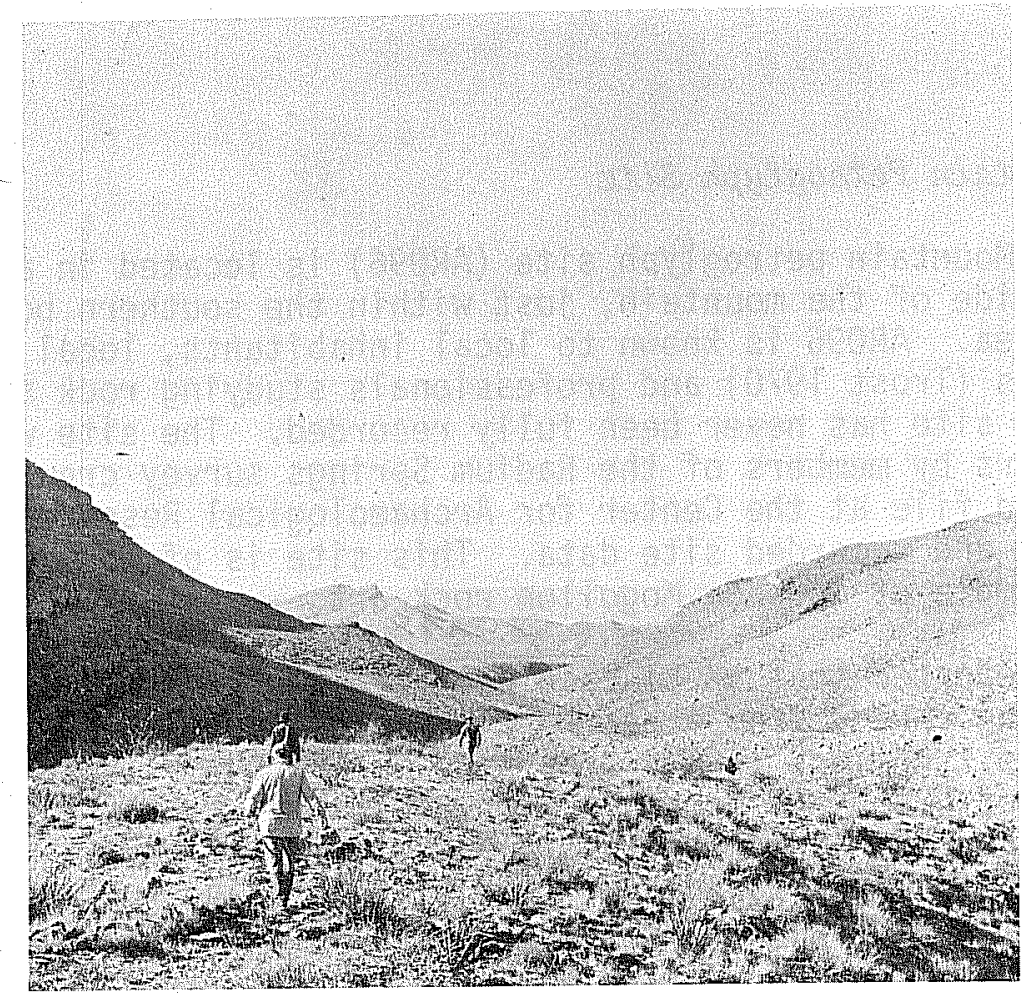

a

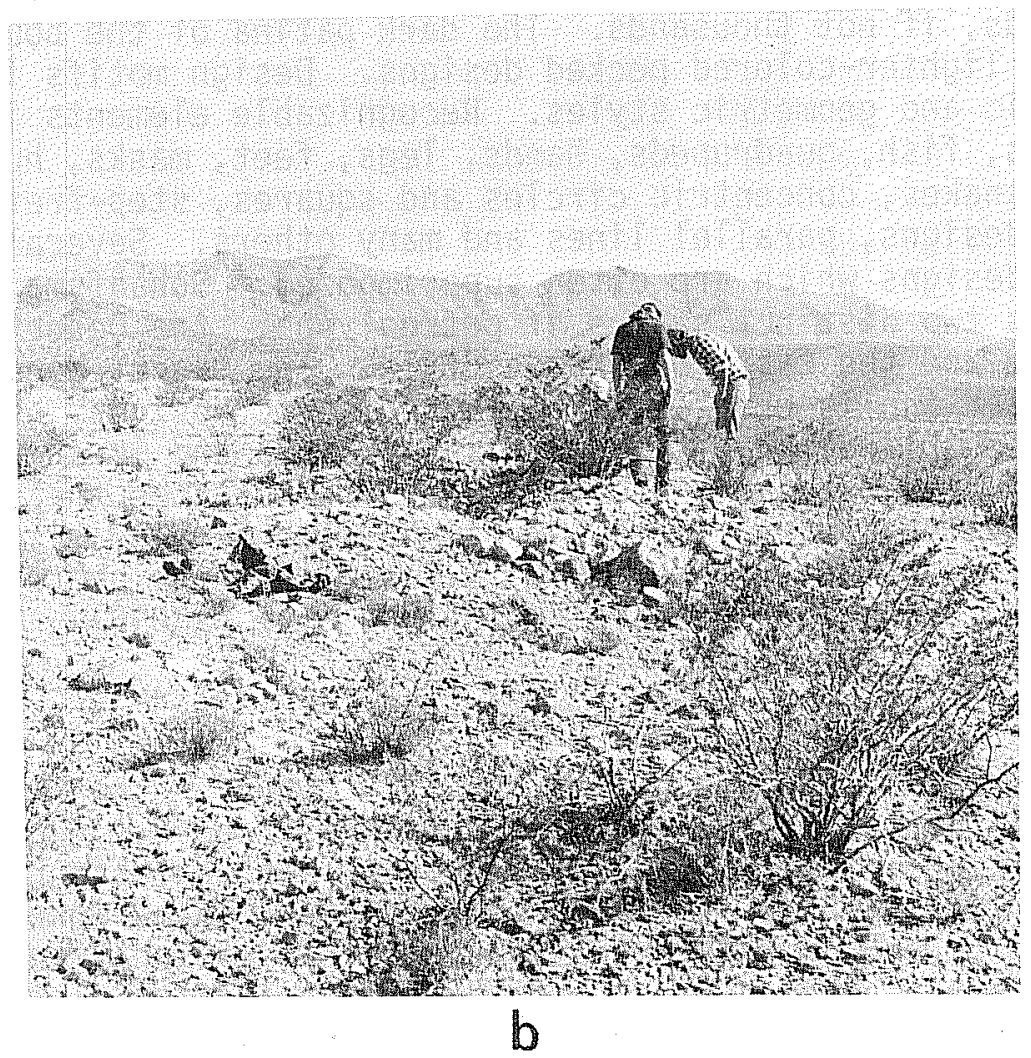

Figure 4. Panoramic Views of Two Sites in Survey Area. a, Apache Gap looking west; b, AR086--pothunted site; Caba170 Mountains in background not far from Truth or Consequences, New Mexico. 


\section{Historic Cemetery}

A smal1 historic cemetery (AR091) was recorded near present-day Salem, New Mexico. The cemetery contains approximately 25 rock-covered graves. Most graves are not marked and are overgrown with vegetation. A few graves are marked by bleached wooden crosses and one grave is surrounded by a wooden picket fence. No permanent markers of metal or carved stone monuments were found. This cemetery is not marked on USGS maps. Several knowledgeable inhabitants of nearby Salem were questioned but no information was available concerning who is buried there, or when the cemetery was used. The deteriorated condition of the cemetery, lack of local knowledge and lack of permanent markers suggest this cemetery has not been in use for the last 30 years or more. It is conceivable that this site dates to the early 1900s. Historic research into $10 c a l$ records and extensive interviews with older local residents may eventually reveal details on AR091 (see Fig. 5).

\section{Ceramic Scatters}

Two sites (see Table 2) were recorded which contained only scattered ceramics. Both sites were situated on or near sand dune areas. Both sites were small and contained two or more types of ceramics but no associated lithics or burned rock. It is quite likely that additional cultural debris is present but was covered by the shifting sand dunes (see Fig. 7,b [site AR013]).

\section{Unassociated Hearths}

These sites (Table 2) were burned rock concentrations or hearths around which artifacts were not found. The lack of associated cultural remains can conceivably be accounted for by the following possibilities: (1) debitage or artifacts were present but not observed by survey crew; (2) these burned rock features were used for a short duration and no cultural debris was left behind; (3) artifacts had previously been collected; (4) artifacts were present but buried; and (5) artifacts and debris eroded away leaving only the heavier burned rock. In any case, there are sites present in the survey area which do not contain any readily visible cultural material and are marked only by the presence of eroding hearths. All of these sites are small and most were found on or around sand dune ridges. AR067 is a site which consists of distinct hearths exposed from 1.2 meters below the existing ground surface; these were noted in the cutbank of several small arroyos. One hearth is slablined and all are marked by burned rock and charcoal-stained soil. Several of these hearths contain charcoal. If these features are tested prior to destruction by erosion, associated cultural debris may be found and radiocarbon dates might be obtained.

\section{Ceramic Villages}

During the 1976 survey five sites (Table 2) were recorded which are known to be or are likely to be Mogollon villages. In addition, many of the large ceramic-bearing campsites may have been villages. Two of the known villages were recorded on BLM land off the designated study sections. Al1 the 


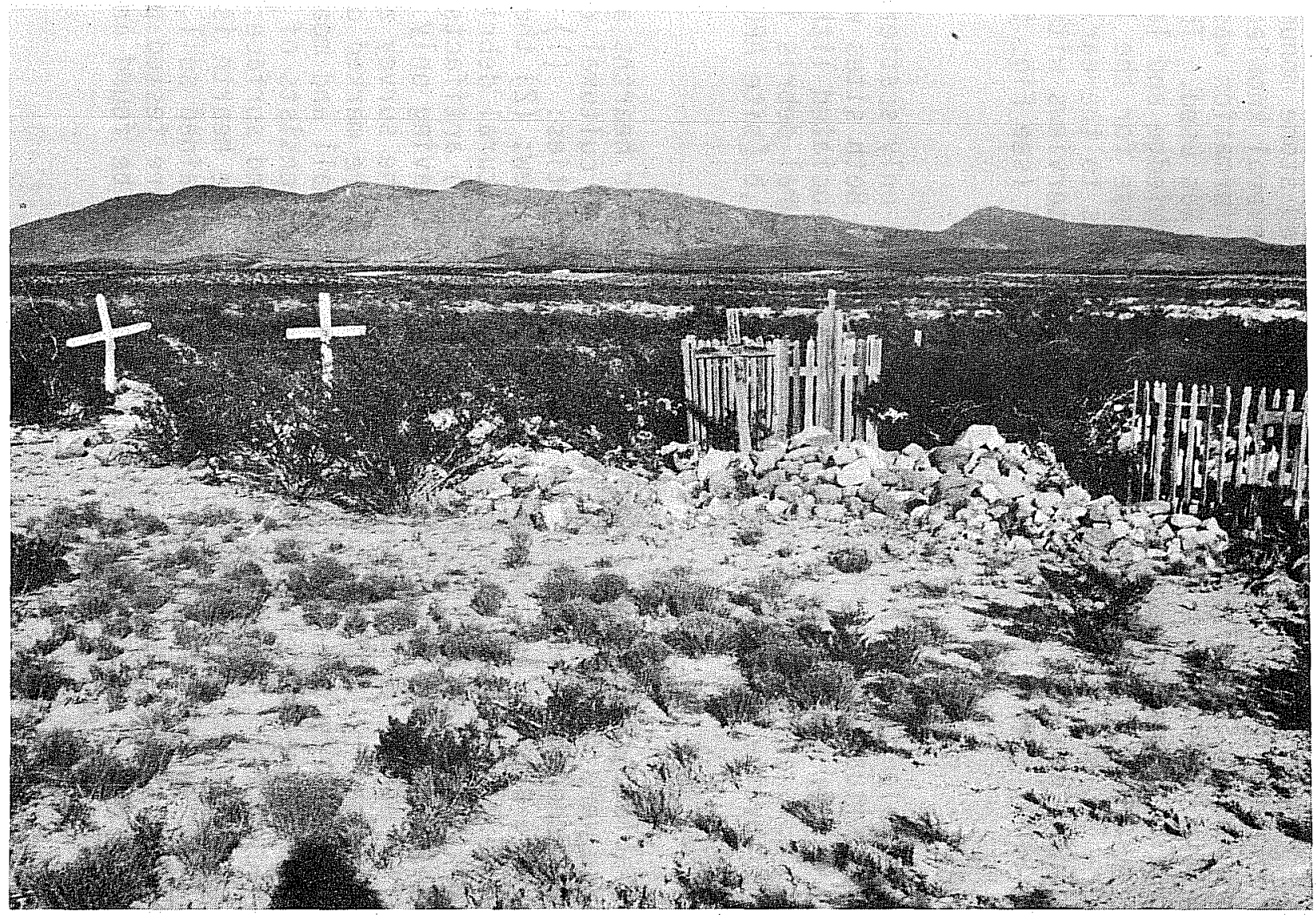

Figure 5. Archaeological Site AR091. Unidentified historic grave site. Looking east across Rio Grande Valley with Caballo Mountains in background. 
village sites are $30,000 \mathrm{~m}^{2}$ or more in horizontal extent and contain relatively high ceramic and lithic densities. Three of the sites have been partially destroyed by pothunters excavating in pithouses. All five village sites are considered important and should be investigated further. A11 five are recommended for consideration for nomination to the National Register of Historic Places. Several of the sites are rapidly being destroyed and are in need of emergency salvage work while intact portions of the sites still exist. Descriptions of all five village sites, in addition to the data in Tables 2 and 3, follow:

AR001 is a large pithouse village located on a flat alluvial outwash (edge of fan) several miles west of the San Andres Mountains. This site is known to local collectors who have excavated several rectangular pithouses; these reportedly contained burned roof beams. A human sku11 was reported from the site. Lithic debitage is widespread but tools are rare--a fact which can be attributed to intensive surface collecting by relic-hunters. Ceramics observed at the site indicate that it may have been occupied during the Mesilla and Dona Ana phases of the Jornada Mogollon. Despite the damage ARO01 has received from pothunting, collecting, sheet wash, and road construction, the site still contains significant buried cultural material and steps should be taken to insure that the remaining deposits are not destroyed (see Fig. 6,a).

AR062 is a large ceramic site situated in a sand dune area in the middle of the Jornada Basin. The large size and dense concentrations of burned rock, ceramics and lithics suggest that AR062 is a village. This site is one of the few sites encountered on the survey which did not appear to have been extensively collected or vandalized. Local collectors were apparently not aware of the site. Deflation in the sand dunes has exposed much of the site including a diverse lithic and ceramic inventory. Ceramics date the site to the Dona Aria phase or later. No evidence of structures was observed but buried features no doubt exist. The quantity and variety of artifacts present on the surface suggest that the site was occupied for a lengthy time period.

AR068 is another Targe ceramic site which is interpreted as a Mogollon village. The site is located on a flat sheet wash even on the edge of an alluvial fan of the Caballo Mountains (east of Caballos). Six square miles were surveyed in the vicinity of AR068 but no sites were found. AR068 contains dense concentrations of ceramics, 1ithics of many types, manos and several large boulder metates. No evidence of potholing was observed and local collectors were unaware of this, or any other large site, in the area. Size, quantity and types of artifacts present suggest AR068 is an early Jornada Mogollon (Mesilla phase) village. Sheet wash has exposed much of the site but significant buried deposits may well be present.

AR089 is an early Mogollon pithouse village located in the Rio Grande Valley near Salem, New Mexico. This site is fairly small but definitely contains buried pithouses, several of which have been excavated by 
local pothunters who found five complete vessels in the floor of one rectangular pithouse. The five vessels were Mimbres Boldface, San Francisco Red and three smudged, neck banded plain culinary jars. These ceramics are relatively early types. Mimbres influence is strong, suggesting the site may not be Jornada Mogollon. Pithouse floors were baked adobe and were $50 \mathrm{~cm}$ to $1 \mathrm{~m}$ below the surface. Despite road construction and vandalism of the site by untrained excavators, substantial buried features still remain. The men who removed five pots from the site believe that 10 to 15 pithouses remain undisturbed. This site faces imminent destruction.

AR092 (Bruton Bead Site) is a huge Mimbres Mogollon village site (covering over a square mile) which lies just outside the survey boundaries but on BLM-controlled land. It is situated on rolling sand dunes along a major arroyo draining out of the San Andres Mountains. The drainage pattern is such that fairly flat sandy areas would be well watered by the San Andres runoff, providing a good agricultural setting. AR092 has been known to collectors as the "Bruton Bead Site" for many years because of the numerous beads found at the site.

While local collectors have been active at the site for a long time, the major destruction of the site occurred quite recently. A pothunter "excavated" much of the site using a bulldozer to outline house floors, in order to permit the removal of Mimbres bowls. Such sickening wholesale vandalism is perhaps the worst example of the massive destruction of archaeological sites in the survey area created by uncontrolled access to the land.

Identifiable house floors were observed surrounded by thousands of potsherds. AR092 is the richest site, in terms of artifact density, recorded during the 1976 survey and has by far the greatest concentration of sherds. Ceramics found at the site indicate a wide time span and suggest that the site was occupied over a very long period. Predominant pottery types are Mimbres Boldface and Mimbres Classic, suggesting that AR092 is one of the Mimbres villages which Lehmer (1948:71) mentioned for the area.

No Mimbres villages have been excavated or recorded east of the Rio Grande. AR092 is an important site which may well represent a major Mimbres population in the Jornada Basin. Large quantities of beads found at the site suggest that it may have served as a bead-manufacturing or distribution center. Ceramics occur at the site which indicate trade from many other areas, including Cibolo White Ware, Playas Red Incised, Chupadero Black-on-White, San Andres Red-on-Terracotta, Three Rivers Red-on-Terracotta, El Paso Polychrome and others. Despite the massive destruction of AR092 further work including mapping, controlled collection and excavation is recommended as an emergency step to salvage what remains. The Bureau of Land Management should take steps to save what is left of what was possibly the largest and most important Mimbres village in the Jornada area. 
majority of these sites were located on dunes or knolls affording a view of the Rio Grande Valley or Jornada Basin. Lithic scatter sites were small and consisted only of flakes, tools or ground stone with no associated ceramics or burned rock. These sites probably represent special activity locations utilized for short durations. Sites such as AR087 contain flake debris, tool fragments and hammerstones, and likely represent knapping stations. The tendency for these sites to be located on knolls or ridges affording an overview of the surrounding area is of interest. None of these sites appeared to contain significant buried deposits.

\section{Lithic Campsites}

Thirty-three sites were recorded on the 1976 survey which are categorized as $7 i$ thic campsites (Table 2). These sites are characterized by (1) the presence of lithics, (2) the absence of ceramics, and (3) the presence of burned rock scatters or features. They range in time from Paleo-Indian (AR093) to Archaic to perhaps Apache. It is quite Tikely some of the sites can be attributed to Jornada Mogollon peoples who occupied such sites for specific purposes of short duration, leaving no ceramics behind. It is also possible ceramics were present at a few of the sites but were either buried or not observed. Dating of these lithic campsites is possible only on the basis of surface observation--if a diagnostic artifact such as a dart point is found. Even then it is impossible to assign such sites to any limited time span (e.g., to within a thousand years or more).

Lithic campsites were often encountered on the survey and were mostly found on sand ridges, and in sand dune areas. A few sites were found on flat sheet wash localities. Many of the sites were found near roads and had few tools indicating heavy surface collecting in the past. The average lithic campsite is sma11 (less than $3,000 \mathrm{~m}^{2}$; however, some are considerably 1arger), situated on a sand dune ridge, has burned rock with scattered lithic debitage, a few tools and a few ground stone fragments. Burned rock features are rarely intact. ARO07 is illustrated in Fig. 6,b.

The small size of the lithic campsites, the sparse nature of cultural debitage and scattered burned rock suggest that most of these sites were used for limited activities. AR061 and AR079 are larger lithic campsites which were utilized for a longer period of time, as indicated by numerous burned rock features and greater quantities of lithic debitage, tools and ground stone. Five sites were recorded which, although they are small, contain intact burned rock features or dense concentrations of $1 i$ thic debris and warrant further study; these are AR002, AR056, AR077, AR083 and AR085.

AR093 (the Flat Lake Ranch Site) is a lithic campsite located in a sand dune blow-out on the south edge of a large extinct playa which has been dry for the past 30 years, according to local residents. The playa is below $4350^{\prime}$ elevation and has no outlet. The $4375^{\prime}$ contour line surrounds it at distances of from one-half to two miles and is the largest flat area in the Jornada Basin. Moving dunes are common in the area and are up to 9.3 meters in height. 


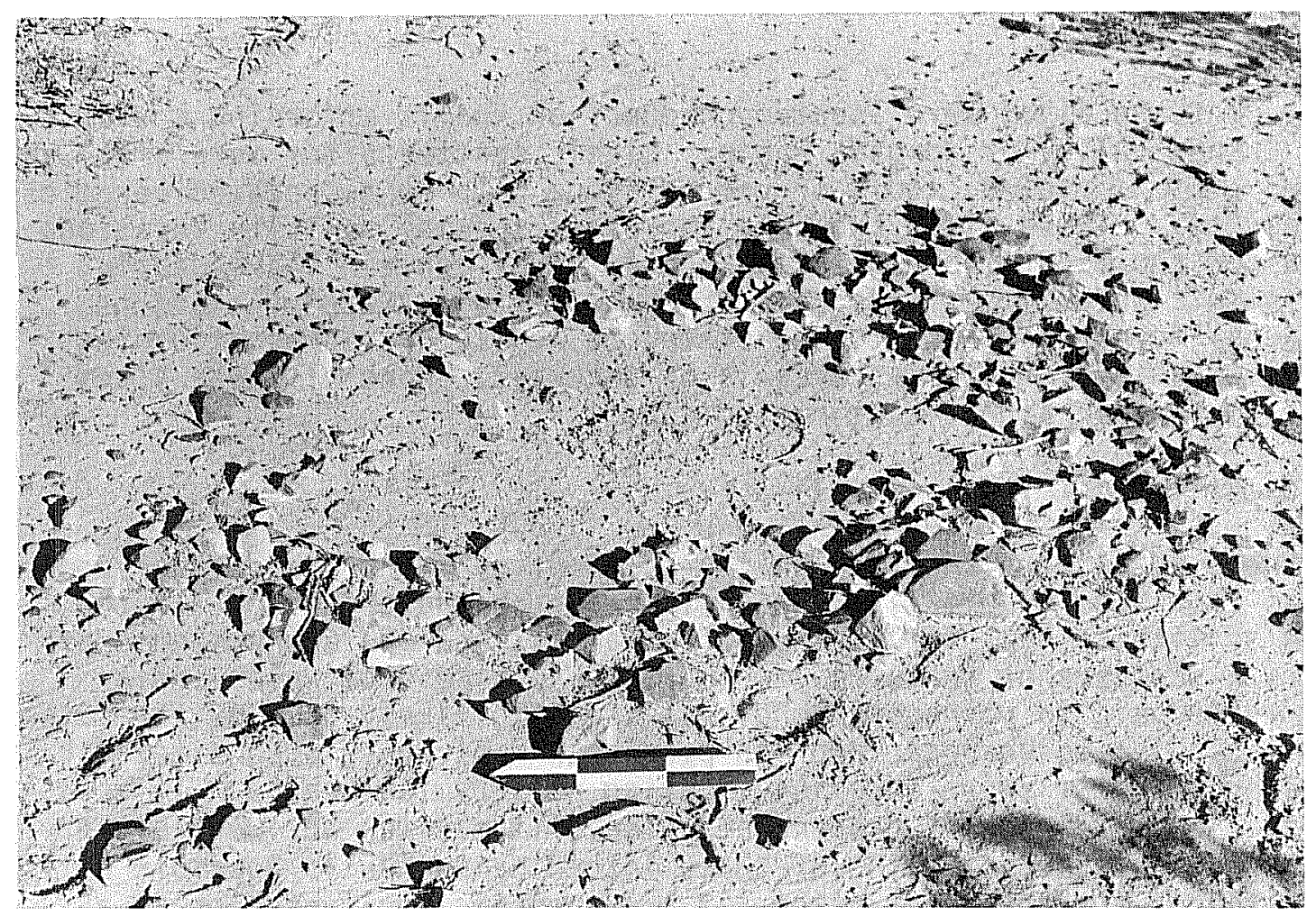

a

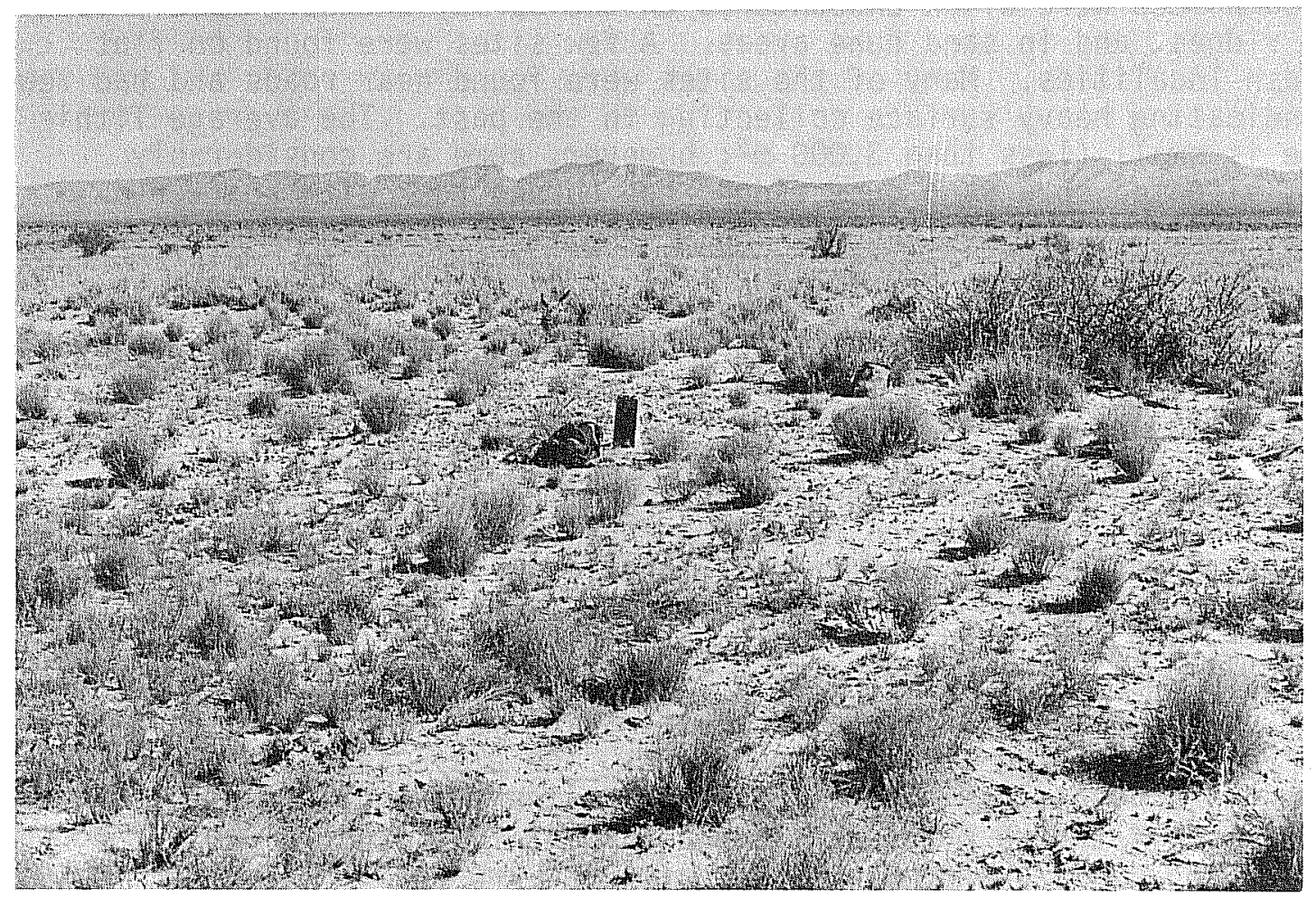

b

Figure 6. Views of Two Archaeological Sites in Radium Springs Area. a, AR001: circular burned rock features; b, AR007: site in foreground, looking across Jornada Draw toward San Andres Mountains. 
A blow-out approximately 3.1 meters deep between two dunes with tops approximately 6.2 meters above the edge of the lake has exposed a thin scatter of knapping debris, an Angostura point base, an end scraper (made on a blade) and scattered burned sandstone rocks.

Vegetation is scarce and consists of yucca, sotol, dwarf mesquite, and an occasional tuft of grama grass.

The Angostura point and the Folsom point found just three-fourths of a mile to the northeast are the only traces of Paleo-Indian occupation observed by us in the area. Both are dune sites overlooking playas and fit into the patterns Judge (1973:125) describes for the central Rio Grande valley. From these small campsites, game could be spotted for a great distance across the flats, and hunts could be efficiently planned.

We have classified the projectile point from AR093 as Angostura (Fig. 9,b), as it is identical to points in the typology collection in the Center for Archaeological Research, and to specimens illustrated in Suhm and Jelks (1962:167). However, Judge (1973:87) has established the tentative classification of Belen for the second most numerous point found in his central Rio Grande Paleo-Indian survey. Two of these appear identical to the AR093 artifact. Angostura has been dated in central Texas ca. 5000-6000 B.C. at the Levi Rockshelter (Alexander 1963). Belen has not yet been dated but Judge places it as earlier than the Cody Complex.

There were 21 total flakes, sorted in the following groups: one primary cortex, three secondary and 17 interior flakes. The implications are that the chert used in the site was decorticated elsewhere and brought to the site as quarry blanks or preforms. The predominant material was a poor quality gray-white felsite identical to that of the Cain quarry site (AR094) which is 12 miles north of Flat Lake.

We believe that this site should be nominated to the National Register of Historic Places.

\section{Ceramic Campsites}

Thirty-eight ceramic campsites were recorded during the 1976 survey, the largest number of sites in any single category (Table 2). Ceramic campsites were sites which (1) contained ceramics, (2) contained burned rock and (3) lacked conclusive evidence of use as a village. Ceramic campsites ranged from very smal1 (less than $500 \mathrm{~m}^{2}$ ) to very large (greater than $20,000 \mathrm{~m}^{2}$; see Table 4). Smaller sites are probably short term occupations. Larger sites were either occupied repeatedly for short durations or occupied over a longer period, i.e., as habitation sites. Many of these larger sites may be village sites which are badly eroded and have been previously collected. Ceramic campsites are usually situated on sand dune ridges, on sandy rises or in a sand dune area. A few ceramic campsites were located on flat sheet wash areas and steeply sloped foothills. Most of the ceramic campsites are badly eroded or deflated and often damaged by collecting, road construction, vehicular off-road traffic and cattle. The sites 
listed below either do not fit the typical ceramic campsite pattern or obviously contain buried deposits. All are recommended for further field excavation or for nomination to the National Register of Historic Places.

AR015: Large site, low ceramic density, and proximity to Point of Rocks suggest this site has general components including Archaic, Mogolion and Apache.

AR081: Large site, high ceramic density and variety. This site may contain buried pithouse structures.

AR080: Sma11 site with two large burned rock features with charcoalstained soil. May be a plant processing locality.

AR060: Small site situated in low drainage area. Site exhibited ceramic, lithic, and ground stone artifacts and burned rock. It probably has buried features.

AR050: Similar to AR060 except located in low dune area.

ARO09

and

AR049: Larger campsites with abundant ceramics, lithics and burned rock features. Buried deposits are likely.

AR017,

AR057,

AR011: Larger campsites with eroded cultural debris. May contain buried features.

AR063 is another ceramic campsite, at which a metate was found (see Fig. $7, a)$. 


\section{TABLE 3}

\section{Radium Springs Survey Site Descriptions}

Key to the Table:

Site Number: AR001 - AR096

Land Form: Major land form on or within one mile of site

$$
\begin{aligned}
& 1=\text { Isolated butte or hill or group of hills } \\
& 2=\text { Major drainage } \\
& 3=\text { Mountains } \\
& 4=\text { Foothi11s } \\
& 5=\text { Runoff slopes } \\
& 6=\text { Mountain pass }
\end{aligned}
$$

Intermittent Streams: Number of intermittent streams shown on USGS maps within one mile of site

Zone: Environmental sampling zone (refer to Section II)

Ground Stone: 1 = Absent 2 = Present (data on distribution of chipped stone and ceramics are found elsewhere in this report)

Hearths: Count of hearths or burned rock concentrations

Severity of Collection: $1=$ Collected $\quad 2=$ Potholed/Vandalized

$3=$ Not previously collected

Economic Activity: Damage to site by cattle industry, road construction, vehicular travel, etc. $0=$ Undisturbed

1 = Badly disturbed 2 = Moderately disturbed

Earliest Date - Latest Date: Dates in A.D. unless marked B.P. Dates indicate time span of pottery types present on site. Undated sites are Tithic sites which do not have accurate time indicators (i.e., distinct projectile points).

Site Type I:

$$
\begin{aligned}
1 & =\text { Ceramic campsite } \\
2 & =\text { Lithic campsite } \\
3 & =\text { Lithic scatters } \\
4 & =\text { Ceramic villages } \\
5 & =\text { Unassociated hearths } \\
6 & =\text { Ceramic scatters } \\
7 & =\text { Bead caches } \\
8 & =\text { Historic cemetery } \\
9 & =\text { Petroglyph site } \\
10 & =\text { Quarry site }
\end{aligned}
$$


Table 3 (continued)

Site Type II:

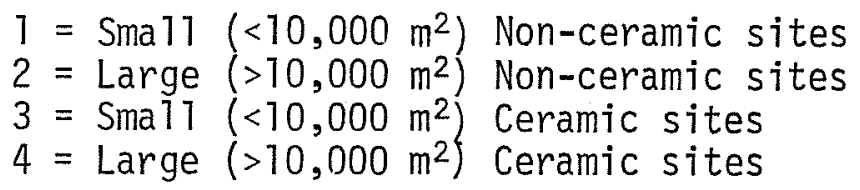

Site Area: Expressed in square meters. Based on area of an ellipse:

$1 / 2$ length $\times 1 / 2$ width $\times 3.14(\mathrm{Pi})=$ area $\left(\mathrm{m}^{2}\right)$

Elevation: Feet above sea level at approximate center of site.

Vegetation: Dominant Form

1 = Mesquite

2 = Mixed mesquite and creosote with black bush or yucca

3 = Creosote

4 = Grasses with black bush or yucca

Soils:

$$
\begin{aligned}
& 1=\text { Sand } \\
& 2=\text { Rocky sand } \\
& 3=\text { Sits (fine powder aeolian and loam) } \\
& 4=\text { Clay (hard packed) }
\end{aligned}
$$

Recommendations:

$1=$ No further action (probably totally eroded and scattered)

2 = Further field evaluation if site is to be disturbed

$3=$ Needs immediate precautions to protect site. Site about to be destroyed and contains valuable information. Preservation measures should include nomination to the National Register of Historic Places.

4 = Contains significant information and should be nominated to the National Register 
TABLE 3

1976 RADIUM SPRINGS SURVEY SITE DESCRIPTIONS

\begin{tabular}{|c|c|c|c|c|c|c|c|c|c|c|c|c|c|c|c|c|}
\hline Site No. & Landform & $\begin{array}{c}\text { Intermittent } \\
\text { Straams }\end{array}$ & Zone & $\begin{array}{l}\text { Ground } \\
\text { Stone }\end{array}$ & Hearths & $\begin{array}{c}\text { Sevarity } \\
\text { of } \\
\text { Collecting }\end{array}$ & $\begin{array}{l}\text { Economic } \\
\text { Activity }\end{array}$ & $\begin{array}{c}\text { A.D. } \\
\text { Dato } \\
\text { Earliest }\end{array}$ & $\begin{array}{c}\text { A.D. } \\
\text { Date } \\
\text { Latest }\end{array}$ & Site & $\begin{array}{c}\text { Type } \\
\text { II }\end{array}$ & $\begin{array}{c}\text { Site } \\
\text { Area }\left(M^{2}\right)\end{array}$ & Elevation & Vegetation & Soil & Recommendations \\
\hline 1 & 5 & 6 & 2 & 2 & 30 & 2 & 2 & 750 & 1350 & 4 & 4 & 125660 & 5075 & 2 & 3 & 3 \\
\hline 2 & 5 & 5 & 2 & 1 & 0 & 1 & 2 & $?$ & $?$ & 2 & 1 & 1257 & 4950 & 2 & 3 & 2 \\
\hline 3 & 4 & 3 & 1 & 1 & 0 & 1 & 2 & 750 & 1350 & 1 & 2 & 3004 & 5575 & 3 & 3 & 1 \\
\hline 4 & 4 & 3 & 1 & 1 & $\mathbf{0}$ & 1 & 1 & 900 & 1350 & 1 & 2 & 628 & 5610 & 2 & 3 & 1 \\
\hline 5 & 2 & 1 & 2 & 2 & 0 & 1 & 1 & $?$ & $?$ & 2 & 1 & 982 & 4605 & 2 & 1 & $i$ \\
\hline 6 & 2 & 1 & 2 & 2 & 0 & 1 & $i$ & ? & $?$ & 2 & $i$ & 785 & 4605 & 1 & 1 & 1 \\
\hline 7 & 2 & 1 & 2 & 2 & 0 & 1 & 1 & 7 & $?$ & 2 & $i$ & 1178 & 4575 & 1 & 1 & $i$ \\
\hline 8 & 2 & 1 & 2 & $i$ & 2 & $i$ & 1 & ? & $?$ & 2 & 1 & 2827 & 5550 & 4 & 1 & $i$ \\
\hline 9 & 2 & 1 & 2 & 2 & 3 & 1 & 2 & 900 & 1400 & 1 & 4 & 12723 & 5585 & 2 & $i$ & 2 \\
\hline 10 & 2 & 1 & 2 & 2 & 0 & 1 & 1 & $?$ & $?$ & 2 & 1 & 785 & 5550 & 1 & 1 & 1 \\
\hline 11 & 2 & 1 & 2 & 2 & 3 & 1 & 1 & 900 & 1350 & 1 & 4 & 17671 & 5560 & 1 & 1 & 2 \\
\hline 12 & 2 & $i$ & 2 & 2 & 1 & 1 & $i$ & $?$ & $?$ & 2 & $i$ & 1767 & 5540 & 1 & $i$ & 1 \\
\hline 13 & 2 & 1 & 2 & 1 & 0 & 1 & 2 & 900 & 1350 & 6 & 2 & 1963 & 0 & 1 & $i$ & 1 \\
\hline 14 & 2 & 3 & 2 & 1 & 1 & 1 & 2 & 1150 & 1400 & 1 & 2 & 1257 & 4340 & 1 & 1 & 1 \\
\hline 15 & 2 & 3 & 2 & 2 & 30 & 1 & 2 & $?$ & $?$ & 1 & 4 & 376980 & 4380 & $i$ & $i$ & 2 \\
\hline 16 & 2 & 3 & 2 & 1 & 8 & 1 & 2 & $?$ & $?$ & 2 & 3 & 38876 & 4360 & $i$ & $i$ & 1 \\
\hline 17 & 2 & 3 & 2 & 1 & 2 & $i$ & 2 & ? & ? & 5 & 1 & 353 & 4360 & $i$ & 1 & 1 \\
\hline 18 & 2 & 3 & 2 & 1 & 2 & 1 & 2 & $?$ & $?$ & 5 & 1 & 628 & 4360 & 4 & 1 & $i$ \\
\hline 19 & 2 & 3 & 2 & 1 & 4 & 1 & 2 & ? & ? & 2 & 1 & 3141 & 4360 & 1 & $i$ & $i$ \\
\hline 20 & 2 & 3 & 2 & 1 & 1 & 1 & 2 & $?$ & $?$ & 2 & 1 & 157 & 4400 & 2 & $i$ & 1 \\
\hline 21 & 2 & 3 & 2 & 2 & 5 & 1 & 2 & $?$ & $?$ & 2 & 1 & 9817 & 4410 & 1 & 1 & 1 \\
\hline 22 & 2 & 3 & 2 & 2 & 0 & 1 & 2 & $?$ & $?$ & 3 & 1 & 707 & 4440 & 2 & 2 & 1 \\
\hline 23 & 5 & 2 & 2 & 2 & 3 & 1 & 1 & $?$ & $?$ & 2 & 1 & 1178 & 4625 & 2 & 1 & 1 \\
\hline 24 & 5 & 2 & 2 & 2 & 0 & 1 & 1 & 1100 & 1300 & 1 & 2 & 785 & 4625 & 2 & 1 & 1 \\
\hline 25 & 5 & 3 & 2 & 1 & 7 & $i$ & 1 & $?$ & $?$ & 5 & 1 & 1178 & 4615 & 1 & $i$ & 1 \\
\hline 26 & 5 & 4 & 2 & 2 & 4 & $i$ & 1 & $?$ & $?$ & 2 & 1 & 5498 & 4610 & 2 & $i$ & $i$ \\
\hline 27 & 5 & 5 & 2 & 1 & 10 & $i$ & 1 & $?$ & $?$ & 2 & 3 & 15707 & 4610 & 1 & $i$ & 1 \\
\hline 28 & 5 & 3 & 2 & 2 & 26 & 1 & 2 & 900 & 1400 & 1 & 4 & 39229 & 4650 & 1 & 1 & 2 \\
\hline 29 & 5 & 5 & 2 & 2 & 18 & $i$ & 1 & $?$ & $?$ & 2 & 3 & 47122 & 4670 & 1 & 1 & 1 \\
\hline 30 & 5 & 5 & 2 & 2 & 40 & 1 & 1 & 900 & 1350 & 1 & 4 & 86391 & 4630 & 2 & 1 & 1 \\
\hline 31 & 5 & 6 & 2 & 1 & 2 & 1 & 1 & $?$ & $?$ & 2 & 1 & 314 & 4620 & 2 & 1 & 1 \\
\hline 32 & 5 & 6 & 2 & 2 & 3 & 1 & 0 & i & ? & 2 & $i$ & 707 & 4645 & 2 & 1 & 1 \\
\hline 33 & 5 & 6 & 2 & 2 & 9 & i & 1 & 900 & 1400 & 1 & 4 & 19634 & 4650 & 2 & 1 & $i$ \\
\hline 34 & 5 & 6 & 2 & 2 & 12 & $i$ & 0 & 900 & 1400 & 1 & 4 & 18849 & 4670 & 2 & 1 & 1 \\
\hline 35 & 5 & 6 & 2 & 2 & 25 & 1 & 1 & 900 & 1350 & 1 & 4 & 26506 & 4635 & 2 & $i$ & 1 \\
\hline 36 & 5 & 6 & 2 & 1. & 0 & $i$ & 1 & 1200 & 1350 & 6 & 2 & 79 & 4660 & 2 & $i$ & 1 \\
\hline 37 & 5 & 6 & 2 & 2 & 12 & 1 & 0 & 900 & 1350 & 1 & 2 & 4418 & 4665 & 2 & $i$ & 1 \\
\hline 38 & 5 & 6 & 2 & $i$ & 7 & $i$ & 1 & $?$ & $?$ & 2 & 1 & 6872 & 4690 & 2 & 1 & 1 \\
\hline 39 & 5 & 6 & 2 & 1 & 10 & 1 & 1 & 900 & 1350 & 1 & 2 & 3848 & 4700 & 1 & $i$ & 1 \\
\hline 40 & 5 & 4 & 2 & 2 & 0 & 1 & 2 & $?$ & ? & 2 & 1 & 7854 & 4615 & 1 & 1 & 1 \\
\hline 41 & 5 & 5 & 2 & 2 & 0 & 1 & 1 & $?$ & $?$ & 3 & 1 & 79 & 4620 & 2 & 2 & 1 \\
\hline 42 & 5 & 5 & 2 & 2 & 0 & 1 & 1 & 900 & 1350 & 1 & 2 & 3829 & 4625 & 1 & 2 & 1 \\
\hline 43 & 5 & 5 & 2 & 2 & 2 & $i$ & $i$ & $?$ & $?$ & 2 & 1 & 353 & 4640 & 2 & 2 & $i$ \\
\hline 44 & 5 & 5 & 2 & 2 & 1 & 1 & 1 & 900 & 1350 & 1 & 2 & 491 & 4825 & 2 & 1 & 1 \\
\hline 45 & 5 & 5 & 2 & 2 & 10 & $i$ & $i$ & $?$ & $?$ & 2 & 1 & 8835 & 4825 & 2 & $i$ & $i$ \\
\hline 46 & 5 & 5 & 2 & 2 & 15 & 1 & 1 & 900 & 1350 & 1 & 4 & 10210 & 4835 & 2 & 1 & $i$ \\
\hline 47 & 5 & 5 & 2 & 2 & 3 & $i$ & $i$ & $?$ & $?$ & 2 & 1 & 1060 & 4800 & 2 & 2 & 1 \\
\hline 48 & 5 & 5 & 2 & 2 & 3 & 1 & 1 & 900 & 1400 & 1 & 2 & 6774 & 4775 & 2 & 1 & 2 \\
\hline 49 & 5 & 5 & 2 & 2 & 4 & 1 & 1 & 900 & 1400 & 1 & 2 & 7068 & 4825 & 2 & 2 & 2 \\
\hline 50 & 5 & 5 & $?$ & $?$ & $?$ & 1 & 1 & noto & 1.350 & $i$ & 2 & 707 & 4815 & 2 & 1 & 2 \\
\hline
\end{tabular}




\begin{tabular}{|c|c|c|c|c|c|c|c|c|c|c|c|c|c|c|c|c|}
\hline 51 & 5 & 5 & 2 & 2 & 5 & 1 & 1 & 900 & 1350 & 1 & 2 & 707 & 4845 & 2 & 2 & 1 \\
\hline 52 & 5 & 5 & 2 & 2 & 6 & 1 & 2 & 900 & 1350 & 1 & 2 & 942 & 4845 & 1 & 1 & 1 \\
\hline 53 & 5 & 0 & 2 & 3 & 0 & 1 & 0 & 900 & 1350 & 1 & 2 & 1178 & 4770 & 1 & 1 & 1 \\
\hline 54 & 5 & 0 & 2 & 1 & 0 & 1 & 2 & $?$ & $?$ & 3 & 1 & 785 & 4880 & 1 & 2 & 1 \\
\hline 55 & 5 & 0 & 2 & 1 & 1. & 1 & 1 & $?$ & $?$ & 1 & 2 & 79 & 4790 & 1 & 2 & 1 \\
\hline 56 & 5 & 0 & 2 & 2 & 4 & 1 & 1 & $?$ & $?$ & 2 & 1 & 314 & 4755 & 1 & 1 & 2 \\
\hline 57 & 5 & 0 & 2 & 2 & 4 & 1 & 1 & $?$ & $?$ & 1 & 2 & 4712 & 4712 & 1 & 1 & 2 \\
\hline 58 & 2 & 1 & 2 & 1 & 0 & 1 & 0 & $?$ & $?$ & 3 & 1 & 785 & 4750 & 1 & 1 & 2 \\
\hline 59 & 2 & 1 & 2 & 1 & 0 & 1 & 1 & 900 & 1350 & 1 & 2 & 314 & 4750 & 1 & 1 & 1 \\
\hline 60 & 5 & 1 & 2 & 2 & 2 & 1 & 0 & 775 & 1350 & 1 & 2 & 314 & 4650 & 4 & 1 & 2 \\
\hline 61 & 5 & 1 & 2 & 2 & 8 & 1 & 1 & ? & $?$ & 2 & 3 & 20616 & 4725 & 1 & 1 & 2 \\
\hline 62 & 5 & 2 & 2 & 2 & 10 & 3 & 1 & 300 & 1400 & 4 & 4 & 29452 & 4675 & 1 & 1 & 4 \\
\hline 63 & 5 & 2 & 2 & 2 & 6 & 1 & 2 & 900 & 1350 & 1 & 4 & 10995 & 4660 & 1 & 1 & 2 \\
\hline 64 & 5 & 2 & 2 & 2 & 0 & 1 & 1 & $?$ & $?$ & 2 & 1 & 491 & 4650 & 2 & 1 & 1 \\
\hline 65 & 5 & 2 & 2 & 1 & 2 & $i$ & $i$ & $?$ & $?$ & 2 & 1 & 1963 & 4630 & 2 & 1 & 1 \\
\hline 66 & 6 & 3 & 3 & $i$ & 0 & 1 & $i$ & 900 & 1350 & 1 & 2 & 785 & 5650 & 3 & 3 & $i$ \\
\hline 67 & 6 & 3 & 3 & 1 & 4 & 1 & 0 & $?$ & $?$ & 5 & 1 & 314 & 4760 & 3 & 3 & 2 \\
\hline 68 & 5 & 4 & 3 & 2 & 0 & 3 & 0 & 900 & 1350 & 4 & 4 & 37934 & 4690 & 3 & 3 & 4 \\
\hline 69 & 5 & 0 & 2 & 1 & 8 & 1 & 0 & $?$ & $?$ & 2 & 1 & 471 & 4425 & 1 & 1 & 1 \\
\hline 70 & 5 & 2 & 2 & 1 & 2 & 1 & 0 & $?$ & $?$ & 2 & 1 & 1767 & 4455 & 1 & 1 & $i$ \\
\hline 71 & 5 & 2 & 2 & 2 & 0 & 1 & 1 & 900 & 1350 & 1 & 2 & 314 & 4465 & 2 & 1 & 1 \\
\hline 72 & 5 & 1 & 2 & 2 & 2 & 1 & 0 & 900 & 1350 & 1 & 2 & 1257 & 4465 & 1 & 3 & 1 \\
\hline 73 & 5 & 2 & 2 & 1 & 1 & 1 & 2 & 900 & 1350 & 1 & 2 & 314 & 4500 & 1 & 1 & 1 \\
\hline 74 & 5 & 2 & 2 & 1 & 3 & 1 & 2 & $?$ & $?$ & 5 & 1 & 471 & 4520 & 1 & 1 & $i$ \\
\hline 75 & 5 & 1 & 2 & 2 & 4 & 1 & 1 & 900 & 1350 & 1 & 2 & 2945 & 4525 & 2 & 1 & 1 \\
\hline 76 & 5 & 1 & 2 & 2 & 3 & 1 & 1 & 900 & 1350 & 1 & 2 & 314 & 4800 & 1 & 1 & 1 \\
\hline 77 & 5 & 1 & 2 & 2 & 2 & 1 & 2 & $?$ & $?$ & 2 & 1 & 884 & 4800 & 4 & 1 & 2 \\
\hline 78 & 5 & 1 & 2 & 2 & 0 & 1 & 2 & 1000 & 1350 & 1 & 2 & 707 & 4775 & 1 & 1 & 1 \\
\hline 79 & 1 & 3 & 2 & 2 & 1 & 1 & 1 & $?$ & $?$ & 2 & 3 & 141367 & 4400 & 2 & 3 & 2 \\
\hline 80 & 1 & 3 & 2 & 1 & 2 & 1 & 1 & 900 & 1350 & 1 & 2 & 491 & 4450 & 2 & 3 & 2 \\
\hline 81 & 1 & 6 & 2 & 2 & 15 & 1 & 2 & 300 & 1350 & 1 & 4 & 94245 & 4470 & 2 & 3 & 2 \\
\hline 82 & 3 & 4 & 4 & 2 & 0 & 1 & 1 & 1150 & 1400 & 1 & 2 & 393 & 4920 & 3 & 3 & 1 \\
\hline 83 & 3 & 4 & 4 & 1 & 4 & 1 & 0 & $?$ & $?$ & 2 & 1 & 4712 & 4840 & 2 & 3 & 2 \\
\hline 84 & 3 & 4 & 4 & 1 & 0 & 1 & 1 & $?$ & $?$ & 3 & 1 & 353 & 4920 & 3 & 3 & 2 \\
\hline 85 & 3 & 4 & 4 & 1 & 1 & 1 & 0 & ? & $?$ & 2 & 1 & 1 & 4590 & 2 & 3 & 2 \\
\hline 86 & 3 & 4 & 4 & 1 & 0 & 2 & 0 & $?$ & $?$ & 7 & 3 & 314 & 4640 & 3 & 3 & 2 \\
\hline 87 & 2 & 3 & 4 & 1 & 0 & 1 & 1 & ? & $?$ & 3 & 3 & 11781 & 4240 & 3 & 4 & 1 \\
\hline 88 & 2 & 3 & 4 & 1 & 0 & 1 & 1 & $?$ & $?$ & 3 & 1 & 1963 & 4240 & 3 & 3 & 1 \\
\hline 89 & 2 & 2 & 4 & 2 & 0 & 2 & 2 & 750 & 1350 & 4 & 4 & 13744 & 4130 & 2 & 3 & 3 \\
\hline 90 & 2 & $\mathbf{3}$ & 4 & 1 & 0 & 1 & 1 & $?$ & $?$ & 3 & 1 & 314 & 4320 & 3 & 2 & 1 \\
\hline 91 & 2 & 3 & 4 & 1 & 0 & 3 & 1 & 1900 & ? & 8 & - & 1963 & 4160 & 2 & 3 & 2 \\
\hline 92 & 2 & 3 & 2 & 2 & 9 & 2 & 2 & 700 & 1400 & 4 & 4 & $2,000,000+$ & 4500 & 1 & 1 & 3 \\
\hline 93 & 2 & & 2 & 1 & 0 & 1 & 2 & 9000BP & $7000 \mathrm{BP}$ & 2 & 1 & 400 & 4395 & 1 & 1 & 4 \\
\hline 94 & 1 & 3 & 2 & 1 & 0 & 1 & 2 & $?$ & $?$ & 10 & 2 & 11812 & 4500 & 3 & 3 & 4 \\
\hline 95 & 5 & 4 & 1 & 1 & 0 & 3 & 2 & 700 & 1300 & 7 & 3 & 314 & 5245 & 2 & 1 & 1 \\
\hline 96 & 1 & 4 & 2 & 1 & 0 & 1 & 2 & 900 & 1300 & 9 & 4 & 31415 & 4300 & 3 & 3 & 4 \\
\hline
\end{tabular}


TABLE 4

Mean Areas of Certain Site Categories

Site Category* $\quad \underline{N}$

$\begin{array}{lllll}\text { Lithic scatters } & 8 & 2,095.969 & 1,398.062 & 3,954.317\end{array}$

Lithic campsites $\quad 32 * * \quad 10,301.930 \quad 4,640.906 \quad 26,252.938$

$\begin{array}{lllll}\text { Ceramic campsites } & 38 & 20,052.887 & 10,226.973 & 63,043.305\end{array}$

*Because of the very limited samples in the first seven site categories (quarry site, petroglyph site, historic cemetery, bead caches, ceramic scatters, unassociated hearths and ceramic villages), mean data could not be computed.

**These represent sites for which valid observations were available. 


\section{THE ARTIFACTS}

In this section, the two major classes of artifacts found during the Radium Springs survey--lithics and ceramics--are described and illustrated. Lithic analysis was done by Stephen L. Black and Thomas R. Hester and ceramic studies were carried out by Erwin Roemer, Jr. and Paul R. Katz.

The emphasis during the fieldwork was on observation and recording, and in line with BLM specifications large samples of artifacts were not collected, except in unusual circumstances. An example of the latter is site AR095 where a cache of beads had been exposed. Only by collecting these materials could they be properly analyzed and evaluated (Appendix II); had they been left in place, they would have become trophies for the next relic-collector to happen along.

Artifact sampling was done primarily to aid in the evaluation of site temporal span and cultural affiliation. In addition, "type" specimens, e.g., of pottery or of particular kinds of rock used in tool manufacture, were collected.

We have prepared a number of 7 ine drawings and photographic illustrations of the collected artifacts and hope that their publication in this report will be of aid to future workers in the area. The specimens themselves are stored at the Center for Archaeological Research and are available to qualified researchers for further study. 


\section{LITHICS}

Stephen L. Black and Thomas R. Hester

\section{Introduction}

During the 1976 Radium Springs survey a variety of lithic artifacts were observed on sites in the area. As specified by the BLM contract, sampling was strictly limited to diagnostic artifacts and a few type samples. As a general rule, all projectile points were collected and representative examples of other tool types present on sites in the area were picked up. This limited sampling strategy served to indicate the range of lithic artifacts encountered within the survey area. The surface density of ground stone and chipped stone tools was estimated for each site by the survey crew. Time limitations did not allow careful examination of entire site areas, and thus these density figures reflect minimum numbers of lithics present on sites. Many sites may have considerable buried cultural deposits. As has been previously pointed out, "arrowhead" hunters frequent the survey area and are particularly interested in complete points, bifaces, metates, pestles, and well-made tools of any type. This factor adds a further bias to the nature and frequency of lithic artifacts left on site surfaces.

The lithics observed or collected during the 1976 survey have been divided into morphological and/or functional categories. It should be noted that lithic descriptions in New Mexican archaeological reports--especially those in early reports--are often quite vague and leave much interpretation to be done. A variety of terms have often been used to describe a given artifact; for example, concave scraper, hollow scraper and spokeshave have been applied to notched lithic artifacts. Projectile points have not been sorted into types as done in Texas (cf. the Handbook of Texas Archeology of Suhm, Krieger and Jelks 1954). This is largely due to the emphasis placed on ceramic cultures by Southwestern archaeologists and perhaps reflects, in part, a general lack of widespread distinctive projectile point styles (cf. Fitting 1972:45). A detailed description of the projectile points found during the survey is provided to facilitate comparison of survey area specimens with those in other areas of New Mexico. In some previous studies in nearby areas (cf. Levine and Mobley 1976:59, Skinner, Steed and Bearden 1973), Texas type descriptions (most of which have specific temporal, spatial and cultural attributes) have been loosely applied to projectile points in central New Mexico and far west Texas.

The artifacts are described in terms of range of variation observed in field and collected samples. Because the lithic sample collected was so small the actual numbers of these specimens are not indicated for each group. Rather, these descriptions serve to indicate the kinds of lithic tools that can be expected to be found during the course of future research in the area. Descriptions include: material types used, size range, shape range, workmanship, transverse sections, and functional interpretations based on wear patterns. Transverse sections were described using DiPeso's (1974:Vo1. 7) terminology. In a number of categories, we have provided a description of what a "typical specimen" generally looks like. 


\section{Artifact Descriptions}

In the brief artifact descriptions that follow, an effort has been made to present a maximum amount of descriptive data with a minimum of verbiage. Thus, we have used incomplete sentences in many instances.

\section{Bifacial Artifacts}

Quarry blanks (Fig. 8,3-g)

Description: Thick unfinished bifaces. Represent initial stages of bifacial reduction--making thick blanks roughly shaped but not appreciably thinned. Some of these specimens may have been made from flakes; others, on cobbles. Generally oval shaped. Transverse section: plano-convex, bi-plano and biconvex. Materials mostly low grade chert and felsite. A few are made from glossy chert and one of agate.

Measurements: Length: $7.8-4.7 \mathrm{~cm}$; width: $3.3-6 \mathrm{~cm}$; thickness: $1.5-2.4 \mathrm{~cm}$; weight: $29.2-76.7 \mathrm{gm}$. Typical specimen: $6.5 \mathrm{~cm} \times 4.8 \times 2 \mathrm{~cm} ; 51.3 \mathrm{gm}$; felsite.

Function: First stage of bifacial reduction.

Preforms: (not illustrated)

Description: These bifaces represent further reduction; they have been partially thinned and shaped. Most of these are broken, presumably during manufacturing. Rectangular and rounded bases; bi-convex transverse sections. A few specimens have marginal retouch indicating use after breakage. Materials: glossy and dull cherts, felsite and basalt.

Measurements: Length: $3-5 \mathrm{~cm}$ (broken specimens indicate greater range); width: 2.5-6.8 cm; thickness: $1.8-1.4 \mathrm{~cm}$; weight: (complete) 5.5-26.7 gm, (broken) 6.7-43.5 gm, indicating range in weight much greater.

Function: Probable second stage of bifacial reduction; thinning and final shaping along edges not completed. Most specimens appear to have been broken during manufacturing due to flaws within material or mistakes by the knapper.

"Finished" bifaces (Fig. 8,a-d)

Description: These bifaces are marginally retouched and appear to have been finished to form sharp and thin cutting edges, with low edge angles. Shapes ovate, rectangular-based, and rounded base. Most specimens are broken. Materials: glossy gray chert (over 60\%), a glossy and semi-glossy cherts. Material much better than blanks or preforms. 

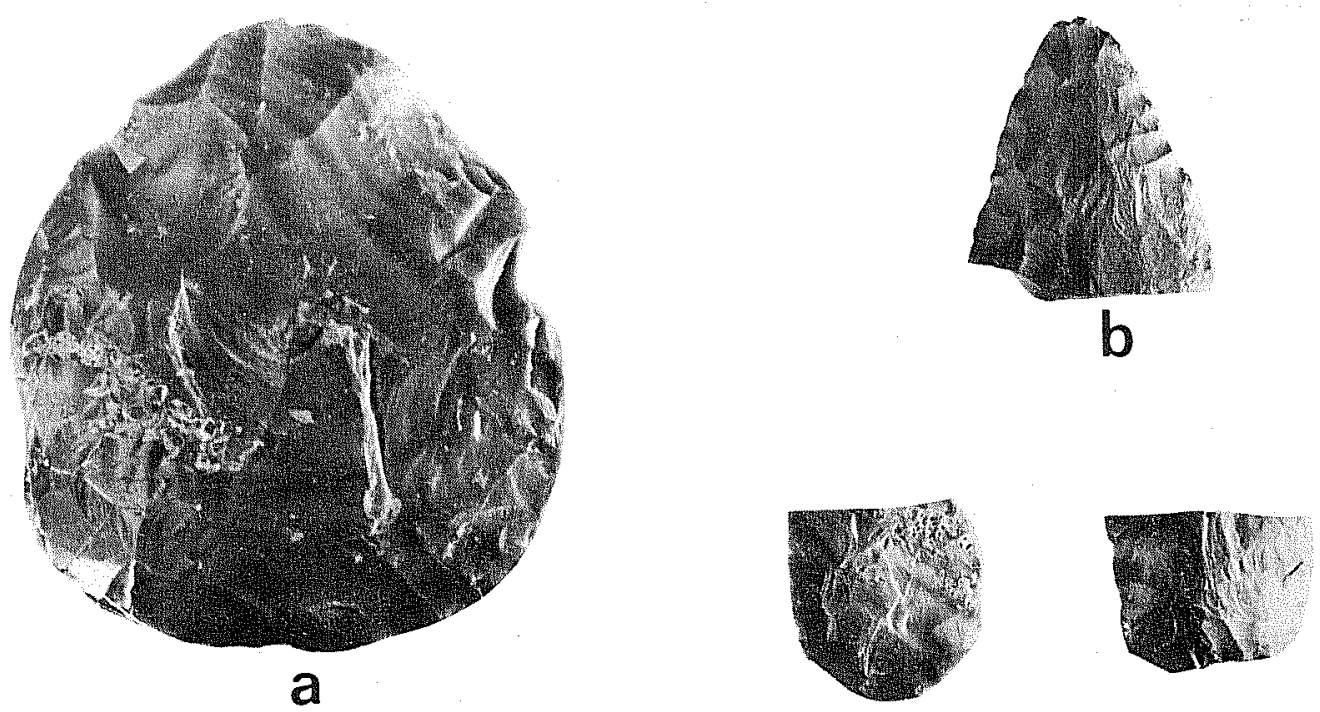

C

d

\section{\begin{tabular}{c|c|c|c|c|c|} 
& 1 & 1 & 1 & 1 & 1 \\
cm & 1 & 2 & 3 & 4 & 5
\end{tabular}}
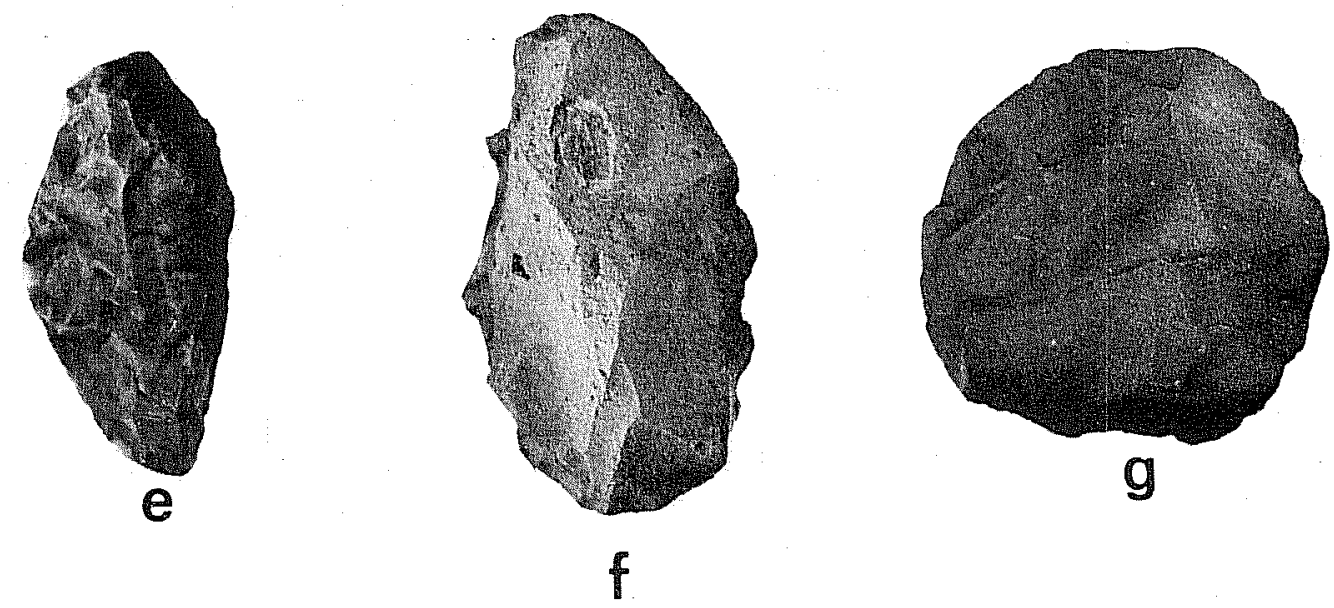

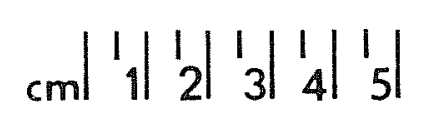

Figure 8. Bifacial Artifacts. a-d, finished bifaces (AR009; AR062; RS031, SW4; R032, SW4); e-g, quarry blanks (AR063, AR094, AR056). 
Measurements: Two complete specimens, both are ovate. Dimensions of first: $8 \times 6.8 \times 1.6 \mathrm{~cm} ; 1-1.2 \mathrm{gm} ;$ bit angle $41-49^{\circ}$. Second specimen: $4.2 \times 3.3$ $x .8 \mathrm{~cm} ; 12.5 \mathrm{gm}$; edge angle $44-48^{\circ}$. A11 broken bifaces fall within range indicated by two complete examples.

Function: Used as cutting tools as indicated by parallel striations and step fractures observed microscopically on both faces along edges.

Projectile Points

In the following descriptions, all linear measurements are in centimeters, and weights are expressed in grams. Measurements of fragmentary specimens are enclosed in parentheses. General provenience data are also provided, and the following abbreviations are used: RSO (programmed survey section; no specific site found and specimens are isolated surface finds); SW (indicates the "sweep" number during which the specimen was collected); ARO (specific site recorded during survey activities). One specimen was found during the process of delineating one of the survey sections; its provenience here is recorded in terms of township and range. More detailed provenience data are on file at the Center for Archaeological Research.

Folsom (Fig. 9,a). The specimen is a basal fragment of a Folsom fluted point made of 1 ight gray chert. Fluting is present on both faces; while the base is fragmentary, a portion of a basal "nipple" (striking platform) is apparent. Fine parallel flaking is present on the body perpendicular to the flutes. Length of the fragment is $(2.8) \mathrm{cm}$; width is $2.1 \mathrm{~cm}$; thickness is $14 \mathrm{~cm}$; and it weighs $3.2 \mathrm{gm}$. Prov.: RS027, SWI.

Angostura (Fig. 9,b). This basal fragment of a lanceolate late PaleoIndian point appears to fall within the Angosturea type as defined by Suhm, Krieger and Jelks (1954). It has a slightly concave base; the lateral edges are dulled. Flake patterning is difficult to discern due to weathering. The material of manufacture is a dull pink to beige chert. Length is (1.9) $\mathrm{cm}$; width, $2.0 \mathrm{~cm}$; thickness, $.5 \mathrm{~cm}$; and it weighs $2.1 \mathrm{gm}$. Prov.: AR093.

Expanding Stem Points (Figs. 9, 10). There are a series of projectile points, apparently dart points (although some, like Fig. 10,0, may have been arrow points) with expanding stems formed by corner notching. These range from large, well-flaked specimens such as the example shown in Fig. 9,c to smaller and more crudely worked specimens, as exemplified by the specimen in Fig. 10,c. Of particular interest is the point shown in Fig. 9,e. It bears a great deal of resemblance to early stemmed dart point forms found in the late Paleo-Indian and pre-Archaic phases in central and southwestern Texas (cf. Sollberger and Hester 1972). 

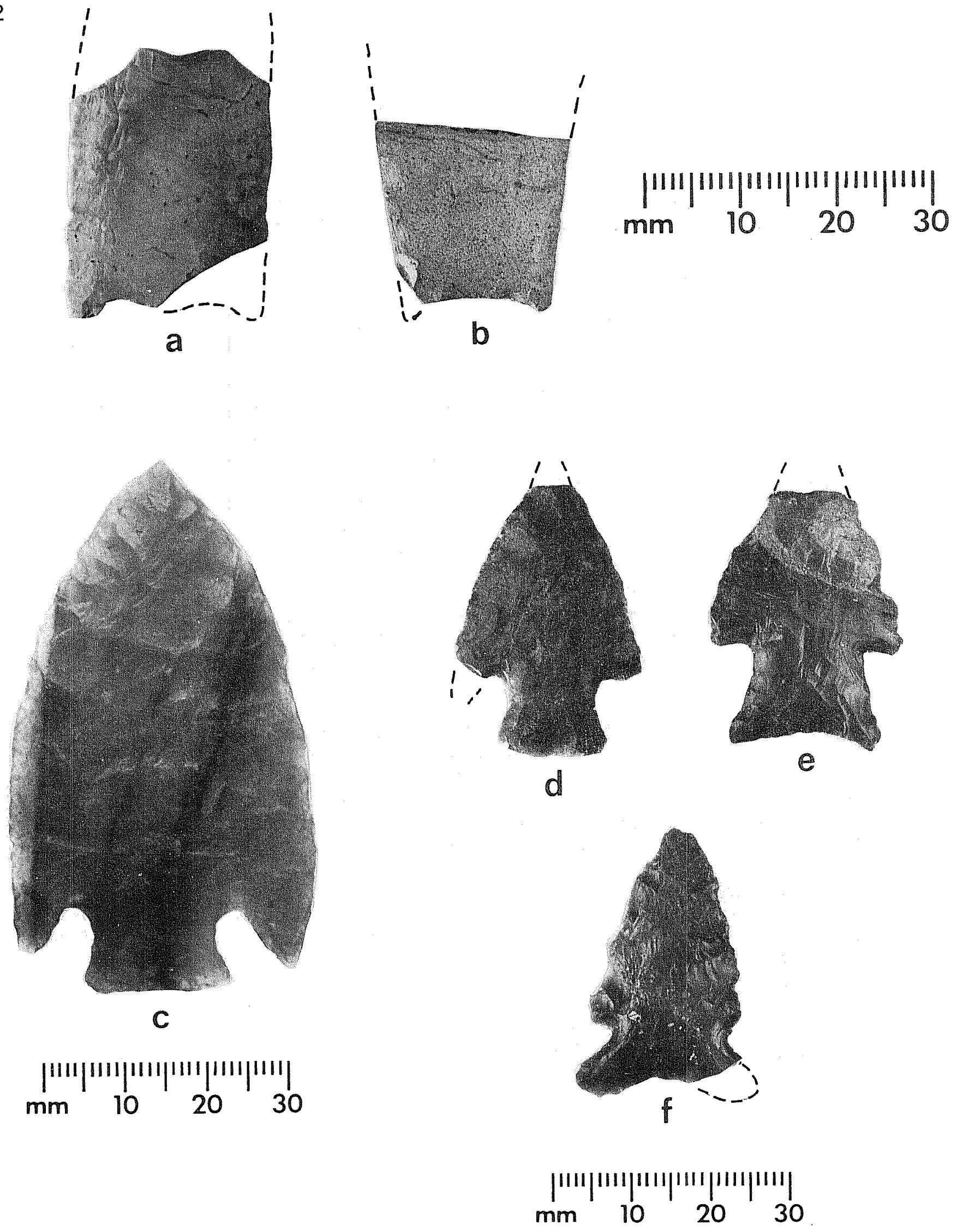

Figure 9. Projectile Points from Radium Springs Survey Area. a, Folsom, RS027 SW1; b, Angostura, AR093; c, AR023; d, AR004; e, AR077; f, AR012. 


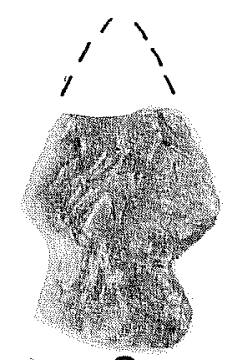

a

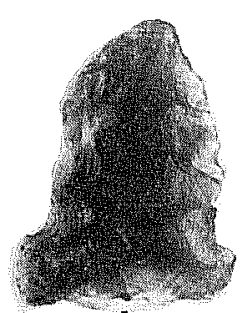

b

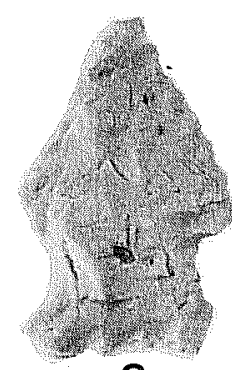

C
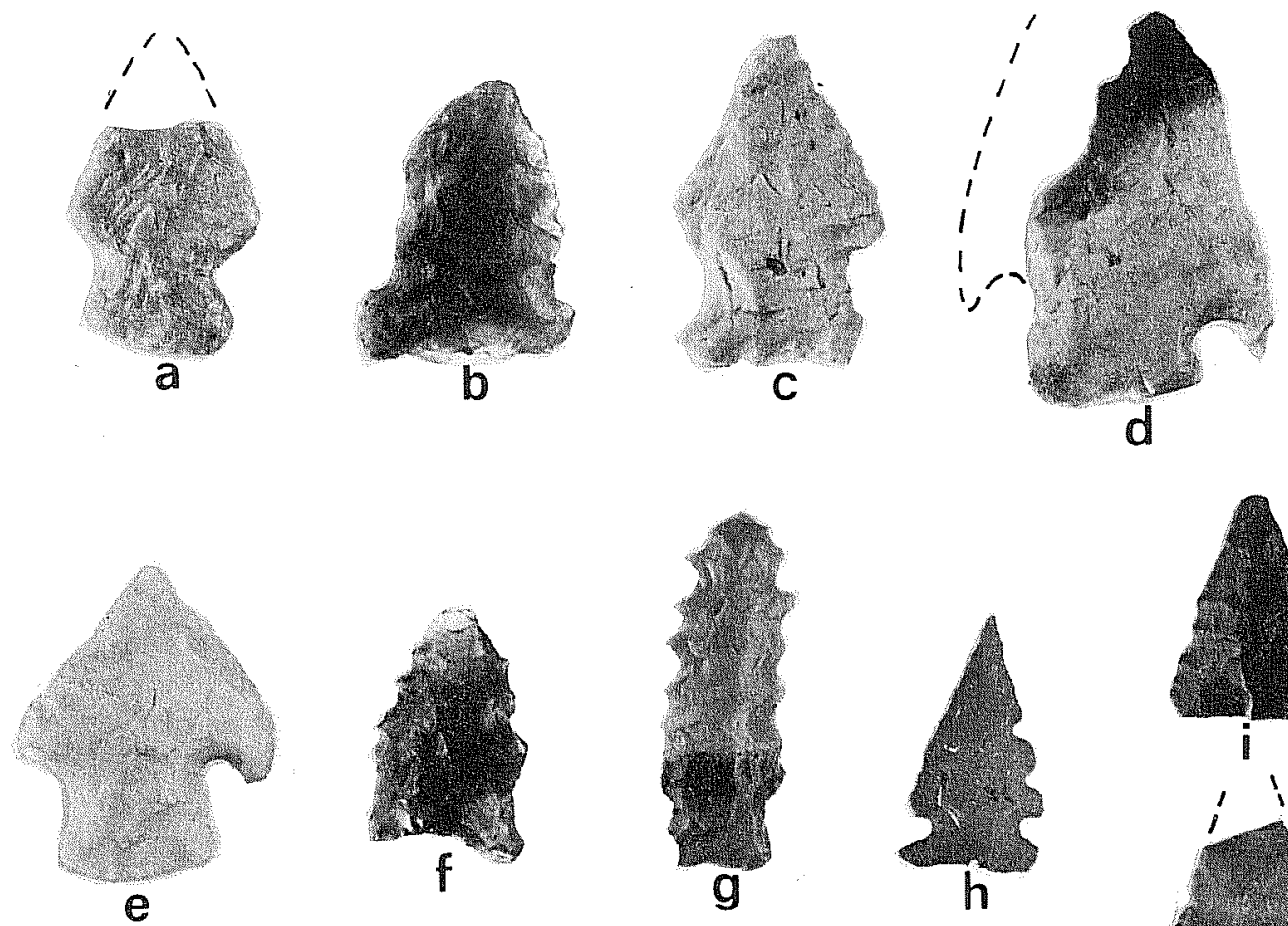

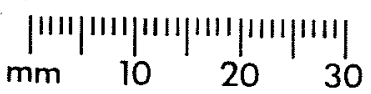
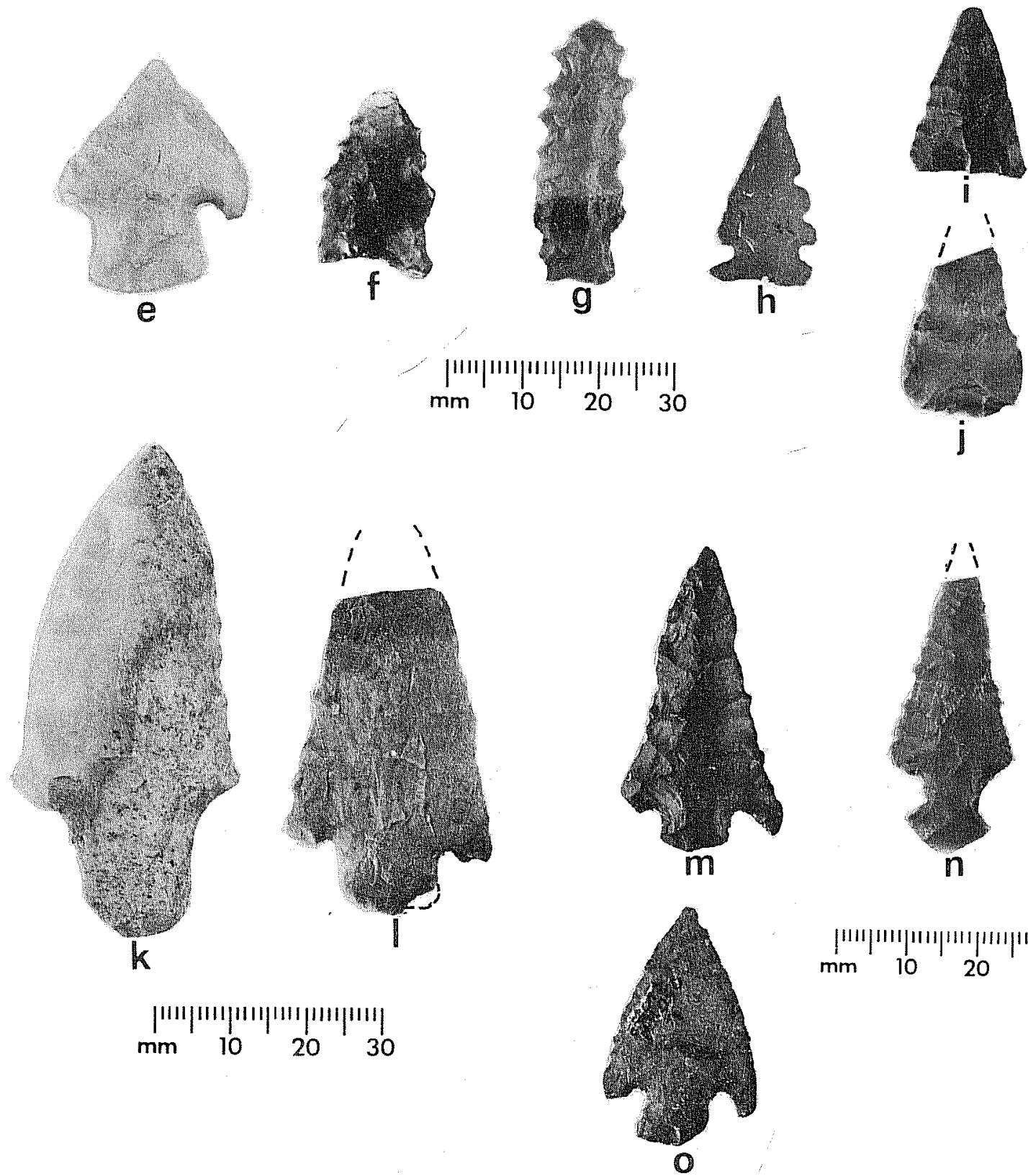

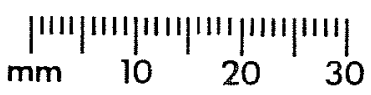

Figure 10. Projectile Points from Radium Springs Survey Area. a, AR063; b, AR007; c, RS015, SW2; d, AR002; e, AR062; f, RS019, SW4; g, AR061; h, AR062; i, AR062; j, AR042; k, T14S, RIF, Section 10; 1, RSO23, SW1; $\mathrm{m}, \mathrm{RS} 013, \mathrm{SW} 3 ; \mathrm{n}, \mathrm{ARO20} ; 0, \mathrm{ARO50}$. 
Dimensions and comments regarding these expanding stem dart points are given below:

\begin{tabular}{|c|c|c|c|c|c|c|}
\hline Fig. Ref. & $\frac{\mathrm{L}}{(\mathrm{cm})}$ & $\frac{W}{(\mathrm{~cm})}$ & $\frac{T}{(\mathrm{~cm})}$ & $\frac{W t}{(g m)}$ & Material & Prov. \\
\hline $9, c$ & 6.3 & 3.7 & .65 & 15.3 & $\begin{array}{l}\text { light gray, } \\
\text { translucent } \\
\text { chert }\end{array}$ & AR023 \\
\hline $9, d$ & $(3.4)$ & $(2.3)$ & .4 & 3.2 & $\begin{array}{l}\text { dark gray } \\
\text { chert }\end{array}$ & AR004 \\
\hline $9, e$ & $(3.2)$ & 2.4 & .6 & 4.3 & $\begin{array}{l}\text { dark gray } \\
\text { chert }\end{array}$ & AR077 \\
\hline $10, c$ & 3.2 & 2.1 & 1.0 & 3.3 & $\begin{array}{l}\text { white-gray } \\
\text { chert }\end{array}$ & $\begin{array}{l}\text { RS015 } \\
\text { SW2 }\end{array}$ \\
\hline $10, d$ & 3.9 & $(2.4)$ & .6 & 5.0 & $\begin{array}{l}\text { white-gray } \\
\text { chert }\end{array}$ & AR002 \\
\hline $10, e$ & 3.0 & 2.4 & .6 & 3.7 & white chert & AR062 \\
\hline 10,0 & 3.2 & 2.1 & .4 & 2.2 & $\begin{array}{l}\text { black-mottled } \\
\text { brown chert }\end{array}$ & AR050 \\
\hline
\end{tabular}

$\begin{array}{lllllll}\text { not illus. } & 2.7 & 1.6 & .4 & 1.8 & \begin{array}{l}\text { white-gray } \\ \text { chert }\end{array} & \begin{array}{l}\text { RS019 } \\ \text { SW4 }\end{array}\end{array}$

$\begin{array}{llllll}\text { not illus. (2.0) } & 2.0 & .5 & 1.9 & \text { black chert } & \text { RS006 }\end{array}$

AR006

Side-Notched Points (Figs. 9, 10). The side-notched points series includes specimens which functioned as dart and arrow points. The specimen in Fig. 9,f is side-notched, and has a concave basal edge; it appears to be a dart point. Others, like the smaller specimens illustrated in Fig. 10,a,b and the sidenotched, bulbous stem point in Fig. 10, $\mathrm{n}$, may have been arrow points.

Descriptive data for these specimens follow:

$\begin{array}{ccccccc}\text { Fig. Ref. } & \left.\frac{\mathrm{L}}{\mathrm{cm}}\right) & \frac{W}{(\mathrm{~cm})} & \frac{\mathrm{T}}{(\mathrm{cm})} & \frac{W t}{(\mathrm{gm})} & \underline{\text { Material }} & \text { Prov. } \\ 9, \mathrm{f} & 3.4 & (2.1) & .5 & 2.6 & \begin{array}{l}\text { dark gray } \\ \text { chert }\end{array} & \text { AR012 } \\ 10, \mathrm{a} & (2.3) & 1.8 & .5 & 2.2 & \begin{array}{l}\text { gray-white } \\ \text { mottled chert }\end{array} & \text { AR063 } \\ 10, \mathrm{~b} & 2.7 & 1.9 & .6 & 2.8 & \begin{array}{l}\text { brown-gray } \\ \text { chert }\end{array} & \text { AR007 } \\ 10, \mathrm{n} & (3.7) & 1.6 & .4 & 2.1 & \begin{array}{l}\text { dark gray } \\ \text { chert }\end{array} & \text { AR020 }\end{array}$


Rectangular-Stemmed Points (Fig. 10, $k, 1$ ). Two large dart points have rectangular stems and broad triangular bodies. The complete specimen shown in Fig. 10,k is made of white-gray chert. It is $6.9 \mathrm{~cm}$ long, $2.3 \mathrm{~cm}$ wide, 1.1 $\mathrm{cm}$ thick and weighs $20.6 \mathrm{gm}$. Prov.: T145, R12, S10. The second specimen is fragmentary, lacking the distal tip and a portion of the stem. It is made of light gray chert. Parallel flake scars are noted on the body. Length is (4.1) cm; width, $2.9 \mathrm{~cm}$; thickness, $.6 \mathrm{~cm}$; and it weighs $7.8 \mathrm{gm}$. Prov.: RS023, SWT.

Lozenge-Shaped Points (not illustrated). Two unstemmed projectile points are lozenge-shaped in outline, with their size and weight indicative of use as arrow tips. One specimen is complete. It is made of gray-white translucent chert; length is $3.8 \mathrm{~cm}$; width, $1.5 \mathrm{~cm}$; thickness, $.5 \mathrm{~cm}$; and it weighs $2.7 \mathrm{gm}$. Prov.: RSO03, SW2. The second specimen lacks the distal tip; flaking is crude and there are denticulations along a section of one lateral edge. It is made of white chert. Length is $(3.4) \mathrm{cm}$; width, $2.0 \mathrm{~cm}$; thickness, $.4 \mathrm{~cm}$; and it weighs $2.7 \mathrm{gm}$. Prov.: AR070.

Small Triangular Points (Fig. 10, $i, j$ ). Both are small arrow points. The complete specimen is made of pale gray chert; it is $2.2 \mathrm{~cm}$ long, $1.5 \mathrm{~cm}$ wide, $15 \mathrm{~cm}$ thick, and weights $1.3 \mathrm{gm}$. Prov.: AR062. The second specimen has a somewhat rounded base and is lacking the distal tip. It is made of light brown-gray chert. Length is $(2.2) \mathrm{cm}$; width, $1.5 \mathrm{~cm}$; thickness, $3 \mathrm{~cm}$; and it weighs $1.0 \mathrm{gm}$.

Serrated Points (Fig. 10,f,g,h). The three specimens in this series have serrated Tateral edges. Perhaps a better characterization of the treatment of one lateral edge on Fig. 10, h is "multiple side-notching." It somewhat resembles the Temporal type defined as a diagnostic of the Jornada Branch of the Mogolion (Brook 1972).

Descriptive data for the three points are given below:

\begin{tabular}{|c|c|c|c|c|c|c|}
\hline Fig. Ref. & $\left.\frac{\mathrm{L}}{\mathrm{cm}}\right)$ & $\frac{W}{(\mathrm{~cm})}$ & $\frac{\mathrm{T}}{(\mathrm{cm})}$ & $\frac{W t}{(g m)}$ & Material & Prov. \\
\hline $10, f$ & 2.3 & 1.0 & .6 & 1.9 & $\begin{array}{l}\text { translucent } \\
\text { black obsidian }\end{array}$ & RSO15 \\
\hline 10,9 & 3.4 & 1.2 & .5 & 2.2 & $\begin{array}{l}\text { light gray } \\
\text { chert }\end{array}$ & AR061 \\
\hline $10, h$ & 2.5 & 1.4 & .4 & 1.0 & red chert & AR062 \\
\hline
\end{tabular}

Fragmentary Stemmed Point (Fig. 10,m). This specimen is barbed, has a triangular body, and a sTightiy expanding stem. However, the basal edge is broken, and the original stem configuration cannot be determined. It is made of black chert. Length is $(4.0) \mathrm{cm}$; width, $1.7 \mathrm{~cm}$; thickness, $.5 \mathrm{~cm}$; and it weighs $3.4 \mathrm{gm}$. Prov.: RS013, SW3.

Dril1s and Perforators (Fig. $11, d-h$ )

Description: This group of bifacial tools was carefully manufactured for a specific purpose--boring or punching holes. All these tools which have 

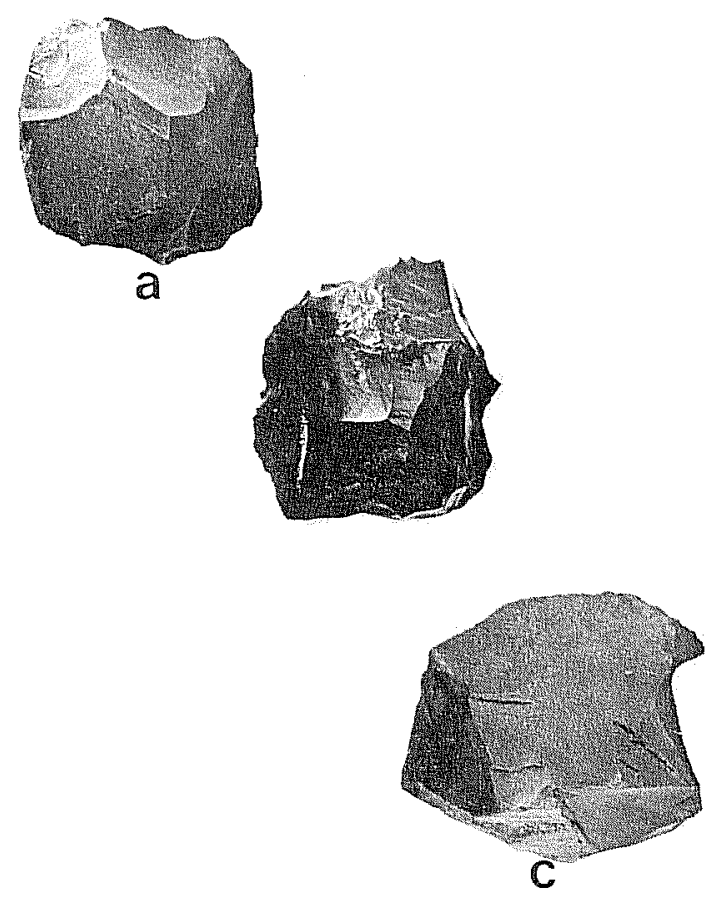

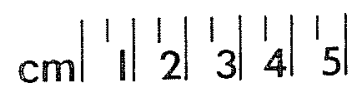
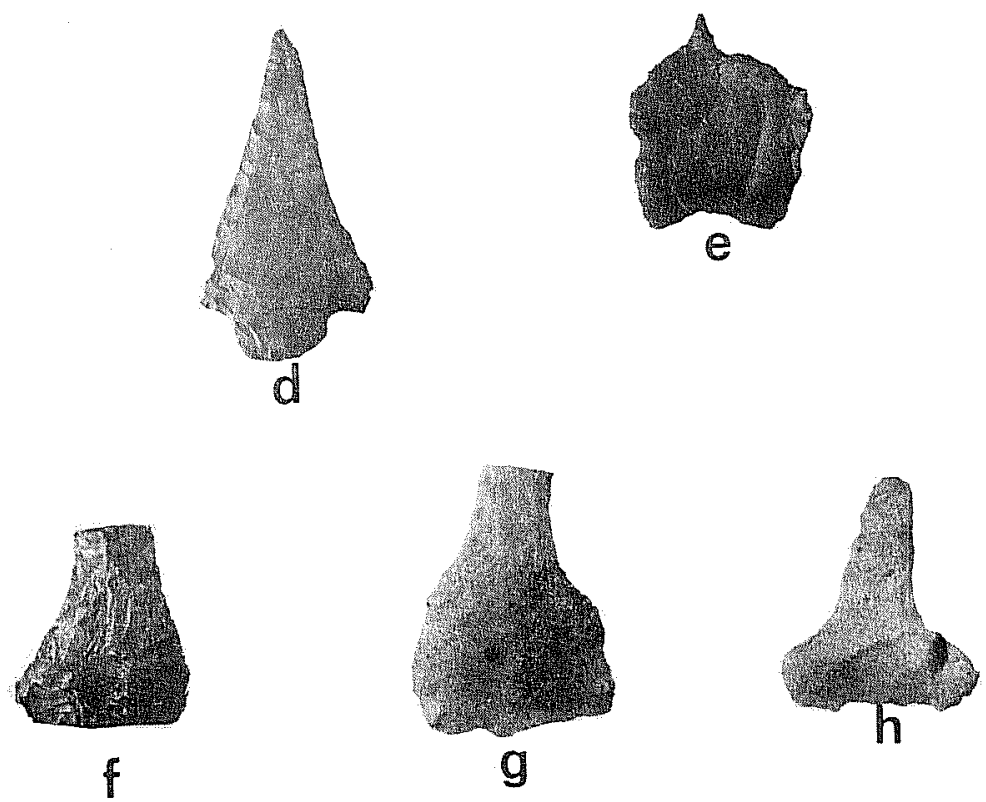

\section{$\operatorname{cm} \mid$\begin{tabular}{lll|l|l|l|}
1 & 1 & 1 & 1 & 1 \\
& & 2 & 3 & 4 & 5
\end{tabular}}

Figure 11. Cores and Driles. a-c, cores (AR068; AR080; RS032, SW1); d-h, dril1s (AR068; AR011; RS032, SW3; AR044; AR030). 
intact base segments have flaring bases which would facilitate either hafting or gripping with hands. Transverse sections are usually asymmetrical and bi-convex. Several of these tools (Fig. 11,d) appear to be reworked projectile points. All of these tools are carefully made of glossy to semiglossy cherts and silicified wood. Most exhibit considerable wear suggestive of long use. Many of these tools; are broken, presumably during usage. Tip sections of drills are usually very thick in relation to width of tip.

Measurements: Length: (complete) 2.7-4.1; width of base: $1.2-2.5 \mathrm{~cm}$; thickness: .4-18 cm; bit length: 1.1-1.9; bit maximum thickness: $.15-.6 \mathrm{~cm}$; bit maximum width: $.4-1.1 \mathrm{~cm}$.

Function: All but one example have rotary wear patterns typical of drills. This pattern is indicated by step fractures occurring on opposite faces of opposite edges. These edges are dulled, occasionally polished, with many minute step fractures and nibbling (see Fig. 21). The one specimen without rotary wear is a triangular biface with a needle sharp point. Step fractures and flake scars occur only on one face or tip indicating that it was never used in rotary fashion. This tool may have been used to punch holes in some soft material, such as leather.

\section{Cores and Flakes}

Cores (Fig. $11, \mathrm{a}-\mathrm{C}$ )

Description: Cores were made from many types of material. Flakes were removed for use in making other chipped stone tools. Fitting (1972) has divided cores from Mimbres area survey into four types: Block, Plano-convex, Bi-convex and Sma11. A11 four types are represented in survey area but a majority of these artifacts would be termed "blocky" in Fitting 's typology. Little of the cortex remains on these artifacts. Most are blocky cores having had flakes removed from various surfaces at many angles. Many cores are very sma11., probably exhausted. Two cores appear to have prepared platforms. Materials include glossy-dull, banded-mottled cherts, basalt, and cherty limestone. In general, larger cores are poorer quality; small cores are fashioned of better quality glassy cherts.

Measurements: Length: $3.5-8 \mathrm{~cm}$; width: $2.4-6.8 \mathrm{~cm}$; thickness: $1.7-5.4 \mathrm{~cm}$; weight: 15-206 gm. Typical specimen: $6.1 \times 5.1 \times 4.1 \mathrm{~cm} ; 110.6 \mathrm{gm}$.

Function: Production of flakes.

Utilized Flakes. Flakes which show wear (nibbling or step fractures) or edge damage but do not appear to have been purposefully retouched. These are perhaps the most numerous artifacts observed on the sites. Most flakes except the very small specimens have a few tiny flakes removed from edge. They were presumably used as cutting or scraping tools for a brief time and discarded. Utilized flakes range from very small to very large and include all types of materials found on survey.

Core Trimmers. Occasionally flakes were found which had battering marks, and/ or flake scars (similar to scraper wear) on dorsal edge. These flakes were 
removed to change angle or direction of core platforms or to create a new platform for removing flakes from cores. Materials include glossy, dull and banded cherts. The term "core rejuvenation flake" could also be used in describing these artifacts.

Debitage and Chunks. Lithic waste in the form of flakes and chunks was very numerous and represents all types of raw material found on survey. These materials were not collected due to sampling restrictions.

\section{Unifacial Artifacts}

"Pulping Plane" (Fig. 12,a,b)

Description: Large heavy unifacial tools made from oblong, angular chert, and basaltic chunks. Material is uniformly of poor flaking quality. Typically, one edge is flaked the entire length of tool. Opposite working edge is a perpendicular face giving the tool a "backed" effect. Transverse sections: Wedge, bi-plano, trapezoidal and irregular.

Measurements: Length: $10-17 \mathrm{~cm}$; width: $4-8 \mathrm{~cm}$; thickness: $1.2-4.3 \mathrm{~cm}$; bit angle: $55-80^{\circ}$; weight: $160-600 \mathrm{gm}$. Typical specimen: $15 \mathrm{~cm} \times 7 \mathrm{~cm} \times$ $3.3 \mathrm{~cm} ; 500 \mathrm{gm}$; bit angle $70^{\circ}$.

Function: Wear patterns inconclusive. All flake scars removed from one face; no striations. Step fractures on worked face only. May have served as chopping or scraping tool or both, probably as hand held tool (see Hester and Heizer 1972 for a discussion of similar tools, which they term "scraper planes").

End Scrapers (Fig. 12,h)

Description: Flake tools with worked edge on end or ends of flake only. Bit angles tend to be steep. Worked end always convex. Transverse section is plano-convex. Variety of material used included chert, quartzite, and felsite.

Measurements: Length: $2.3-7 \mathrm{~cm}$; width: $2.3-6 \mathrm{~cm}$; thickness: $9-1.8 \mathrm{~cm}$; weight: $7.2-55.8 \mathrm{gm}$; bit angle: 50-79\%. Typical specimen: worked on one end; quartzite; bit: $2.5 \mathrm{~cm}$ long; $5.7 \mathrm{~cm} \times 3.6 \mathrm{~cm} \times 1.7 \mathrm{~cm} ; 32 \mathrm{gm}$; bit angle $60-68^{\circ}$.

Function: As the term implies, this tool form was used for some sort of scraping task. Step fractures on bit. No striations observed under microscopic study.

End-Side Scrapers (Fig. $12, i, j$ )

Description: Flake tools worked on one or both ends, and one or both lateral edges. Most often one end and adjacent sides are worked producing a working edge of semi-circular outline. These tools usually exhibit very careful workmanship. Transverse section is plano-convex. Most of these 

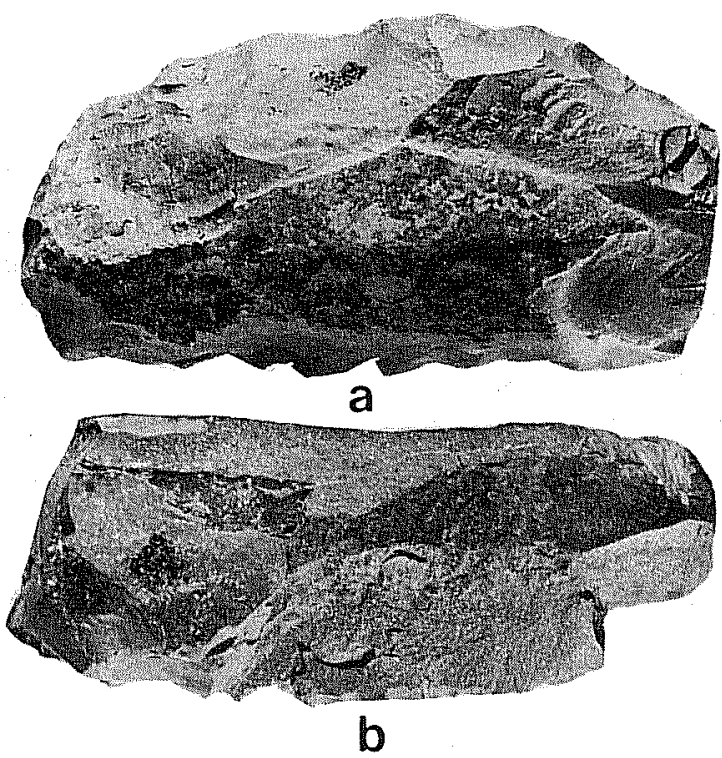

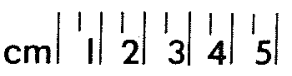
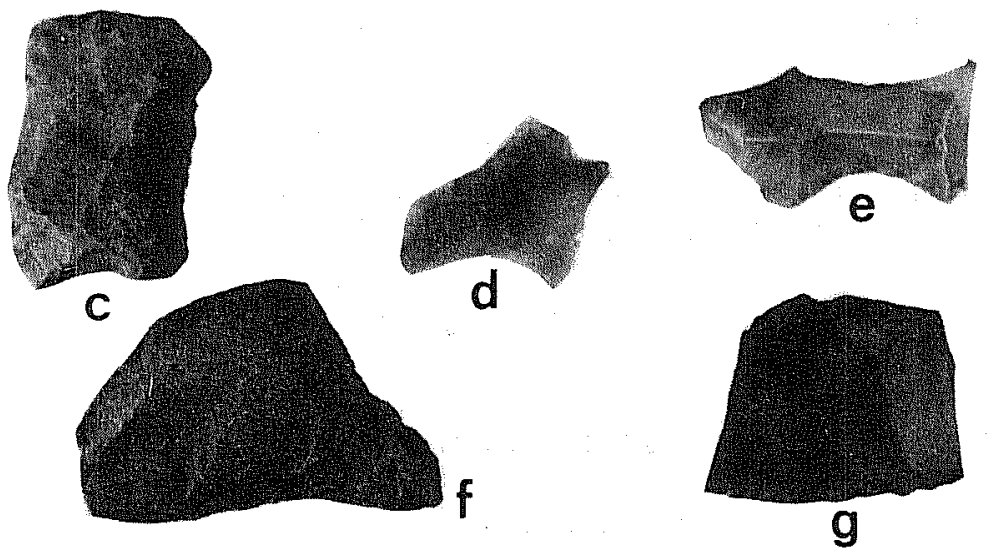

$$
\mathrm{cm}\left|\begin{array}{l|l|l|l|l|l|}
1 & 1 & 1 & 1 & 1 \\
& 2 & 3 & 4 & 5
\end{array}\right|
$$
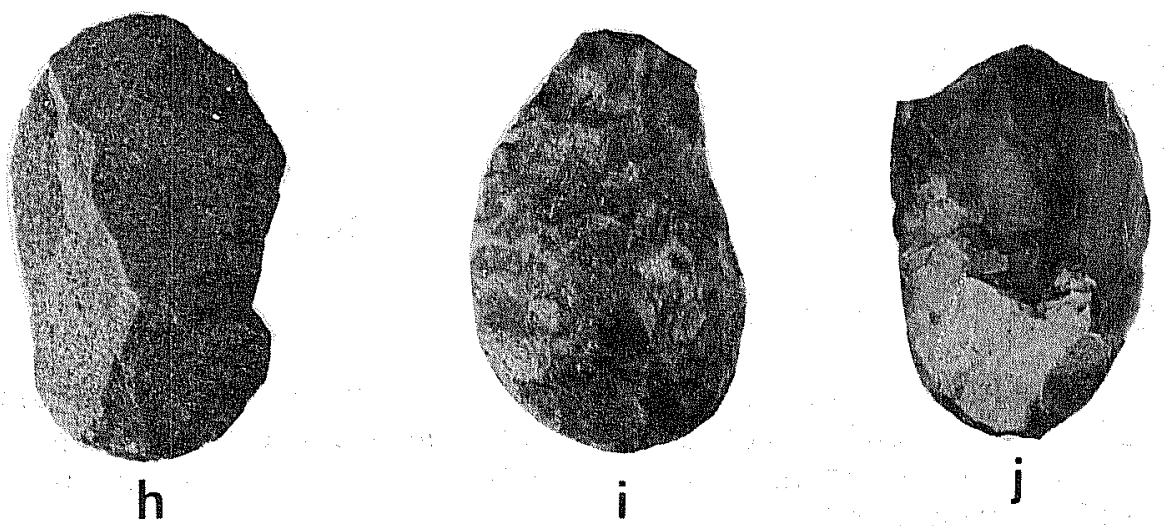

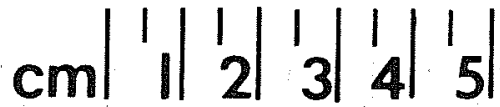

Figure 12. Unifacial Artifacts. a, pulping plane (AR011); b, pulping plane (RS013, SW2); c, multi-purpose scraper (AR035); d, concave scraper (AR044); e, concave scraper (AR062); f, side scraper (AR062); g, side scraper (AR001); $h$, end scraper (AR084); $i$, end-side scraper (ARO68); $j$, end-side scraper (RSO33, SWI). 
tools were worked on all available edges, and usually on dorsal face. occasionally, tool is worked on alternate faces of opposite lateral edges. Materials are glossy and grainy cherts, fine grained quartzite. Flaking quality of material usually very good.

Measurements: Length: $3.1-7.4 \mathrm{~cm}$; width: $2.3-5.7 \mathrm{~cm}$; thickness: $.6-2.1 \mathrm{~cm}$; weight: $7.2-84 \mathrm{gm}$; bit angles : $50-85^{\circ}$. Typical specimen: worked on one end and both sides; convex bit outline; mottled glossy chert; $5.1 \mathrm{~cm} \times 3.4 \mathrm{~cm} \times$ $1.1 \mathrm{~cm} ; 20.7 \mathrm{gm}$; bit angle $60-70^{\circ}$.

Function: Apparently similar to that of the end scraper category.

Multipurpose Scrapers (Fig. 12,c)

Description: Unifacial tools having several types of trimmed edges, usually including one or more concave bits and one or more convex or straight bits. Irregularly shaped and sized but a 11 are characterized by at least two different types of working bits. Material includes glossy chert to cherty stone.

Measurements: Length: $3.4-10 \mathrm{~cm}$; width: $3-4.5 \mathrm{~cm}$; thickness: $1-3.8 \mathrm{~cm}$; weight: $15-138 \mathrm{gm}$; bit angles: $60-90^{\circ}$. Sample was too small to permit description of a "typical" specimen.

Function: Given the variation in bit types and angles, multi-functional scraping tasks are presumed.

Oval Plano-Convex Scrapers (not illustrated)

Description: Oval outline, with thick plano-convex transverse section. Worked on all edges of dorsal face. Material, size, and workmanship vary considerably. Materials are cherty limestone to glossy chert; most are coarse quality cherty inaterial.

Measurements: Length: $3.8-8.5 \mathrm{~cm}$; width: $1.5-6.5 \mathrm{~cm}$; thickness: $1.1-2.8 \mathrm{~cm}$; weight: $9-202 \mathrm{gm}$; bit angles: $65-85^{\circ}$. Typical specimen: $6 \mathrm{~cm} \times 3.5 \times 2.4 \mathrm{~cm}$; $60 \mathrm{gm}$; bit angle $66-84^{\circ}$.

Function: Step fractures on ventral face indicate probable use as scraper.

Concave Scrapers (Fig. 12,d,e)

Description: These are also called "hollow scrapers" and "spokeshaves." They are small flake tools with a distinct, well-worked concave bit on one or two edges. Most specimens have two such bits. Materials include glossy cherts and silicified wood.

Measurements: Length: $2-4.5 \mathrm{~cm}$; width: 1.9-3.1 cm; thickness: $.3-1.1 \mathrm{~cm}$; weight: $2-8.1 \mathrm{gm}$; bit angle: $60-77^{\circ}$; bit lengths: $1.8-3 \mathrm{~cm}$. Typical specimen: $3.8 \mathrm{~cm} \times 3.0 \mathrm{~cm} \times .3 \mathrm{~cm} ; 2.5 \mathrm{gm}$; bit angle $70-75^{\circ}$.

Function: Often assumed to be woodworking tools, perhaps shaft smoothers. No definitive wear patterns were seen under high magnification. 
Side Scrapers (Fig. 12,f,g)

Description: Includes all unifacial tools worked on one or more edges and not fitting within above categories. As would be expected, these tools range widely in all respects--size, material, shape, bit angle, etc. A majority of these tools are well to fairly well worked on longest edge of tool. Al1 are worked on dorsal surface. Materials vary from glossy to dul1 cherts, felsite, basalt, and quartzite.

Measurements: Length: $2.9-8 \mathrm{~cm}$; width: $2.2-5.2 \mathrm{~cm}$; thickness: $.7-2 \mathrm{~cm}$; weight: $6-76.5 \mathrm{gm}$; bit angles: $55-75^{\circ}$. Typical specimen: semi-glossy grey chert careful1y worked on entire length of longest edge; $5.8 \mathrm{~cm} \times 3.7 \times 1.4$ $\mathrm{cm} ; 30.9 \mathrm{gm}$; bit angle $69^{\circ}$.

Function: Step fractures on worked face only; no striations observed.

Flake Scrapers (not illustrated)

Description: Flakes and flake fragments carefully worked on one face along one or two edges. Bit angles tend to be lower than other scrapers. Some flakes have serrated or partially serrated edges. These tools vary considerably with respect to shape, size, material, etc.

Measurements: Length: $2.8-9.5 \mathrm{~cm}$; width: $2.2-5.8 \mathrm{~cm}$; thickness: $4-2.4 \mathrm{~cm}$; weight: $7-8.7 \mathrm{gm}$; bit angles $45-80^{\circ}$. Insufficient sample for the description of a "typical" specimen.

Function: Most appear to have functioned as scrapers while some serrated examples were used as cutting or sawing tools.

\section{Miscellaneous Chipped Stone Artifacts}

Grooved and Shaped Obsidian Fragment (Fig. 13,d)

This unusual artifact is made of dark gray obsidian. Exterior surface is rough and has been shaped. A groove has been worn into this object approximately $.7 \mathrm{~cm}$ in length and shows linear striations and polish evidencing. extensive usage. Fragmentary nature of artifact precludes understanding of original shape or purpose.

Saws (Fig. 13,a-c)

Several serrated and semi-serrated flakes and one biface were collected which were clearly used in cutting or sawing functions. Wear patterns visible on these tools show well-worn working edges with striations and some polish parallel to edge on both faces. Flake scars and nibbling present on both faces of tool edge. Fig. 13,c has especially heavy wear; this large serrated tool may also have been used as a graver. Fig. 13, a may have been hafted.

Hafted Scraper (Fig. 13,f)

This is a reworked projectile point suitable for hafting as a scraper. The tip of the artifact has been rounded suggesting such use. 

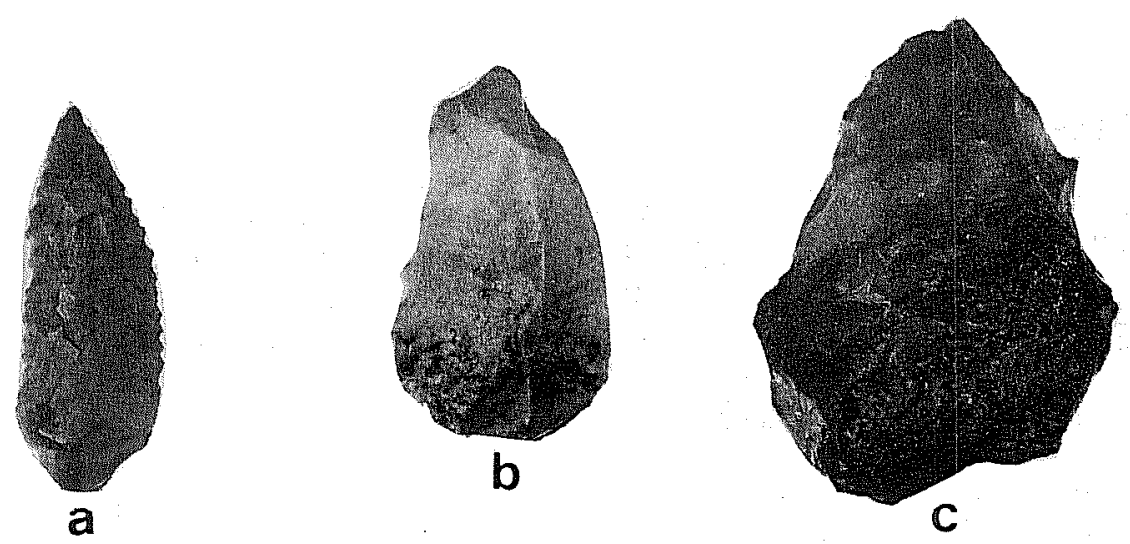

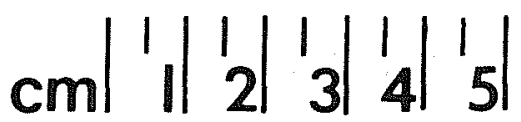

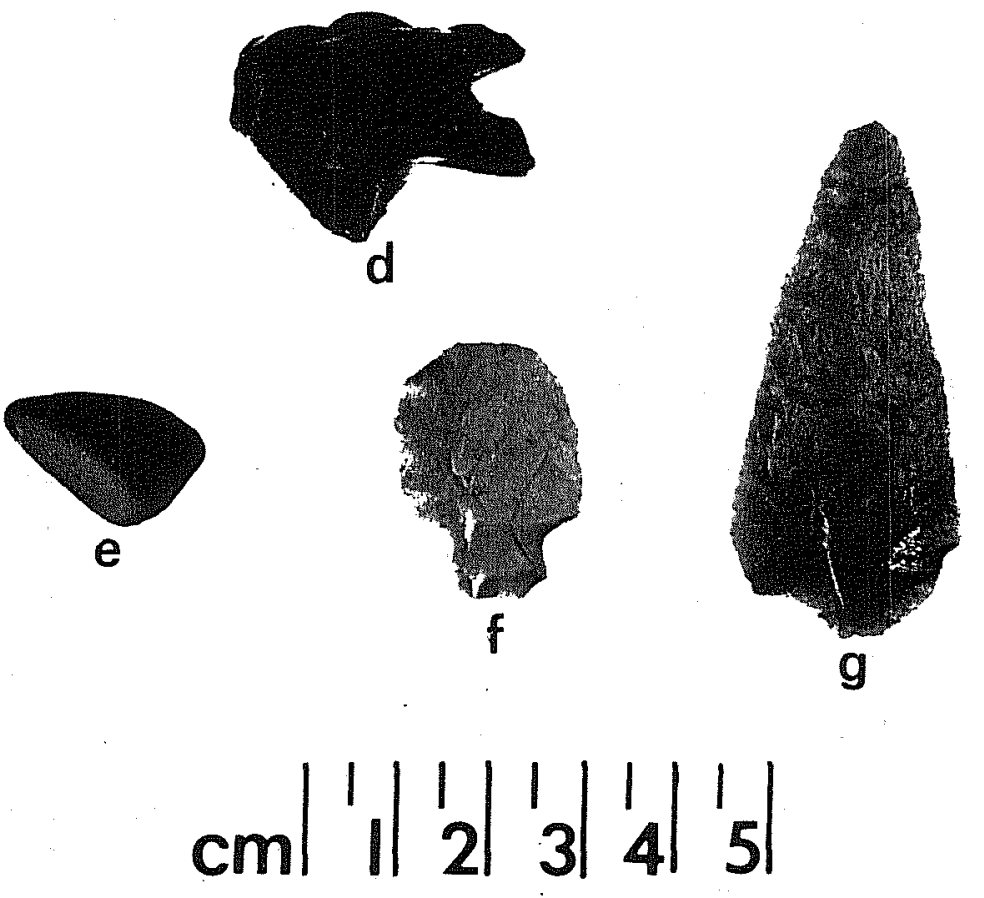

Figure 13. Miscellaneous Chipped Stone Artifacts. a-c, saws (AR011; RS015, SW6; AR068); d, grooved obsidian (AR012); e, polishing pebble (AR049); $f$, hafted scraper (RSO29, SWI); $g$, alternately-beveled flake tool (AR009). 
Alternately Beveled Flake Tool (Fig. 13,g)

This artifact has a steep bevel on opposite faces of both edges. : There is very little wear of any kind visible along edges. Function of this artifact is unknown.

\section{Ground, Pecked and Polished Stone Artifacts}

Metates (Fig. 7,a)

Metates were not collected at all except for several small broken fragments of unusual material. All metates observed were of slab or shallow basin type. Deep basin or trough metates are known in area but none were observed on survey. Materials utilized include very coarse to medium grain sandstone, metamorphic conglomerate, basalt and felsite. A majority were made of sandstone. See Fig. 7,a as an example of a slab metate found in the field. Most metates observed were fragments.

Manos (Figs. 14-18)

Manos were not collected except for a few examples for studying material types. Materials utilized include medium grain sandstone (predominant), felsite, coarse-conglomerate sandstone and basalt. Transverse sections include wedge, convex/convex, flat/convex, slightly convex/slightly convex. Shape or outline included oval, rectangular, and circular. Most manos were of the one-handed variety but a few two-handed manos were observed. Manos were the most numerous ground stone artifact form observed on survey.

Measurements: length: $10.7-27 \mathrm{~cm}$; width: $7.2-16 \mathrm{~cm}$; thickness: $2.4-4 \mathrm{~cm}$; weight: (490)-2,171 gm.

Hammerstones (Fig. 19,a,b)

Description: Round to subrounded cobbles exhibiting bash or batter marks on most of surface. Several specimens are broken. Hammerstones were made of dense cherty material, quartzite and felsite.

Measurements: (complete) ranges from $5.3 \times 4.5 \times 3.7 \mathrm{~cm}, 110.5 \mathrm{gm}$ to $8.2 \times$ $6.6 \times 6.4 \mathrm{~cm}, 487.3 \mathrm{gm}$. Typical example: $6.8 \times 5.9 \times 5.5 \mathrm{~cm}, 283.8 \mathrm{gm}$. Dark gray cherty limestone with white impact marks on entire surface.

Function: Used in hammering tasks, probably stone-working and for plant/ animal resource processing.

Polishing Pebble (Fig. 13,e)

This is a very small $(2.3 \times 1.6 \times 1.7 \mathrm{~cm} ; 4.5 \mathrm{gm})$ pebble. Material is some sort of sedimentary pink material. Pebble is plano-convex in transverse 

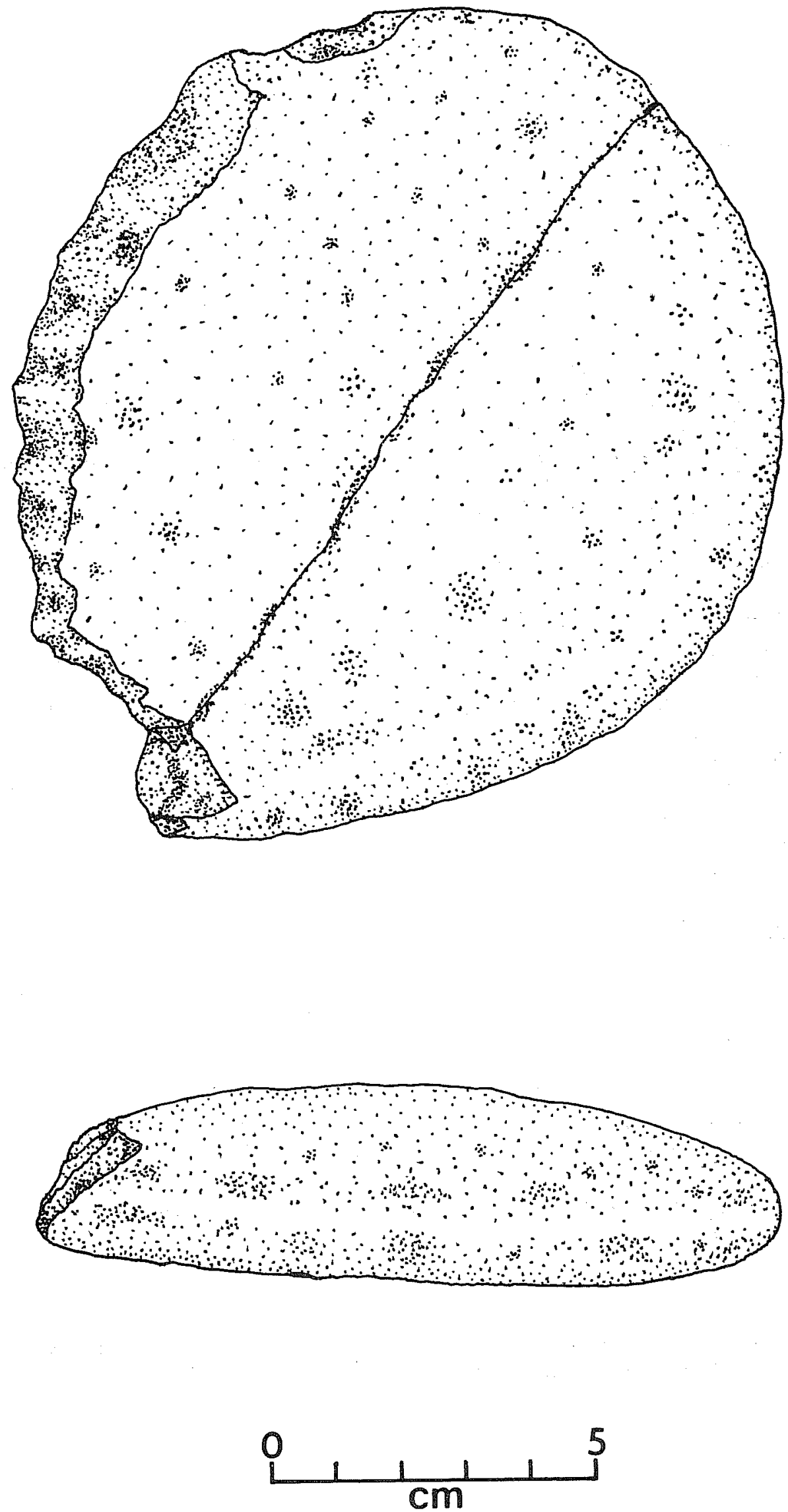

Figure 14. Ground Stone Artifact. Mano of porous light brown/gray 

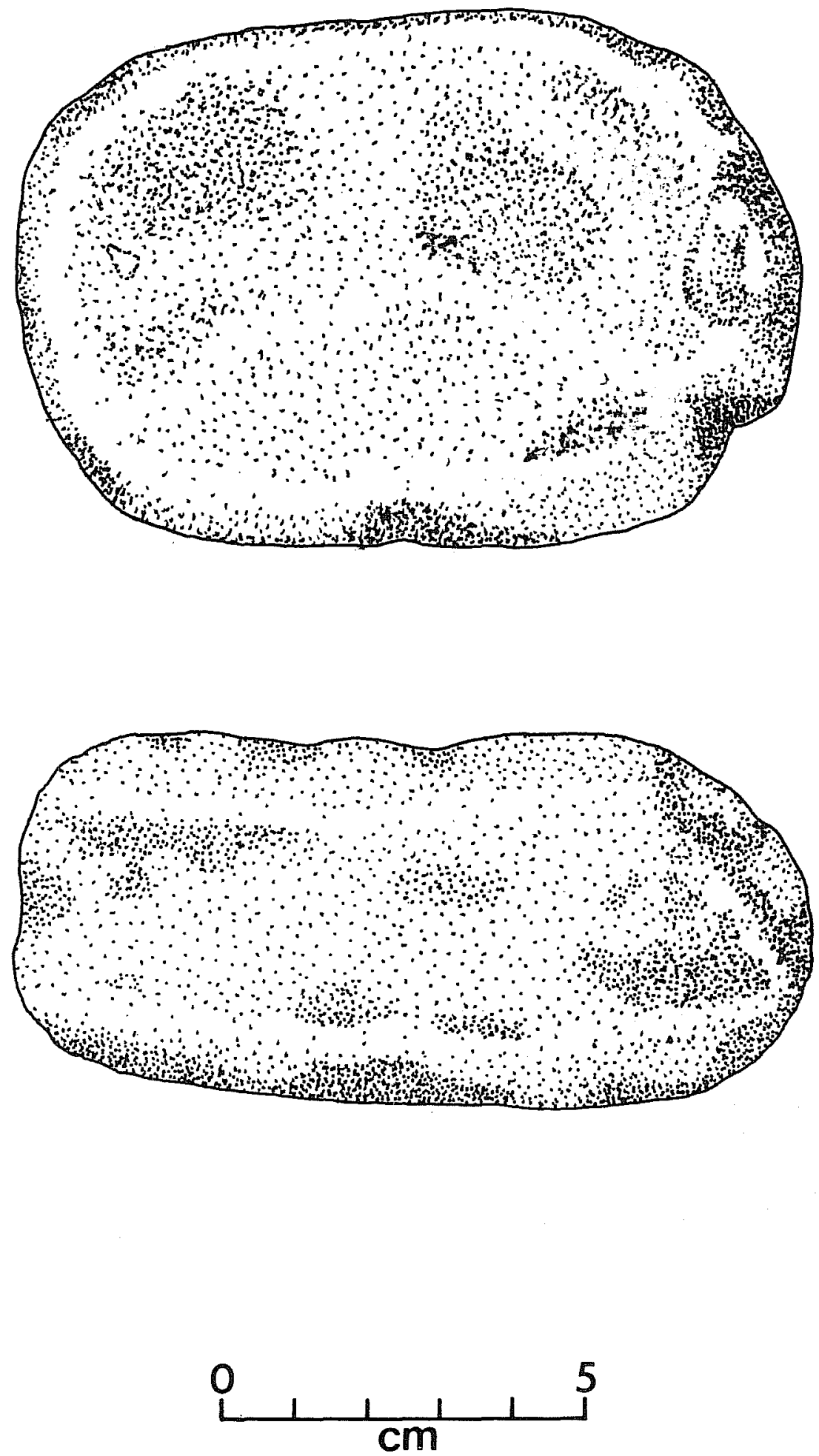

Figure 15. Ground Stone Artifact. Mano of brown coarse-grained sandstone, with heavy caliche encrustation. AR005. 

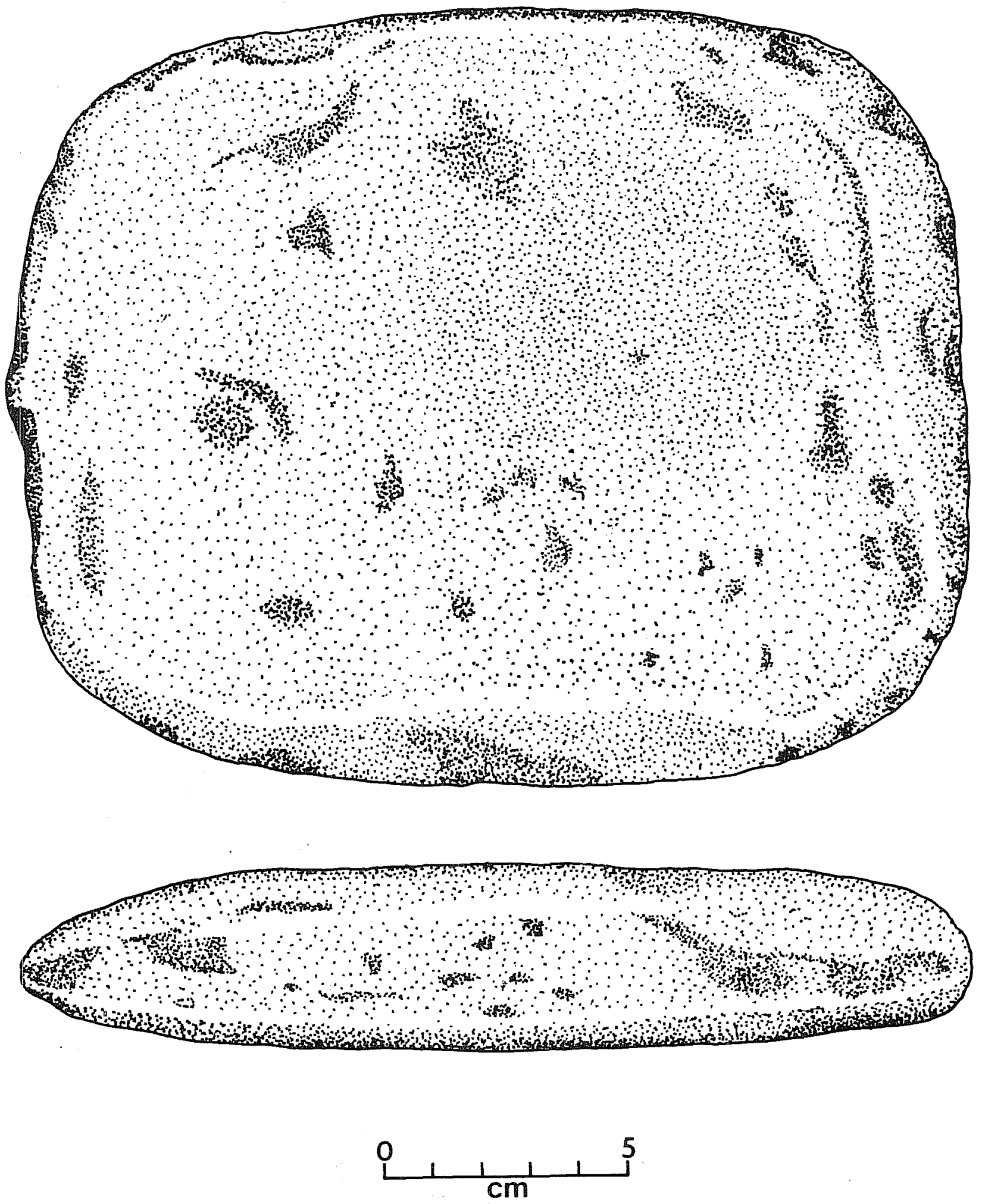

Figure 16. Ground Stone Artifact. Two-handed mano of brown/gray medium grain sandstone. RSO01. 

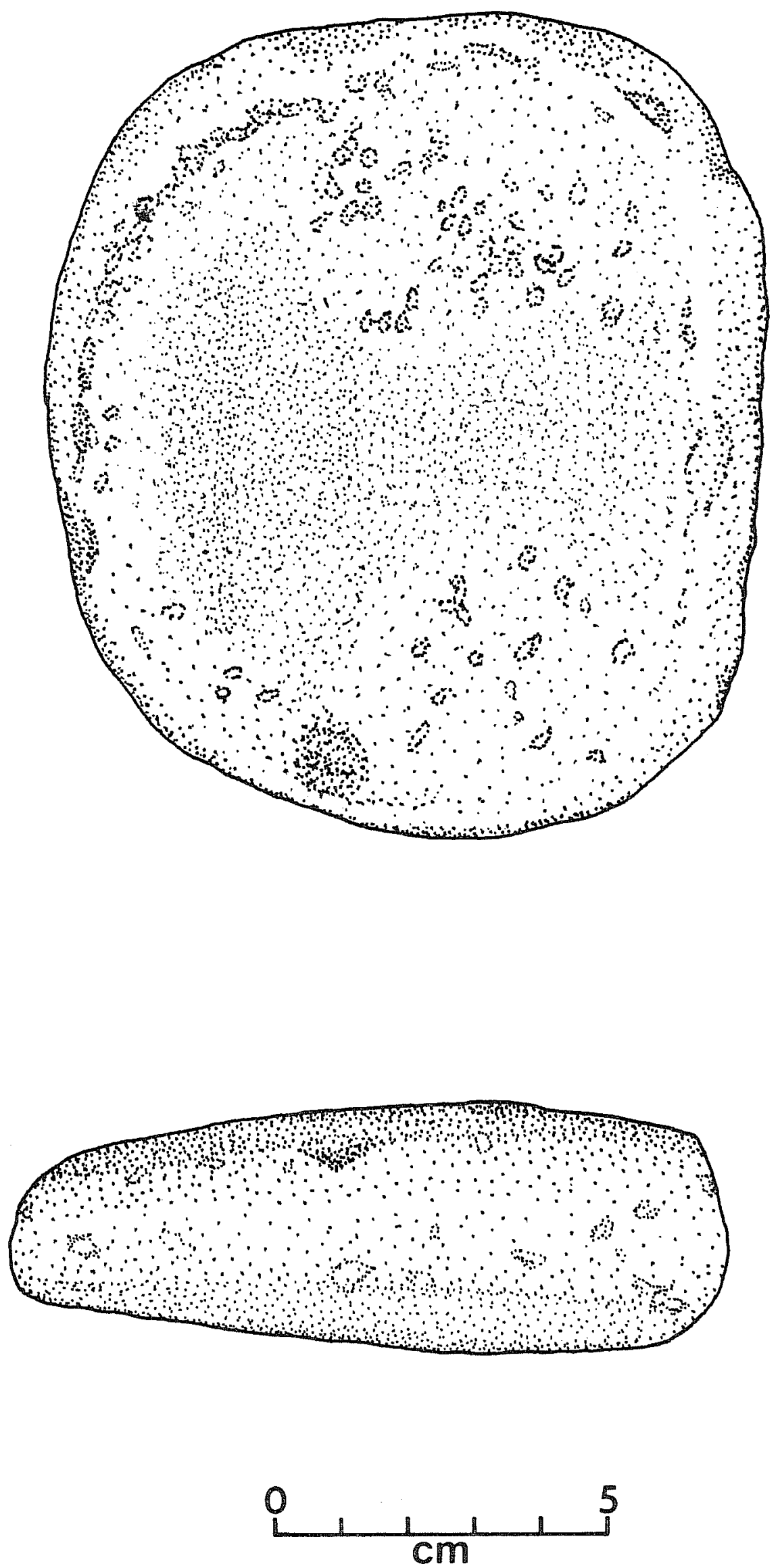

Figure 17. Ground Stone Artifact. Mano of brown medium-grained sandstone. Edges obviously pecked while shaping. AR078. 

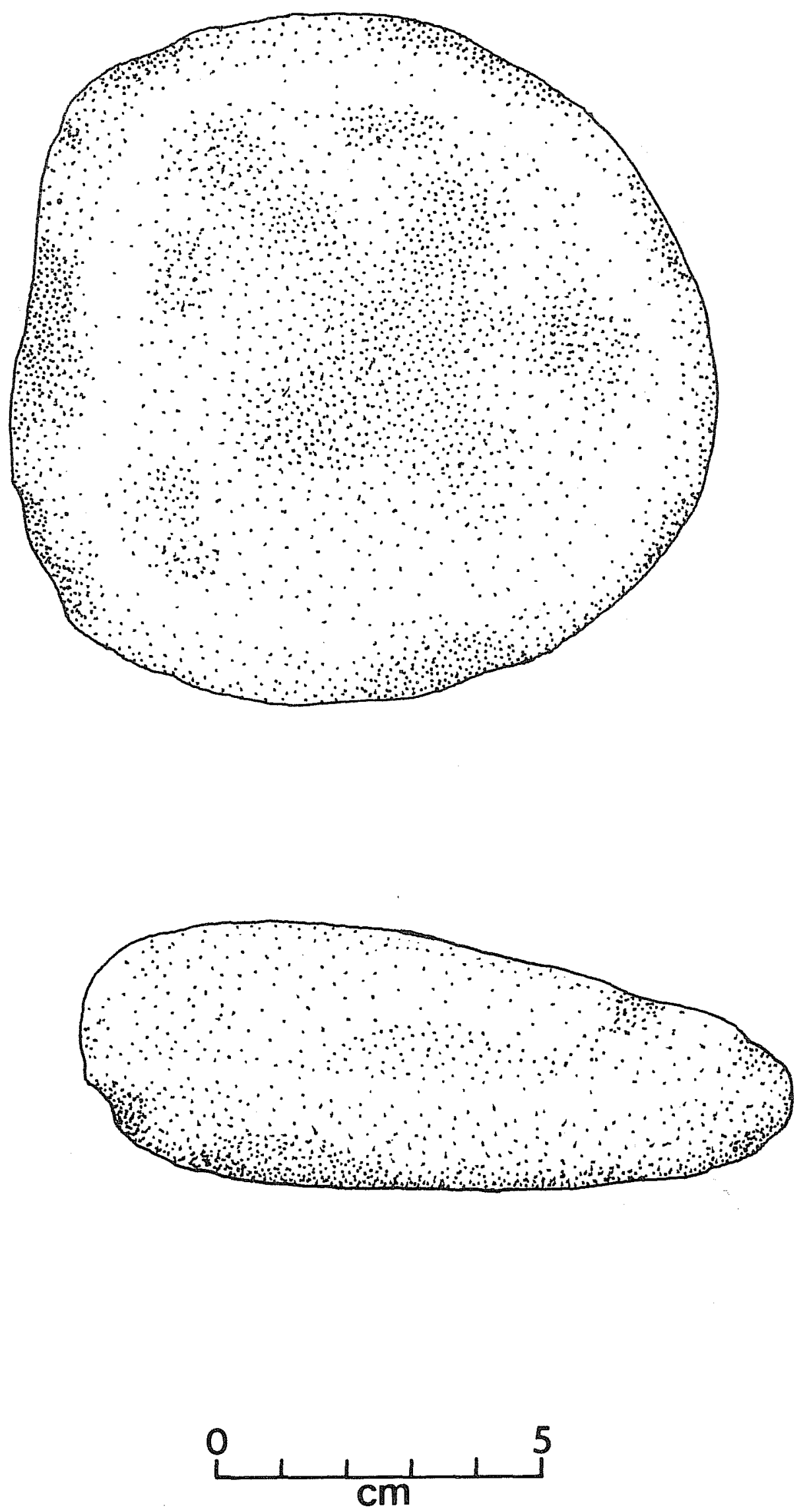

Figure 18. Ground Stone Artifact. Rhyolite mano with heavy use indicated on both surfaces. RS015, SW5. 
section. One surface is flat and has been heavily worn. Wear striations are not parallel and run in several directions indicating pebble used in circular motion in grinding or smoothing tasks. This pebble was found at AR049, a ceramic site, and probably was used as a pottery smoother.

\section{Rubbing Stone (not illustrated)}

This artifact is an oblong quartzite stream-worn cobble. The flat sides of the tool are worn smooth, used in a circular motion to grind or polish. Edges or ends of artifact show signs of battering wear. DiPeso (1974:Vol.7) notes a Seri ethnographic account of a similar artifact called Hupf. During a six-day period the Hupf was used for 13 different functions including a hammer, an axe, a grinding stone, a projectile, a saw, a chopper and a plane. The artifact found on the survey was very similar in description to the Seri Hupf. It measures $7.8 \mathrm{~cm} \times 6.7 \times 4 \mathrm{~cm}$ and weighs $294 \mathrm{gm}$. Approximately one-third of the tool is missing. This tool exhibits several kinds of wear and undoubtedly served many functions.

\section{Mica-Schist Artifacts}

A number of specimens of various forms of schist were observed on sites in the survey area. These specimens were of a fragmentary condition; many were just thin spalls. Two forms of recognizable artifacts were found: oblong pestles and flat, thin slabs. Materials utilized were identified by Dr. Richard McGehee, UTSA geologist, and include mica-schist, garnet-mica schist, mica-garnet schist, hornblend mica-schist and muscovite schist. Similar artifacts were found at Casas Grandes by DiPeso (1974) and in the McGregor Range Survey (Beckes et al. 1977).

Pestles (Fig. 19,c,d)

These oblong specimens were rectanguloid in transverse section with all unknown edges rounded. Dr. McGehee stated these artifacts exhibited a pronounced linear alignment typical of minerals present in the specimens. He was also of the opinion that naturally worn mica-schist rocks downstream from the geologic source would appear much the same. Most of the artifacts collected or observed were broken on both ends. Two had intact ends (Fig. 19). Both of these exhibit battering-type wear which would be expected if used as pestles. It is suggested that these mica-schist specimens were collected from stream beds as water-worn and smoothed oblong specimens and used as pestles without further modification.

Measurements: The pestles were fragmentary. Length: $(12.4)-(22) \mathrm{cm}$; width: 5.1-6.4 cm; thickness: 2-3.1 gm; weight: $(209)-(556) \mathrm{gm}$.

Mica-Schist STabs (Fig. 20)

Several specimens of mica-schist mineral were found which were of a very flat, thin, tablet form. In fact, the surface of one of these slabs was worn in the center suggesting use as very fine grinding palette, perhaps for paint 

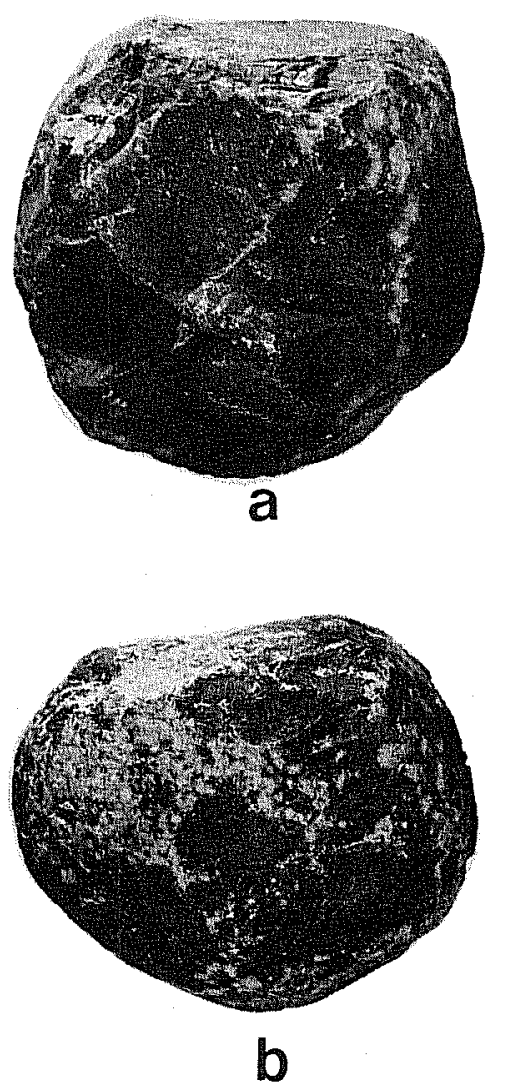

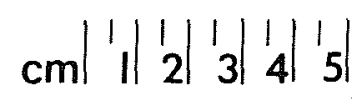

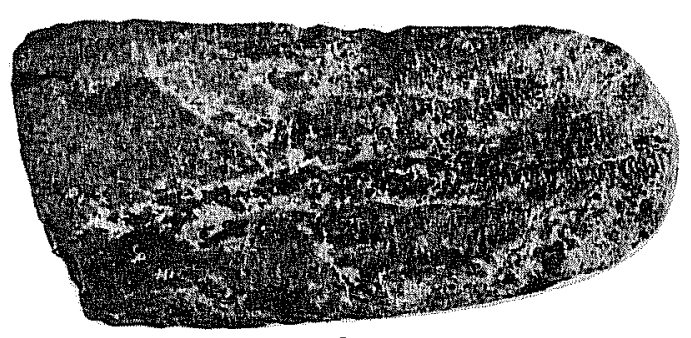

C

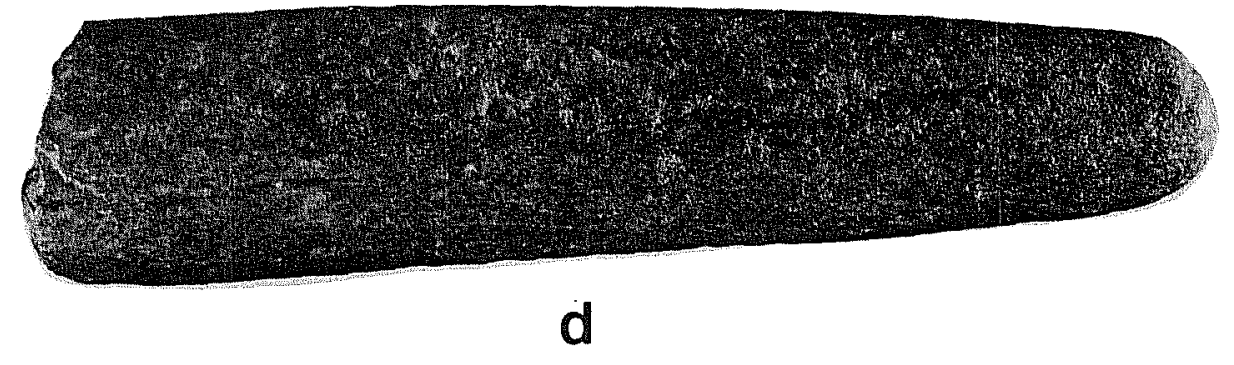

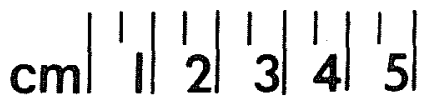

Figure 19. Hammerstone and Mica-Schist Artifacts. a,b, hammerstone (AR062); c,d, mica-schist pestle (AR032; AR060). 

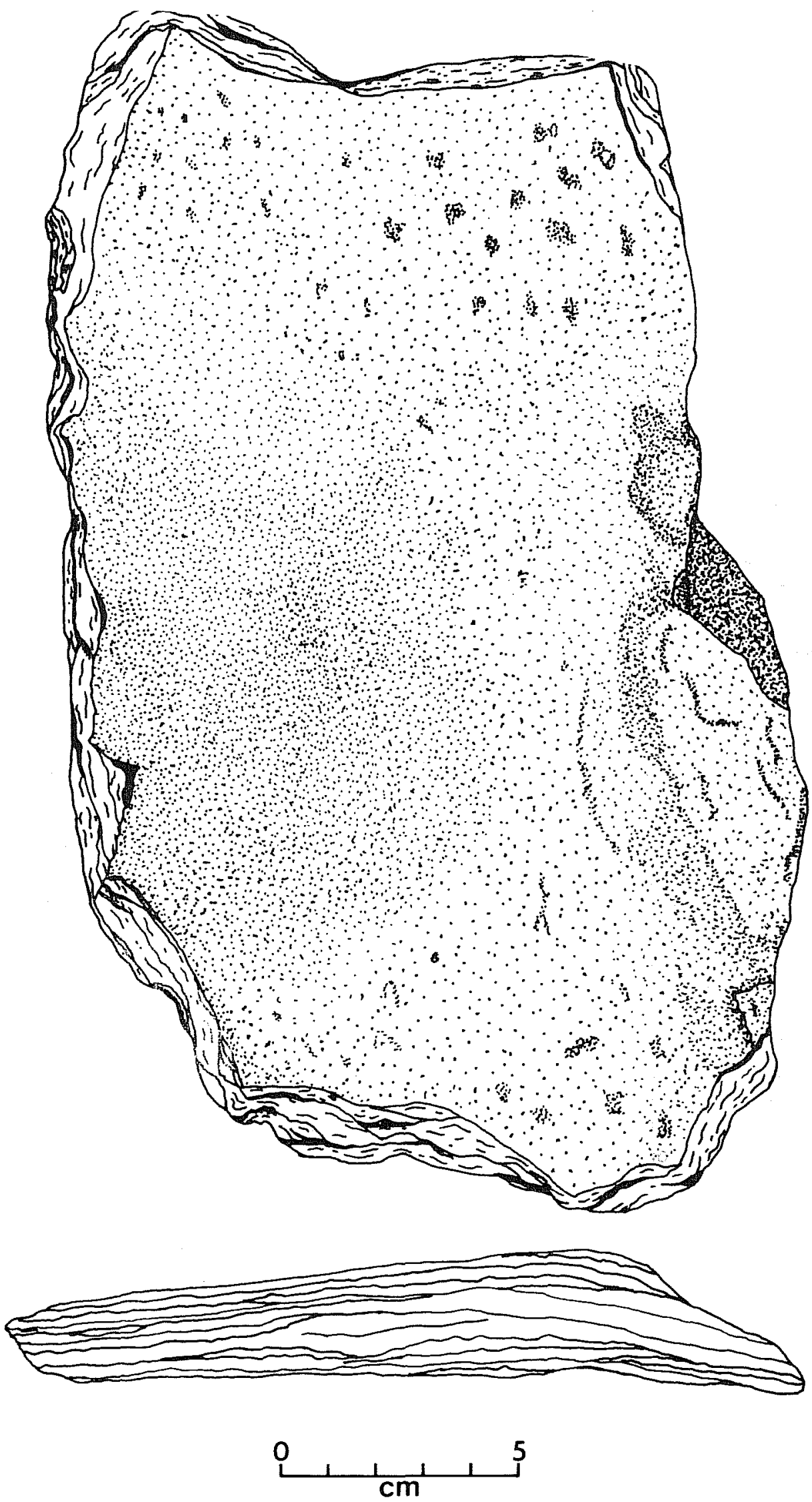

Figure 20. Mica-Schist Artifact. Mica garnet schist slab (densely shaded area indicates highly ground portion). ARO11. 
pigment. Heavy use similar to that of metates would have soon destroyed these thin mica-schist slabs. Most of the slab-type mica-schist specimens were observed in a fragmentary state, broken in thin sheets along natural cleavages. The only relatively complete specimen was $27 \mathrm{~cm}$ long, $15.5 \mathrm{~cm}$ wide, $2.4 \mathrm{~cm}$ thick, and weighed 1,380 gm.

\section{Wear Pattern Examinations}

Detailed wear pattern studies utilizing microscopic examination and replicative experiments are quickly becoming standard procedure in archaeological lithic research (cf. Hester and Heizer 1973 for a bibliography of published research in this field). Redman (1973:9-10) has pointed out the value in combining morphological descriptions and functional analysis by relating wear patterns to tool morphology. He has also noted the difficulty of examining total samples and recommends probability sampling for choosing representative examples of tool types for functional analysis. The small sample size from Radium Springs was not conducive to probability sampling and time limitations allowed examination of a relatively few artifacts within major tool categories, concentrating on those artifacts of particularly questionable function. Definite interpretive statements are not possible in most cases. In many cases, negative evidence suggested use of the artifact in some other function (i.e., the tool showed no edge damage typical of use as a cutting tool). A few general wear patterns were observed which are typical of a particular artifact function. Photomicrographs were taken to record certain types of wear. As other researchers have found, it proved to be difficult to obtain clear photographs illustrating details obvious to the eye. In an effort to reproduce wear patterns several large flakes removed from a single core were utilized in different tasks. A flake used as a scraper for removing fiber from a piece of seasoned wood produced wear patterns clearly distinguishable from the flake used to cut a groove into the same piece of wood.

Scraper wear was produced by using a tool unidirectionally, with the tool edge perpendicular to the material being worked. Repeated use of the tool resulted in many small flake scars (nibbling) and step fractures being removed on the dorsal face of the tool. Scraper wear tends to leave an even edge on a tool by removing al1 protrusions or protruding platforms from manufacture of the tool edge. Striations were sometimes visible after use of the scraper on relatively hard surfaces, where they appeared perpendicular to the scraping edge.

When a tool was used in a cutting or sawing motion a very different wear pattern was formed. Flake scars occurred on both faces along the edge used. Edges were often uneven and became very du11. Repeated usage on hard objects gave the edge a ground appearance. Flake scars and wear striations appeared at an acute angle to the edge--sometimes almost paralleling the edge. Polish appeared occasionally as a narrow band on both faces of an edge. Serrated tools showed dulling of the edge which often obscured the original flake scars.

Drills or perforators showed a very distinctive wear pattern. Flake scars, step fractures and striations occurred on alternate faces of opposite edges. 
Many of these tools appear almost ground smooth, indicating heavy use (see the photomicrograph in Fig. 21). Almost all of these tools were apparentiy used in a rotary fashion in only one direction.

Other distinct wear patterns which were often resent and usually visible to the unaided eye are battering marks and grinding surfaces. Ground surfaces obviously result from repeated contact with abrasive materials. Microscopic examinations occasionally showed curving striations resulting from usage in a circular motion. Battering marks appear on tools (such as hammerstones) as generally white or Tighter colored marks caused by the crushing impact of blows to the exterior surface. Repeated use of a tool as a hammerstone leaves much of the implement battered and thus easily recognizable.

\section{Lithic Sources}

Lithic artifacts and debitage observed on Radium Springs survey sites indicate that a very wide range of 1 ithic materials was utilized, including cherts ("flint"), jasper, agate, silicified wood, felsite, quartzite, basalt, sandstone, mica-schist, rhyolite, andesite, obsidian, calcite and limestone. It is of obvious value to recognize sources of 1 ithic procurement as they can indicate trade relations, distance traveled to obtain material, and intersite relations. This task is much easier when the study area has a restricted 1ithic type availability. Katz (1976), studying Kansas City Hopewell sites, was able to distinguish between two varieties of local cherts and foreign or intrusive cherts. This enabled him to make certain conclusions regarding use of specified types and amount of imported material. R. N. Jack (personal communication) and Hester and Mitchel1 (1974) have carried out limited research with obsidian sources in New Mexico, utilizing trace element analysis. Several obsidian artifacts collected during this survey are presently undergoing geologic source analysis (see Appendix III). Lithics present in the 1976 survey, however, offer a much more complicated situation. A study of lithic sources available in the general survey area which would enable sources to be linked with site samples would require resources and time equivalent to that spent on the entire 1976 survey. General source areas can be noted and will indicate general availability of lithics in the survey area.

Major lithic source areas in or adjacent to the survey area include: San Andres Mountains, Rio Grande Valley, Point of Rocks, Cabal10 Mountains and San Diego Mountain. The San Andres Mountains offer a wide variety of cherts, sandstone and some mica-schist. The Caballo Mountains offer fine grain silicas (cherts and jasper), quartzite and sandstone. The Rio Grande Valley, especially gravel deposits, offers any mineral which can be found north of the survey area. Quartzite cobbles are especially common. Silicified wood, agate and cherts are all found in these gravel deposits. Point of Rocks is a volcanic intrusion which provides large quantities of andesite basalt. Sandstone outcrops can be found near Point of Rocks. San Diego Mountain is a volcanic plug which, as pointed out by Hammack (1962), offers a wide variety of silicates, rhyelite, and others. Obsidian is available in the Organ Mountains south of the survey area and in the Mule Creek area to the west. As can be seen, it is difficult to isolate a particular source for most lithic tools found in the area. 


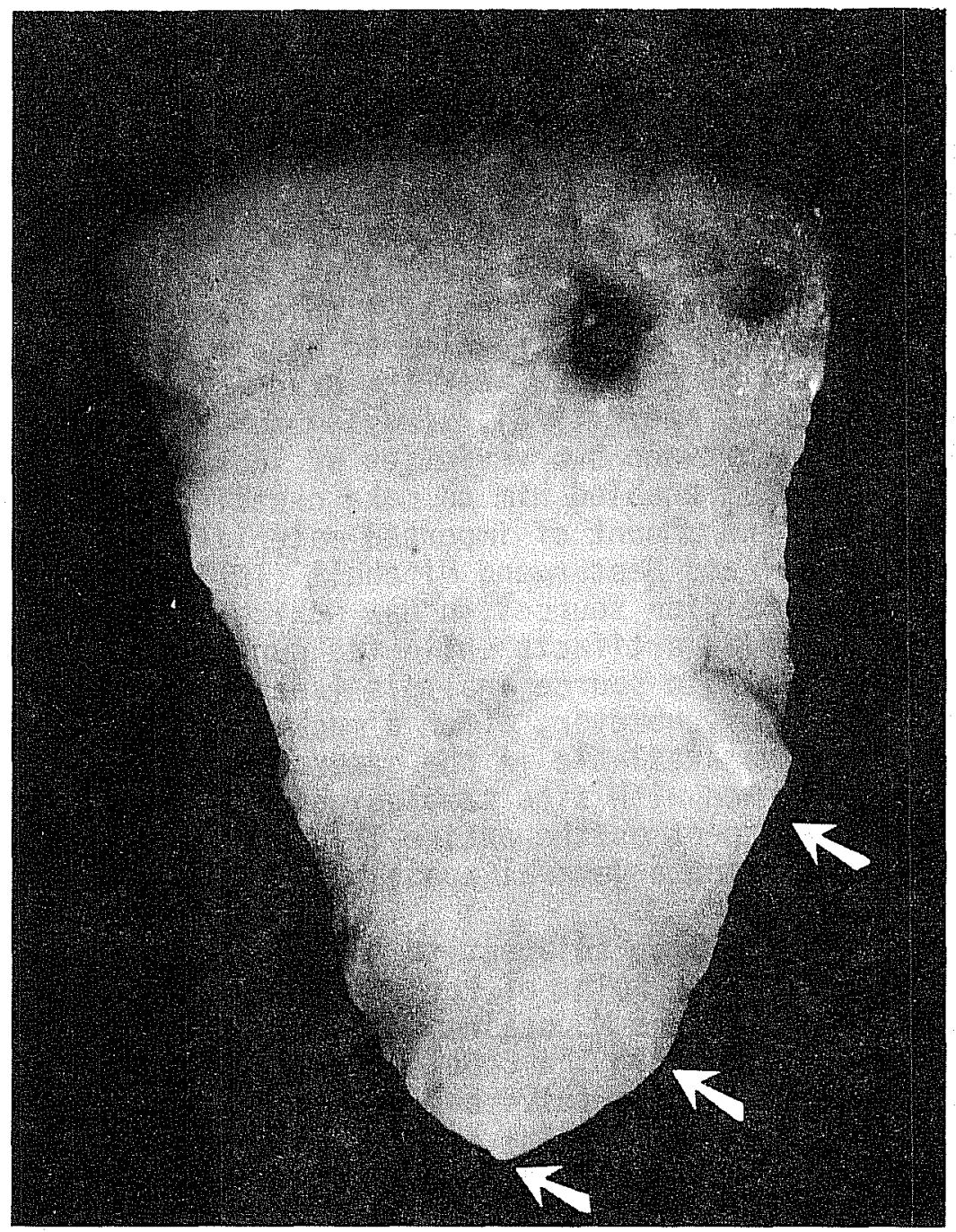

Figure 21. Photomicrograph of Drill Tip from AR002. Arrows indicate nibbling and polish caused by rotary usage. 
Two prehistoric quarry sites were reported from adjacent areas prior to the survey. Schaafsma (1974) mentions the Treadwell Mine and LA 2999. Both apparently are along the Rio Grande Valley, but neither have been adequately reported. The 1976 survey recorded a quarry site, AR094 (the Cain quarry), located on small hills approximately nine miles north of Point of Rocks. The Cain quarry is an outcrop of felsite--a light grey-brown volcanic material. Flaking quality of the material is poor but it can be made into tools. Numerous Cain quarry felsite tools and flakes were found on sites during the survey. Four sites occurring up to 10 miles from the quarry contained this material.

\section{Tool Type Distributions}

As previously mentioned, small sample size and sampling bias do not permit broad conclusions to be made on tool distributions. However, some general trends and associations can be noted, albeit with caution.

Ceramics were present on roughly 50 percent of the sites found on the survey. The presence of ceramics indicates a fairly restricted time range and these artifacts serve as the major means of assigning cultural affiliations and chronology based on surface observations. Absence of ceramics is often taken to mean the site is older ("Archaic") in time. Other plausible explanations include (1) ceramics present but unobserved, (2) lithics left by ceramic peoples who did not leave sherds behind, and (3) lithics left by later Apache who rarely utilized ceramics. Whatever the case, distributions of tool types present on "ceramic" sites were compared to those present on "lithic" sites.

In general, 1ithic tools were more numerous on ceramic sites. This is expected, because these are generally the better preserved sites. of all tool types, multipurpose scrapers, end scrapers, preforms, finished bifaces and projectile points occur more frequently at lithic sites. A11 other tool types occur most often at ceramic sites.

Certain tool forms most often occur together. These include end-side scrapers, side scrapers, marginally retouched flakes, hammerstones, quarry blanks, cores, manos, utilized flakes and serrated saws. This obviously indicates a wide range of tool manufacture and utilization, as would be expected at larger village sites such as AR067, AR068 and AR001. More restricted to01 form variations are present at smaller sites utilized for special purposes or on an occasional basis. Future research directed at defining tool kits and comparing distribution of tool forms will of necessity involve intensive sampling using collecting methods which reduce or eliminate sampling bias. Controlled surface collections at larger sites may serve to pinpoint areas of intrasite activities. 


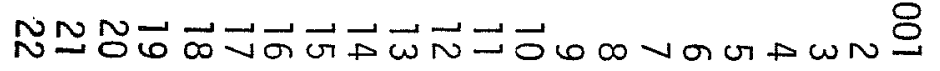

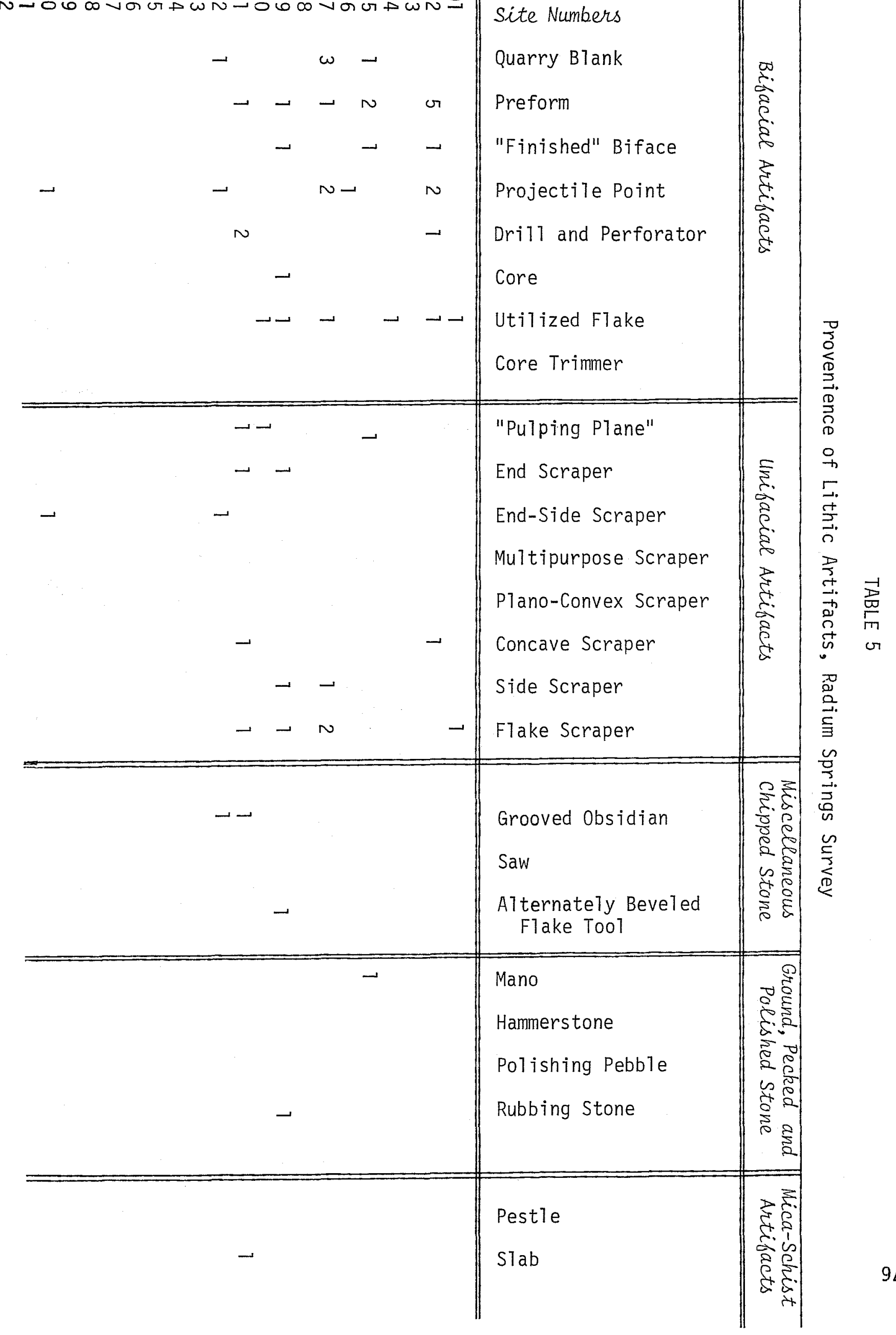



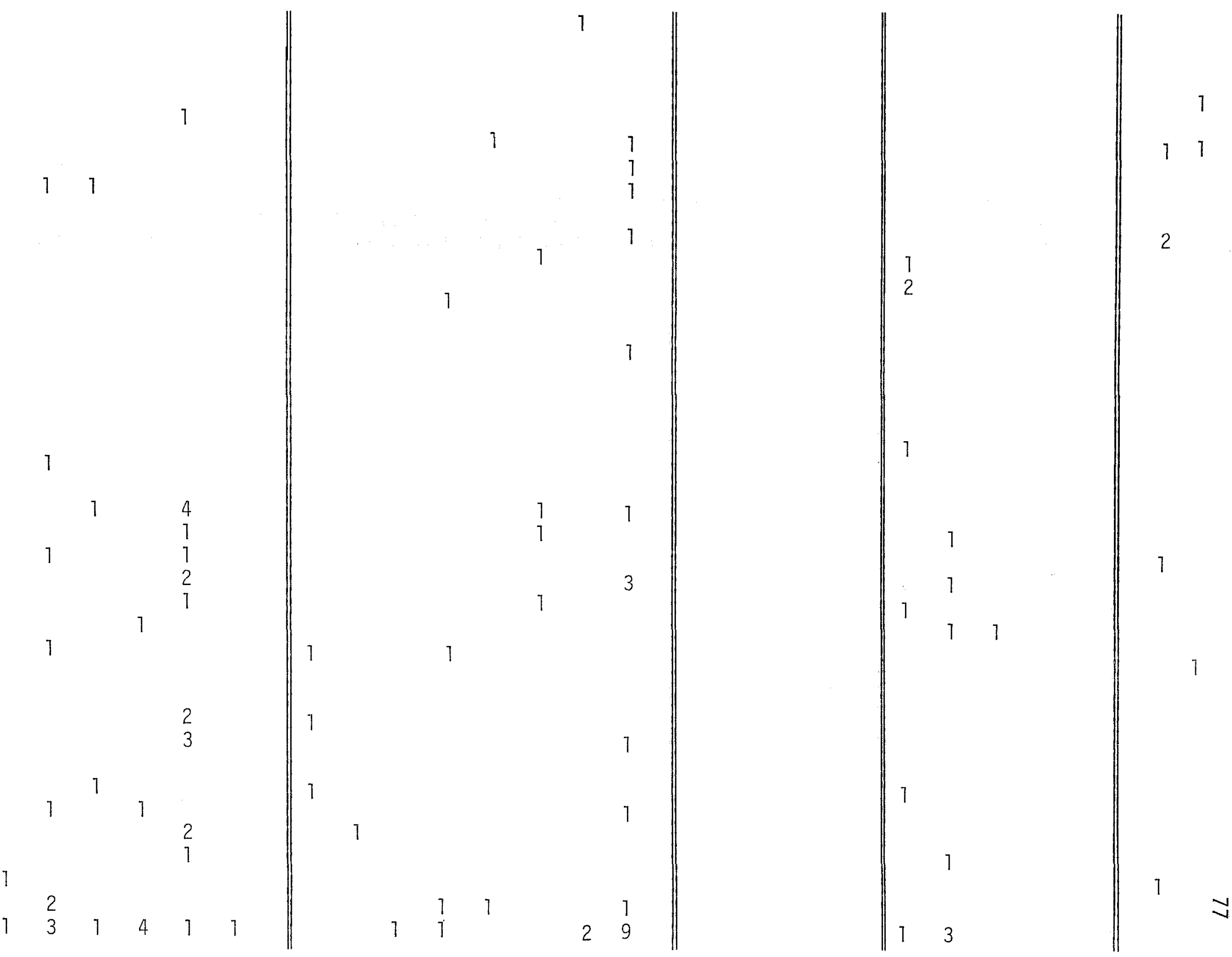


\author{
CERAMICS \\ Erwin Roemer, Jr. and PauT R. Katz
}

\title{
Introduction
}

This section of the report provides two basic kinds of information, both dealing with the culture history of the survey area. Pottery types and wares have been described in detail and accurately dated in adjacent regions. The identification of sherds recovered in the survey area and their assignment to known types or wares yields data relevant for both site occupation dating and the directions of either travel or influence into the area.

A discussion of collection procedures precedes a detailed description of each ceramic grouping documented in the survey area. These descriptions are admittedly paraphrased from both original and subsequent descriptions, and appropriate references are provided. Because of the culture-historical value of ceramic specimens and the relatively unknown area in which the survey was conducted, it was felt that a compendium of pottery descriptions would be of benefit to future researchers and BLM staff members working in the Radium Springs area.

\section{Collection}

Ceramic specimens, predominantly potsherds, were noted at 43 sites within the survey design area and three sites outside this designated area. This represents $49 \%$ of the 88 survey area sites recorded and $48 \%$ of the total number (96) of sites recorded.

As the purpose of ceramic collection was not to determine the proportion of each recognized type or ware, but rather to document the presence of each for culture historical purposes, a grab sample technique was employed for a11 but the largest sites. In the case of AR001, a series of linear transects were established for tighter control of the collection procedure.

Small samples of each identifiable type or ware were collected, and every unidentifiable sherd was collected for more detailed analysis in the laboratory. If the resulting ceramic collection is larger than was originally intended, this is not due to any lack of ability among the field crew in recognizing known types. Rather, the considerable erosion, weathering and abrasion by domestic animals which characterized most sites resulted in a high proportion of unidentifiable pottery. Whenever it was obvious that several sherds were from the same vessel and could be joined together, all were collected. Finally, several sherds were collected which were not associated with a recorded site, their assignment to an uncommon or previously undocumented type outweighing their isolated provenience.

In addition to the presence of a specific type or ware at a site, record was made of the overall ceramic density characterizing each site. To avoid the time-consuming procedure of actually counting every sherd, three categories were established and integrated into the field coding criteria. Ceramic sites were divided according to whether they had from one to nine sherds in 
evidence, from 10 to 99 , or more than 100 sherds. For purposes of discussion, these relative densities might be designated as Light, Moderate, and Heavy (see Table 6).

of the 43 ceramic sites recorded in the survey design area, $24(56 \%)$ were termed Light Density; 13 (30\%) were Moderate; and only $6(14 \%)$ were Heavy. Calculation of the number of sherds per square meter of site area resulted in very small fractions, a variation of from 0.008 to 0.3 sherds per $\mathrm{m}^{2}$. Computer analysis provided a weak but interesting correlation, however, between sites with large areas and light to moderate sherd densities. It is suspected that the larger sites reflect multiple activities, only some of which involved the use of pottery; the smaller sites with pottery may reflect fewer activities, more of which had uses for ceramic utensils.

Concerning ceramic distribution throughout the survey area, it appears that pottery was fairly evenly represented; that is, the sites at which pottery was documented did not tend to cluster to any significant degree.

Description

JORNADA DISTRICT

Jornada Brown (ca. A.D. 800-1200, see Table 7)

Published description: (Breternitz 1966; Human Systems Research 1973; Jelinek 1967; Runyan and Hedrick 1973)

Paste: Soft, granular, and friable; color ranges from light brown, dark brown, reddish-brown to black, depending on amount of original carbon content and degree of firing; black carbon streak common

Temper: Profusion of feldspars and/or quartz, with or without some mica and magnetite; other documented combinations are: feldspar and sand, gypsum and/or sand (often with hematite and mica), quartz sand or sandstone (crushed); never limestone, bone, sheil, or crushed sherds

Core: Outside light buff to light ochre red; depending on carbon content and firing, center may be gray to black

Surface treatment: Smoothed and semi-polished with considerable variation of smoothing, accomplished by scraping, wiping, rubbing, and floating; vessel color has wide range of 1 ight buff-brown to dark red, depending on clay or firing; fire clouds common

Decoration: None

Forms: Jars predominate, round-bottomed without necks, usual1y large (up to 20 inches) with simple direct rim edges

Distribution: Westward to Lake Valley (at the eastern foot of the Black Range); generally north of Carrizozo, New Mexico, to north of Kenna, New Mexico; south to Villa Ahumada, Chihuahua; west to New 
Mexico-Arizona state Iine; east into the Llano Estacado, Texas, and east of El Paso up to about 150 miles; focus is in the northern Jornada area of the Mogollon

Remarks: Jornada Brown is very similar to El Paso Brown, but the former typically has finer temper, surface polishing, straight rims, and generally thinner vessel walls.

Radium Springs Survey: Identified at 19 sites, Jornada Brown is the second most commion pottery type documented in the survey area.

Jornada Painted (Jornada Bichrome, Jornada Polychrome; A.D. 900-1350).

Published description: (Human Systems Research 1973)

Paste: Same as Jornada Brown

Temper: Same as Jornada Brown

Core: Same as Jornada Brown

Surface treatment: Same as Jornada Brown

Decoration: Use of crude motifs of black or red paint below rim, in some cases as a crude geometric design within a bowl interior; sometimes red pigments cover an entire interior or exterior vessel surface

Forms: Same as Jornada Brown

Distribution: Same as Jornada Brown

Remarks: This pottery type typically occurs as a very small percentage relative to Jornada Brown.

Radium Springs Survey: Specimens were present at only three sites (AR001, 48, 81), and al1 were badly eroded. It ranks sixth in overal1 popularity among recovered types, allong with San Francisco Red, Mimbres Black-on-White, and Pitoche Rubbed-Ribbed.

E1 Paso Brown (A.D. $800-1200)$ *

Published description: (Human Systems Research 1973; Runyan and Hedrick 1973)

Paste: Same as Jornada Brown

Temper: Like that described for Jornada Brown, but the particles tend to be larger, ranging from fine to $3 \mathrm{~mm}$ (average $1.4 \mathrm{~mm}$ )

*This date range, differing from the traditional A.D. 900-1350, has been suggested by recent work conducted in the region. (Michael Whalen, personal communication). 
Core: Same as Jornada Brown

Surface treatment: Smooth matte, with temper protruding surface; no slip or floating; considerable variation in smoothing but no actual polishing (as opposed to Jornada Brown); color range similar to Jornada Brown

Decoration: None

Forms: Jars and bowls, similar to Jornada Brown

Distribution: North of Carrizozo, New Mexico, to north of Kenna, New Mexico, south to Villa Ahumada, Chihuahua, Mexico; west to the New Mexico-Arizona state Tine; up to 150 miles east of El Paso, Texas, and into the Llano Estacado, Texas; focus in the Rio Grande Valley near E1 Paso

Remarks: The possibilities for confusion between Jornada Brown and El Paso Brown are known to al1 researchers in the region, although most maintain their distinctiveness in the literature.

Radium Springs Survey: Sherds identified as E1 Paso Brown were recovered from 29 sites, making it the most common pottery type documented within the survey area. See Fig. 22,a,b.

El Paso Polychrome (A.D. 1200-1350)

Published description: (Hawley 1950; Human Systems Research 1973; Runyan and Hedrick 1973)

Paste: Grayish-brown to black to various reds, depending on clay sources; contains much carbon material; color of paste proportional to original carbon and firing temperature; very friable

Temper: Same as Jornada Brown and El Paso Brown

Core: Same as Jornada Brown and EI Paso Brown

Surface treatment: Similar to Jornada Brown and El Paso Brown, but floated

Decoration: Crude, alternating lines of black and red; massed colors, stepped patterns, mainly black and red-on-brown but in various combinations; paint is thin and the red is often fugitive; jars and ollas have upper decoration below rim, bowls have their interior rim areas painted

Forms: Bowls and jars; bowls are deep, rounded, with usually direct, flat and slightly rounded rims; jars and ollas have wide mouths, round or flat bottoms and commonly wide bodies, constricted necks recurving to a flaring lip; rims typically flare and thicken at edges, which are usually direct and either rounded or flat 

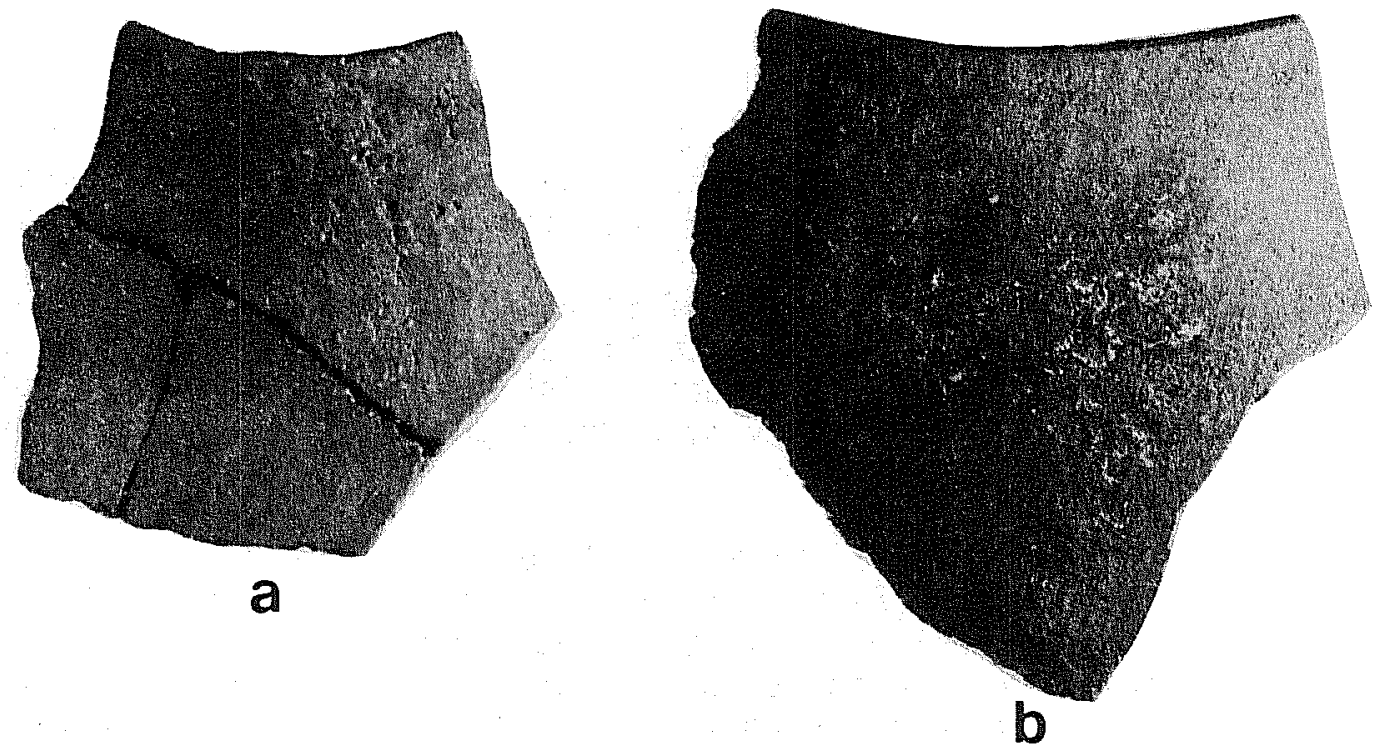

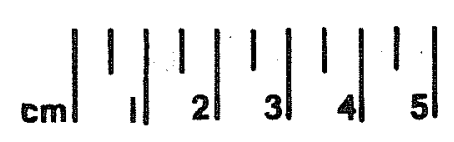

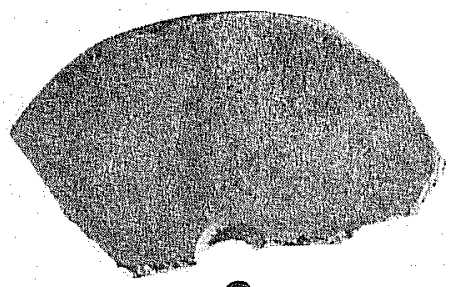

c
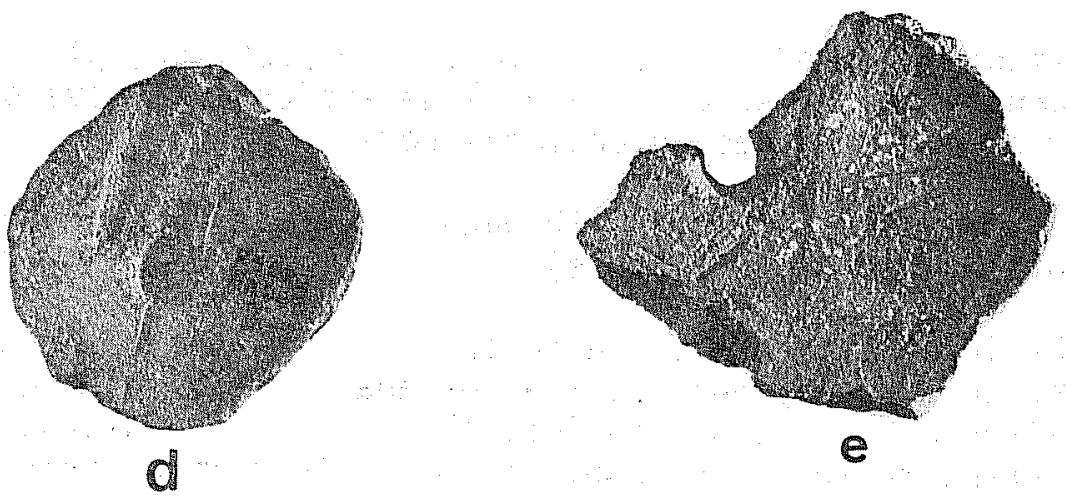

e

\section{\begin{tabular}{l|l|l|l|l|l|l|} 
& 1 & 1 & 1 & 1 & 1 \\
& & & 2 & 3 & 4 & 5
\end{tabular}}

Figure 22. El Paso Brownware Rim Sherds and Modified Sherds. a, AR075; b, AR050; c-e, modified sherds: c, AR068; d, AR068; e, AR037. 
Distribution: From the vicinity of Lincoln and Nogal, New Mexico, south to Villa Ahumada, Chihuahua, Mexico, and in the immediate southeastern area of Arizona, back to about 30 miles east of Carlsbad, New Mexico, and into the Llano Estacado of Texas

Remarks: The ubiquitousness of El Paso Polychrome in the Mogolion region and beyond suggests large-scale manufacture or trade. The apparently hasty and crude finish has been proposed by some to denote the possibility of a "no deposit-no return" use involving trade goods.

Radium Springs Survey: El Paso Polychrome sherds were identified at five sites (AR001, 36, 49, 62, 78) in the survey area, suggesting late Mogolion activity. Their abundance at EI Paso phase sites to the south is not mirrored in the survey area, however. Along with Seco Corrugated, this is the fourth most prolific type documented.

Chupadero Black-on-White (A.D. 1150-1400+)

Published description: (Hawley 1950; Human Systems Research 1973; Runyan and Hedrick 1973)

Paste: Hard, well fired, uniform gray color

Temper: Combinations of small particles of stone (e.g., andesite quartz, hornblend diorite, basalt), depending on area of manufacture

Core: Uniformly light to dark gray; no carbon streak

Surface treatment: One side always smoothed, sometimes both; black mineral paint decoration on smooth side, which is usually uneventy slipped white or gray-white; unsmoothed surface often horizontally striated

Decoration: Hatched and solid lines in opposition, often showing hasty connections; also diamond outline series, negative geometrics, broad border lines, occasional dots

Forms: Bowls and pitchers with handles; bowls often have flat disc bottoms (no coils at base)

Distribution: Southern Torrance and eastern Socorro Counties, New Mexico, usually east of the Jornada del Muerto, and south of the Estancia Valley, New Mexico; throughout the Fularosa Basin and Sacramento Mountains south into the Chiku Basin; southeast into Chaves, Eddy, and Lea Counties, Hew west to Deming, New Mexico 
Remarks: Considered a trade ware, it is one of the most popular Mogollon intrusives.

Radium Springs Survey (Figs. 23,24): Chupadero Black-on white was found at nine sites in the survey area, making it the third most popular type documented.

WESTERN MOGOLLON DISTRICT

Alma Plain (A.D. 300-1300)

Published description: (Breternitz 1966; Hawley 1950; Human Systems Research 1973)

Paste: Brown to buff, coarse; may be gray or black; sometimes zoned from dark gray interior to brown exterior, lighter outer color appearing as a veneer not exceeding one-third of vessel wa11

Temper: Coarse, angular, and rounded grains of quartz and heterogeneous material

Core: Various colors, sometimes appearing as one of three zones

Surface treatment: Irregular smoothing apparent; lightly polished; no slip, no paint, surface colors range from brown to gray; firing mottling common

Decoration: None

Forms: Jars predominate, few bowls

Distribution: Northern Chihuahua to the Mogollon rim; western New Mexico south of Quemado; east-central and southeastern Arizona

Radium Springs Survey: Alma Plain is one of the earliest dated Mogol'lon types and has been considered a possible antecedent of later plain wares such as ET. Paso Brown. Its greatest density is west of the survey area, nearer the Arizona state line, and it was not expected in any quantity. Some Alma Plain possibly remained unidentified due to its undistinguished appearance but it was from two sites (AR062, 81) within the survey area. The bead vessel from AR095 is a variety of Alma Plain. It is the seventh (next to last) most popular type identified.

San Francisco Red (A.D. 700-1100)

Published description: (Hawley 1950; Human Systems Research 1973)

Paste: Gray, shading to brown at surface; porous

Temper: White rounded and angular particles; some sand 

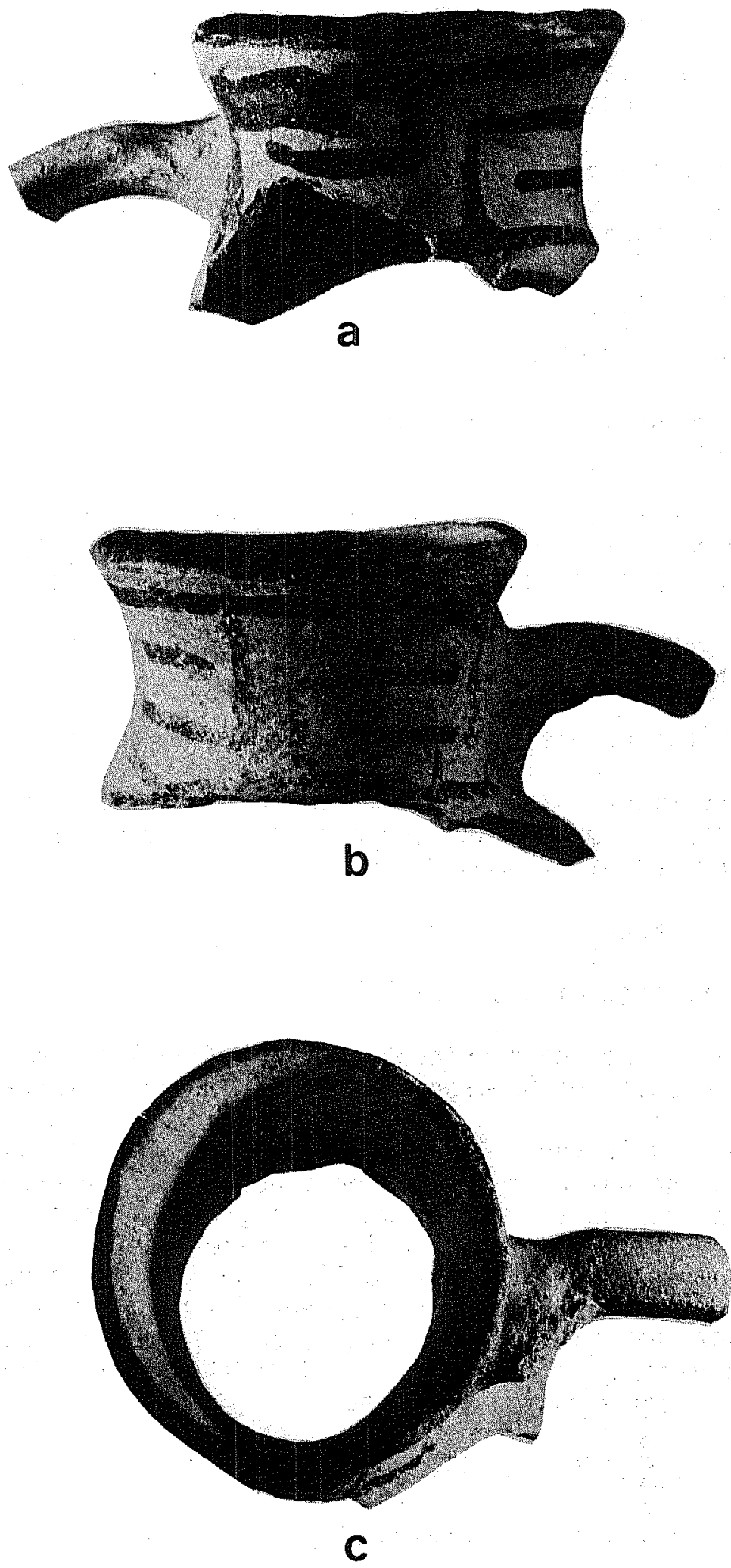

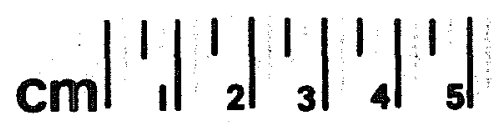

Figure 23. Vessel Fragment. a-c, views of Chupadero Black-on-White 

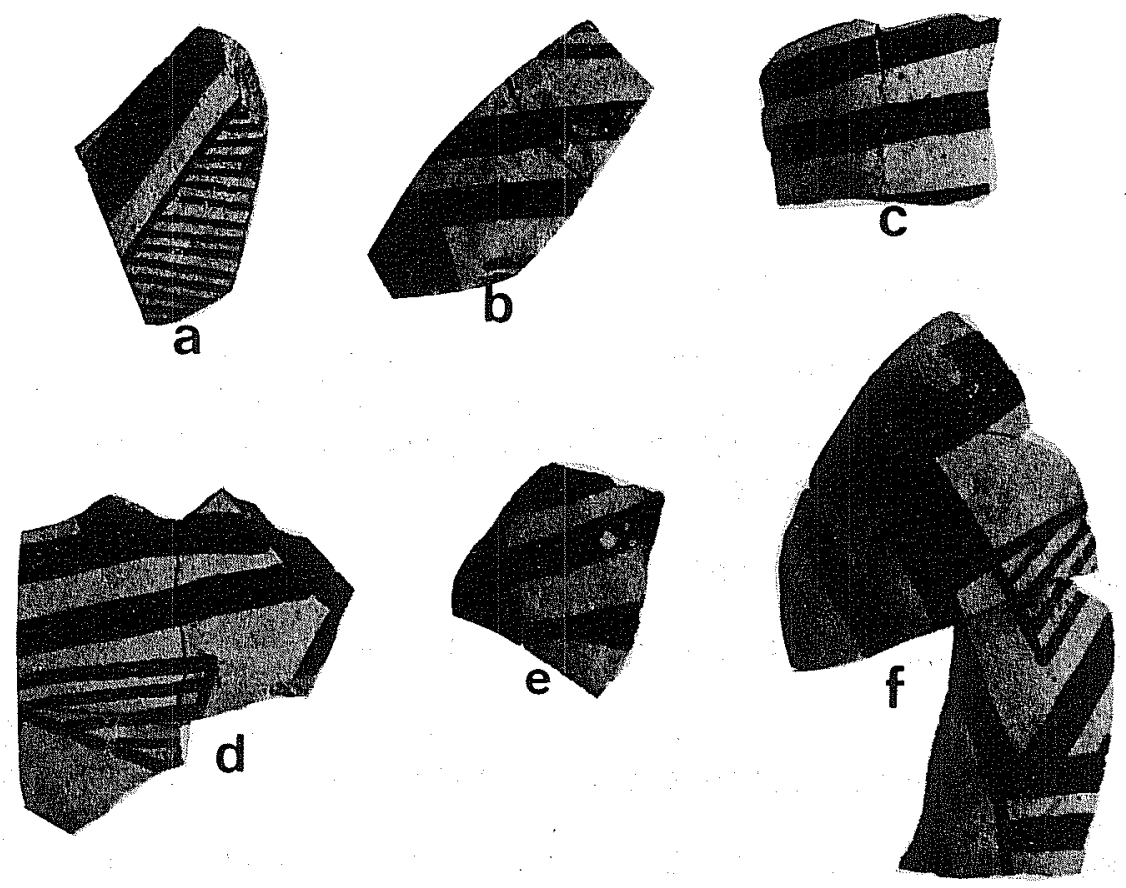

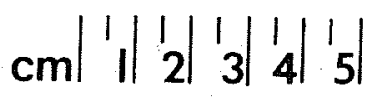
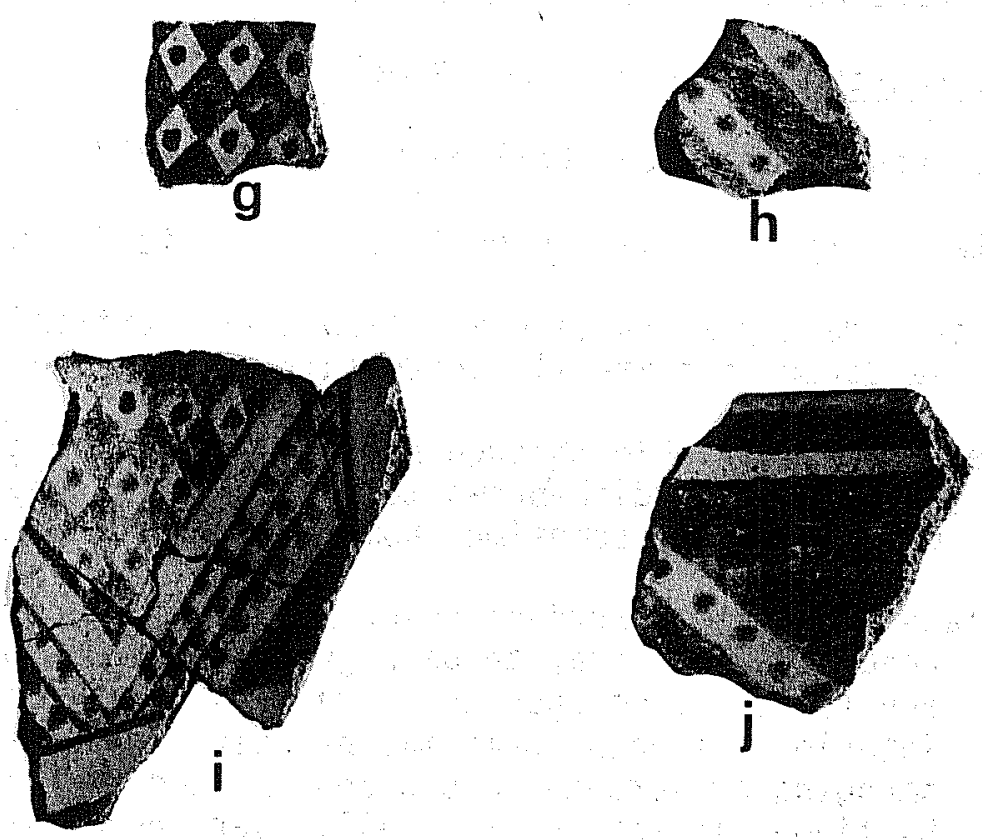

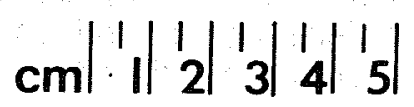

Figure 24. Pottery Fragments. a-f, Chupadero Black-on-White, none with rims. a, AR034; b-f, RS029 SW2, from same vessel, isolated find; g-j, AR013, Socorro Black-on-White, same vessel. Note $d$, rim of vessel. 
Core: Undistinguished

Surface treatment: Bow1s have smoothed interiors, with red to brown thin stip and are polished; exteriors are slipped and less well smoothed on both bowls and jars; scraping marks or light smudging may be evident

Decoration: Slip only

Forms: Bowls and jars (a possible variant form is shown in Fig. 26,j)

Distribution: San Francisco and Mimbres River drainages and area in between; southeastern Arizona and southwestern New Mexico

Remarks: Thought to be a possible antecedent, or at least related to, Playas Red of the Chihuahuan District.

Radium Springs Survey: San Francisco Red was recorded at three sites (AR001, 3, 81) and probably was present at more; identification would be difficult if the distinctive slip was removed by weathering. It ranks sixth in popularity of recovered types, along with $E T$ Paso Painted, Mimbres Black-on-White and Pitoche Rubbed-Ribbed.

Seco Corrugated (ca. A.D. 1100-1300+)

Published description: (Wilson and Warren 1973)

Paste: Temper usually so profuse that paste is undistinguished

Temper: Mainly a rhyolite ash flow tuff, containing quartz grains, feldspar, biotite(?), white tuff matrix, and lithic fragments

Core: Color variable through section, typically grading from surface colors (of reddish-brown to gray or dark gray) to gray or dark gray interior; sometimes homogeneous

Surface treatment: Surface color is oxidized, colors varying from reddish-brown, gray to dark gray, interiors of bowls and jars are typically smudged and burnished (friction polished), but interiors of both forms may be only scraped smooth with no smudging or scraped smooth and smudged; exteriors corrugated by finger indenting, typically over the entire vessel but sometimes only on jar necks; by scraping, the indentations are smoothed so that individual coils and indentations are obscured but not obliterated; light polishing may be evident on peaks also; some sherds show numerous smal1, irregular plain areas and more rarely plain coils; no paint or patterned indentations; average wall thickness $6 \mathrm{~mm}$

Decoration: None 
Forms: Large bowls and jars both common

Distribution: Not we11 known; the type site (in Sierra County, New Mexico) is near the study area and corrugated sherds similar to Seco Corrugated are common throughout the area.

Radium Springs Survey (Fig. 25): Seco Corrugated was found at five sites (AR009, 13, 24, 62, 81) within the survey design area, ranking with El Paso Polychrome as the fourth most comimon type documented.

Mimbres Boldface (Mangus Black-on-White) (A.D. 775-1000+)

Published description: (Breternitz 1966; Hawley 1950; Human Systems Research 1973; Runyan and Hedrick 1973)

Paste: Grayish-brown, dull white toward surface; moderately fine; porous

Temper: Quartz sand, other particles of coarse, angular, soft material, and a little magnetite and mica

Core: Light gray to gray black; also yellow gray to soft brick red

Surface treatment: Exteriors smoothed (slightly bumpy), unslipped, gray to dark gray; interiors poorly smoothed, slipped in chalky white paint, then partially polished and painted with black iron oxide; slipping is often irregular

Decoration: Large and careless black painted patterns; narrow parallel lines, wavy hachure lines; wide areas of white between design; decorations up to rim; some life forms suggesting Hohokam influence

Forms: Hemispherical bow1s, seed jars, jars, and pitchers

Distribution: The Mimbres Valley; Mimbres River and its tributaries; north boundary is the Pinos Altos Range, east of the Mimbres Mountains, west of the Burro Mountains; peripheral and intrusive occurrence goes much further, to the east through the Tularosa Basin, Lea and Eddy Counties, New Mexico, southeast through the Sacramento Mountains

Remarks: The distinctive designs and temper serve to distinguish this type from other black-on-white wares; in addition, the less durable white slip often erodes away from the black design and can be thumbnail scratched (as opposed to Chupadero Black-on-White).

Radium Springs Survey (Figs. 26,27): This type was found at four sites (AR001, 60, 71, 81) in the survey design area. It is the fifth 
Figure 25. Textured Pottery. a, Pitoche Rubbed-Ribbed, probably a sma11 o11a (AR055); b, Seco Corrugated, form appears to be that of a shallow bowl (AR062); c, fragment of curved vesse1 neck, possibly Alma Neck Banded (AR048); d, punched sherd, type unknown (AR081); e, punched and faintly red painted sherd, possibly a type of Playas Red (AR062); $f$, unidentified sherd (AR089); g, coiled and scalloped sherd, probably Three Circle Neck Corrugated type (AR092); $h$, Seco Corrugated bowl fragment (AR009); $i$, unidentified eroded rim sherd with coarse striations (AR092); $j$, "tongue" sherd, perhaps a variant of San Francisco Red (AR048). 

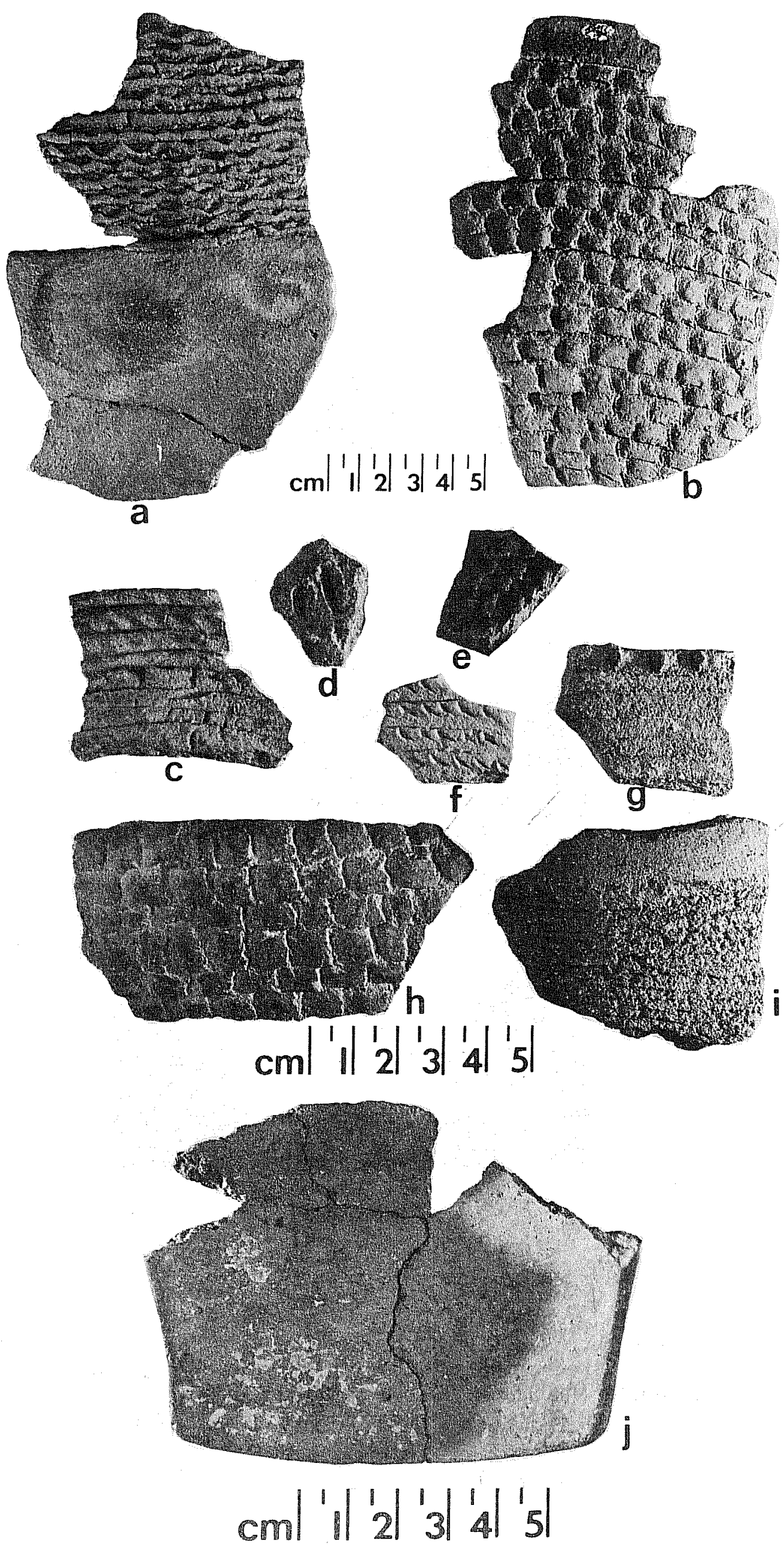

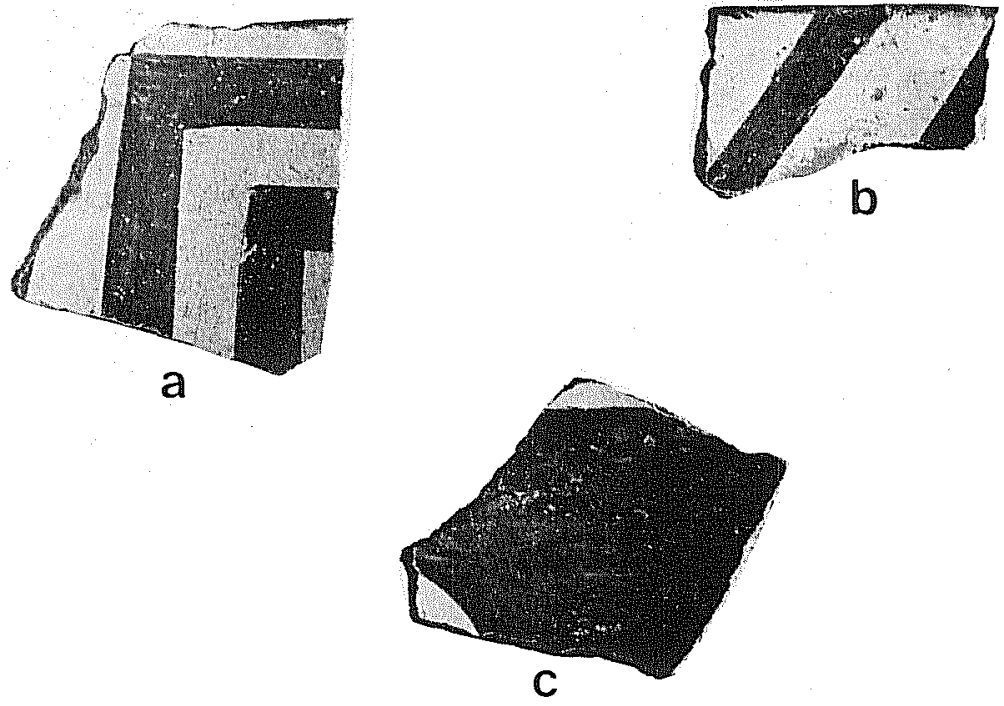

$\mathrm{cm}\left|\begin{array}{l|l|l|l|l|}1 & 1 & 1 & 1 & 1 \\ & 2 & 3 & 4 & 5\end{array}\right|$

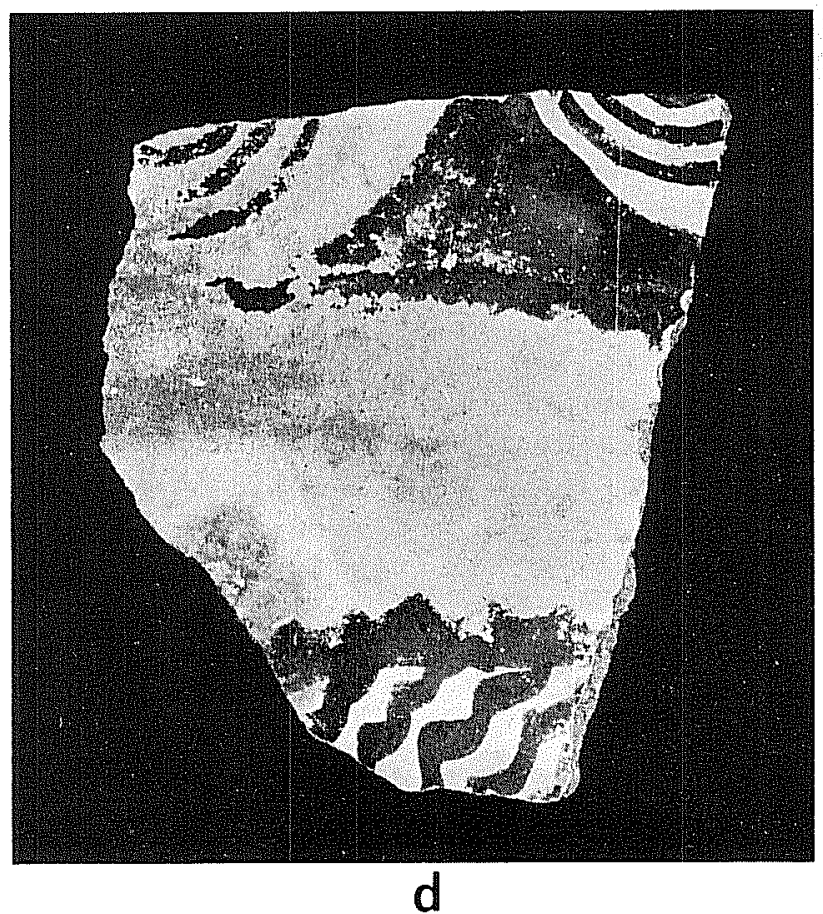

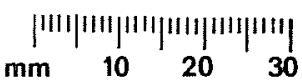

Figure 26. Mimbres Black-on-white Boldface Sherds. a, rim sherd, fired brown-on-white (AR092); b, rim sherd, fired brownon-white (AR092); $c$, sherd showing large segment of painted design (ARO92); d, exterior painted sherd (ARO71). 
most popular type documented. It is often associated with Mimbres Black-on-White sherds, but only one site (ARO01), of the seven where one or the other was documented, yielded both together.

Mimbres Classic Black-on-White (ca. A.D. 1000-1300)

Published description: (Breternitz 1966, Hawley 1950; Human Systems Research 1973; Runyan and Hedrick 1973)

Paste: Moderately fine, porous, friable, light to dark gray; oxidized colors range from yellow-gray to soft brick red

Temper: Quartz sand, fine to medium

Core: Same as Mimbres Boldface

Surface treatment: Interior and exterior better smoothed than Mimbres Boldface; interior heavily slipped with white, polished and painted with black iron oxide; white slip may extend over rim lip to exterior

Decoration: Accurate hatching in very fine rarrow black 7 ines, opposed to solid figures; animal and human figures on bow bottoms, often combined

Forms: Bowls

Distribution: Similar to that of Mimbres Boldface recovered almost everywhere in the Jornada Mogollon area and often in quantity as far as EI Paso; even occurs east of the Pecos River into the Llano Estacado

Remarks: This is one of the most famous and distinctive types because of the technically precise linear designs and figures and artistic originality. It is derived from Mimbres Boldface.

Radium Springs Survey: Recovered from three sites, it ranks sixth in overall popularity at sites within the survey design area. See Fig. 27.

SOCORRO DISTRICT

Pitoche Rubbed-Ribbed (dates indeterminate, but probably after A.D. 1100)

Published description: (Hawley 1950; Human Systems Research 1973)

Paste: Soft, friable, brown to black, sandy

Temper: Sand, with some crystalline inclusions and white specks

Core: Undistinguished 
Figure 27. Mimbres Black-on-White Pottery. a, Classic rim sherd (AR092); b, Classic rim sherd (AR092); c, Boldface rim sherd (AR092); d, Boldface rim sherd (AR092); e, Classic rim sherd (AR092); f, Boldface rim sherd (AR092); g, Classic rim sherd (AR092); $h-j$, Classic sherds: $h$, interlocking scroll design (AR092); $j$, portion of animal head with eye visible (AR092). 

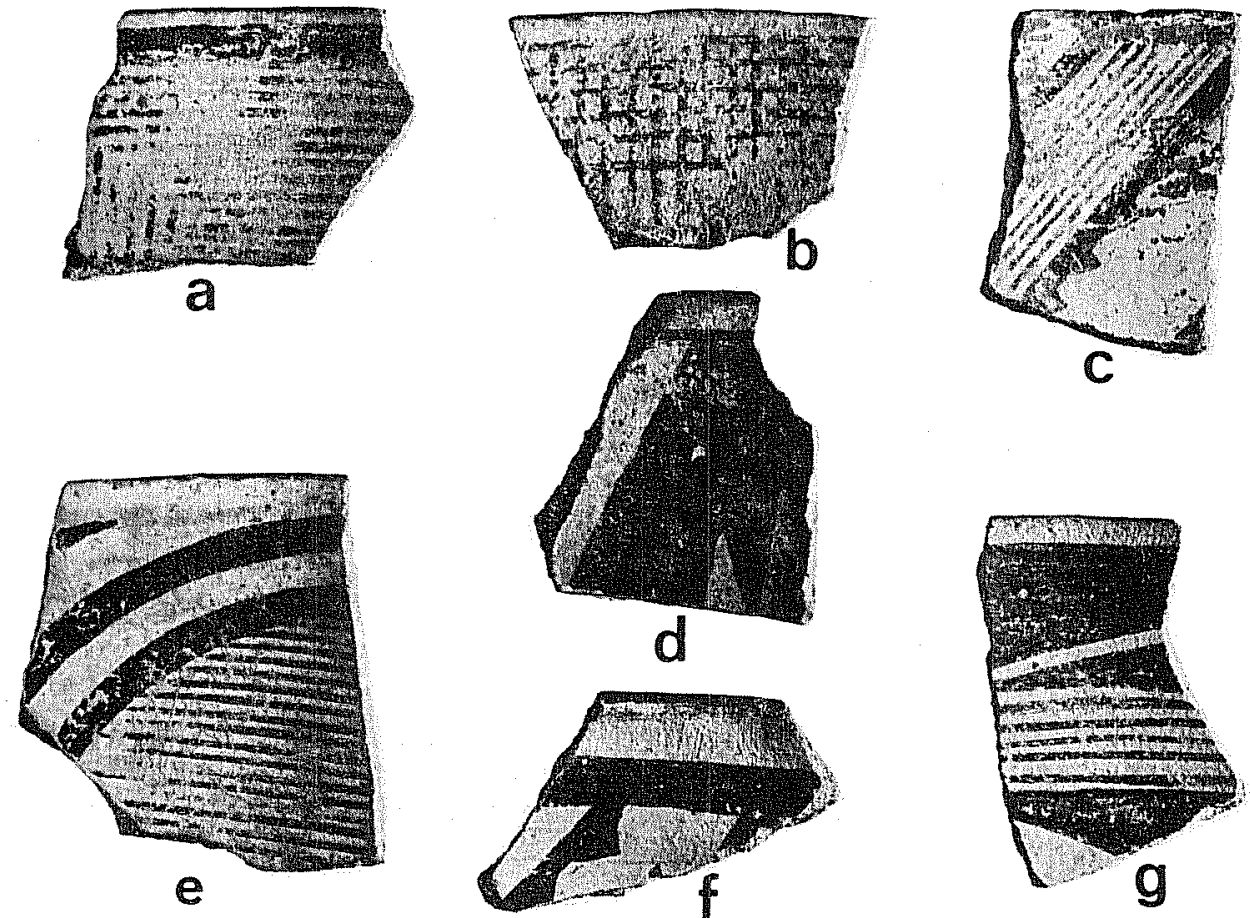

$\mathrm{cm} \mid$\begin{tabular}{lll|l|l|l|}
1 & 1 & 1 & 1 & 1 \\
& 1 & 2 & 3 & 4 & 5
\end{tabular}
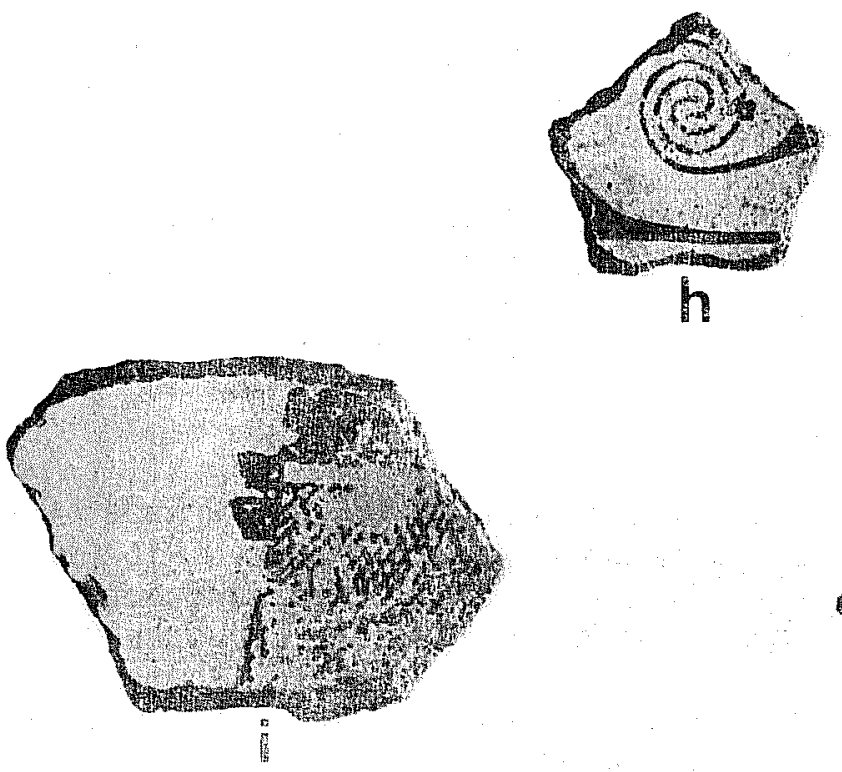

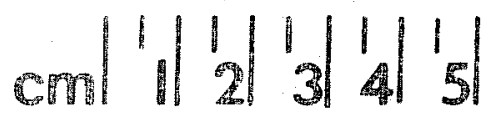


Surface treatment: Some vessels completely smoothed but most still retain evidence of soiling on upper vessel body, each coil averageing 4-5 mm or less; coiling had three variations: flat, clapboard, ribbed; occasional indentations but frequently with combined coiling

Decoration: None

Forms: Jars, with short necks and marked flaing or everted rims

Distribution: Indefinite, but focus within Socorro district

Remarks: Fragments are difficult to distinguish from other banded or corrugated wares such as Alma and Seco.

Radium Springs Survey (Fig. 25): Documented at three sites (AR001, $55,60)$, ranking sixth in popularity among identifiable types along with Jornada Painted, San Francisco Red, and Mimbres Classic Black-on-White.

Socorro Black-on-White

Published description: (Hawley 1950; Human Systems Research 1973; Runyan and Hedrick 1973)

Paste: Fine; gray to dark bluish-gray, occasionally black

Temper: Fine sand and crushed dark stone

Core: Undistinguished

Surface treatment: Thin white slip, matching the paste; temper often apparent through slip on bowl interiors; decorated surface usually gives impression of matte finish; exterior has a careless slip

Decoration: Black iron paint which may turn a reddish-brown or even glaze; hatched lines broader than space between them; wide lines; checkerboard with or without dots, opposed hatched and solid figures; black bow1 rims; good execution

Forms: Bowls and jars

Distribution: Socorro district west of the Rio Grande; Rio Puerco (of the east) and Rio San Jose with 7 imited Rio Grande extensions mark the northern existence; south to around Socorro, New Mexico; west of the Grants, New Mexico, southern lava flow

Remarks: Finish is much tougher than Mimbres types, being similar to Three Rivers Red-on-Terracotta.

Radium Springs Survey (Fig. 24): This type was recorded at one survey design site (AR013), ranking eighth in popularity of documented types along with the two Chihuahuan district types. 


\section{CHIHUAHUAN DISTRICT}

Playas Red Incised (A.D. 1060-1340)

Published description: (Hawley 1950; Human Systems Research 1973; Runyan and Hedrick 1973)

Paste: Coarse brown, dark gray-black

Temper: Clear quartz and feldspar, sometimes with clear, red, or yellow sand; variable texture

Core: Reddish-brown to reddish-yellow, carbon streak frequent

Surface treatment: Unslipped and floated or slipped, oxidized red or red-orange with low to high luster; polished and unpolished

Decoration: Incised texturing most common, although indenting, punching, corrugating possible

Forms: Bow7s, jars, effigies

Distribution: Chihuahuan culture area generally, most frequent in Casas Grandes and Santa Maria drainages; found in lesser amounts in southern New Mexico and Arizona and intrusive throughout the Jornada Mogolion culture area

Remarks: Playas Red may also be plain (i.e., no incisions, etc.). It has been speculated that a relationship may exist between Playas Red and San Francisco Red.

Radium Springs Survey: Playas Red Incised was recovered from one site within the survey design area (AR062). A single sherd, it ranks lowest in popularity among identifiable types, along with Socorro Black-on-White and Ramos Polychrome. Some of the unidentified worn sherds from other sites with red trace remains may be Playas Red fragments. A possible sherd is shown as Fig. 25,e.

Ramos Polychrome (A.D. 1060-1340)

Published description: (Hawley 1950; Human Systems Research 1973; Runyan and Hedrick 1973)

Paste: Fine, compact, buff

Temper: Red, black, pink, and yellow quartz sand and white angular feldspar

Core: Typically white, ranges from 1 ight gray through pink to very pale brown; sometimes carbon streak, medium gray core 
Surface treatment: Jar exteriors, bowl interiors well smoothed, floated, sometimes polished; jar interiors and bowl exteriors are less well finished

Decoration: Mellow ivory color background (vessel surface) with red or maroon and dark gray or black paint patterns, typically narrow linework, figures filled in black or red; paneled bands, dots, ticks, generally complex designs

Forms: Bowls, jars, effigies.

Distribution: The Casas Grandes drainage; intrusive throughout the Jornada Mogollon area, east to the Pecos River into Texas

Radium Springs Survey: This type is represented at one site (AR003) and as an isolated find (RS027). It ranks lowest in popularity along with Socorro Black-on-White and Playas Red.

TYPES DOCUMENTED OUTSIDE THE SURVEY DESIGN AREA

Three Rivers Red-on-Terracotta (A.D. 1150-1300)

Pub7ished description: (Hawley 1950; Human Systems Research 1973; Runyan and Hedrick 1973)

Paste: Medium to hard; uniform terracotta color; consistent material, apparentiy from the same source

Temper: Various feldspars with sand or quartz; gypsum with or without sand; temper constitutes $20-30 \%$ of vesse 1

Core: Uniform terracotta in most cases

Surface treatment: Polished; floated; no slip; red paint design

Decoration: Narrow lines, with triangles along them

Form: Bowls, round-bottomed and shallow with direct rims; some jars

Distribution: Southern New Mexico to the Arizona state line; Manzano Mountains into Chihuahua, Mexico; in the El Paso area; 30 miles south of Silver City, New Mexico; and as far as the Llano Estacado in Texas

Remarks: This is a very distinctive type, always having impressive hardness, slick polish, and color. 
Radium Springs Survey (Fig. 28): A single sherd was recovered at AR092, outside the survey design area. The type is intrusive from the Three Rivers area in the Tularosa Basin east across the San Andres Mountains. It is commonly found in middle and late phase Mogollon sites and was expected in greater quantity.

San Andres Red-on-Terracotta (A.D. 1100-1300)

Published description: (McCluney 1962)

Paste: More crumbly than Three Rivers Red-on-Terracotta

Temper: More than Three Rivers Red-on-Terracotta

Core: Dark reddish brown to light red; carbon streak

Surface treatment: Highly polished; often painted like Three Rivers Red-on-Terracotta, but paint is thinner

Decoration: Broad line motifs

Form: Bowls, jars, pitchers

Distribution: Abundant in northern Tularosa Basin east of the Rio Grande between the San Andres and Capitan Mountains, 10 miles south of Alamogordo, New Mexico, and north to around Corona, New Mexico

Remarks: This type was once considered a variant of Three Rivers Redon-Terracotta, but has slight differences in temper, design, and finish.

Radium Springs Survey: Like Three Rivers Red-on-Terracotta, the type was found only at AR092. It is very similar to Three Rivers Red-on-Terracotta. See Fig. 28,b.

Three Circle Neck Corrugated (A1ma Neck Indented) (A.D. 700-1300)

Published description: (Hawley 1950; Human Systems Research 1973)

Paste: Similar to Alma Plain

Temper: Sand, similar to Alma Plain

Core: Similar to Alma Plain

Surface treatment: Lower body of vessel is plain like Alma Plain; upper neck corrugated with plain narrow coils, deep and overlapping; sometimes coils are buffed and polished; bottom coil frequently pressed into scallops with instrument; gray-brown in color 
Figure 28. Pottery Fragments from AR072 and AR092. a, AR092, rim sherd. Three Rivers Red-on-Terracotta. Two parallel 1 ines circle rim interior and triangles are evident on left area of sherd; $b$, AR092, rim sherd, San Andres Red-on-Terracotta; c, AR092, San Andres Red-on-Terracotta. Apparently of same vessel as b. Design seems to have been fired to more black than red color; $d$, AR092, unidentified Black-on-White bowl sherd; e, AR072, unidentified Black-onRed sherd; f, AR092, Salado (Roosevelt Red) ware. Not readily identifiable on Pinto Polychrome or other variants. 

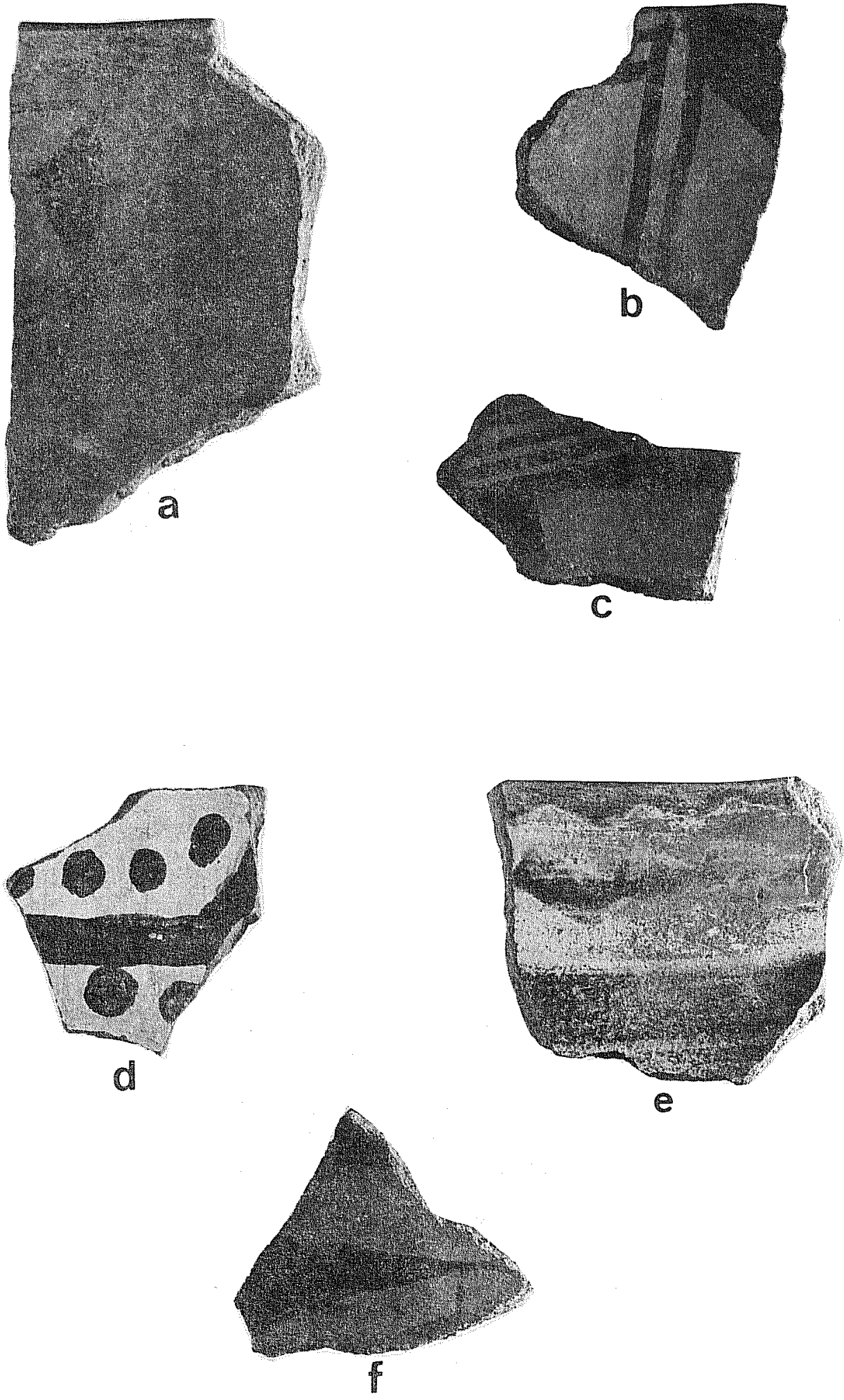

$\mathrm{cm}\left|\begin{array}{l|l|l|l|l}1 & 1 & 1 & 1 & 1 \\ & 2 & 3 & 4 & 5\end{array}\right|$ 
Decoration: None

Forms: Jars and pitchers

Distribution: Same as Alma Plain

Remarks: This type is assumed to have been derived from Alma Plain.

Radium Springs Survey: One small sherd of Three Circle Neck Corrugated (with the distinct scalloped coil below bands) was found at AR092, outside the survey design area.

Alma Neck Banded (A.D. 700-1300) Similar to Alma Neck Indented (Three Circle Neck Corrugated), but lacking the indented or scalloped bottom coil. Two possible sherds were recovered at AR092, outside the survey design area (Fig. 25, C).

St. Johns Polychrome (A.D. 1175-1300)

Published description: (Hawley 1950; Human Systems Research 1973;

Runyan and Hedrick 1973)

Paste: Fine, gray to cream, hard; medium texture, slightly crumbly, occasionally friable; strong vessel walls

Temper: Crushed sherd and some sand

Core: S1ip and core contrast

Surface treatment: Bowls slipped inside and out with a thick red or orange-red slip, frequently crackled; interior designs in thick black paint, well polished over; sometimes white paint used on interior to outline black designs

Decorations: Interior has longitudinal hatching with interlocking scrolls opposing solid and hatched technique; exterior has simple keys, stepped figures, triangles, and animal forms

Forms: Bow1s, rarely dippers or jars

Distribution: Focus is around St. Johns, Arizona, with a 50-mile radius; one of the most widespread Southwestern pottery types

Remarks: Can be expected throughout the Mogollon area.

Radium Springs Survey: One bowl sherd of this type was recovered from AR092, outside the survey design area. 
Roosevelt Red (A.D. 1250-1400)

Published description: (Hawley 1950; Human Systems Research 1973)

Paste: Oxidized with core color of gray to black to tan to brick red

Temper: Abundant water-worn fine sand

Surface treatment: Bowl interiors well smoothed, coated all over with a thick, creamy white slip, almost never crazed, slightly gritty, and never polished; bowl exteriors have a thin red slip, well polished with horizontal striations evident; jar exteriors wel1 smoothed, coated with white slip on upper vessel body and thin red slip on lower body, usually gritty, crazed

Decoration: Decorations in black carbon paint over white slip; bowl interiors usually completely covered in overall pattern; less frequently there is a horizontal band design leaving an open hole in the bottom; decoration never goes to the rim, which is usually plain; bowl exteriors usually unpainted; jars often have a broken black line around the shoulder separating the white slip; solid elements are tapering triangles, scrolls with scalloped edges, steps, keys, and small mazes

Forms: Bowls predominate; jars, figurines

Distribution: Area south of Mogollon rim concentrated in Tonto, Roosevelt, and Gila Basins, Verde and San Pedro Valleys, and near Globe and Gafford, Arizona; intrusive in other parts of Arizona, southeastern New Mexico, Chihuahua, and Texas

Remarks: Variant types (Pinto Polychrome, Gila Polychrome, Tonto Polychrome) are defined by differences in decorative elements.

Radium Springs Survey (Fig. 28,f): Onty one sherd was recorded, from AR092 outside the survey design area. It was too fragmentary to determine the specific type of Roosevelt Red ware.

\section{Cibola White}

Published description: (Mera 1935)

Paste: Very fine, white-gray, compact, not easily friable

Temper: Does not predominate; appears to be dark crushed (basaltic?) stone and quartz; very fine to $.07 \mathrm{~cm}$

Core: Slightly darker gray in center grading into gray-white, on one specimen; a uniform light gray on the other 
Surface treatment: White surface on both sides; one sherd seems to have a white slip interior, white float exterior, the other sherd just the opposite; all surfaces are fairly smooth, white and chalky, especially the interior of the former sherd; the exterior of latter has the most resistant surface, with a dul1 gleam from original polishing

Decoration: White slip only

Forms: Bow1s

Radium Springs Survey: The two sherds tentatively assigned to this type were recovered from AR097.

\section{Unidentifiable Potsherds}

During the course of the survey a number of sherds were collected which at the time were thought to have diagnostic value. Subsequent analys is was unable to assign them to any of the above types of wares. These include six plain brownware sherds which might represent either Alma Plain, Jornada Brown or EI Paso Brown, or unpainted portions of the painted varieties of the latter two. Nine sherds with remnants of red paint might represent Jornada Painted, San Francisco Red or Lincoln Black-on-Red, the latter type not documented but expected in the survey area. A group of six textured potsherds might represent either Alma Banded or Seco Corrugated. All these sherds were so badly weathered and fragmented that accurate typing was precluded. It is a iways possible that they actually represent types or wares not specifically documented by sherds collected from within the study area. It must be remembered that six different types of pottery were recorded outside the sections designated by the survey design.

\section{Modified Potsherds}

Worked sherds refer to specimens which were intentionally altered by rounding their edges. The result is a disc, averaging $4 \mathrm{~cm}$ in diameter, usually characterized by a hole drilled through the center of the object. Suggestions as to the function of these artifacts include spindle whorls (those with holes in the center), pottery scraping tools, gaming pieces, or pendants (also necessitating the hole). Four worked sherds were recovered from the survey, two of them outside the sample area:

1. (Jornada Brown, AR068) A disc fragment with smoothed edges, broken at central biconical hole; projected disc diameter approx. $6 \mathrm{~cm}$; sherd $0.6 \mathrm{~cm}$ thick (Fig. $22, \mathrm{c}$ )

2. (San Francisco Red, AR068) A roughly rounded sherd approx. $6 \mathrm{~cm}$ diameter, with drill holes begun on each side and not wel1 aligned; sherd $0.6 \mathrm{~cm}$ thick (Fig. 22,d)

3. (Jornada Brown, interior smudged, AR089) A disc sherd fragment with about $25 \%$ of its edge area rounded and smoothed; $0.8 \mathrm{~cm}$ thick 
4. (Jornada Brown, AR092) A roughly rounded sherd disc, smoothed crudely on edges; $3.5 \mathrm{~cm}$ diameter, $0.55 \mathrm{~cm}$ thick; no hole

Mended sherds are characterized by the presence of one or more holes drilled through the vessel wall either to stop a crack from widening or to bind across a crack to close it. Three sherds evidenced holes that are thought to be single remnants of a pair that once bound a vessel crack tight, perhaps with sinew or fiber cord. The suggestion that they were holes for a cord handle is not likely from a structural point of view; and the mending proposition is supported by the sherds being broken close to the hole or actually through it. One was recovered outside the survey design area.

1. (El Paso Brown, AR037) A biconical hole, $0.6 \mathrm{~cm}$ wide, broken; sherd, $0.68 \mathrm{~cm}$ thick (Fig. 22,e)

2. (Jornada Brown, AR062) A nearly straight cylindrical hole, 0.48 wide, broken; sherd, $0.43 \mathrm{~cm}$ thick

3. (San Andres Red-on-Terracotta, AR092) A biconical hole approximately $2 \mathrm{~cm}$ from rim edge; vertical cracked edge nearby; biconical, but predominately exterior dri1led; hole, $0.3 \mathrm{~cm}$ wide; sherd, $0.8 \mathrm{~cm}$ thick

Unidentifiable Ceramic Artifact or Vessel Appendage

One specimen has two nearly square corners and a curvature which does not reflect a typical vessel shape (Fig. $25, j$ ).

Recovered at AR048, this sherd may be a variety of San Francisco Red. The concave (interior?) side has a worn, polished red slip. Temper appears to be crushed quartz and perhaps gray chert, abundant and protruding through the surface; particle size ranges up to $.12 \mathrm{~cm}$. At the break the sherd is $.55 \mathrm{~cm}$ thick. The convex (outer?) side is unslipped brown but polished and apparently floated. The term "tongue" was applied to this sherd for lack of anything better. It is possible that it is part of a very large ladle or some type of flange or spout from a vessel. 


\section{Summary}

It was stated in the introduction to this section that the documentation of pottery types and wares provides two kinds of culture-historical data: occupation chronology and directions of interaction between the survey area and adjacent regions.

The two most commonly identified types within the survey design area are E1 Paso Brown and Jornada Brown; the former was documented at 29 sites (67\% of all sites with ceramics) and the latter at 20 sites (46\% of all sites with ceramics). As the accepted temporal span for both types is A.D. 900-1350 it can be assumed that the survey area was significantly utilized during this particular period. The next three: most popular types recovered (Chupadero Black-on-White at nine sites, El Paso Polychrome and Seco Corrugated at five sites) reflect a slightly later and narrower temporal span than the above two types: from A.D. 1100 to 1400 .

The presence/absence nature of ceramic collection procedures precludes any statements at this time as to the relative human populations implied by pottery type variability. Type frequencies as well as their presence at a particular site would have to be determined before interpretations could be made as to population increases reflected by additional types later in time, or population consolidation reflected by these types appearing at much fewer sites later in time.

Likewise, the nature and degree of external relationships relative to the survey area can only be briefly stated at this point. Based on the documented foci of the identified types and wares, only the northern portion of the Jornada district is coincident with the survey design area. This is reflected by the presence of Jornada Brown pottery at almost half the ceramic-bearing sites. Nevertheless, as El Paso Brown occurs at two-thirds of the ceramic sites, perhaps the main thrust of occupation during this period has its origins to the south of the survey area, in the vicinity of El Paso (Fig. 29).

Based on the presence of other pottery types and wares (Fig. 29), the western and northern adjacent areas seem to provide secondary sources of influence and perhaps population; Chupadero Black-on-White and Socorro Blackon-White have a northern focus, and the Mogolion pottery (Alma Varieties, San Francisco Red, Mimbres types) occur most frequently to the west. The eastern area and regions farther south than EI Paso are very poorly represented, primarily by single sherds at single sites of such types as the Chihuahuan redwares and terracotta wares from the east.

Despite the postulated documentation of influences or population movements from different adjacent regions, computer analys is of the pottery type distributions within the survey area shows very little spatial clustering. No determinations could be made at the type level; and even at the district 
level the associations were weak. Pottery types assigned to the Jornada and Western Mogollon districts did tend to be associated; but it is felt that this reflects their occurrence at more sites than those types from other districts, more than any cultural implications. While the latter can be assumed, the results from this survey cannot document them specifically.

Computer analysis of ceramic densities at the various recorded sites is another aspect of the study which should be investigated further. A weak correlation does exist between larger sites and sites with lower medium ceramic density. It is suspected that this reflects activity specilization limited to certain intrasite areas, whereas the smaller sites with ceramics employed this type of artifact in all portions of the site.

It must be noted in conclusion that a total of 21 types and wares were identified from all sites (96) recorded, although only 14 types and wares were documented at the 88 sites within the survey design area. From a percentage point of view, $30 \%$ of the identified pottery types were documented at an additional $8 \%$ of the recorded sites. These figures suggest that for ceramics, at least, the survey design area was too smal1. 
Figure 29. Pottery Intrusives in the Radium Springs Area. Arrows indicate probable derivation of pottery from the following districts:

1. Chihuahuan district: Playas Red Incised, Ramos Polychrome.

2. Western Mogollon district (Mimbres drainage area): Mimbres Boldface and Classic Black-on-White.

3. Salado (Roosevelt Red) wares.

4. Western Mogollon district (San Francisco drainage, Reserve area): San Francisco Red, Alma wares, Seco Corrugated.

5. St. Johns Polychrome.

6. Socorro district: Socorro Black-on-White, Pitoche Rubbed-Ribbed.

7. Jornada district (Chupadero Mesa): Chupadero BTack-on-White.

8. Jornada district (Three Rivers area): Three Rivers Red-on-Terracotta, San Andres Red-on-Terracotta.

9. Jornada district (El Paso area): El Paso Polychrome, El Paso Brown. 


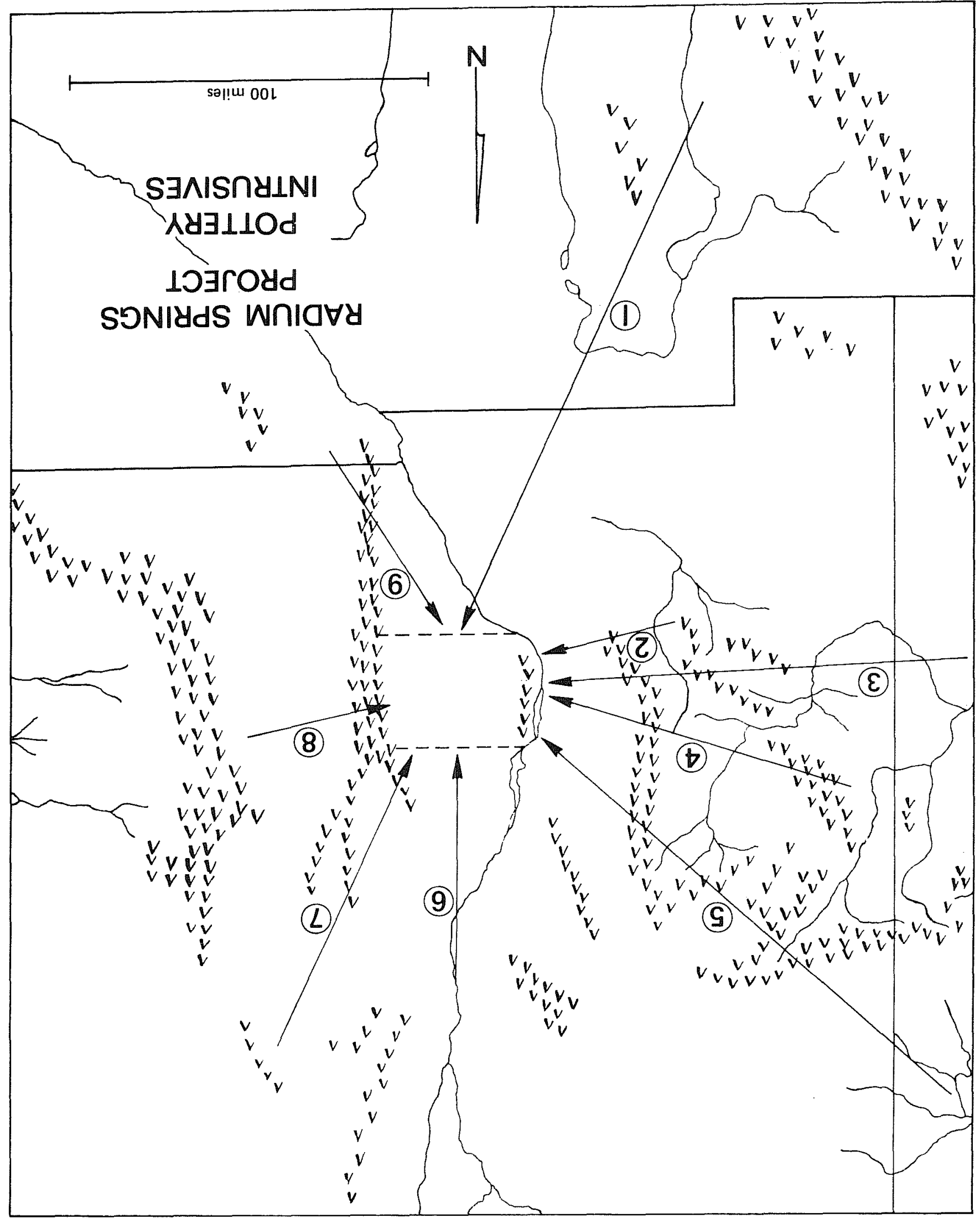


TABLE 6

RADIUM SPRINGS CERAMIC SITE SURFACE DENSITIES POTTERY TYPES PRESENT, DISTRICTS OF ORIGIN, AND PERCENTAGES.

\begin{tabular}{|c|c|c|c|c|c|c|c|c|c|c|c|c|c|c|c|}
\hline \multirow[b]{2}{*}{$\begin{array}{c}\text { SITE } \\
\text { NO. }\end{array}$} & \multirow[b]{2}{*}{$\begin{array}{l}\text { CERAMIC DENSITY* } \\
\text { LoW } \\
\text { Medium } \\
\text { High } \\
\end{array}$} & \multicolumn{5}{|c|}{ Jornada District } & \multicolumn{5}{|c|}{ Western Mogollon District } & \multicolumn{2}{|c|}{$\begin{array}{l}\text { Socorro } \\
\text { District }\end{array}$} & \multicolumn{2}{|c|}{$\begin{array}{c}\text { Chihuahua } \\
\text { District }\end{array}$} \\
\hline & & 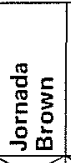 & 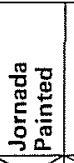 & 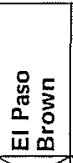 & 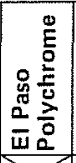 & 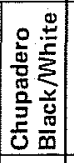 & $\frac{\widetilde{E}}{\frac{\pi}{\alpha}}$ & 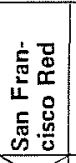 & 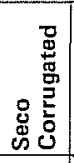 & 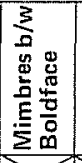 & 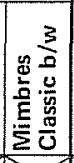 & 竞题 & 总莒 & 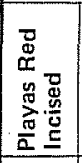 & 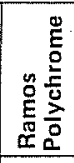 \\
\hline ARO01 & High & & & & & & & & & & & $x$ & & & \\
\hline ARO03 & Medium & & & & & & & & & & & & & & \\
\hline ARO04 & Low & & & & & & & & & & & & & & \\
\hline ARO09 & High & & & & & $>$ & & & & & & & & & \\
\hline AR011 & Medium & & & & & & & & & & & & & & \\
\hline ARO13 & is Medium & & & & & & & & $<$ & & & & 3 & & \\
\hline AR014 & Low & & & & & $x$ & & & & & & & & & \\
\hline ARO15** & Low & & & & & & & & & & & & & & \\
\hline ARO24 & Low & & & & & & & & & & & & & & \\
\hline $\mathrm{ARO} 28$ & Low & & & & & 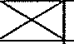 & & & & & & & & & \\
\hline ARO30 & Low & & & & & & & & & & & & & & \\
\hline ARO33 & Low & & & & & 2 & & & & & & & & & \\
\hline ARO34 & Low & & & & & $x$ & & & & & & & & & \\
\hline ARO35 & Low & & & & & & & & & & & & & & \\
\hline ARO36 & Low & & & & & & & & & & & & & & \\
\hline ARO37 & Low & & & & & & & & & & & & & & \\
\hline ARO39 & Low & & & & & & & & & & & & & & \\
\hline ARO42 & Low & & & & & & & & & & & & & & \\
\hline ARO44 & Low & & & & & & & & & & & & & & \\
\hline ARO46 & Low & & & & & & & & & & & & & & \\
\hline ARO48 & High & & & & & $x$ & & & & & 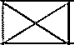 & & & & \\
\hline ARO49 & Medium & & & & & 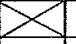 & & & & & & & & & \\
\hline ARO50 & Low & & & & & & & & & & & & & & \\
\hline AR051 & Low & & & & & & & & & & & & & & \\
\hline ARO52 & Low & & & & & & & & & & & & & & \\
\hline ARO53 & Low & & & & & & & & & & & & & & \\
\hline ARO55 & Low & & & & & & & & & & & $2<$ & & & \\
\hline $\mathrm{ARO}^{2} 7^{* *}$ & Low & & & & & & & & & & & & & & \\
\hline ARO59 & Low & & & & & & & & & & & & & & \\
\hline ARO60 & Medium & & & & & & & & & & & $<$ & & & \\
\hline ARO62 & it High & & & & & 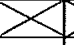 & & & 4 & & & & & 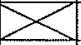 & \\
\hline ARO63 & Medium & & & & & & & & & & & & & & \\
\hline ARO66 & Low & & & & & & & & & & & & & & \\
\hline ARO68 & High & & & & & & & & & & & & & & \\
\hline AR071 & Medium & & & & & & & & & $><$ & & & & & \\
\hline ARO72 & Medium & & & & & & & & & & & & & & \\
\hline ARO73 & 5. Medium & & & & & & & & & & & & & & \\
\hline AR075 & is Medium & & & & & & & & & & & & & & \\
\hline AR076 & Medium & & & & & & & & & & & & & & \\
\hline AR078 & Medium & & & & 8 & & & & & & $\infty<$ & & & & \\
\hline AR080 & Low & & & & & & & & & & & & & & \\
\hline ARO81 & $\Rightarrow$ Low & & & & & & & & & & & & & & \\
\hline AR082 & High & & & & & $x$ & & & & & & & & & \\
\hline \multicolumn{2}{|c|}{ TOTAL SITES FOR EACH TYPE } & 20 & 3 & 29 & 5 & 9 & 2 & 3 & 5 & 4 & 3 & 3 & 1 & 1 & 1 \\
\hline \multicolumn{2}{|c|}{$\begin{array}{l}\text { \% OF POTTERY TYPE FOR SURVEY } \\
\text { DESIGN CERAMIC TYPES }\end{array}$} & $\begin{array}{l}50 \\
0 \\
8\end{array}$ & $\begin{array}{l}\infty \\
0 \\
0\end{array}$ & ষ্ণ & Eั & $\begin{array}{l}\text { @̊ } \\
\stackrel{\text { N }}{ }\end{array}$ & \begin{tabular}{l}
$\stackrel{10}{0}$ \\
\hdashline
\end{tabular} & $\begin{array}{l}\infty \\
\sigma \\
0\end{array}$ & $\underset{\mathscr{E}}{\tilde{E}}$ & $\begin{array}{l}\mathscr{8} \\
\stackrel{9}{0} \\
0\end{array}$ & 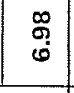 & $\begin{array}{c}\infty \\
0 \\
i\end{array}$ & $\stackrel{M}{\stackrel{M}{N}}$ & $\stackrel{M}{N}$ & $\stackrel{m}{\text { ñ }}$ \\
\hline \multicolumn{2}{|c|}{$\begin{array}{l}\text { \% OF DISTRICT TYPES FOR SURVEY } \\
\text { DESIGN CERAMIC TYPES }\end{array}$} & \multicolumn{5}{|c|}{90.87} & \multicolumn{5}{|c|}{30.29} & \multicolumn{2}{|c|}{6.99} & \multicolumn{2}{|c|}{4.66} \\
\hline
\end{tabular}

* Ceramic Density is field estimate of all surface pottery: Low $=10<$ sherds; Medium $=10-.100$ sherds; High $=100>$ sherds.

** At ARO15 and ARO57 only unclassifiable sherds were recovered.

is Presence of rim sherds in ceramic sample. 
TABLE 7

Pottery Type Temporal Spans and Archaeological Culture Phases

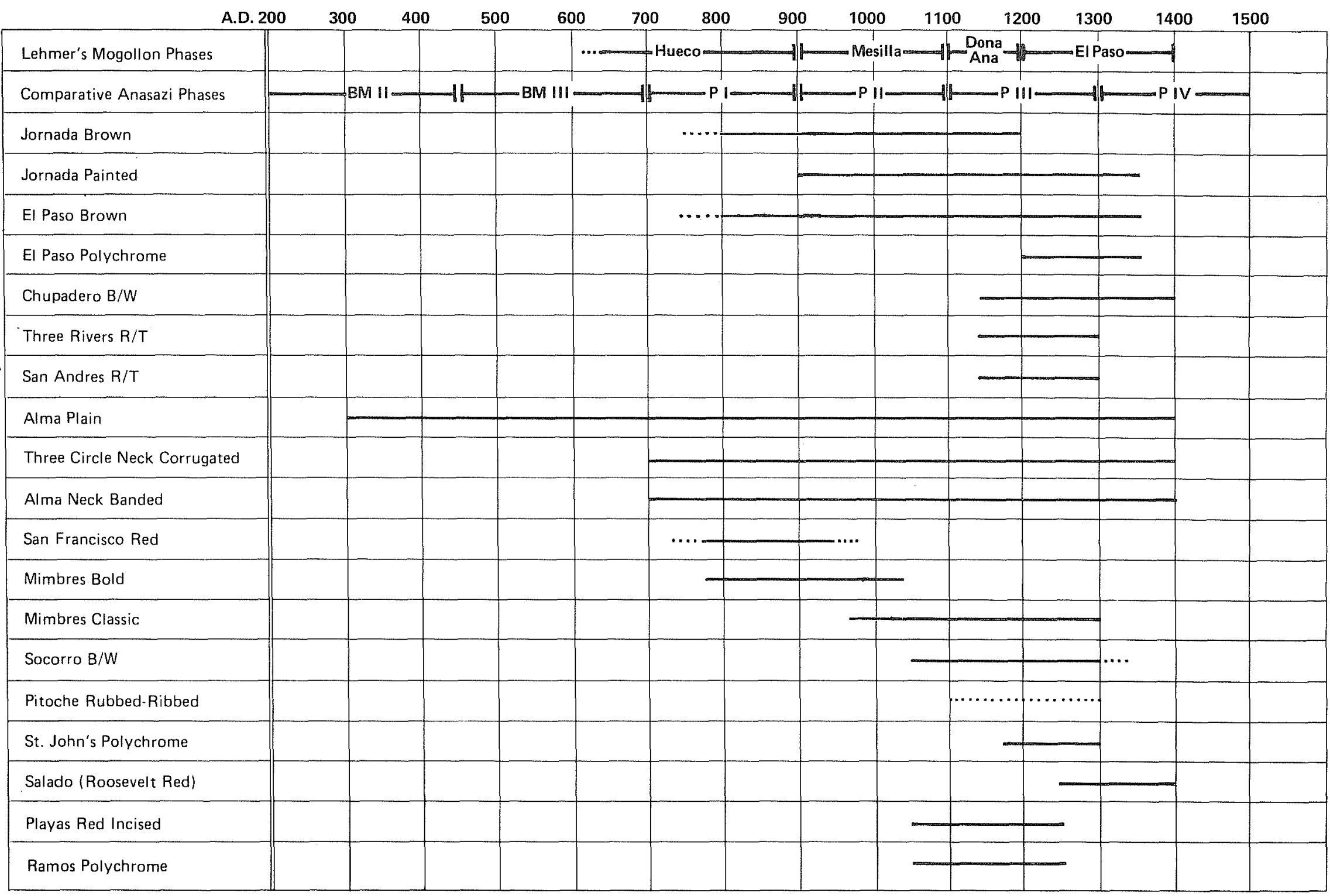





\title{
VII. INTERPRETATIONS, PREDICTIVE MODELS AND RECOMMENDATIONS
}

\author{
Joe1 D. Gunn, James E. Ivey and Thomas R. Hester
}

Uniform and Informant Models

In the discussion of the Radium Springs research design (Section II), it was noted that one of our major concerns was with the problems of disproportionate sampling. One effort to reduce this bias somewhat was made through the use of site distribution information provided by local people ("local informant's model"). Frequencies that we have since calculated suggest that the local informant's model of site distributions was correct in general outline. In the interest of methodology and explicit treatment of the data, a statistical test of the significance, or goodness-of-fit (Sokal and Rohif 1969:549), between the observed and expected frequencies was devised.

Before attempting to calculate the goodness-of-fit, it will be recalled from Section II that the sample was disproportioned (Mueller 1974:32) in favor of Zones I and II. In order to remove the effect of this disproportioning the number of sites discovered in a zone (Table 8,b) was divided by the area surveyed (Table 8,c) to get the number of sites found per section (Table 8,d). From this value the projected frequency of sites for the zone was calculated (Table $8, f$ ) by multiplying it times the total area in sections of zones (Table $8, e)$.

The observed projected frequency was then tested against two distribution mode1s. The first is a uniform distribution. The question asked in this exercise is: "Are the sites uniformly distributed over the landscape?" The second test is the "informant model" because the expected site frequency is derived from our local informant's expectations of the number of sections in which sites would occur per zone.

The $x^{2}$ values for each of these models is shown in the totals row of Table 8. The critical value for an $x^{2}$ test with three degrees of freedom (d.f.=\# of Zones-1) at a probability of less than .001 is 16.3. The statistical inference, that both models are significantly different from the observed frequencies, is not to be taken uncritically. The uniform model was tested not because we had any expectation that sites were uniformly distributed over the landscape; the intention was to determine what the relation of the $x^{2}$ test would be to a clearly unrealistic model and use the results of this test to gauge the effect of al ternative models. As Table $8, i$ shows, the uniform model is very different from the observed distribution when compared to the informant model. Thus, while the informant model can be technically rejected on the basis of an $x^{2}$ distribution table, it is less so by comparison to the uniform distribution. We conclude that our informant was in large part correct in his assessment of the distribution of sites in the survey area. Further, we believe that the character of the distribution can be explained by extensive depositions in Zone III which are deeply buried sites in the foothills of the Caballo Mountains. The reason for these depositions is determined by presently unknown factors of precipitation and hydrology. It seems likely to us that precipitation falls on the higher elevations on the mountains but not on the valley floor to the east. Consequently, detritus 
TABLE 8

DISTRIBUTIONAL ANALYSIS OF SITES FOUND DURING RADIUM SPRINGS SURVEY

\begin{tabular}{|c|c|c|c|c|c|c|c|c|c|c|c|c|c|}
\hline (a) & (b) & (c) & (d) & (e) & (f) & $(g)$ & (h) & (i) & $(j)$ & $(k)$ & (1) & $(m)$ & $(n)$ \\
\hline Zone & $\begin{array}{l}\text { \# of } \\
\text { Si tes } \\
\text { Found }\end{array}$ & $\begin{array}{l}\quad \# \text { of } \\
\text { Sections } \\
\text { Surveyed }\end{array}$ & $\begin{array}{r}\text { Sites } \\
\text { per } \\
\text { Section }\end{array}$ & $\begin{array}{l}\text { Area } \\
\text { of } \\
\text { Zone }\end{array}$ & $\begin{array}{l}\text { Projected } \\
\text { Observed } \\
\text { Frequency } \\
\text { of Sites }\end{array}$ & $\begin{array}{c}\text { Uniform } \\
\text { Model } \\
(\% \text { of Survey Area })\end{array}$ & $\begin{array}{r}\text { Uniform } \\
\text { Mode } \\
\text { Expected } \\
\text { Site } \\
\text { Frequency }\end{array}$ & $\begin{array}{l}\text { Uniform } \\
\text { Model } \\
\frac{(0-E)^{2}}{E}\end{array}$ & $\begin{array}{r}\text { Informant } \\
\text { Mode1 } \\
\text { \# of } \\
\text { Sections } \\
\text { With Sites }\end{array}$ & $\begin{array}{r}\text { Informant } \\
\text { Mode } 1 \\
\text { \# of } \\
\text { Area } \\
\text { With Sites }\end{array}$ & $\begin{array}{c}\text { Informant } \\
\text { Mode1 } \\
\text { Expected } \\
\# \text { of } \\
\text { Distribution }\end{array}$ & $\begin{array}{r}\text { Informant } \\
\text { Mode } 1 \\
\text { Expected } \\
\text { Site } \\
\text { Frequencies }\end{array}$ & $\begin{array}{l}\begin{array}{c}\text { Informant } \\
\text { Mode }]_{2} \\
\frac{(0-E)^{2}}{E}\end{array}\end{array}$ \\
\hline I & 2 & 3 & .5 & 71 & 36 & 11.1 & 183 & 118.1 & 10 & 14.0 & 13.2 & 217 & 751.0 \\
\hline II & 74 & 19 & 4.1 & 332 & 1361 & 51.8 & 853 & 302.5 & 220 & 66.3 & 62.7 & 1032 & 104.9 \\
\hline III & 3 & 9 & .3 & 190 & 57 & 29.6 & 487 & 379.7 & 5 & 2.6 & 2.5 & 41 & 6.2 \\
\hline IV & 8 & 2 & 4.0 & 48 & 192 & 7.5 & 123 & 38.7 & 11 & 22.9 & 21.6 & 356 & 75.6 \\
\hline \multirow[t]{2}{*}{ Totals } & $87^{*}$ & 33 & & 641 & 1646 & 100.0 & 1646 & $x^{2}=839.0$ & & & 100.0 & 1646 & $x^{2}=337.7$ \\
\hline & & & & & & & & $V=.41$ & & & & & $V=.26$ \\
\hline
\end{tabular}

*87 of the 96 total sites recorded were used for the analysis reported in the table. 
is transported to the valley floor but because of the rain shadow no further transport is provided to carry the material down the valley and out of the region.

\section{Optimal Utilization Model}

Having determined that the sites found in the course of the survey were nonuniform in distribution, we next examined their distribution when broken down into size categories.

Sites were divided into four groups according to size (1arge or sma11) and presence or absence of ceramics. The dividing 1 ine between small and large sites was set at $10,000 \mathrm{~m}^{2}$ on the basis of inspection of a site area frequencies histogram; $10,000 \mathrm{~m}^{2}$ is the point where the "curve" becomes flat.

It was assumed that non-ceramic sites generally predated those containing ceramics, although this probably is not always true. The distributions of these types were then compared to that predicted by the "optimal utilization" mode 1 .

What we have termed the "optimal utilization model" is, in principle, a central place theory scheme of site distribution. Sites are presumed to be divided between large base camps and small exploitation camps. As in central place theory, the exploitation camps are arranged about the base camp in a hexagonal pattern. In contrast to central place theory, however, we do not assume the adjacent hexagons to be packed. The base camps are seasonal loci at which uniformly distributed subsistence items are concentrated for transport to permanent winter camps in the foothills of the San Andres Mountains.

As long as foodstuffs are available within a nominal walking distance of the base camp, gathering concentrates around its perimeter. As the immediate area is more extensively exploited, however, substations are established to exploit the more distant areas. For reasons made explicit in central place theory these substations are arranged in a hexagonal pattern, notably optimal spacing with minimized travel distance to any point in the sector. We do not assume that the substations are the nodes of the adjacent hexagon. Since the gatherers exploit a radius around each temporary camp, such an arrangement would only result in walking to a point half of whose radius of exploitation was already harvested. It is the hexagons of exploitation radi $i$, then, that are packed rather than the hexagons formed by the pattern of base and exploitation camps.

As a consequence, each hexagonal pattern will be separated from nearby hexagons by at least double the nominal walking and gathering distance. In practice the hexagons would probably be dispersed in an unpacked system to avoid overlapping radii.

Because of the disjointed nature of the nodes, or camps, the ratio of base camps to exploitation camps should be 1:6. This ratio can be used in goodness-offit evaluation of site relations were the uniform and informant distributions to test the validity of the idea. One of the elements of the idealized central place theory model is that the sites be on an unbounded plain over which resources were uniformly distributed. While the Jornada del Muerto is not 
TABLE 9

OPTIMAL UTILIZATION MODEL

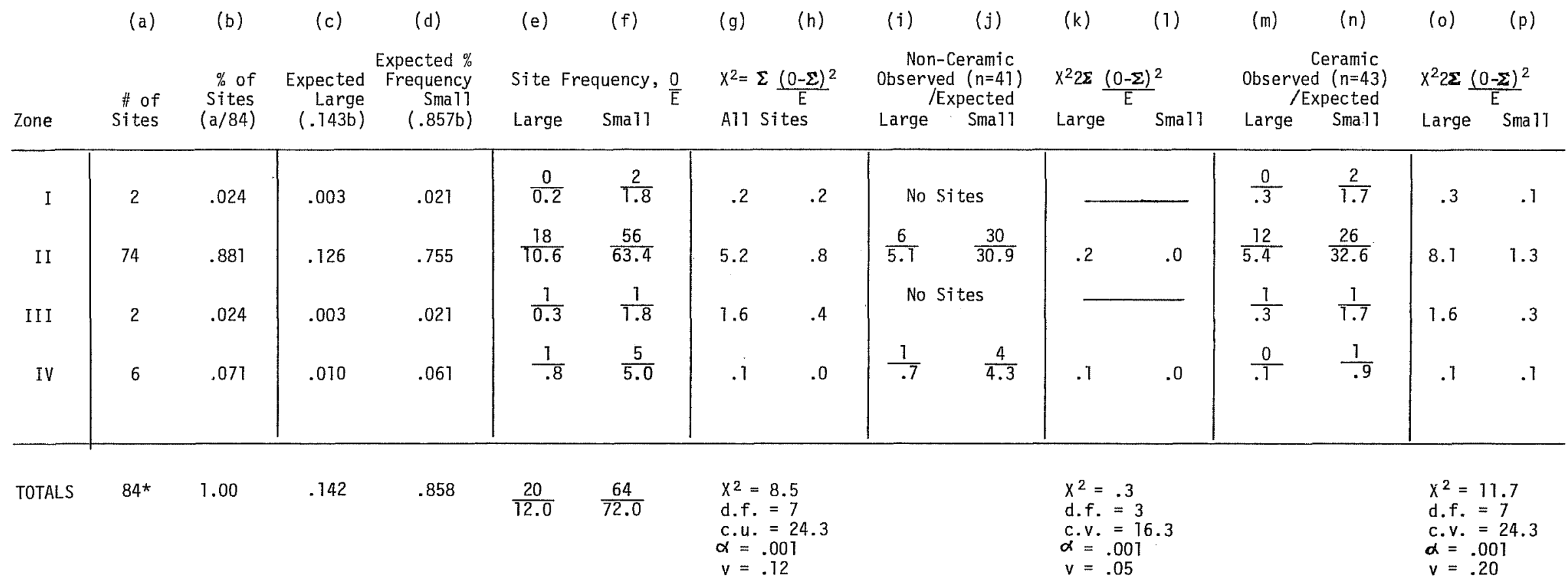

* Sites not in survey area and of questionable size eliminated 
without topographic variation there was almost surely never a more ideal place to test the model's effectiveness as a conceptual device.

The 1:6 ratio of large to small sites converts to percentages of $14.3 \%: 8.7 \%$.

In Table 9,a-d the expected values are calculated and e-h show how the observed distribution is found. The $x^{2}$ value at the bottom of columns $g-h$ indicates that the fit between the optimal utilization model and the data is relatively good.

The $x^{2}$ values for the non-ceramic sites (columns $i-1$ ) and ceramic sites (columns $m-p$ ) show that there is a remarkable amount of heterogeneity within the overall data structure.

It is apparent that non-ceramic sites fit the "optimal utilization" pattern very wel1. Zones I and III have no non-ceramic sites; this is probably related to the erosion/deposition characteristics of these areas, as discussed above. If most of the non-ceramic sites are Archaic, they have been exposed to the elements for a considerable time, and the frequencies of those in the areas of highest environmental stress would naturaliy have been somewhat attenuated.

It is equally apparent that the ceramic sites do not fit the model as well. The ratio for these sites seems to be on the order of two small to each large. Explanations come to mind for this: (1) the cultural patterns. associated with ceramics produce a different ratio of small to large sites, implying a different mechanism of land utilization--possibly associated with agriculture; or (2) the dividing point between small and large sites is different for ceramic sites. The second possibility prompted an examination of the area distribution curve for ceramic sites alone and for non-ceramic sites alone. This examination indicates that the division point should probably remain at $10,000 \mathrm{~m}^{2}$ for ceramic sites and should probably be raised to about $12,000 \mathrm{~m}^{2}$ for non-ceramic sites. Such a change would have little effect on the $x^{2}$ scores for non-ceramic sites.

It is concluded that the apparent difference in large to small site ratios between non-ceramic and ceramic sites represents a real difference, and that this difference stems from a different utilization pattern.

It should be noted that in the case of ceramic sites, Zones I and IV have insufficient numbers of sites for a meaningful $X^{2}$ test. Again, a mechanism causing an alteration of site frequencies in these zones may be the explanation, but the fact that some sites of this type were found. indicates that perhaps a cultural influence is at work.

A third alternative that must be considered is that the ceramic and lithic sites are a part of the same settlement pattern but of different functional importances. The higher $X^{2}$ would then be a product of analyzing a partsystem rather than any meaningful relationship. As can be seen in Table 9, the lithic and the lithic and ceramic analyses are virtually the same in significance. 
TABLE 10

SITE DENSITY, RADIUM SPRINGS AREA

a. Mean Density, Sites Per $\mathrm{km}^{2}$

Site Type 1

2

3

4

Zone

\begin{tabular}{rrrrr} 
I & 0 & 0 & 0.193 & 0 \\
II & 0.644 & 0.558 & 0.129 & 0.257 \\
III & 0 & 0.043 & 0 & 0.043 \\
IV & 0.772 & 0.193 & 0.193 & 0 \\
\hline
\end{tabular}

b. Mean Density with $\pm 34 \%$ Confidence Interval (1 Standard Error)

Sites Per $\mathrm{km}^{2}$

\begin{tabular}{rlrrrr} 
& 1 & 2 & 3 & 4 \\
\hline & & & 0 & $0.193 \pm 0.184$ & 0 \\
II & 0 & 0 & $0.559 \pm 1.381$ & $0.129 \pm 0.151$ & $0.257 \pm 0.380$ \\
II & $0.644 \pm 1.151$ & $0.043 \pm 0.065$ & 0 & $0.043 \pm 0.065$ \\
II & 0 & $0.193 \pm 0.220$ & $0.193 \pm 0.220$ & 0 \\
\hline
\end{tabular}

c. $68 \%$ Confidence Interval, Sites Per $\mathrm{km}^{2}$

\begin{tabular}{rlccc} 
& \multicolumn{1}{c}{1} & \multicolumn{1}{c}{3} & \multicolumn{1}{c}{4} \\
\hline I & No Estimate & N.E. & $0.009-0.377$ & N.E. \\
II & $0-1.795$ & $0-1.939$ & $0-0.280$ & $0-0.637$ \\
III & N.E. & $0-0.108$ & 0. N.E. & $0-0.108$ \\
IV & $0-2.015$ & $0-0.413$ & $0-0.413$ & N.E. \\
\hline
\end{tabular}

d. Area to be Surveyed for a 50\% Probability of Finding One Site, $\mathrm{km}^{2}$

\begin{tabular}{rrrrr} 
& 1 & 2 & 3 & 4 \\
\hline I & N.E. & N.E. & 5.18 & N.E. \\
II & 1.55 & 1.79 & 7.75 & 3.89 \\
III & N.E. & 23.25 & N.E. & 23.25 \\
IV & 1.30 & 5.18 & 5.18 & N.E. \\
\hline
\end{tabular}


At this time, however, it is beyond our ability to determine the contemporaneity of lithic and ceramic sites. So we are by default dependent on our original assumption that the two types of sites are temporally disassociated.

Because of the grossly differing sample sizes in the various tests the $x^{2}$ coefficients cannot be compared directly. Cramer's V, calculated as

$$
V=\left(\frac{\frac{X^{2}}{N}}{d \cdot f}\right)^{1 / 2}
$$

where $N=$ Number at sites and d.f. = degrees of freedom, removes the effect of different sample and vector sizes between the various tests. The tests are ranked on $V$ in Table II.

TABLE 11. Cramer $V$ for Various Models

$\begin{array}{ll}\text { Optimal Utilization - Lithic Sites } & .05 \\ \text { Optimal Utilization - Lithic and Ceramic Sites } & .12 \\ \text { Optimal Utilization - Ceramic } & .20 \\ \text { Informant's Distribution } & .26 \\ \text { Uniform Distribution } & .41\end{array}$

If this ranking is assumed to be a measure of the relative power of the various concepts the optimal utilization distribution is clearly in the lead. Any subsequent research in the Radium Springs survey area should include as a part of its design the survey of a large enough block of land in Zone II to use standard central place pattern fitting techniques to test for the presence of the proposed model.

\section{Site Density}

In addition to examining the models discussed above, we also carried out a study of site density for each major type of site within each of the four environmental zones. Densities of site distribution and their range at the $68 \%$ level of confidence are presented in Table 10. These are calculated using the approach of A. E. Rogge (see Ful1er, Rogge and Gregonis 1976).

Rogge's method for estimating the number of sites per unit area based on a stratified sampling is as follows:

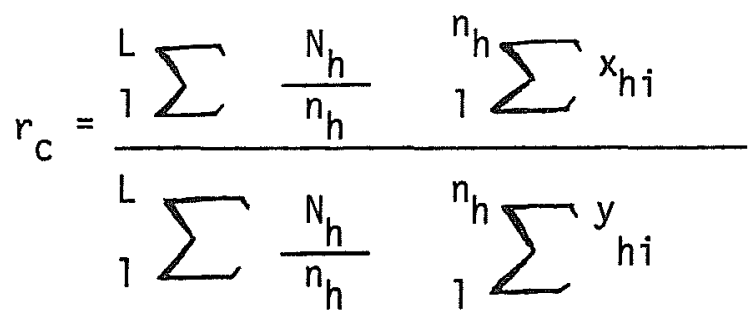


where $r_{c}=$ combined ratio estimate of number of sites per unit area

$L=$ number of strata (zones)

$N_{h}=$ number of sample units in stratum $h$

$n_{h}=$ number of sample units surveyed in stratum $h$

$N_{h} / n_{h}=$ reciprocal of the sampling fraction

$x_{h j}=$ number of sites in sample unit $i$ in stratum $h$

$y_{h i}=$ number of units of area in sample unit $i$ in stratum $h$

Because of the conditions of our survey, this equation was more complicated than necessary:
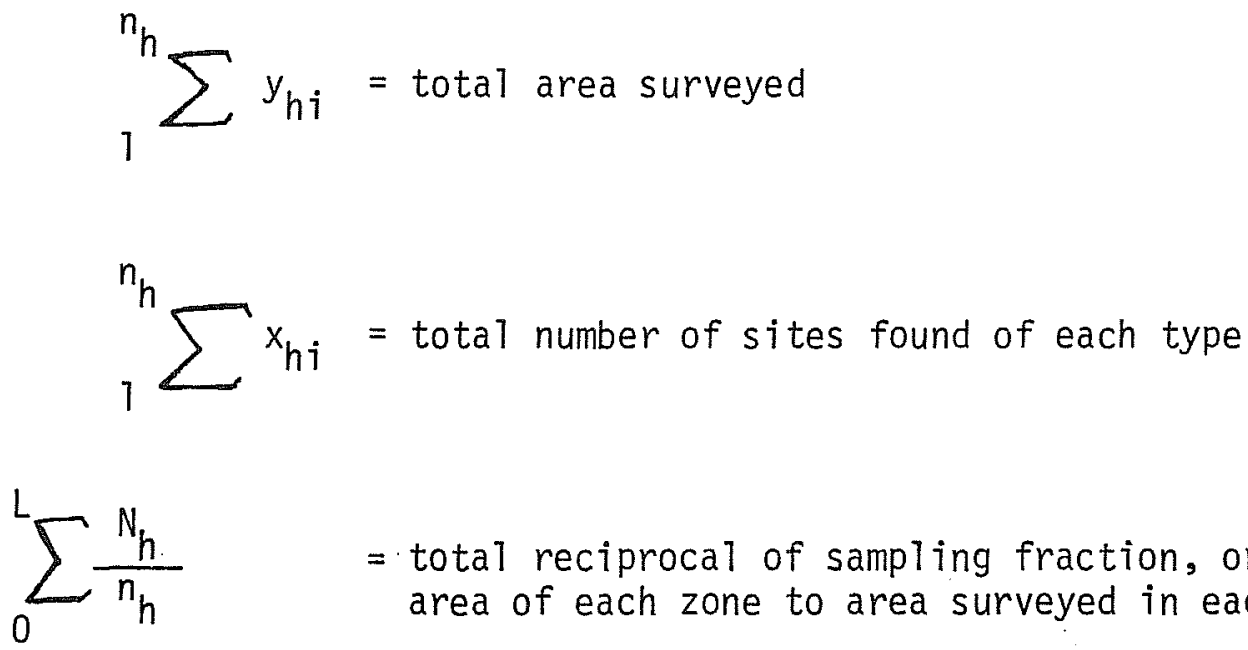

$=$ total reciprocal of sampling fraction, or ratio of total area of each zone to area surveyed in each zone.

Since in each case we are interested primarily in the density for each zone rather than for the entire survey area, the summations across the zones may be omitted. The reciprocal of the sampling fraction cancels, leaving:

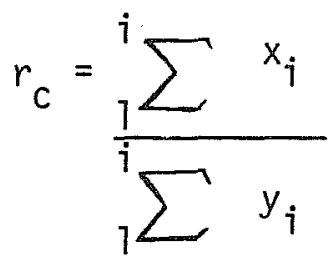

where $i=$ number of sample units.

This equation says that the combined ratio estimate of site density in each zone is equal to the ratio of the total number of sites in each zone to the total area surveyed in each zone. Sample units are all the same size, one square mile or $2.592 \mathrm{~km}^{2}$. Therefore: 


$$
r_{c}=\frac{X}{Y}
$$

where $X=$ total number of sites in zone

$Y=$ total area surveyed in zone

For the sake of clarity, Rogge's alphanumerics were changed to mnemonic letters:

$r_{C}=D$ : site density of each site type in each zone

$X=t$ : number of sites of each type in zone

$Y=a$ : area surveyed in zone

This makes Rogge's simplified equation:

$$
D=\frac{t}{a}
$$

which is a clear and straightforward relationship. This computation must be carried out for each type of site in each zone.

Rogge's method of estimating the level of confidence of these densities, modified and transliterated for our purposes, begins with the calculation of the standard error of the number of sites of each type in each zone:

$$
S . E=\sqrt[D]{\sum_{1}^{n} \frac{(t-m)^{2}}{n-1}}
$$

where S.E. = standard error (standard deviation)

$$
\begin{aligned}
D= & \text { density of sites of each type per } \mathrm{km} \text { in each zone } \\
n= & \text { number of sections in each zone } \\
t= & \text { number of sites of each type in each section } \\
m= & \text { mean number of sites of each type per section } \\
& \text { for all sections surveyed in zone }
\end{aligned}
$$

This says that the standard error of the number of sites of each type in each zone is equal to the square root of the product of the density of sites per $\mathrm{km}^{2}$ and the variance in the number of sites of each type per $\mathrm{km}^{2}$ surveyed in each zone.

The density arrived at by these equations represents a mean density. The standard error gives us a method of estimating the probability that the actual number of sites found in a given zone by a survey of previously unexamined sections would be reasonably close to the mean density stated here. The usual 
statement of this density and a probability estimate for it is as presented in Table 10,b; the probability is stated in terms of an interval, giving a range of densities and a probability that the actual number found will be within this range, quite similar to the method used in expressing radiocarbon dates. An interval of one standard error is equivalent to a probability interval of $34 \%$--that is, the expression (mean density \pm S.E.) states that there is a $68 \%$ chance that the actual density of sites found in a survey of a new area in a given zone would fall between the values of (mean density - S.E.) and (mean density + S.E.). Intervals appropriate to other probabilities are determined by multiplying the standard error by the proper amount, as determined by consulting the "Areas of a Standard Normal Distribution" tables to be found in most statistics texts.

\section{Discussion of Density Results}

The highest site densities are found among small non-ceramic sites in Zones II and IV, followed by large non-ceramic sites in Zone II. The greatest range of error is also found in these three sites and zone combinations. It will be noted that in all cases but the small ceramic sites in Zone I, the error is larger than the mean density. This simply means that there is considerable variation in the number of sites in any given section or square kilometer, which reduces the accuracy of any predictive statistics.

Table 10,d indicates the area to be surveyed to find one site if the mean density were an accurate statement of the density of a uniformly distributed number of sites. In actuality there is a $50 \%$ probability that a site will be found within this area. This is because the area given is equal to the inverse of the site density (in Zone II, type 1, for example, a density of 0.644 sites per $\mathrm{km}^{2}$ is the equivalent of $\frac{1}{0.644}$, or $1.55, \mathrm{~km}^{2}$ per site), which

is the mean of an assumed normal distribution. This means that as a survey is carried out, the first few square feet examined have minuscule probability of containing a site. This probability increases as the amount of area surveyed increases, and reaches $50 \%$ when the mean area has been surveyed. This table is presented as an illustration of the uses of these numbers as estimates of the probable number of sites to be found in any survey area.

In general, it should be kept in mind that the densities presented here are based on a $5 \%$ survey of a huge area. Rogge's work indicates that the situation is not necessarily so vague as it seems; his theoretical work implies that it is reasonably likely that the actual density of sites throughout the zones is quite close to the mean density figures presented in Table 10,a, and that the areas to be surveyed in Table 10,d would probably have a much higher chance than $34 \%$ of containing a site. Further refinements of estimates can and should be made by examining Tables 8-10 and noting other topographic characteristics shared by sites. Obviously some areas within a zone would have a far better chance than others of containing sites. Further refinement of the zone-wide density estimates and confidence intervals would require additional random sampling. 


\section{TABLE 12}

Rotated Principal Components Matrix for Environmental and Cultural Relationships in the Radium Springs Survey Area

\section{ENVIRONMENT}

\section{VECTORS}

I II III

IV V VI $h^{2}$

\section{East}

Elevation (North)

Physiographic Transect Loc. $\quad-.7$

Physiographic Orientation

Vegetation (Mesq-0ther)

Soil (Sand-Other)

Water Source

-.7
-.4

.8

$\begin{array}{ll}.8 & .8\end{array}$

\section{CULTURE}

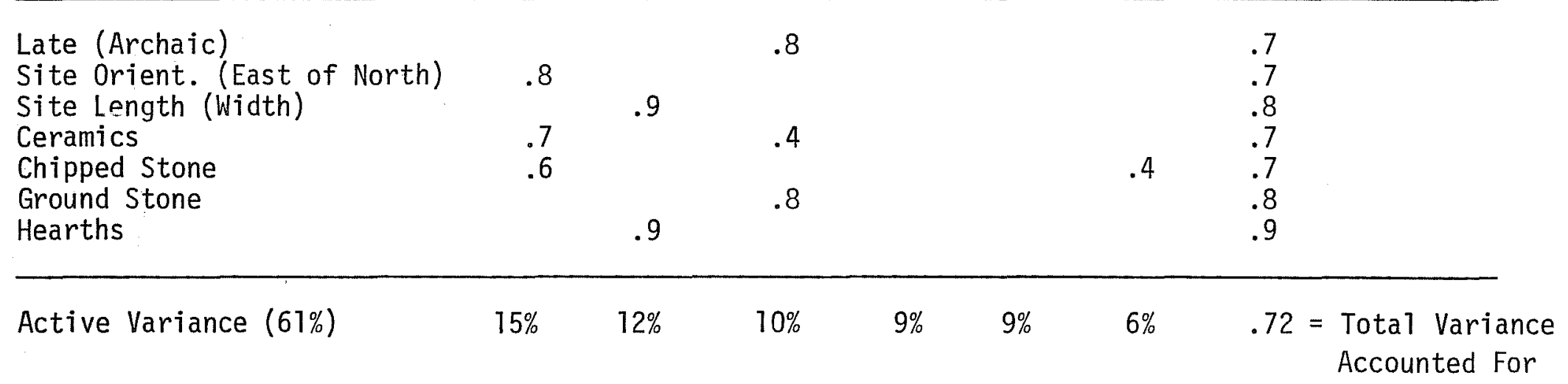




\section{Environmental and Cultural Relationships}

The major presumption which informed the collecting of data for the Radium Springs analysis is that some proportion of the behavior which human beings exhibit, and which is recorded in the archaeological record, is governed by factors of the environment. With this thought in mind we attempted to metrically describe the environment of each site in terms of not only its Cartesian location but also its characteristics as a source of water, shelter and subsistence. In the following discussion we will attempt to delineate the probable environmental preferences of the people who inhabited the Jornada del Muerto. In the first analysis the problem will be dealt with at a rather general level by analyzing the data from the site survey forms. Because of unforeseen logictical problems, we found it difficult to get site survey forms from the field to our computer facility on a regular basis. However, it should be kept in mind that, assuming the solution to particular logistical problems, this analysis could have run simultaneously with the survey (on a dayto-day basis if need be). In the second analysis we attempt to incorporate the results of the laboratory analysis into the study.

Table 12 is a varimax rotated principal axis matrix (Nie et al. 1975:479) which has been partitioned into environmental and cultural variables. Each column in the matrix represents a statistically independent trend in the data. If it is acceptable to assume that cultural traits will be correlated with the environmental phenomena to which they are causally related, then cultural and environmental traits which are causally related will appear on the same columns or vectors of the matrix. Two vectors in the matrix are related to the environmental indicators we have defined, causal Vectors I and VI. Between them, these two constitute $21 \%$ of the active variance in the system as defined by the 14 analyzed variables. Purely cultural components, Vectors II and III account for $22 \%$ while the interaction of environmental influences in Vectors IV and $V$ accounts for $18 \%$ of the system's behavior.

The first vector shows that the location of sites on the physiographic transect (and the distance to water) is inversely correlated with site orientation, amount of ceramics and 7ithics (Fig. 30). Larger amounts of ceramics and lithics located closer to sources of water are a reasonable relationship in any circumstance. Why sites should be oriented more toward the north on the upland, and to the south closer to water courses, is not immediately apparent.

Vector VI shows that chipped stone tends to be located in areas where mesquite is sparse and other types of vegetation are prominent. Mesquite is thought to be a recent intruder in the area so the relationship is not direct. The aboriginal populations did not use chipped stone on or around whatever vegetation complex the mesquite has replaced.

Vectors IV and $V$ are special cases because they both represent a great dea 1 of natural variation which seems to be influencing the way sites are located relative to physiographic features. Vector IV shows that sites farther east tend to be located to the side of physiographic features and they tend to be on sand. Sites to the west are on other soil types and tend to be on the tops of features. Vector $V$ shows that sites which are farther north 
and higher in elevation are farther from water resources on the tops of topographic features. Conversely, those to the south and lower in elevation are closer to water and located to the side of features.

The two purely cultural vectors show that larger sites have more $1 i$ thics and more hearths. This leads to no surprises but it is interesting that the number of hearths should be so totally related to size of the site. If there were functional variability between sites, the number of hearths relative to site size could vary significantly.

The remaining cultural trend, Vector III, is the Archaic-Late cultural continuum. The only time-related changes in the valley involve a gradual increase in ceramics and ground stone.

Any enviro-cultural system described numerically as we have done here is going to be composed of those environmental and cultural variables which are specified and measured and those which are unspecified and as yet unknown. If we take some things for granted, we can say that $61 \%$ of the variance between environment and culture, in the narrow sense they are defined in this study, are accounted for by the foregoing analys is and $39 \%$ of the variance in culture are as yet of unknown sources. Fig. 31 i17ustrates cultural and environmental interaction in a causal diagram.

Fig. 37 is defined without feedback and as such is probably more simple than the real interaction. Interpretation of the causal forces in a matrix like Table 12 is purely a matter of theory, and so we are obligated to consider alternative interpretations. One possibility is to further partition the variance into feedback loops. Let us assume that "culture" per se is an unknown causal agent in the system, the effects of which we can read from the structure of archaeological materials collected in the survey. In the case where a vector contains loadings in both the environmental and cultural sections of the matrix, we are observing a demonstrated causal relationship between environmental stimulus and cultural response as in Vectors I and IV.

This is illustrated in Fig. 32 by the $E$ to $C$ relationship of $21 \%$. What of the other vectors which show no activity across the environmental and cultural subsystem boundaries? The purely environmental Vectors IV and $V$ are not purely environmental in the sense that culture is not involved. The physiographic-environmental context of a site is selected by cultural criteria. These variables, then, reflect the effect of unseen cultural influences on the preselection of site locations. In a sense they are the products of the effect of culture on environment. This is shown in Fig. 32 as an $18 \% \mathrm{C}$ to $\mathrm{E}$ relationship.

Vectors with only cultural variables show the effect of culture on cultural distributions of materials at $22 \%$. Unknown relationships of unknown causal directions are illustrated as before at 39\% but the ambiguity of the causal relationships is shown by arrows in both directions.

While this discussion is methodologically incomplete, it does serve to outline a synopsis of prehistoric enviro-cultural relationships in the Radium Springs survey area and provide rough estimates of the magnitude of those interactions. Future research in the area should consider these relationships as hypotheses around which research designs could be constructed. 


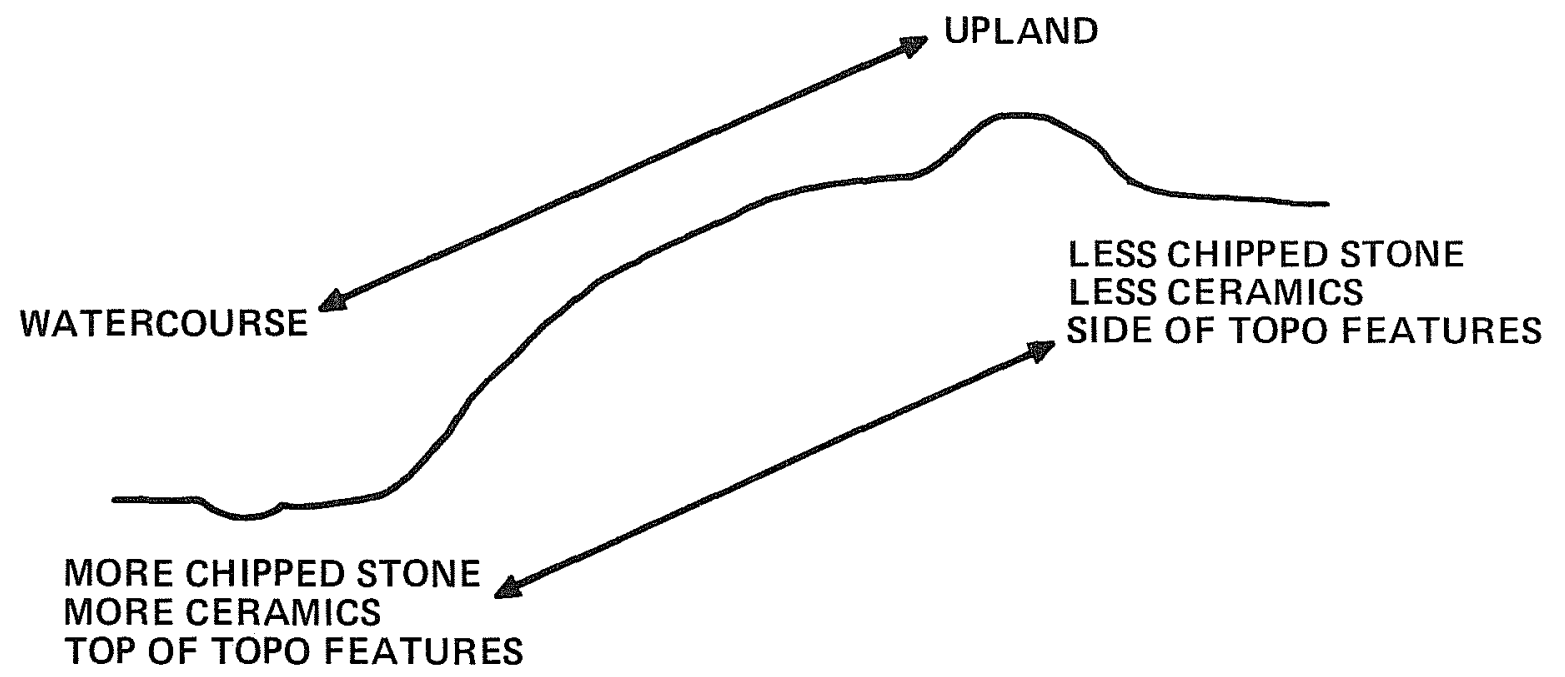

Figure 30. Physiographic Transect and Related Variables. 


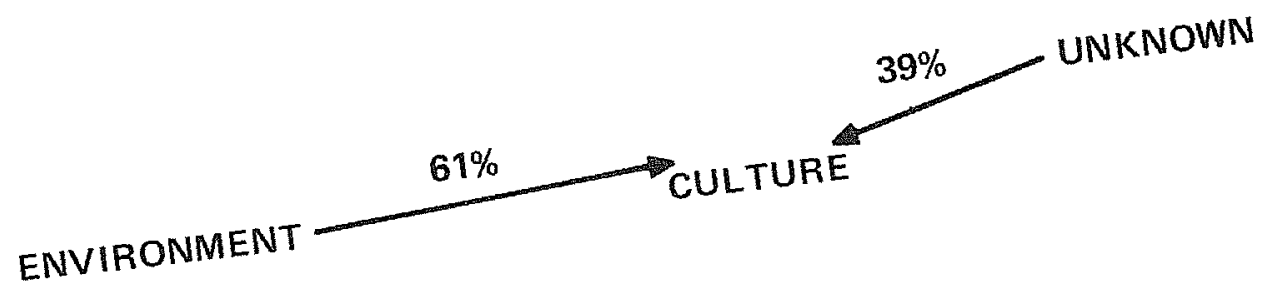

Figure 31 . Recursive Interac
and Factors As Yet Unknown.

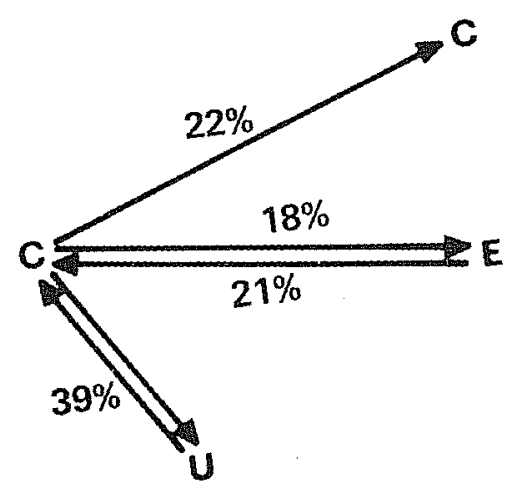

Figure 32. Non-recursive Interaction 
The larger principal components analysis was calculated in 59 variables. These included all of the variables in the site survey analys is except ceramics and lithics and all of the ceramic and lithic types which had variance. All variables were converted to binary states. This was done to avoid the problem of correlation coefficient attenuation which happens when binary variables (presence or absence of ceramic types, etc.) and continuous variables, with large numbers of states (such as elevation in meters), are correlated (Doreian 1972). The effect of attenuation (1owering) is to produce spurious independence in the correlation matrix.

The results of this analys is must be considered very tenuous relative to lithics since there was only a marginal attempt to sample the large quantities of lithics in the survey area as per contract specifications. The ceramics, on the other hand, are accurately represented. Al1 results are offered as numerically inferred hypotheses to be tested by fieldwork and are in no sense meant to be taken as conclusions.

Using a scree-test (Rumme1 1970:364), it was determined that there were 14 substantialiy important components in the data. These were rotated to varimax criteria.

These 14 components represent $67 \%$ of the variance in the original data matrix.

\section{TABLE 13}

\section{Rotated Principal Components Results for} Post-Laboratory Analys is

VECTOR

I.

Mimbres Boldface

Mimbres Classic

Pitoche Rubbed-Ribbed

Unidentified Painted Ware

Unidentified Corded/Banded/Incised Ware
LOADING

COMMUNAL ITY

COMMENT*

II .

Ornaments

A7ma Plain

Seco Corrugated

Playas Red Incised

Concave Scraper

Core Trimmer

$\begin{array}{ll}.89 & .89 \\ .44 & .79 \\ .56 & .70 \\ .55 & .77 \\ .76 & .89\end{array}$

$\begin{array}{ll}.76 & .70 \\ .73 & .82 \\ .39 & .58 \\ .92 & .92 \\ .39 & .67 \\ .58 & .83\end{array}$

$\begin{array}{ll}B & T_{W} \\ B & T_{W} \\ U & T_{W}\end{array}$

77

$W$

\footnotetext{
$*(B=$ Burial Ware; $U=$ Utility; $T=$ Trade; Subscripts $n, e, s, w=$ direction of trade importation).
} 
TABLE 13 (continued)

III.

Late

Archaic

Hearth (Limestone)

Jornada Brown

E1 Paso Brown

Site Type (Large Sites?)

$.87 \quad .84$

$.86 \quad .87$

$.42 \quad .63$

$.51 \quad .65$

$.78 \quad .79$

$\begin{array}{ll}.66 & .85\end{array}$

U

U

IV.

Hearth (Basalt)

$.84 \quad .75$

Hearth (90\% BasaTt)

$\begin{array}{ll}.68 & .53\end{array}$

Hearth (Basa1t/Limes tone/Sands tone)

.78

.70

Unidentified Plainware

.43

.72

V.

North

Unidentified Plain

Pulping Plane

End Scraper

Concave Scraper

$\begin{array}{ll}.43 & .75 \\ .53 & .72 \\ .60 & .54 \\ .56 & .57 \\ .43 & .67\end{array}$

TABLE 14

Rotated Principal Components Results for Post-Laboratory Analys is

NAME

VI.

Seco Corrugated

Preforms

Finished Bifaces

VII.

Worked Potsherds

End-Side Scraper

Plano-Convex-Ova 7

Quarry Blanks

Preforms

Drills \& Perforators

Cores

Core Trimmer

VIII.

East

Soi 1 (Sand-0ther?)

Ground Stone

End Scraper
LOADING

COMMUNALITY

COMMENT*

.46

.55

.72

.58

.68

.74

.64

.56

.62

.56

.42

.41

.44

.63

.72

.56

.53

.53

.68

.64

.73

.83

$\begin{array}{rr}.64 & .65 \\ -.81 & .69 \\ .50 & .52 \\ -.46 & .57\end{array}$

$*(B=$ Burial Ware; $U=$ Utility; $T=$ Trade; Subscripts $n$, e, $s, W=$ direction of trade importation). 
TABLE 14 (continued)

IX.

El Paso Polychrome

Hammerstone

Cores

$\begin{array}{lll}.51 & .69 & T_{S} \\ .51 & .64 & \\ .58 & .73 & \end{array}$

$X$.

Collecting Damaged Site

.69

E1 Paso Polychrome

.42

Mimbres Classic

Flake Scraper

.58

.57

Utilized Flake

.49

.67

.69

.79

.64

.54

$X I$.

Chupadero Black-on-White

Mimbres Classic

Concave Scraper

.49

Manos

XII.

Multipurpose Scraper

Plano-Convex-Oval (Scraper?)

.67

.79

.50

.74

XIII.

North

Topography

Vegetation

Hearth (Basalt/Limestone)

XIV.

Hearth (Limestone)

Ramos Polychrome

Pestle
$-.67$
${ }_{B}^{T_{S}} T_{W}$

$$
{ }^{S} T_{W}
$$

$\mathrm{T}_{\text {ne }} \mathrm{T}_{\mathrm{w}}$

\section{Time and Environment}

Based on Tables 13 and 14 (above), we can make a number of observations. Vector III suggests that larger sites are more frequent later in time and that later and larger sites have Jornada Brownware and El Paso Brownware consistently associated with them. Both are utilitarian types of pottery which might be expected to be the staple indicators of change through time. In addition, limestone hearths were present where these trends appeared. From these associations we infer a tendency for the increased use of utilitarian brownwares through time, perhaps at the expense of perishable containers and perhaps a more sedentary character to prehistoric lifeways. For as yet undetermined reasons limestone was more frequently used in later times. There is no indication of directional preferences in the use of 7 imestone which would probably result from a shift in regional locations of sites. It is therefore possible that limestone was preferred to basalt and carried over distances to use-points, thus randomizing the pattern.

Vector VIII is an environmentally-related tendency. It properly shows that soils to the east are sandy and other soil types are found to the west. 
Related to this physiographic fact is the presence of ground stone to the east and sandy region while end scrapers appear more frequently to the west with clays. This vector could lead one to very cautiously hypothesize plant processing in the sand hills with ground stone and hide processing in the west, perhaps during climatically wetter times.

Vector XIII contains the north coordinate and negatively related to it the physiographic transect and vegetation. Toward the south, then, sites are more often on the uplands between water courses and the vegetation is more frequently non-mesquite varieties. Associated with the south also are combination basalt-limestone hearths.

Vector IV shows that various hearth types typically occur together in the same sites. It also demonstrates that these hearth types are typically associated with unidentified sherds of plainware pottery.

Vector V shows a tendency for "pulping planes," end scrapers and concave scrapers to be more frequently present toward the north of the survey area. Unidentified plainware sherds also appear in a systematic fashion in the north.

Vector I contains both of the Mimbres varieties of pottery which are typically found as burial goods and Pitoche Rubbed-Ribbed is a utilitarian ware. The other two categories are unidentifiable scrap pottery.

\section{Lithics}

Vector VII is a complex of lithics, particularly bifaces and quarry materials. The sites with such a combination of tools are clearly workshops. There are no indications of direction or other environmental relationships. This could be taken to mean that sites containing the Vector VII lithic complex are uniformly spread over the survey area. If further study shows them to be potential base camps, this vector supports the central place or maximum utilization model tested in the predictive models portion of this section.

The association of preforms and finished bifaces in Vector VI suggests sites at which bifacial thinning was important. Why Seco Corrugated, a utility ware, should be associated with bifacing is obscure but it does suggest that the execution of such duties within the valley was a late rather than early trait. While Vector VI is conceptually close to the lithic complex in Vector VII, the fact that the two are statistically independent may suggest an earlier date for the purely lithic Vector VII as inferred from the association of ceramics with Vector VI.

\section{Ornamentation}

Vector II is composed of utilitarian wares and two lithic types. While we offer no interpretation of the functional aspect of the vector it is interesting to note the presence of ornaments with the cluster. Perhaps the possibility of using the tools and containers for manufacture and storage of ornaments should be considered for testing in future research. 


\section{Questions}

Several vectors are difficult to interpret and could easily be the products of sampling error, spurious correlations, and any number of other problems that make this analysis very tenuous. Vector IX is composed of El Paso Polychrome, a tradeware from the south, hammerstones and cores. Vectors $X$, $X I, X I I$, and XVI are composed of similarly obscure combinations of 1 ithics and ceramics which may someday be meaningful, but for which we have no plausible interpretation now. They are the very lowest vectors as far as accounting for variance is concerned. They could be simply error variance with no real meaning; although this is as a matter of judgement somewhat unlikely in this case, since the number of substantively important vectors was conservatively estimated.

In summary, the analys is shows that there are directional and environmental tendencies in the data which can be justifiably investigated by archaeological research. Among the hypotheses to be considered is the possibility of differential land use between sandy and clay (other) soil zones, and vegetation zones. The valley appears to have been occupied on a more sedentary basis later in time ( $i . e$. , the prehistoric period during the Jornada Branch times before Apache occupation). The types of hearths and the use of varying emphases in chipped stone technology also appear to be potentially rich topics for future research. In addition, vectors which cannot be immediately interpreted may prove to be useful sources of hypotheses as our understanding of the Radium Springs Survey area matures and the vectors are reconsidered in the right of that maturity.

\section{Recommendations}

Our recommendations, on a site-by-site basis, are listed in Table 3 . Most sites fall into Categories 1 and 2 (see key to Table 3). Category 1 sites are those that, in all probability, have been essentially destroyed by erosion. They are scattered remnants, with iittle remaining archaeological potential. In Category 2 we have placed sites which cannot be fully evaluated at this time. Some of these sites may be significant, but due to the lack of field time or to minimal erosion they could not be adequately assessed. If any of the Category 2 sites are found to be within areas slated for modification, they should be field-checked again prior to being disturbed.

Sites in Categories 3 and 4 are important ones. All should be nominated to the National Register of Historic Places. The three sites in Category 3 (AR001, AR089, AR092) are presently being damaged, primarily through the vandalism of relic collectors. The sites are on federally-controlled lands, and we urge that steps be taken to insure their protection. The five sites in Category 4 (AR062, AR068, AR093, AR094, AR096) are of outstanding importance, and we recommend their immediate nomination to the National Register. Even though some of these were found outside the selected survey sections, we have documented their existence and they should be protected.

We believe that this survey has adequately reported the major kinds of sites within the Radium Springs study area. In addition, we have provided detailed descriptive and illustrative information on these sites and the materials 
recovered from them. We have indicated our estimate of site density, in terms of site type occurrence within specific and environmental zones. However, these data constitute only a limited and very preliminary assessment of the archaeological resources in the vicinity of Radium Springs. Before any modification of government land occurs in this section, we strongly recommend that intensive archaeological surveys be made of those areas that would be affected. 

VIII. APPENDICES 



\section{APPENDIX I \\ NOTES ON THE SITE SURVEY CODING FORMAT, RADIUM SPRINGS SURVEY}

Joe1 D. Gunn and James E. Ivey

The coding format for the Radium Springs survey was designed: (1) to collect the maximum amount of information on site character and context which could reasonably be asked of individual personnel without unduly interrupting a largely team-oriented effort, and to meet the specifications of the BLM contract; and (2) to facilitate rapid coding, checking for completeness and key punching. The form used in the survey is reproduced on the following page. The first section records the location at the site and its designations. The second section is a field estimate of the antiquity of the site [Paleo-Indian, Archaic, and Late (ceramics, villages, arrow points, etc.)]. Site context is determined by answering the eight questions in section three of the form. Topography is the location of a site relative to a physiographic transect which is subdivided at various points between the bottoms of water courses and the tops of upland eminences. Landform within one mile is intended to record any nearby physiographic features which would attract occupation such as natural windbreaks, elevated areas, etc. Site orientation is likewise noted to record relationships to features which would provide a natural attraction to inhabitants such as orientation toward or away from direct sunlight, prevailing winds, etc. Vegetation, soils, distance to the nearest water, wildlife, soil and lithic outcrops might also reflect the availability of attractive resources.

The site dimensions are recorded as maximum length and width and the direction east of north in degrees of the long axis of the site.

Density of various aboriginal and modern features is designed to collect information on the appearance of prehistoric remains and the disruption of those materials by modern collecting, economic, and erosional activity.

The column of recording space down the right side of the form is largely work space which allows the field investigators to expand the coding format based on mutual understanding in the field. Some items which were agreed on by the end of the first week of the survey are entered in this work space since a large reproduction run of the forms was made at that time.

Each underscore on the page represents a computer card key punch column. Any information that is to be entered into the computer must be coded one digit per underscore on, and only on, the underscored spaces. The underscores are aligned so the survey personnel can readily locate the spot where information is to be entered, so the field supervisor can check for completion at a glance, and so key punchers can readily and accurately transcribe the record to cards.

With regard to completeness, a form is complete only when all underscores are filled in. If data are missing a zero is entered. If there is a blank it means that the question was not dealt with. 
RADIUM SPRINGS PROJECT

Zero = Missing Data. If there are any blanks when you walk away from a site, you did something wrong!

Location

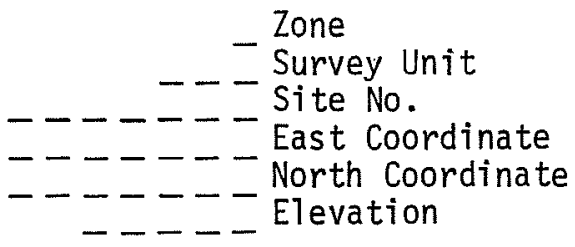

Components (Field Estimates: to be refined in Lab)

$$
\begin{aligned}
& \text { Paleo-Indian (1=Pres, 2=Abs) } \\
& \text { - Archaic (1=Pres, 2=Abs) } \\
& \text { - Late (1-Pres, 2=Abs) } \\
& \text { - Individua1 Find (See Lithic } \\
& \text { - } \text { - Type List) }
\end{aligned}
$$

Site Location

$$
\begin{aligned}
& \text { - Topographic feature at site } \\
& \text { (1=Water Course, 2=Valley Bottom, } \\
& 3=\text { Valley Slope, 4=Upland Margin, } \\
& 5=\text { Upland, } 6=\text { Upland Feature) } \\
& \text { Land form within } 1 \text { mile (see list) } \\
& \text { - Orientation ( } 1=\text { Upon, } 2=N \text {. of } \\
& \text { feature, } 3=E \text {. of feature, } 4=S \text {. of } \\
& \text { feature, } 5=W \text {. of feature) } \\
& \text { _ Vegetation on site (see vegetation } \\
& \text { list) } \\
& \text { Water Source }(1=0 \text { n Site, } 2=<100 \mathrm{~m} \text {, } \\
& -3=<1 \mathrm{~km}, 4=\geqslant 1 \mathrm{~km} \text { ) } \\
& \text { Wildlife in area (see wildlife list) } \\
& \text { - Lithic outcrops (see outcrop list) } \\
& \text { - - Soil type (see soil list) }
\end{aligned}
$$

Site Dimensions

$$
\begin{aligned}
& \text { Long orientation (degrees East of } \\
& \text { North) } \\
& \text { - Meters long } \\
& \text { - }- \text { Meters wide }
\end{aligned}
$$

Density (Site-Wide)

Ceramic $(1=1-10,2=10-100,3=>100)$

- Lithic $(1=1-10,2=10-100,3=>100)$

- Ground stone (count, $9=\geqslant 9$ )

- Ornaments $(1=1-10,2=10-100,3=>100)$

- \# of hearths

- Collecting of site (1=pristine,

- 2=potholed, $3=$ destroyed by human activity)

- Economic Activity ( $1=$ disturbed, 2=

partially dist., 3=wholly dist.)

- Erosion (1=undisturbed, 2=partially

eroded, $3=$ wholly eroded
Ceramic Types:

Comments :

1. Jornada Brown

- 2. Jornada Painted

- 3. El Paso Brown

- 4. El Paso Polychrome

- 5. Chupadero BTack/White

- 6. Three Rivers Red/Terracotta

- 7. San Andres Red/Terracotta

8. Lincoln Red/Black

- 9. Alma Plain

- 10. Three Circle Neck Corrugated

- 11. Alma Neck Banded

- 12. San Francisco Red

- 13. Seco Corrugated

- 14. Mogollon Red/Brown

- 15. Three Circle Red/White

- 16. Mimbres Boldface

- 17. Mimbres Classic

- 18. Pitoche Rubbed-Ribbed

- 19. Socorra Black/White

- 20. St. Johns Polychrome

- 21. Salado (Roosevelt Red)

- 22. Playas Red Incised

- 23. Ramos Polychrome

- 24. Rio Grande G1aze

- 25. Cibola Whiteware

- 26. Unidentified Plain ware

- 27. Unidentified Paint ware

- 28. Unidentified Textured ware

29. "Worked" Potsherds

30. "Mendinghole" Potsherds

- 31. (Not Used)

- 32. Hearth-Basalt

- 33. Hearth-90\% Basalt

- 34. Hearth-Bas-LS (50-50)

- 35. Hearth-LS

- 36. Hearth-LS-SS

- 37. Hearth-SS

- 38. Hearth-Bas-LS-SS

-39 .

$-40$.

-41 .

- 42. Biface-Arrow

- 43. Biface

- 44. Biface-Site Notched

- 45. Biface-Corner Notched

- 46. Scraper-end

- 47. Scraper-side

- 48. Uniface

- 49. Perforators

- 50. Choppers 
Potentially the coded information could be analyzed simultaneously with the progress of the survey. (See section on numerical analysis for further discussion.) Logistics problems in the case of this survey precluded effective simultaneous analysis. When the crew returned to The University of Texas at San Antonio the cards were key punched and various analyses performed. Besides providing the basis for linear analysis of intersite relationships, the computer coding provided readily available tabulations of site characteristics which were used during the writeup phase.

After the lithics and ceramics were analyzed in the laboratory, a second card was added to the existing key punch information for each site based on these endeavors.

While some of the categories did not provide useful information because of the special circumstances of the survey area, especially economic activity and erosion (widespread deflation), the form should be left unchanged in future surveys in the area in the interest of universal applicability.

\section{Suggested Improvements for the Survey Form}

The data that are given to the computer are derived in several ways. As far as we are concerned, the two most important data derivations are (1) "field acquired" and (2) "7aboratory acquired."

1) Field Acquired Data: These can be defined as those pieces of information which can best (or only) be acquired in the field, on site.

2) Laboratory Acquired Data: This information is worked up in the laboratory as a result of artifact analysis, map study, or documentary research.

It is inefficient to include both types of information on the same form, since in effect the laboratory information is peculiar to the project and probably would require a unique format designed to match its needs and goals. The field survey form, on the other hand, should be of such a design as to. permit its use almost anywhere in the world.

We believe the present form is quite good in the sense of universal applicability. It can be adjusted to any area by the setting up (after a brief preliminary inspection of the project area) of appropriate type lists for items $1,11,12,14$, and 16-18.

We recommend changes to the form used for the Radium Springs survey as follows:

1) Place numbers along the left margin indicating the sequential number of each blank of each item.

2) Place an item number immediately to the left of the item-defining phrase. 
3) It is essential that the appropriate 1ists be worked up carefully beforehand and crew menbers be familiarized with the intent of each description on the lists, and how to interpret actual field situations in terms of these lists. Vegetation, wildlife, 1 ithic outcrops, and soil types are qreas of great potential difficulty, and the information intended to be acquired by each item should be made very clear in the minds of all persons involved in the project.

Basically, we are looking at the field form as a framework into which we can plug modules of code-lists, the values of which change from region to region, but all of which are at the same level of resolution so that one region can be compared to another. 


\section{APPENDIX II \\ THE HIGH LONESOME BEAD CACHE}

Thomas C. Kelly

\section{Introduction}

The site designated "The High Lonesome Bead Cache" (AR095) was an accidental discovery on a non-programmed BLM-controlled section. The site was found by crew chief Erwin Roemer while he was looking for a USGS section marker to aid in locating one of the programmed survey sections.

\section{Site Environs}

The section was identified as Section 13, Range 1E, Township 15S and is in Zone 1 of our survey area, the western foothills of the San Andres Mountains. Runoff is southwest from the San Andres Mountains at a slope of 125 feet per mile to the site location at an elevation of 5,250 feet. The site is situated on the north bank of a shallow arroyo that originates a quartermile to the northeast and disappears in flatter land as an alluvial fan approximately one mile to the southwest. According to a local rancher, the site has been just recently uncovered by erosion within this drainage.

The soil in the site area is a very fine red-yellow sand 28 to $30 \mathrm{~cm}$ deep overlying a gray caliche subsoil of undetermined depth. The vegetation is characteristic of the uplands in this area of the San Andres with creosote, mesquite, and grama grass all sparsely represented. Native fauna observed in the area included deer, coyote, jackrabbit, cottontail rabbit, raccoon, ringtai1, rock squirrel, quai1, and rattlesnake.

Investigation at the site

While searching for the above-mentioned section marker, Roemer spotted several white beads and a turquoise pendant and called them to the attention of the field supervisor. The crews were organized to locate and flag the beads and it soon became apparent that the site was of substantial size. An arbitrary reference was established by driving a steel reinforcing rod into the ground southwest of the flagged beads and a metric grid was laid from this point for 10 meters north and east. The beads were picked up and bagged by one meter-squares and their distribution was plotted. A total of 72 beads and the turquoise pendant were collected. The only other artifacts found were three Alma Punched potsherds.

Controlled shovel tests indicated that beads continued to some depth, and a smal1-scale excavation was planned. The time Timitations of the Radium Springs survey were such that further investigations of the site were accomplished by crew members voluntarily in their spare time. 
A total of 17 one-meter squares were excavated. A11 units were assigned an alphabetical designation for easy reference, but all measurements were recorded in terms of meters north and east of the datum point. Squares $C, D, E, G, H, I, L$ were excavated in arbitrary $10-\mathrm{cm}$ levels by trowel into the basal caliche at $30 \mathrm{~cm}$, and all soil was passed through $1 / 8$ inch-mesh screen. Results were evaluated and because of time limitations, the remaining 10 squares were excavated by $10-\mathrm{cm}$ levels to a depth of $20 \mathrm{~cm}$. No appreciable recovery of cultural material was made below $15 \mathrm{~cm}$ except in squares $\mathrm{H}$ and I where a cache pot, beads, and limestone cobbles were found to a depth of $28 \mathrm{~cm}$.

The soil was homogeneous from the surface to the gray caliche sub-soil where a sharp disconformity was noted. The fine sand is moved about by wind and water from year to year. Consequently, both surface and sub-surface distribution of artifacts fall within a rough oval oriented northeast to southwest and centered in the unit where the cache vessel was found. Numbers of artifacts diminish inversely to the distance from unit $H$. Maps are on file at the Center for Archaeological Research showing horizontal and vertical distribution of the artifacts.

\section{Ceramics}

\section{The Cache Pot}

The bottom fragment ( $8 \mathrm{~cm}$ vertically and $16 \mathrm{~cm}$ horizontally) of a black smudgeware pot of Mimbres affinity (Alma Punched) was exposed at 18- $\mathrm{cm}$ depth in unit $H$ at N5.45, E5.85. It was completely filled with large shell and smaller calcite beads. (Fig. 33,a). Many of the beads were standing on edge and wedged in their original stringing order. The bowl was undermined, boxed, and taken to the laboratory of the Center for Archaeological Research (in San Antonio) for excavation and recording. Three additional sherds from unit $\mathrm{H}$ and one from unit I were later fitted to the pot. Fourteen plain sherds and five punched sherds of the pot were found randomly scattered throughout the site. No rim sherds were found.

Mimbres Boldface Black-on-White

Seven sherds of Mimbres Boldface Black-on-White were recovered randomly distributed throughout the site (Fig. $33, \mathrm{~b}$ ).

\section{Lithics}

A single unaltered flake of fine gray chert was found in unit $\mathrm{H}$ at $15-\mathrm{cm}$ depth. In addition, a cluster of fist-sized, limestone cobbles surrounded the beadfilled pot in unit $\mathrm{H}$ and continued into unit I. There were approximately 30 of these irregular cobbles and none were altered by fire or man. However, they were certainly gathered and placed about the pot by man probably as a cairn to mark the pot location. The single flake found near the cache pot is shown in Fig. 33,a. 

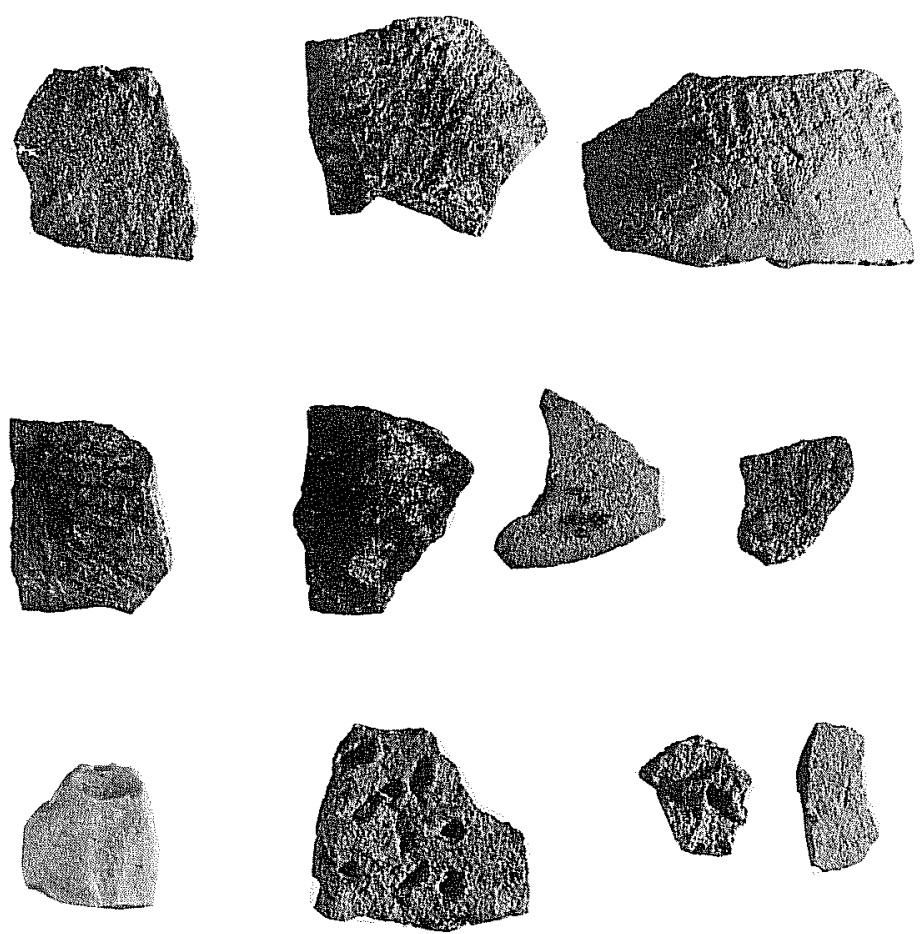

a

$c m\left|\begin{array}{l|l|l|l|l|l|}1 & 1 & 1 & 1 & 1 \\ & & & 3 & 4 & 5\end{array}\right|$
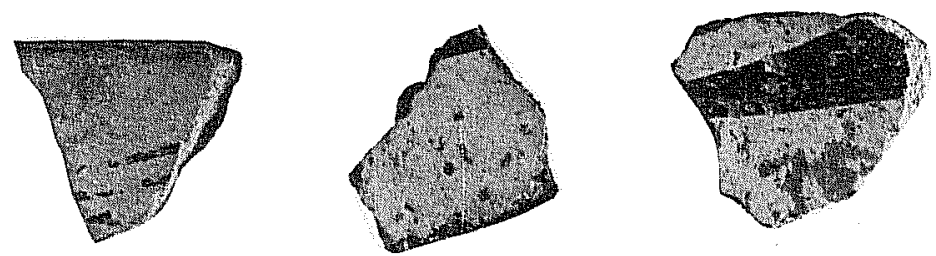

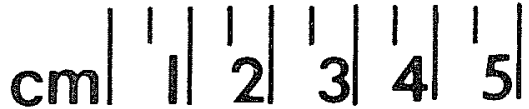

Figure 33. Ceramics and Flake Artifacts Recovered from AR095. a, plainware sherds and chert flake (lower left); sherds appear to be Alma Plain type and belong to the intact vessel base, including the punched fragment (bottom); b, Mimbres Boldface Black-on-White bowl sherds associated with AR095. 
Figure 34. Calcite and Shell Beads from AR095. a, Calcite beads, 5-15 mm diameter. Marine pelecypod beads 16-28 mm; $b$, Calcite and one shell bead magnified $15 \mathrm{X}$. Shell bead exhibiting calcification and the typical accretion rings of marine shells; $c$, upper row--double perforated bead pendants, lower row--typical large she11 beads all made around umbo cavity of marine pelecypod. 


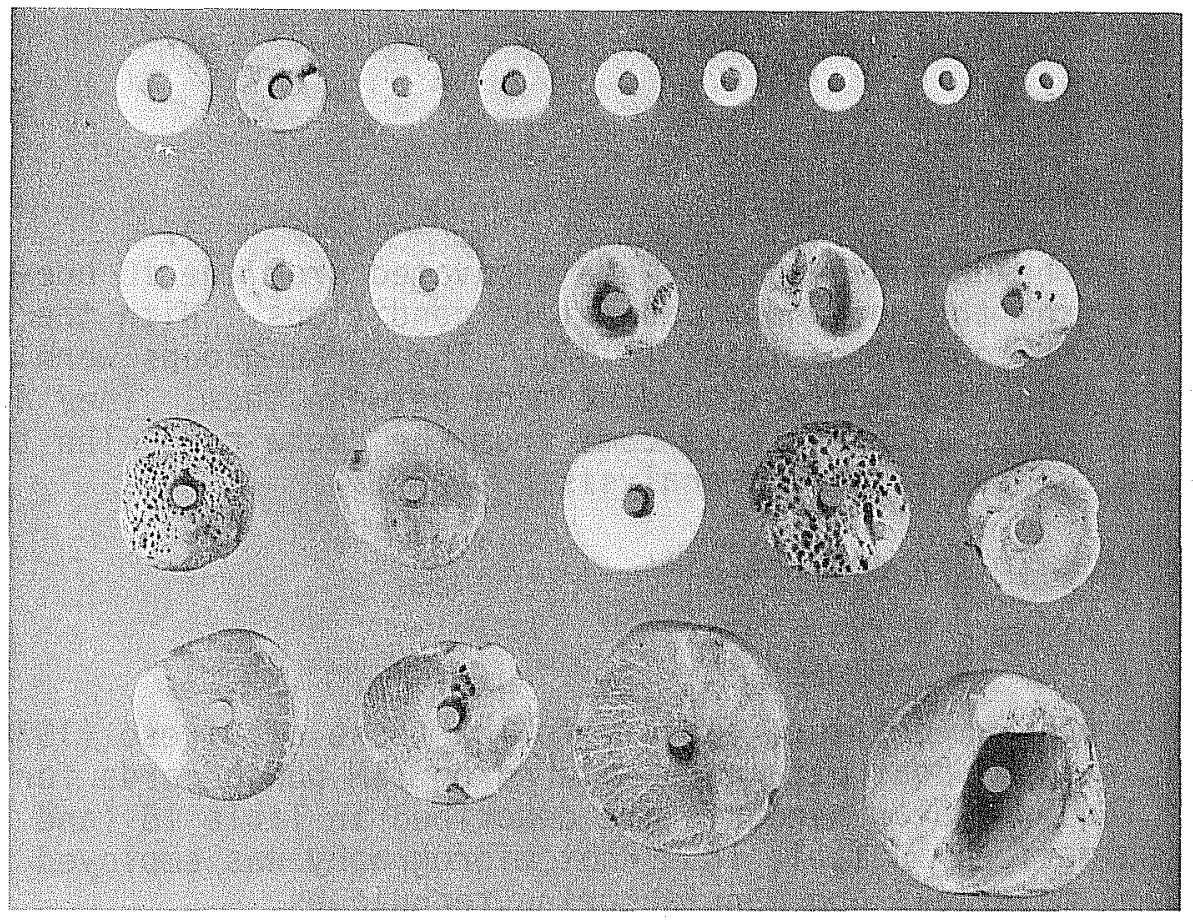

\section{cm| $\left|\begin{array}{l|l|l|l|l}1 & 1 & 1 & 1 & 1 \\ & & 3 & 4 & 5\end{array}\right|$}

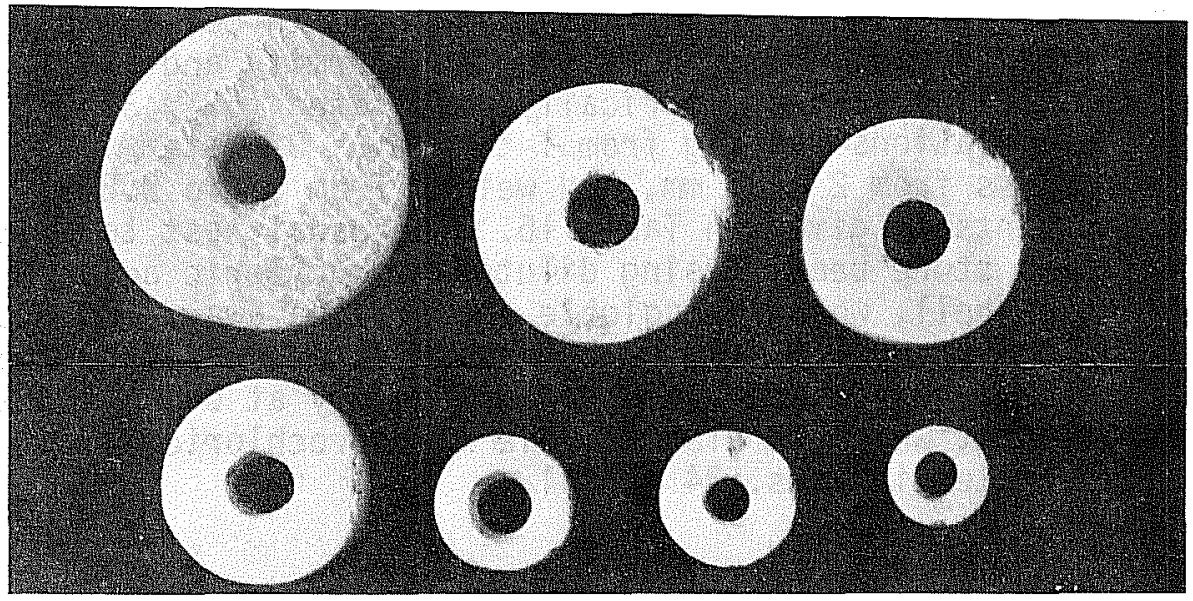

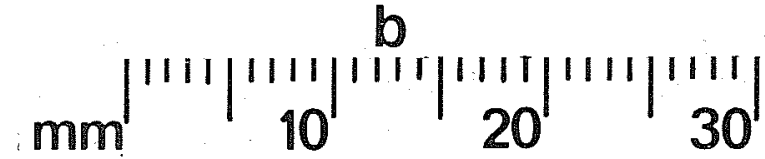
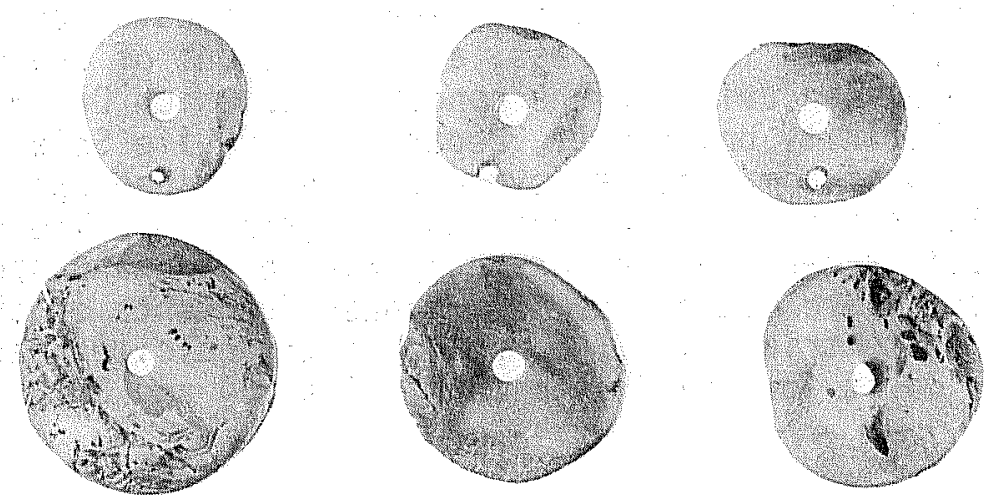

\section{C

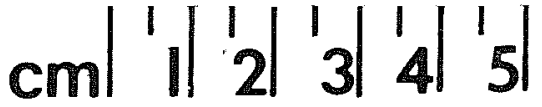




\section{Beads and Pendants}

A total of 393 beads and pendants were excavated from the 10 one-meter squares, and 405 more from the pot under laboratory conditions. With the 73 surface specimens, this brought the total to 871 . The three groups were analyzed separately but no distinction could be made between them. They are all from the same population and must have come from the cache pot. The three groups are combined for the following analysis.

Laboratory Description and Analysis

\section{Procedure}

Measurements and nomenclature closely follow those of DiPeso (1974, Vol. 6:385-389), and the bead data were entered on IBM punch cards for computer analysis. The irregular pendants are described in Table 15 (and Fig. 46). Beads are summarized in Table 16. Photomicrography was employed in studying and recording materials and manufacturing techniques.

Calcite Beads

The numerically predominant bead form (736 or $88 \%$ of the 837 total) is a we11made, symmetrical disc-shaped bead, white to cream in color and well polished. The beads were manufactured with precision, uniformity and skill. They are conically, biconically, and cylindrically perforated $(53 \%, 37 \%$, and $10 \%$ respectively) with perforations varying from 1 to $3 \mathrm{~mm}$. Diameter varies from 5 to $15 \mathrm{~mm}$, thickness from 2 to $7 \mathrm{~mm}$, and weight from .1 to $2.8 \mathrm{gm}$. A summary of bead measurements is given in Table 16. The usual test to distinguish between shell and stone beads (using diluted hydrochloric acid) produces the same reaction as shell, which is soluble and fizzles away. However, under 20x magnification, the structure of a broken bead is made up of hexagonal crystals. Dr. Richard McGehee (Associate Professor of Geology at UTSA) identified the material as calcite, which is also soluble in hydrochloric acid. Views of these beads are illustrated in Figs. 34 and 41 .

\section{She11 Beads}

The shell beads (101 or 12\%) are completely different from the calcite beads. They are larger ( 11 to $33 \mathrm{~mm}$ in diameter, 6 to $15 \mathrm{~mm}$ in thickness), weigh from 6 to $17.6 \mathrm{gm}$, have perforation diameters of 2 to $4 \mathrm{~mm}$, and are buff colored, usually with streaks of pink. They are concavo-convex in section and irregularly wedge-shaped in thickness, as well as out of round. The larger ones have a deep natural concavity in the concave face which Dr. Harold Murray (malacologist at Trinity University, Department of Life Sciences) has identified as the umbo cavity of a marine pelecypod of undetermined species. The hinge line was visible on several specimens despite grinding. The convex or exterior side of the shell is heavily pockmarked by marine worm and sponge holes. The smaller shell beads are often made from broken fragments of she11 and vary from nearly round to triangular. Compared to the calcite beads, these look like home-made "do it yourself" specimens (Figs. 34 and 35). 


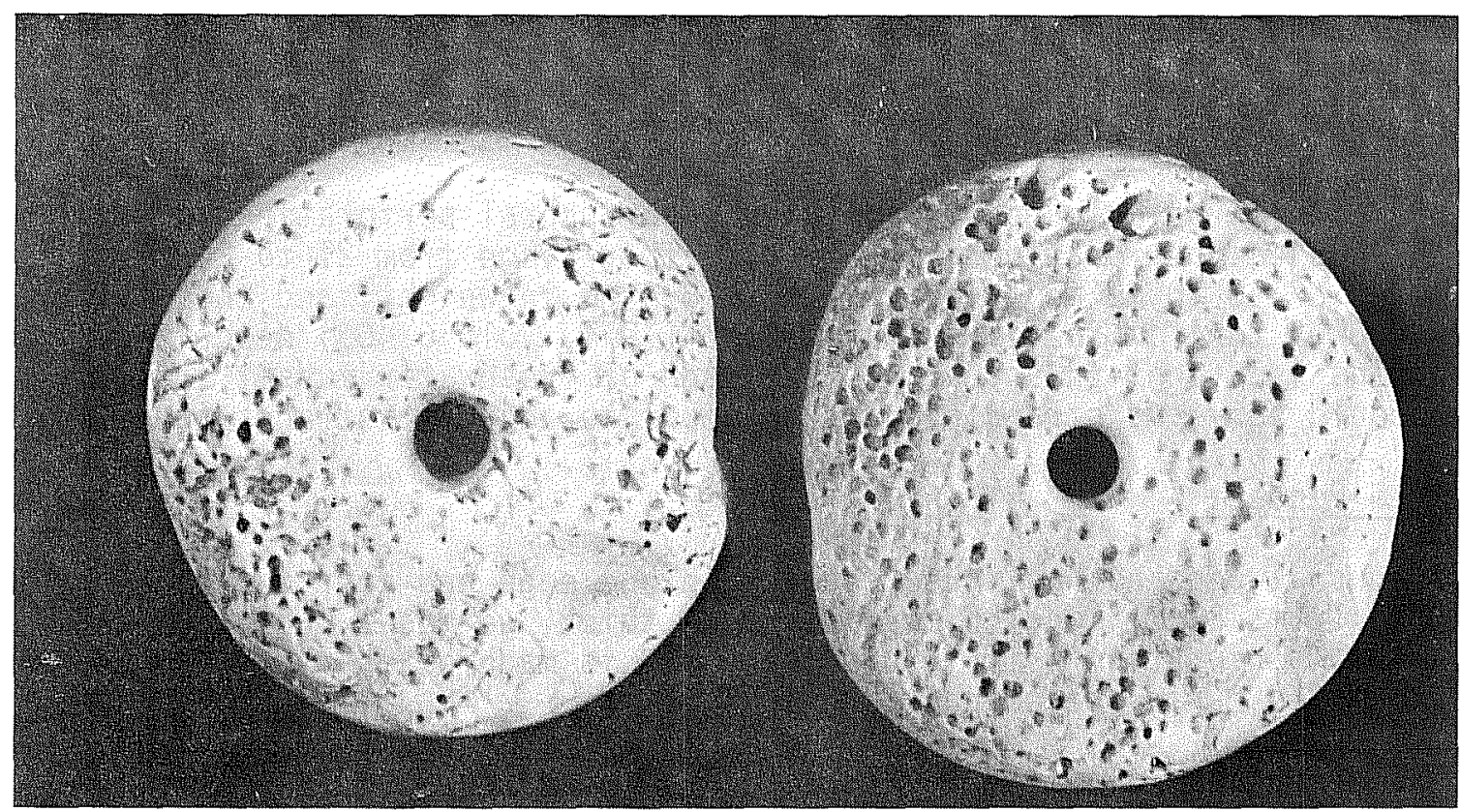

a

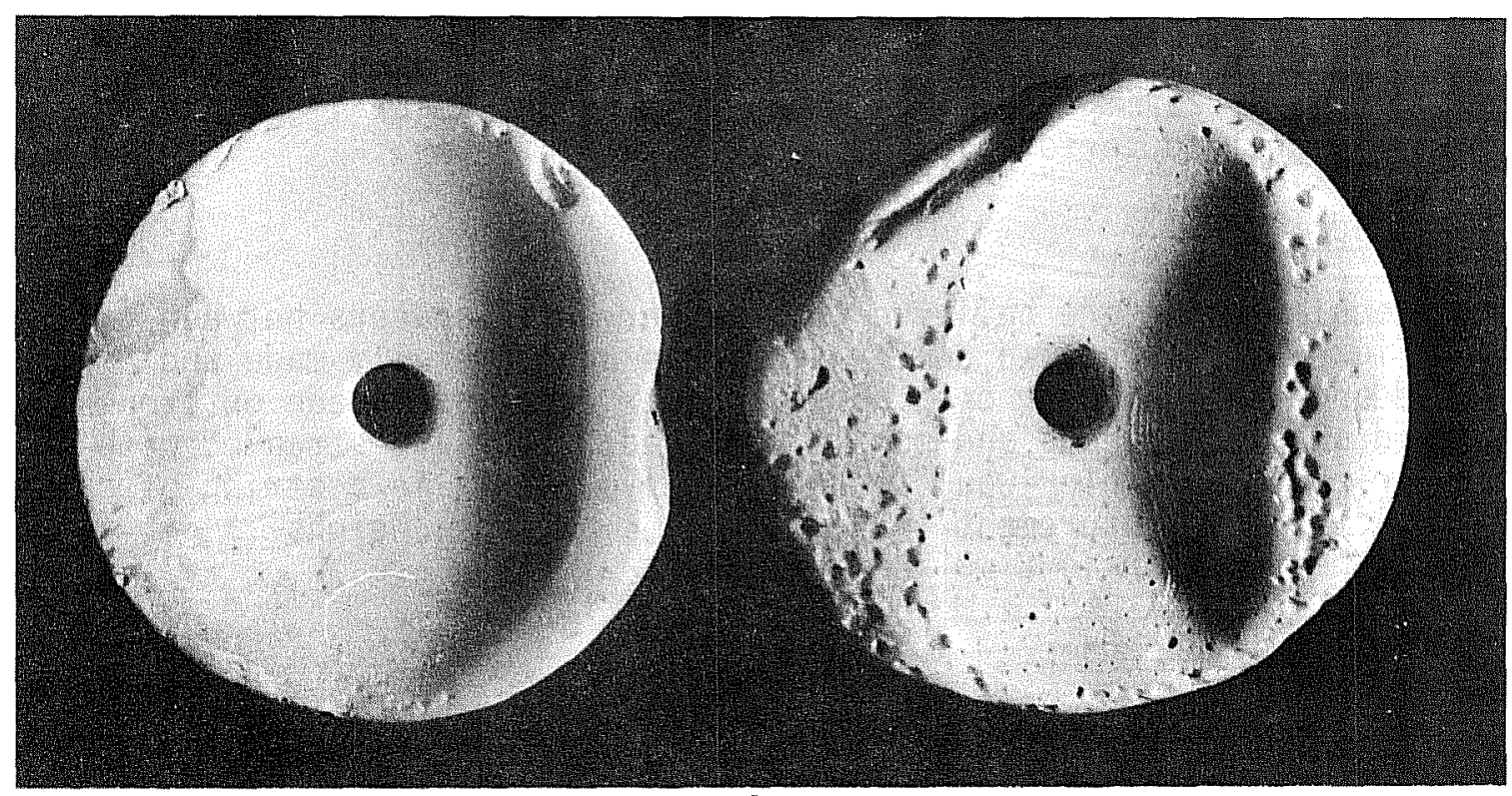

b

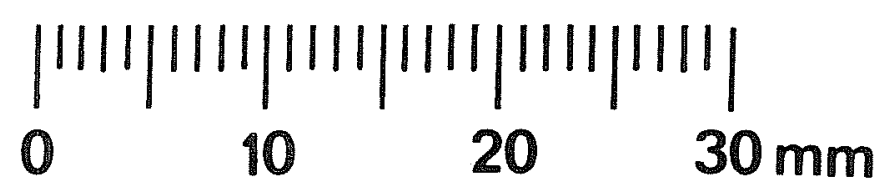

Figure 35. Large Marine Pelecypod Beads from AR095. a, reverse. Note marine worm and sponge holes; $b$, obverse. Bead is made using umbo cavity to reduce perforation depth. 
Double-Perforated Bead Pendants

Four of the large pelecypod beads have a peripheral perforation in addition to the central perforation (Fig. $34, \mathrm{c}$ ). They range from 21 to $24 \mathrm{~mm}$ in diameter, 7 to $10 \mathrm{~mm}$ in thickness, 5 to $8.4 \mathrm{gm}$ in weight, and the perforations vary from 2 to $4 \mathrm{~mm}$ in diameter. DiPeso (1974, Vol. 6:453) describes specimens identical in appearance but made of freshwater mussel shell. These also could serve as strand spacers to separate adjacent strands of beads.

\section{Grooved Pendant}

This unusual pendant has three grooves in one edge and four in the other (Fig. $36, a)$. It is $30 \mathrm{~mm}$ long, $6 \mathrm{~mm}$ wide, $3 \mathrm{~mm}$ thick, weighs $2.0 \mathrm{gm}$, and has a biconical perforation $2 \mathrm{~mm}$ in diameter. It is made of the straight 1 ip of unidentified marine pelecypod.

Dentate Pendants

Three dentate pendants were ground out of unidentified marine pelecypod lips (Fig. 36,a). These look more like teeth than those specimens described by DiPeso (1974, Vo1. 6:437-459) from the Casas Grandes Medio period. Two of the High Lonesome specimens have shallow grooves in the left side. Typical measurements are $22 \mathrm{~mm}$ 1ong, $5 \mathrm{~mm}$ wide, $4 \mathrm{~mm}$ thick, weigh $1 \mathrm{gm}$, and have a $2-\mathrm{mm}$ biconically-drilled perforation.

\section{Spacer Beads}

Four irregular beads are believed to have served as spacers between groups of beads (Fig. 37,a). The two center specimens are carefully made and highly polished and the two outer ones appear rather carelessiy made on broken pelecypod she11 fragments and poorly finished. They are streaked with pink and their shape and color would make effective breaks in a string of calcite beads. A typical measurement is $9 \mathrm{mrn}$ 1ong, $4 \mathrm{~mm}$ wide, weighs $.3 \mathrm{gm}$, and the biconical perforation is $2 \mathrm{~mm}$ in diameter.

\section{Dentalium Tubular Beads}

Two large tubular beads have been identified by Dr. Harold Murray as being made from sections of marine tusk shell (class Scaphapoda, family Dentalium). These were either carelessly cut or broken as one end of each is jagged while the other end has been smoothed (Fig. 36). One is $43 \mathrm{~mm}$ long, $7 \mathrm{~mm}$ in outer diameter, $5 \mathrm{~mm}$ in inner diameter, and weighs $61 \mathrm{gm}$. The other is $24 \mathrm{~mm}$ long, $9 \mathrm{~mm}$ in outside diameter, $6 \mathrm{~mm}$ in interior diameter, and weighs $3.7 \mathrm{gm}$. The exterior has been slightly polished and in cross section is quite round both interior and exterior. DiPeso (1974, Vo1. 6:411) i17ustrates three species of Dentalium from Casas Grandes, but only Dentalium semipolitum has both circular interior and exterior sections. Keen (1958:238) lists the range of Dentalium semipolitum from lower California to Nicaragua. 


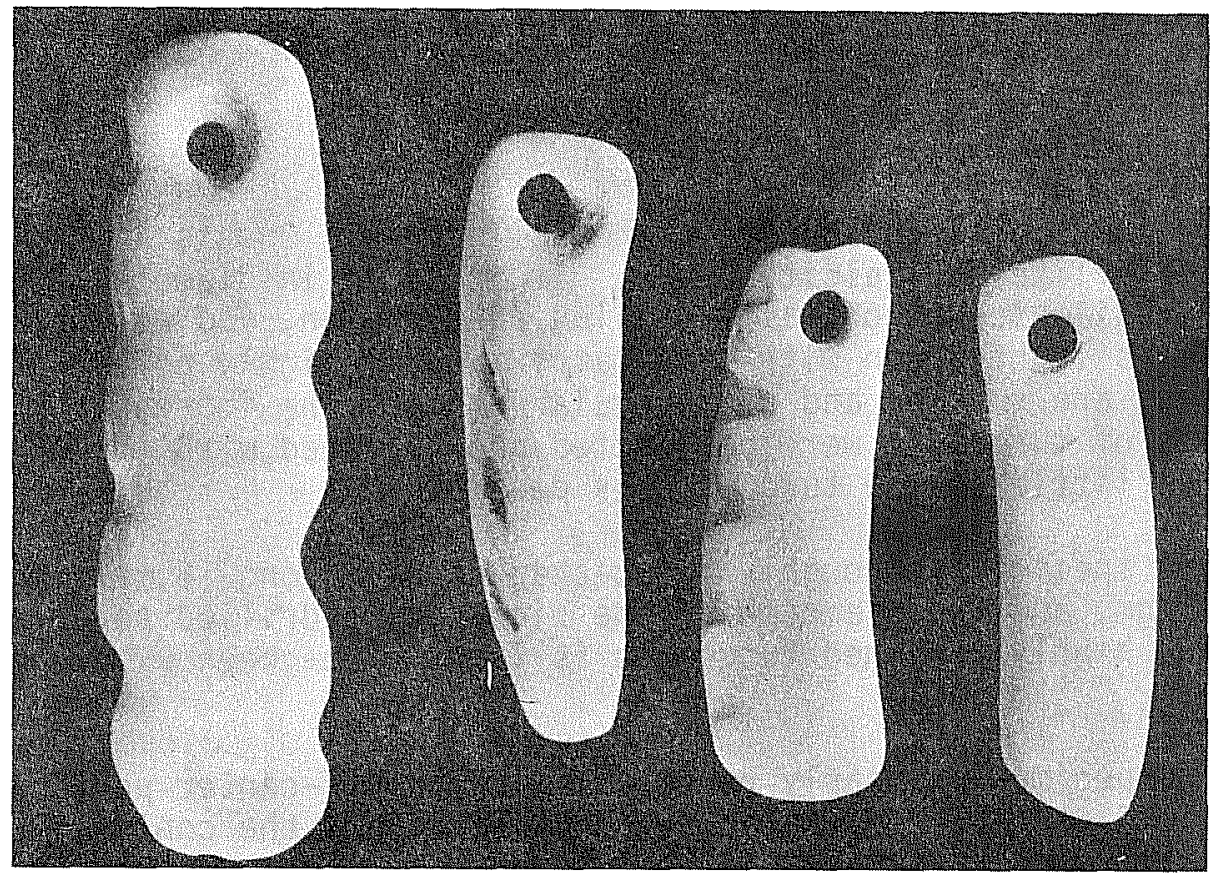

a $\mathrm{mm}||||||||||||||||||||||||||||||$
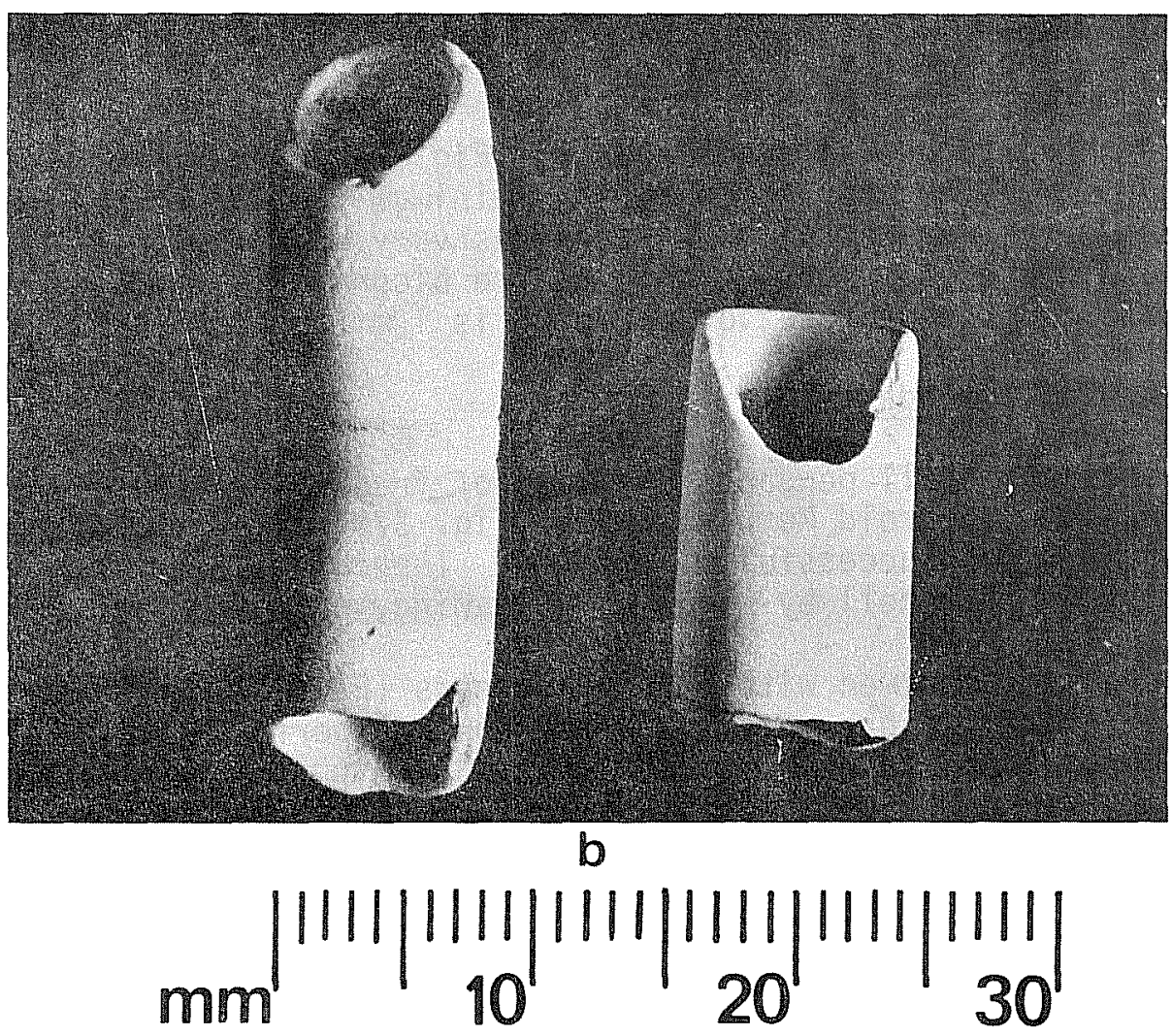

Figure 36. Shell Pendants and Tubular Beads from AR095. a, left to right, grooved pendant, two grooved dentate pendants, plain dentate pendant. A11 of unidentified buff colored marine she11; b, Dentalium tubular beads. Shel1 is Dentalium semipolitum. 
Turquoise Beads

There are four turquoise beads in the collection. One is a regular disc bead made exactly like the calcite beads. It is $11 \mathrm{~mm}$ in diameter, $5 \mathrm{~mm}$ thick, has a 1-mm diameter biconical1y-drilled perforation, and weighs $1.0 \mathrm{gm}$. The turquoise is light green with buff matrix and is highly polished. The other three beads are smaller and of irregular shape. The impression is that small bits of turquoise were perforated and polished with the objective of wasting as little of the turquoise as possible.

The second specimen is roughly heart-shaped, $9 \mathrm{~mm}$ long, $5 \mathrm{~mm}$ wide, $3 \mathrm{~mm}$ thick, weighs $.3 \mathrm{gm}$, and the diameter of the biconically-drilled perforation is $1 \mathrm{~mm}$. The highly polished turquoise is light blue-green with light brown matrix.

The third specimen is nearly round but with an off-center perforation. It is $9 \mathrm{~mm}$ in diameter, $2 \mathrm{~mm}$ thick, weighs $.3 \mathrm{gm}$, and the conically-drilled perforation is $2 \mathrm{~mm}$ in diameter. The turquoise is light green with brown matrix, and is not polished.

The fourth specimen is slightly out of round, $10 \mathrm{~mm}$ in diameter, $4 \mathrm{~mm}$ thick, weighs $.7 \mathrm{gm}$, and the biconically-drilled perforation is $2 \mathrm{~mm}$ in diameter. It is polished blue-green turquoise with brown matrix.

\section{Turquoise Bead Pendants}

There are three turquoise bead pendants (Fig. 29). They are roughly oval in shape, but again the impression is that minimum removal of material was one of the guidelines in manufacture. Lengths vary from 12 to $14 \mathrm{~mm}$, thickness from 2 to $3 \mathrm{~mm}$; each weighs $.4 \mathrm{gm}$; two are biconically, and one conically, perforated; and the perforation diameter is $1 \mathrm{~mm}$ on each.

Iridescent She11 Pendants

Three iridescent shell pendants are made of freshwater mussel shel1 unionidae (according to Dr. Harold Murray). One (Fig. 37) had separated along deposition rings but was successfully restored. They were made from the straight lip portion of the shell by breaking or sawing, grinding, and polishing.

The rectangular specimen with rounded corners (Fig. 37) is $17 \mathrm{~mm}$ long, $11 \mathrm{~mm}$ wide, $2 \mathrm{~mm}$ thick, weighs $.6 \mathrm{gm}$, and the conical perforation is $2 \mathrm{~mm}$ in diameter. One specimen is nearly round (Fig. 37); it is $15 \mathrm{~mm}$ long, $14 \mathrm{~mm}$ wide, $1 \mathrm{~mm}$ thick, weighs $.5 \mathrm{gm}$, and the conically-drilled perforation is $2 \mathrm{~mm}$ in diameter. The restored specimen (Fig. 37 ) is $31 \mathrm{~mm}$ 1ong, $18 \mathrm{~mm}$ wide, $2 \mathrm{~mm}$ thick, weighs $.8 \mathrm{gm}$, and the biconical perforation diameter is $1 \mathrm{~mm}$.

Musse1 she11 was not observed by the Radium Springs survey crew. However, Mr. Daniel C. B. Rathbun (District Manager, Bureau of Land Management, Las Cruces District) writes (1977, personal communication): "Mussel shel1s of indeterminate age have been found near playas, or dry lake beds. Mussels 


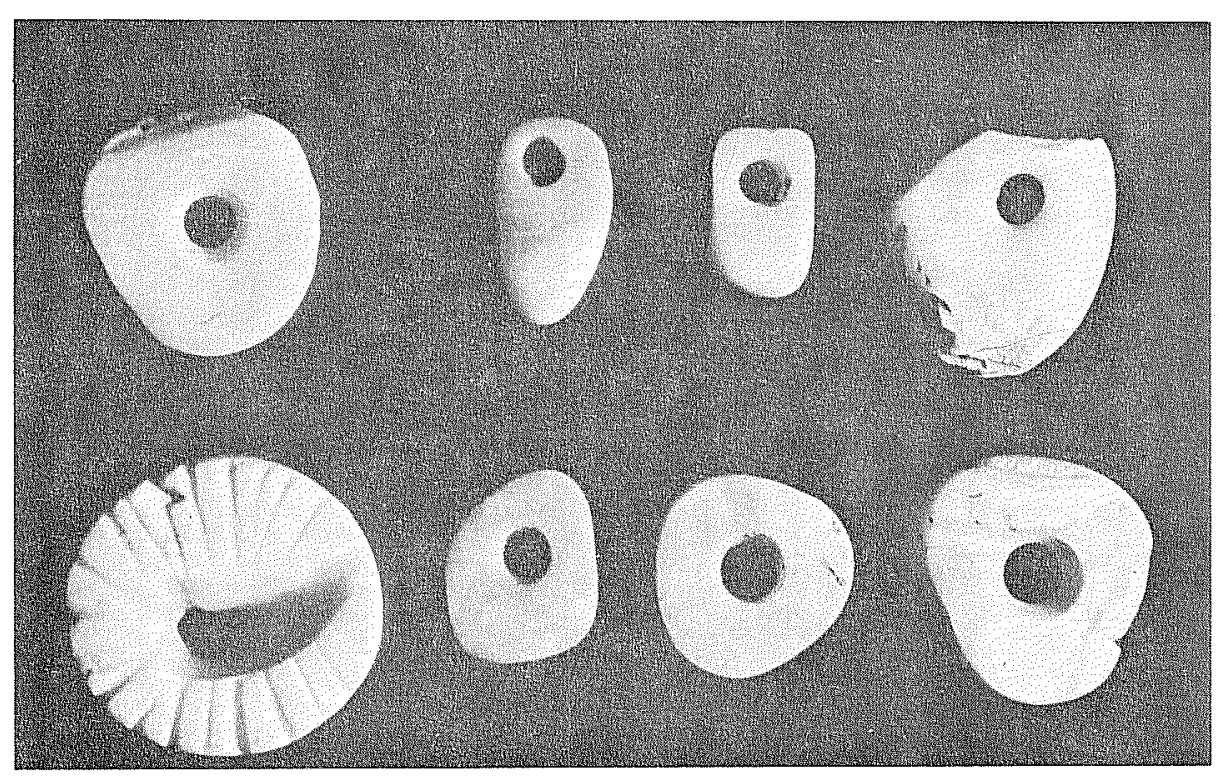

a

$$
\mathrm{mm}||||||||||||||||||||||||||||||||
$$

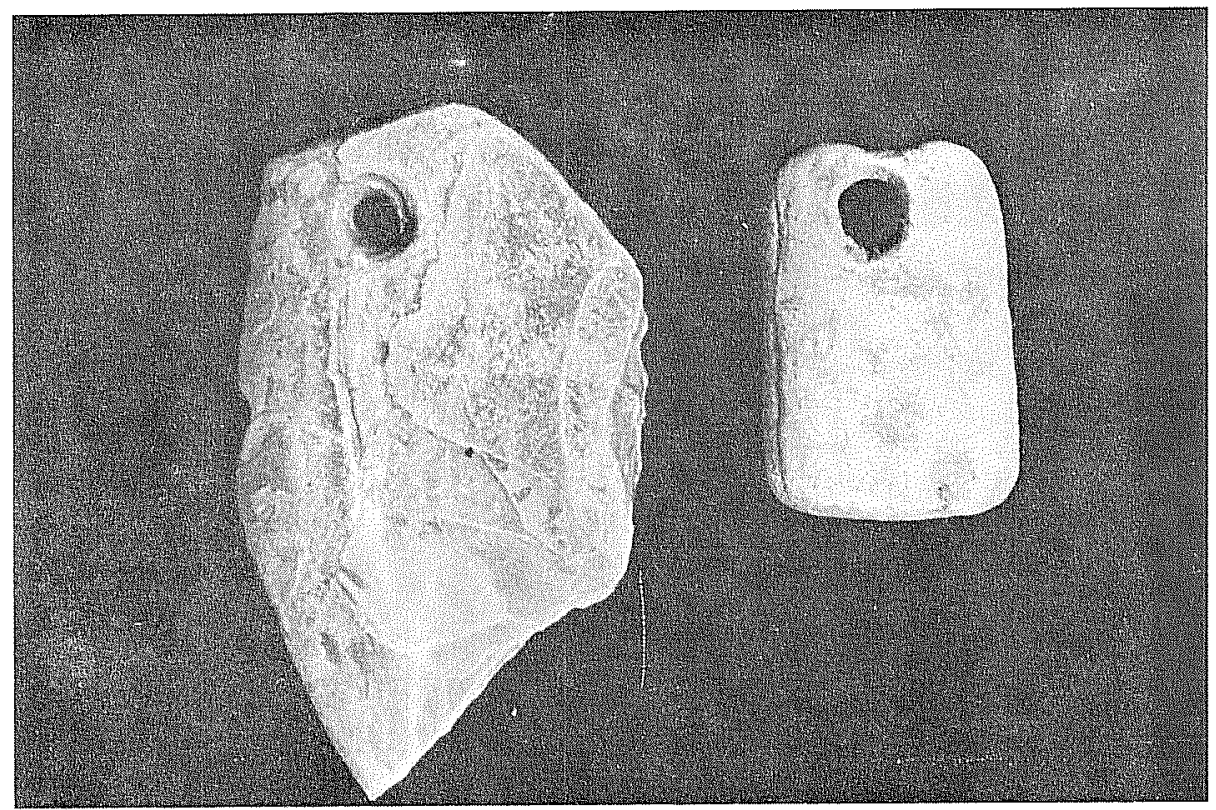

b

$$
\mathrm{mm}^{|||||||||||||||||||||||||||||||| \mid}
$$

Figure 37. Shell Ornaments from AR095. a, she 11 pendants, spacers and strand connector (lower left); $b$, pendants freshwater mussel and marine pelecypod. 


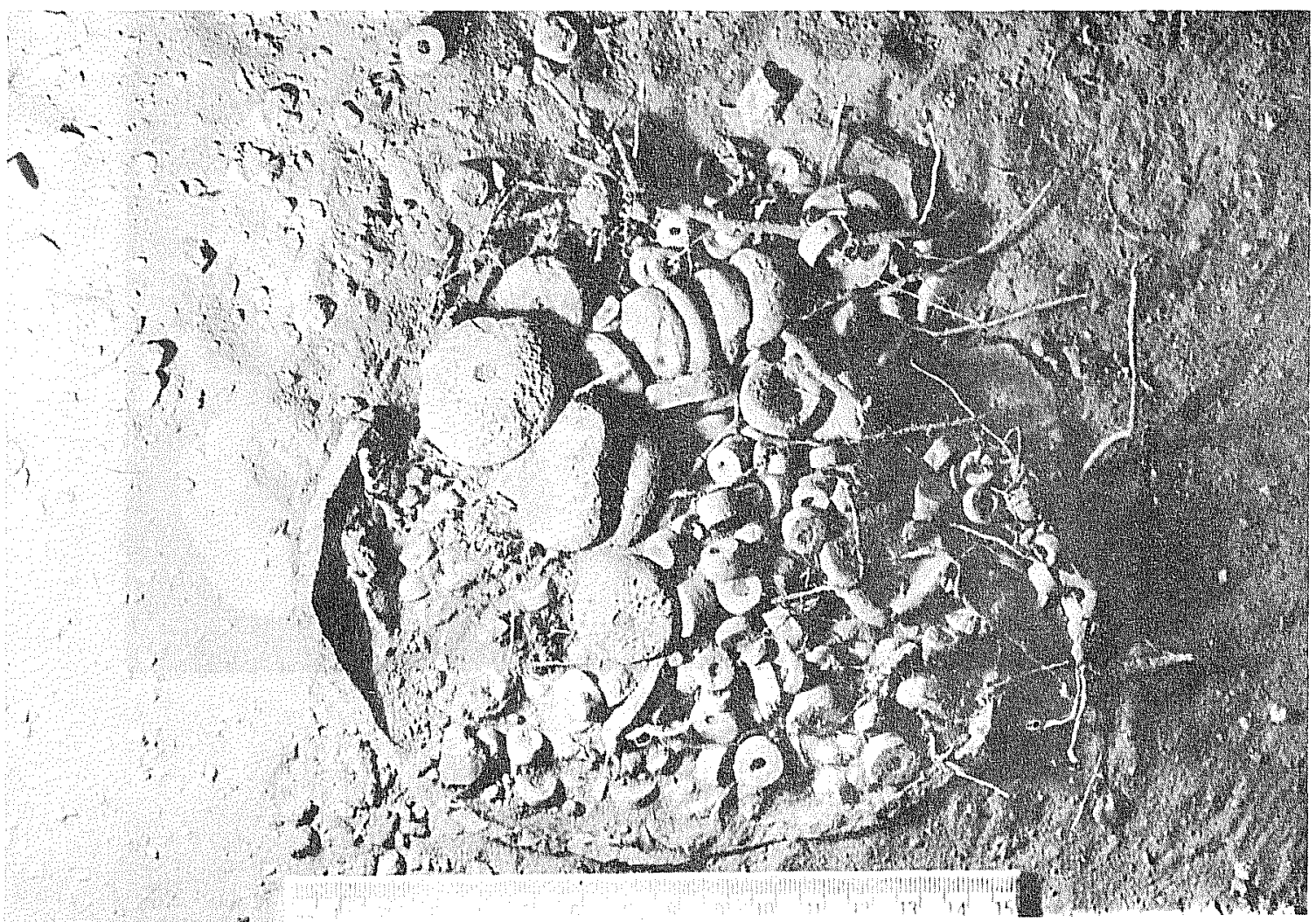

a

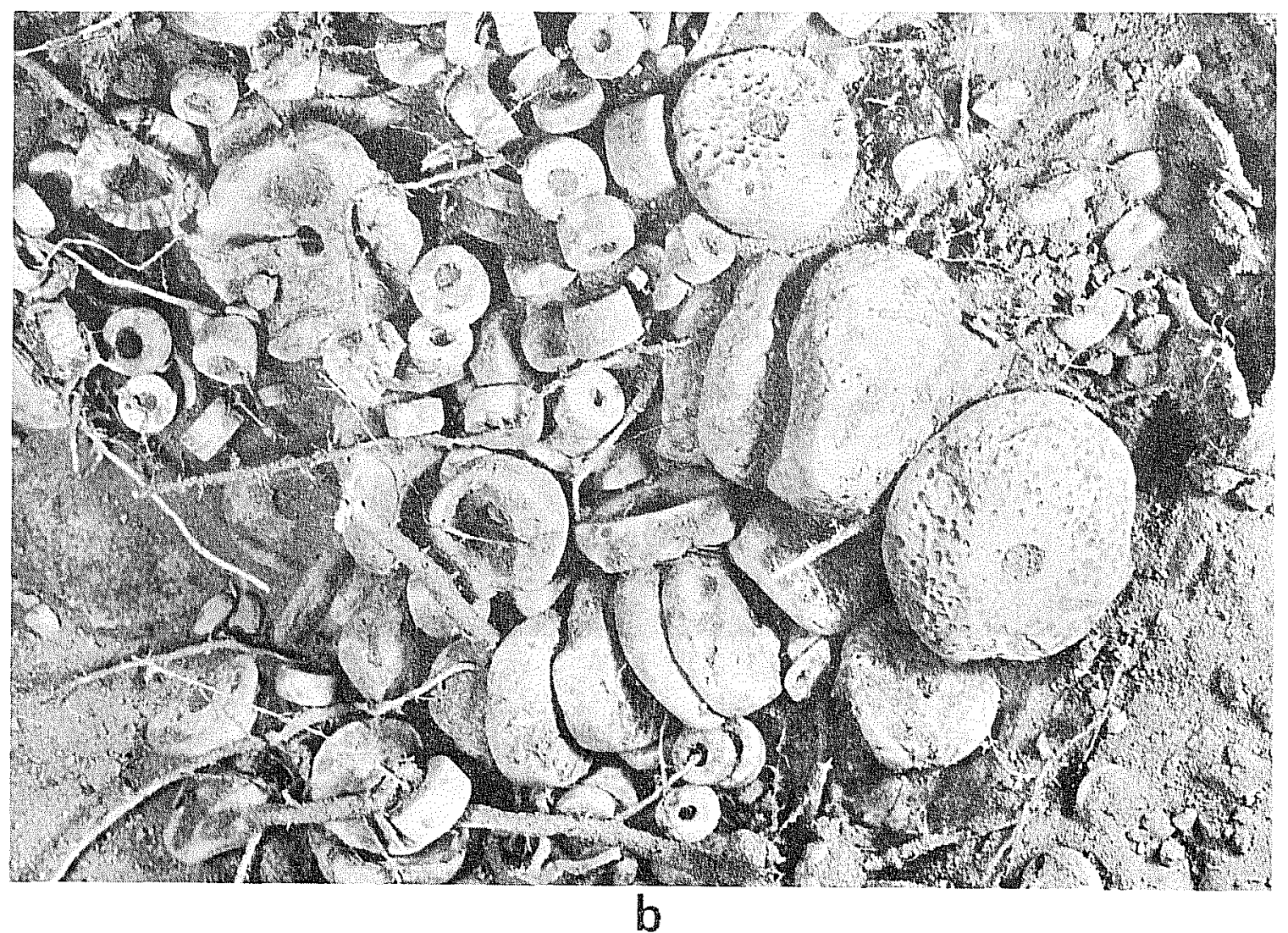

Figure 38. Bead Cache from AR095. a, cache vessel as exposed by excavation. Left end of scale points north; b, partially excavated cache. Strand connector in upper left. Note intrusive creosote root movement of beads. 
may have existed in the Rio Grande at one time. There are no species of freshwater mussel which live in the area today.

\section{Strand Connector}

This incised shell item (Figs. 37,43 ) is $16 \mathrm{~mm}$ in diameter, $5 \mathrm{~mm}$ thick, weighs $1.8 \mathrm{gm}$ and has a half-moon perforation $2 \mathrm{~mm} \times 3 \mathrm{~mm}$ measured on the obverse. There is a deep lens-shaped cut $11 \mathrm{~mm}$ long and $4 \mathrm{~mm}$ wide in the front or incised face. This cut tapers to the perforation in the rear face.

While experimenting with stringing sequences, it was noted that this specimen did not fit anywhere if strung as a bead. As a bead, the 20 incised grooves, supposedly ornamental, would not show. Microscopic examination showed traces of wear polish in two grooves at each end of the lens-shaped cut.

The small strand divider (Fig. 46,\#23) and probably the four double-perforated bead pendants previously noted indicate multiple strands of beads. This artifact would serve perfectly as the common connector of two strings of beads and the four polished grooves would serve the utilitarian purpose of guides to the four string ends. It would act as a fulcrum to tighten the strings, and the knots would fit neatly in the deep groove. The incised grooves would then serve an ornamental function as they would be exposed on the wearer's neck. Possible use of the artifact as a strand connector is illustrated in Fig. $43, b$.

Little mention is made of connectors or clasps in the 1iterature. McGregor (1965:184) mentions loop and toggle bead fasteners.

Strand Divider

A single oval-shaped, bi-perforated specimen of dense shell is tentatively placed in this category. It is $12 \mathrm{~mm}$ long, $7 \mathrm{~mm}$ wide, $4 \mathrm{~mm}$ thick and weighs $.6 \mathrm{gm}$. The central perforation is $3 \mathrm{~mm}$ and the peripheral perforation is $4 \mathrm{~mm}$ in diameter. Both are biconically-drilled. It would fit into DiPeso's classification of strand dividers (DiPeso 1974, Vol. 6:466) but the perforations are only $4 \mathrm{~mm}$ apart center to center. The smallest High Lonesome beads are $5 \mathrm{~mm}$ in diameter, and in experimental stringing this specimen would not serve as a divider because of inadequate distance between the perforations. It was more probably used as a clasp, or to suspend a short pendant, such as our turquoise pendants, clear of the bead string.

Button-shaped Beads

Five unusual transversely-pierced "button"-shaped beads (Fig. 46,\#25-29) were not identified elsewhere in our literature search. They are made by perforating the flanged portion of a hinge segment of pink marine pelecypod shell parallel to the outside of the shell. The outer face is smoothed and polished and the flange is ground down at right angles to the perforation, leaving an artifact resembling an old-fashioned collar button. The perforation parallel to the face of the button puts a crimp or bend into the string when strung along with regular beads. They fit and work perfectly when used to string 
the tubular beads (which have no perforations) as pendants. A string is tied to the button bead, passed up the tube of the tubular bead and secured to the peripheral perforation on one of the double-perforated bead pendants.

The "buttons" range from 11 to $12 \mathrm{~mm}$ in diameter, 5 to $6 \mathrm{~mm}$ in thickness, .5 to $.8 \mathrm{gm}$ in weight, and 1 to $2 \mathrm{~mm}$ in perforation diameter. Two are biconically-perforated, two are cylindrically-perforated, and one is biconical 1 y-perforated.

Laboratory Excavation of the Cache Vessel

Objective

It was hoped that careful excavation of the cache vessel remnant might yield cultural or aesthetic information if the original stringing order could be determined.

\section{Procedure}

The beads were excavated at the Center for Archaeological Research laboratory with an ear syringe and tweezers, with careful photography of each layer of beads. Groups of beads with closely aligned perforations were sequentially numbered and strung as found. The large concavo-convex beads were strung with their concave face to the convex face of the next bead. They must also have been tightly strung when folded into the pot. Consequently, they tend to stay together through the centuries much better than the smaller, flatsurfaced, polished calcite beads. Too, the long (estimated at $2.3 \mathrm{~m}$ ) necklace (or necklaces) strung with beads varying from 5 to $33 \mathrm{~mm}$ in diameter could not be inserted into the pot without many turns and folds, producing voids. When the string disintegrated, the smaller beads dropped into the voids until the pot was broken and filled with sand. Creosote roots must have further caused some dislocation (note Figs. 38,39,40; roots growing through bead perforations). Despite these obstacles, the excavation effort was largely successful.

\section{Findings}

Series of $7,7,5,4$, and 3 of the larger beads were recovered intact (Fig. 41). These were graded within each series. They were in fact still in the exact order, and something about their manufacture was learned by numbering the beads in as straight a line as possible. These beads are individually so irregular that they will not fit when experimentally restrung except when the numbers are exactly lined up. When manufactured, these beads were tightly strung while quite rough, and smoothed by pulling over abrasive surfaces such as grooved stone bead grinders or shaft straighteners, as described by Haury (1931) and DiPeso (1974, Vol. 7:239).

One long series of the calcite beads (12) was found with a turquoise bead at one end and an off-center irregular pink shell bead at the other. The calcite beads graded from 9 to $11 \mathrm{~mm}$ in diameter. Series of $5,4,4,4$ were the longest 


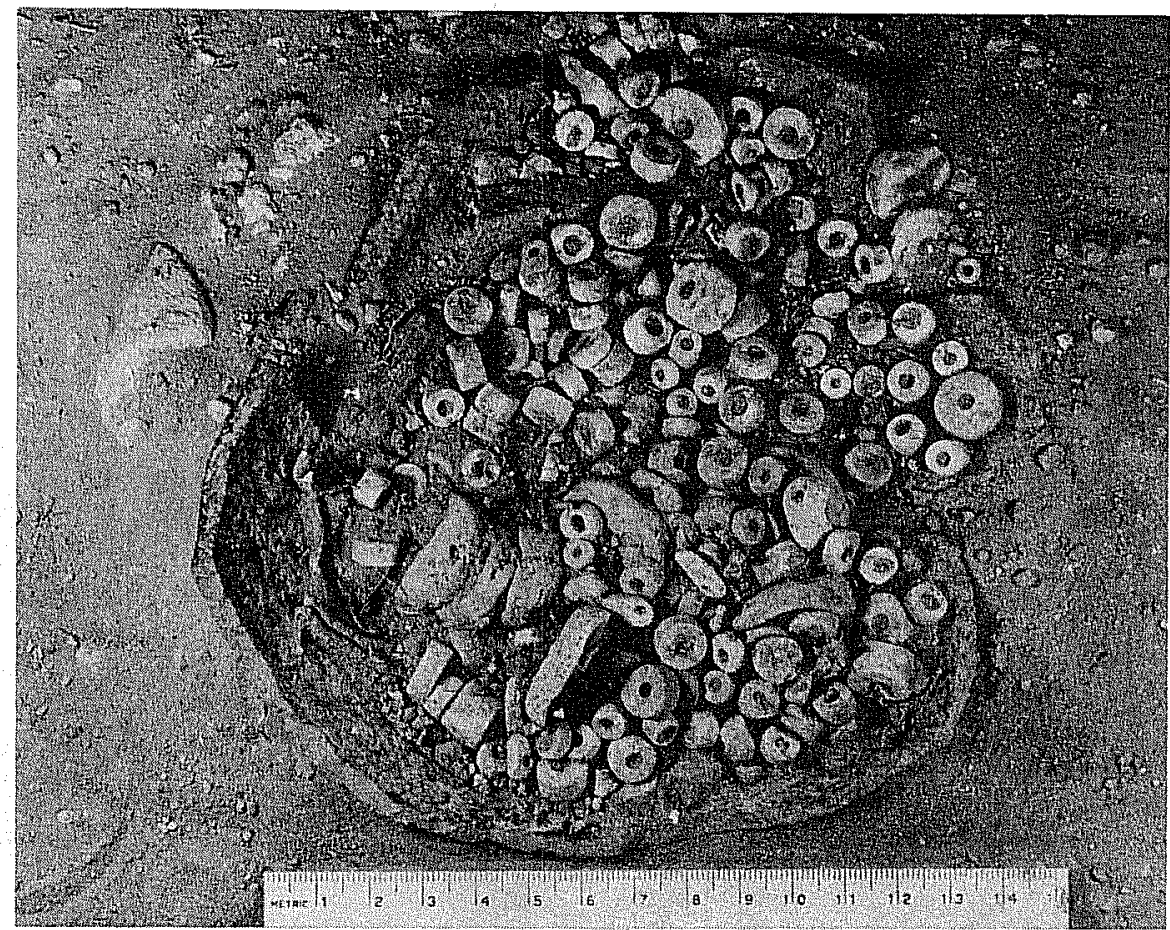

a

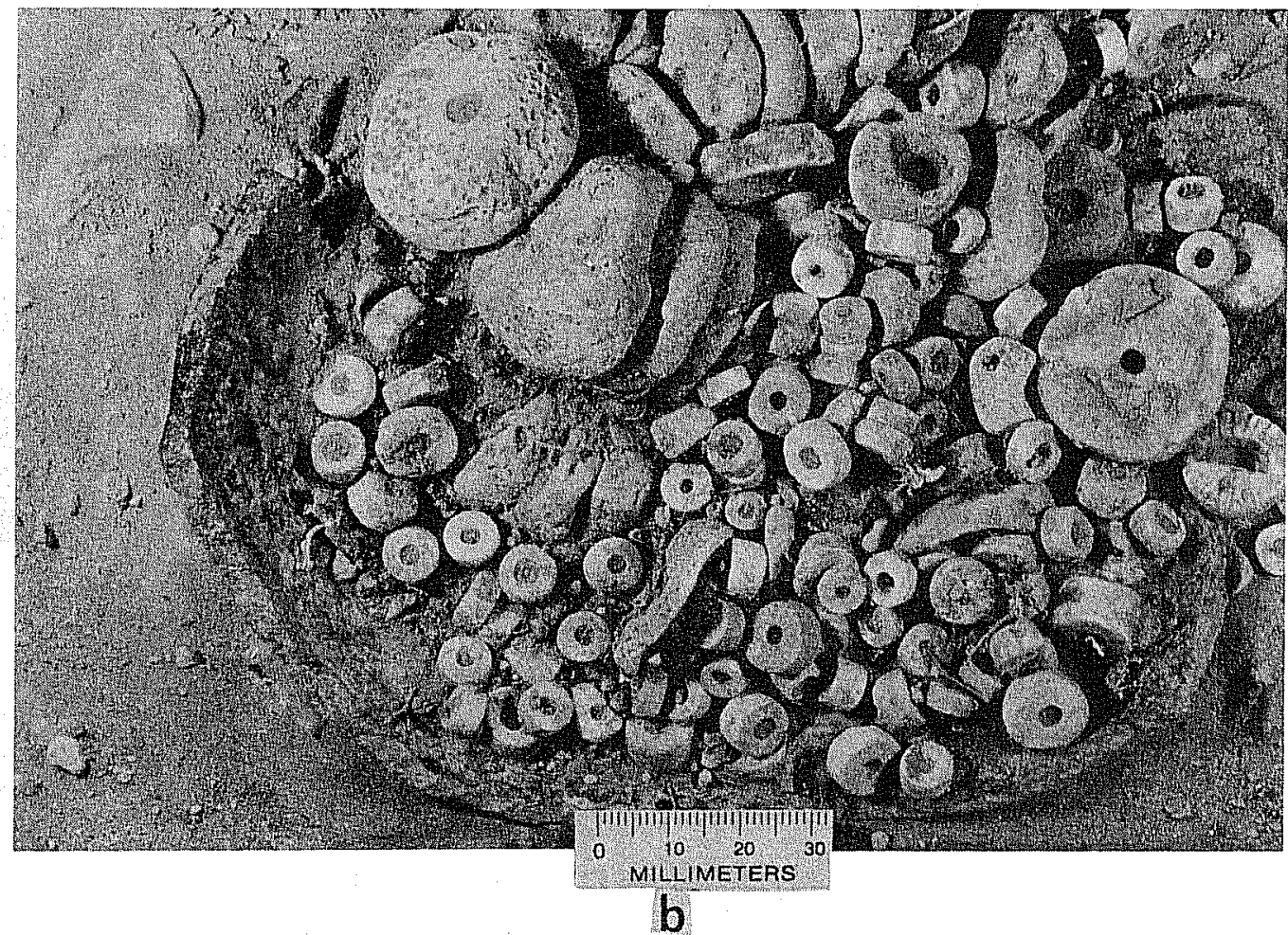

Figure 39. Partially Excavated Bead Cache. a, approaching third leve1. Note turquoise pendant (center) and dentate shell pendant (upper right); b, lower level of cache vessel. Turquoise pendant and she11 pendant (upper right). Large calcite beads as originally strung (lower left). 


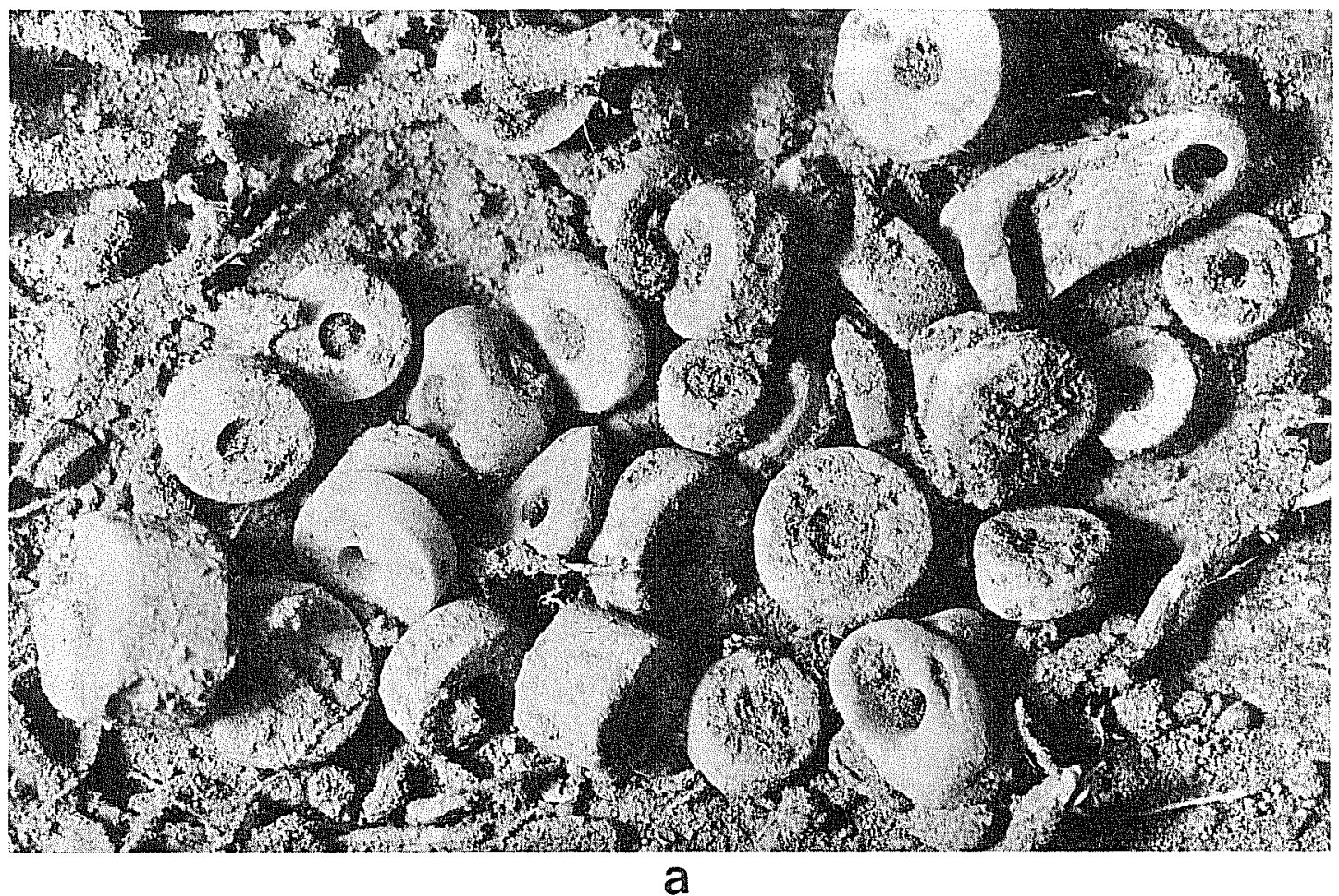

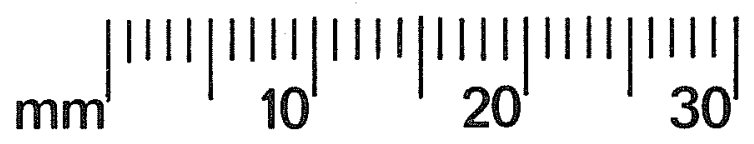

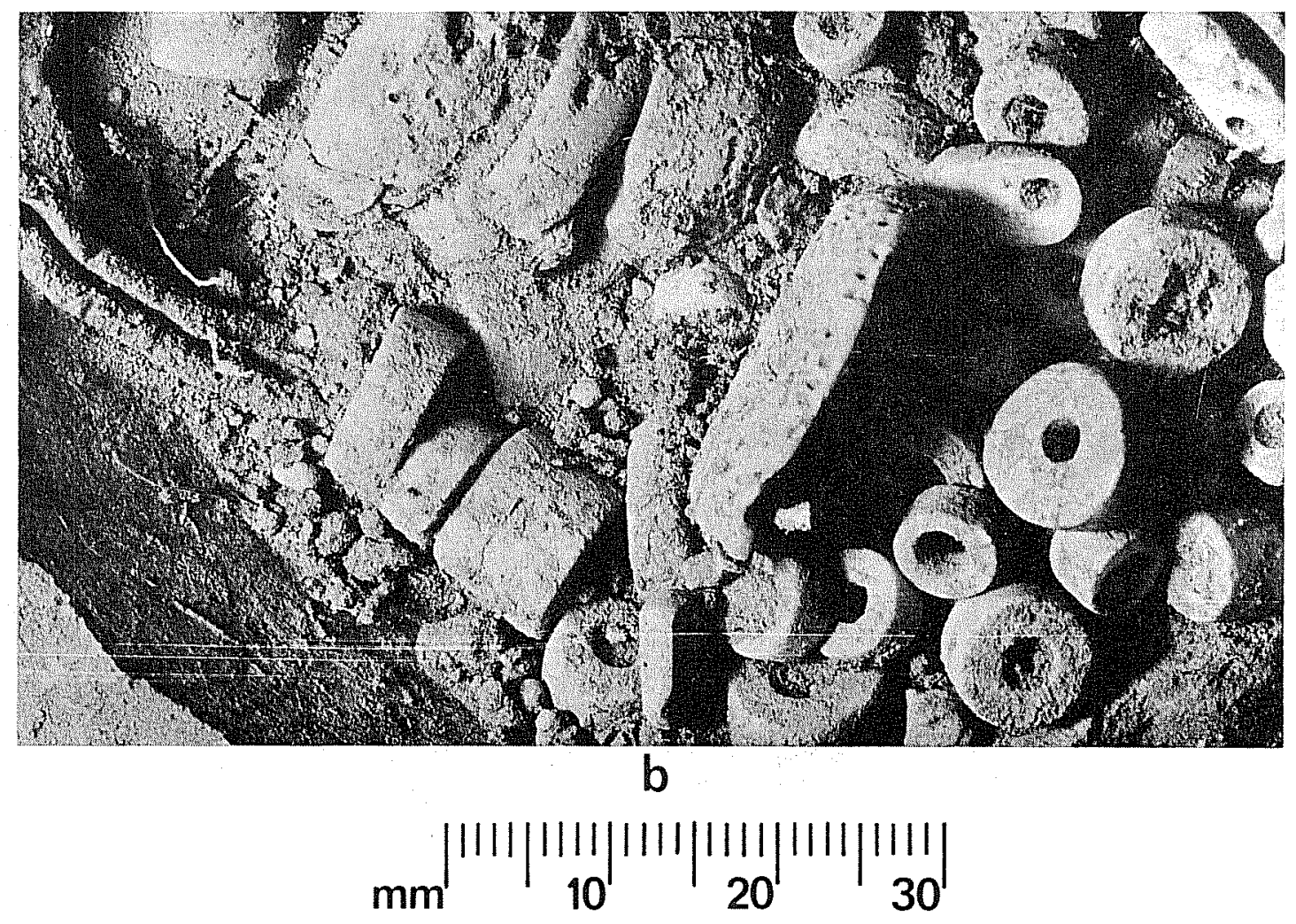

Figure 40. Cache Vessel Under Laboratory Excavation. a, turquoise and shell pendants and several stringing sequences; $b$, largest of shell beads. Turquoise pendant right of center. 


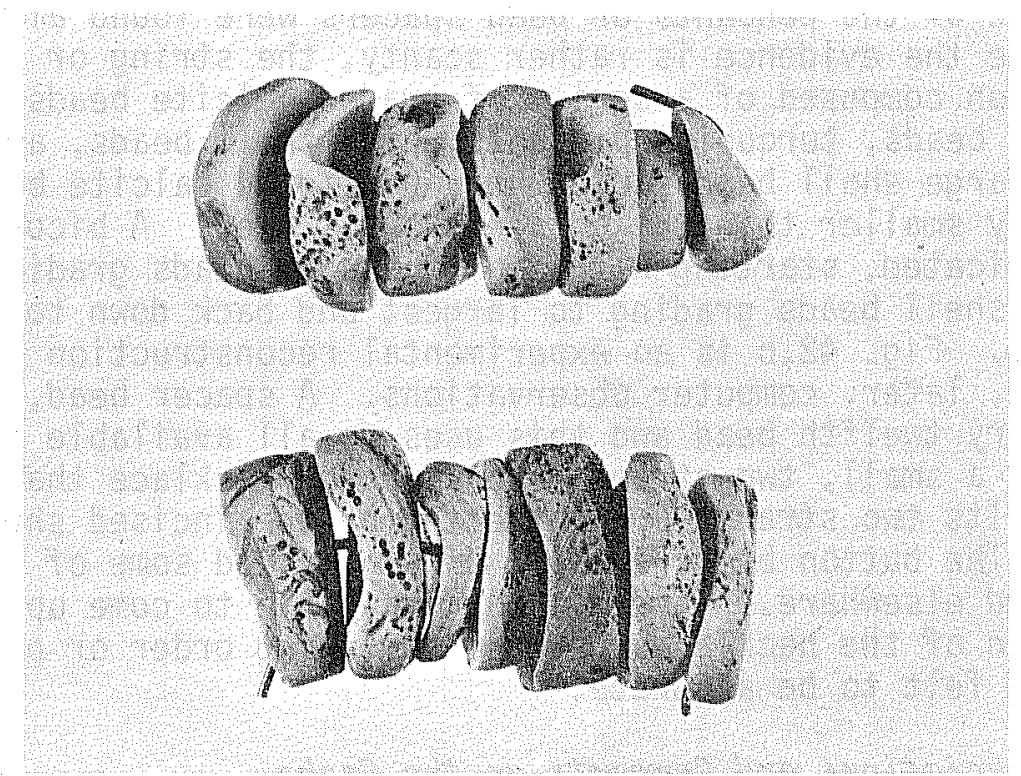

a

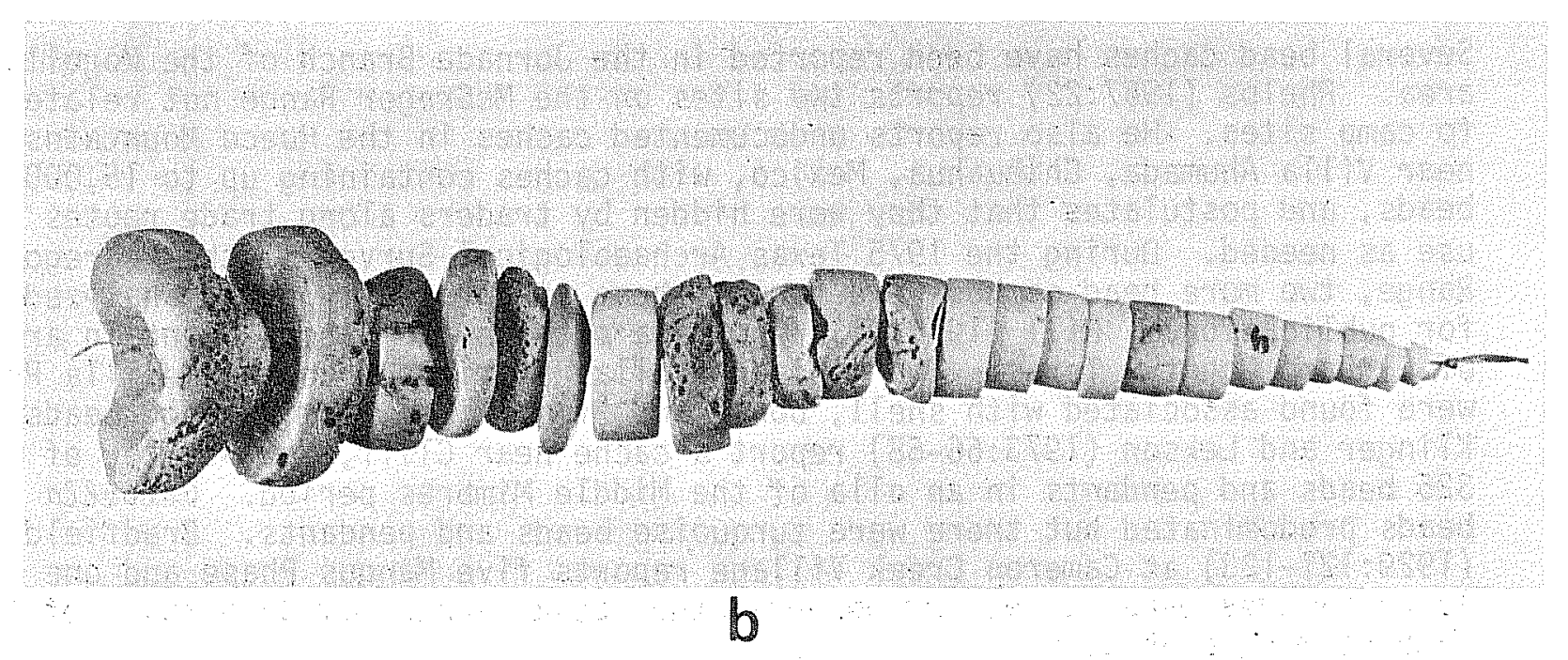

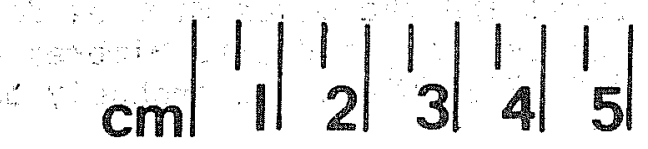

Figure 41. Shell and Calcite Beads. a-b, AR095, concavo-convex beads in original stringing sequence 
remaining series and beads did not vary more than $2 \mathrm{~mm}$ in diameter within each series. None of the pendants or bead spacers were found aligned with each other. While the evidence is rather scanty, the string or strings of beads must have been composed of a series of graded calcite beads broken at intervals by turquoise beads, turquoise pendants, pink shell beads, and shell pendants. Two of the large shell bead series had an aligred calcite bead at one end, both slightly smaller than the adjacent shell baed. A biconical string of beads is indicated, starting with small calcite beads grading up to large, then the smaller shell beads grading to largest and back down to the smallest calcite bead. Fig. $42, b$ is an experimental reconstruction of a necklace based on these and, later, computer observations. A spacer bead, or pendant, is inserted every twelfth bead and this uses up all available spacers and pendants. Fig. 42, a is a small, two-strand reconstructed necklace that uses up all remaining beads. Its two strands are connected by the incised shell connector bead Fig. 43,b. The button beads are out of place, and some of the pendants need to be located elsewhere. Time was not available to come up with the final configuration of the necklaces but the stringing order or portions of the necklaces is felt to be accurate.

Cultural Associations and Comments on the Cache

Previous Bead Caches

Ceremonial or religious caching of beads has been previously recorded throughout the Southwest. Stevenson (1904:116) and White $(1962: 179,216)$ are examples, and, more recently, DiPeso (1974, Vol. $7: 238$ ) reports a jar full of beads buried in the bottom of a reservoir at Casas Grandes.

Several bead caches have been reported in the Jornada Branch of the Mogollon area. Phelps (1967:22) reports two sites on the McGregor Range not related to camp sites. He also reports undocumented caches in the Hueco Mountains and near Villa Ahumada, Chihuahua, Mexico, with caches containing up to 15,000 beads, and postulates that they were hidden by traders along trade routes for use as needed. During the 1975 Texas Archaeological Survey of the McGregor Range, two more bead caches were found (these are presently being analyzed for publication). Hi11 (1971:91) reports a site in the Sabina Mountain area of El Paso County, Texas. Two miniature ollas attributed to the Mesilla Phase were found associated with shell, bone, and "fossilized worm casing" beads. K1 inger and Lekson (1973:66-68) report a cache near Cliff, New Mexico, of 325 beads and pendants in an olla of the Middle Mimbres period. Olivella beads predominated but there were turquoise beads and pendants. Bradfield (1929:121-123) at Cameron Creek Village reports five Mangus Phase and one later Mimbres bead caches and observed that bead caches may be a trait of the Mimbres Mangus Phase.

\section{High Lonesome Ceramics}

The Alma Punched cache vessel and the seven Mimbres Boldface Black-on-White sherds (all apparently from one pot) indicate Mimbres association for the cache. A time frame of A.D. 775-1000 would probably be appropriate for the site (see Ceramics Section). 
The Mimbres Boldface vessel could have been intrusive, another cache pot, or the cover over the Alma Punched vessel. The absolute lack of other artifacts plus the uniform distribution of the sherds of both vessels would tend to eliminate the intrusive theory. The fact that only one rim sherd from either pot (the Boldface vessel) was recovered indicates that the site was partially uncovered in the past, the vessels broken, upper portions and presumably some beads swept clear of the immediate area and the remnants reburied, only to be partially exposed again recently. If the Mimbres Bold vessel was the cover for the cache, then it would have been even more exposed than the cache pot and fewer sherds would remain (seven Mimbres Bold vs. 19 Alma Punched). The cache pot, with an estimated one-fourth of the vessel remaining when discovered, could easily have contained all 877 recovered beads in its original configuration, as the remnant held 405. A careful search for sherds and beads made for .25 mile up and down the arroyo failed to reveal a single bead or sherd outside the immediate site environs.

Beads and Pendants

The High Lonesome beads do not fit into any of the published caches. Even Casas Grandes, commercial bead manufacturing center that it was, has nothing like the large marine pelecypod beads. Nor does the site have calcite beads al though 10,000 gm of mined calcite was reported (DiPeso 1974, Vol. 7:466). The largest concavo-convex she 11 bead reported at Casas Grandes was $7 \mathrm{~mm}$ in diameter, and the largest shell disc bead was $19 \mathrm{~mm}$ in diameter (DiPeso 1974, Vol. $6: 430)$, as compared to the 16 to $33 \mathrm{~mm}$ range of the High Lonesome shel1 beads. The only calcite reference found, and that is questionable, was from the distant Winona Site where McGregor (1965:198) describes two distinctive forms of beads of fine, hard, white, crystalline rock (calcite?), highly polished and carbonized.

The High Lonesome beads were probably manufactured in the local Jornada area. Identical calcite beads were found in the Radium Springs survey area at AR084 30 miles away, at AR062 four miles west, and at the large Mimbres village (AR092) 15 miles south. This village (one square mile in size) has been known to collectors for many years as the "Bruton Bead Site." Despite massive bulldozer "archaeology" at the site, it should be explored as the possible manufacturing locus of the calcite beads.

The source of pure calcite (white marble) is unknown, but Mr. Daniel C. Rathbun (personal communication, 1977) states that "there is a deposit of anchoritic marble in Radium Springs. Material from this deposit comes in many colors, including white. Some of it may appear to have a crystalline structure under microscope. There is also a deposit of travertine near Hatch. The travertine is white to buff in color. Some of it is marbleized." Hatch is 25 miles west-southwest of the "Bruton Bead Site" (ARO9?).

Dr. Harold Murray, who examined the shell artifacts, concluded that with the exception of some freshwater mussels the shell species came mainly from the Pacific. All of the very large, deeply concavo-convex beads (of unidentified pink/orange 


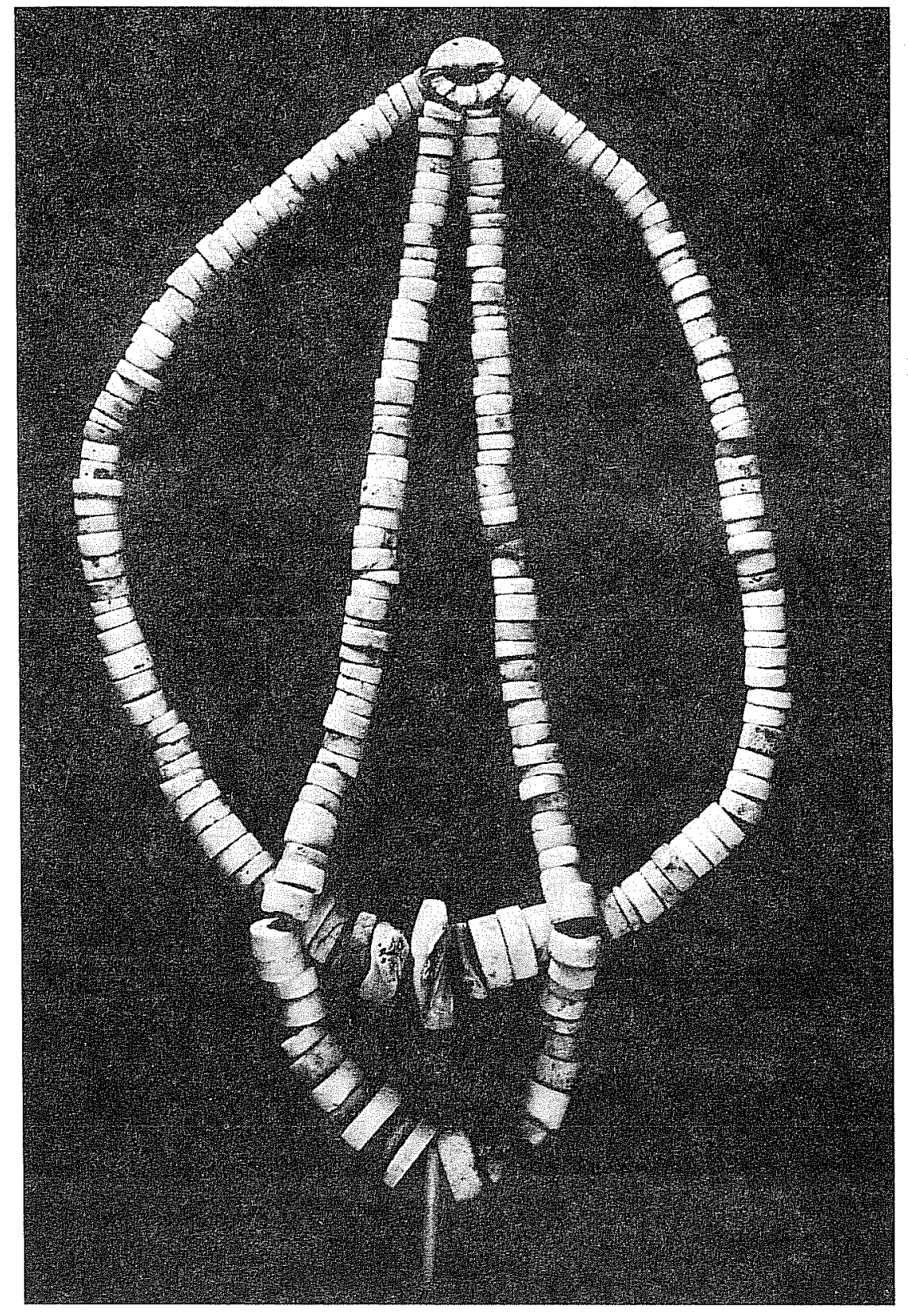

a

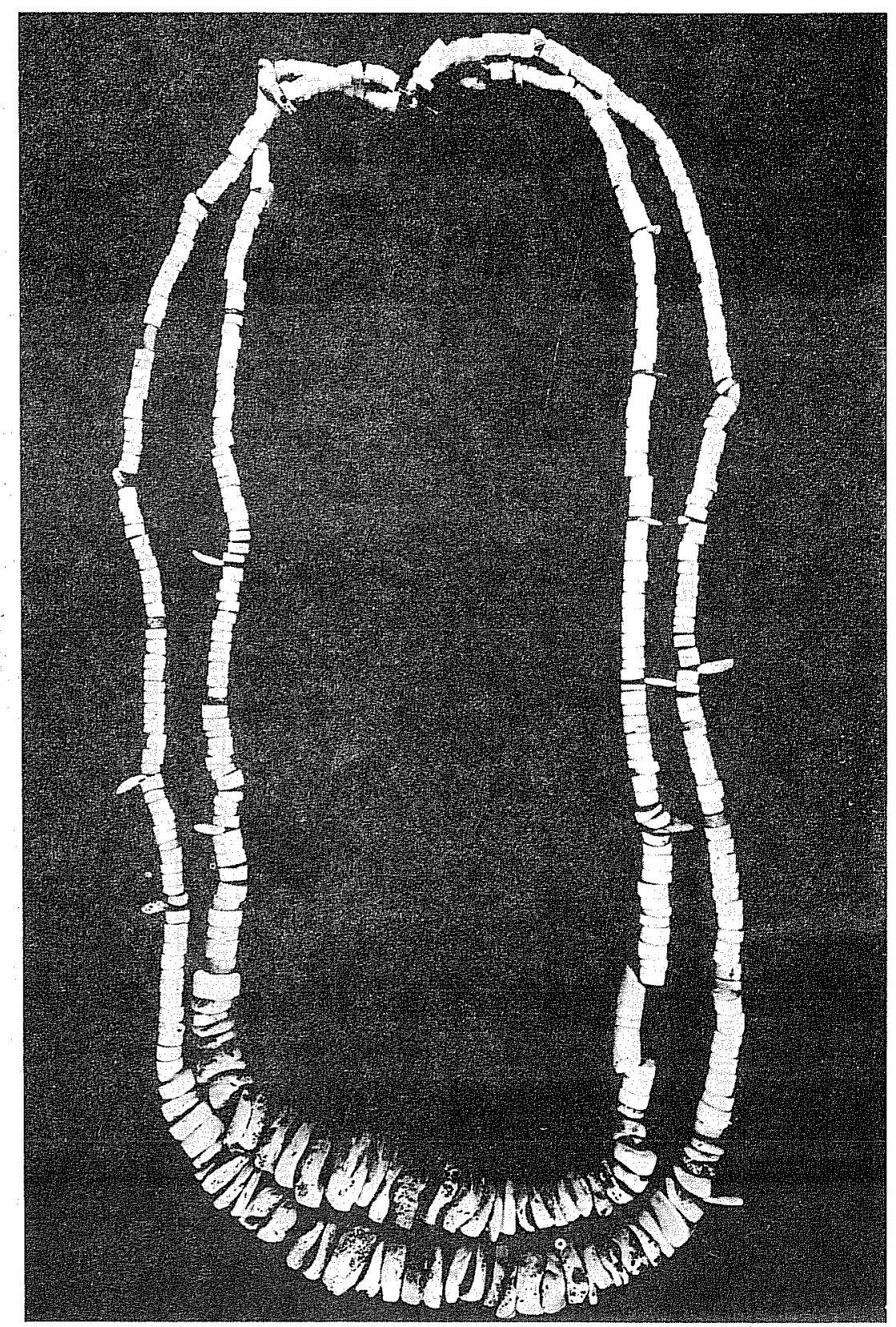

b

Figure 42. Experimental Reconstruction of High Lonesome Beads. a, beads strung with spacers or pendants every 12 th bead; $b$, graduated strands. Note strand connector. Total length of all strands 3.24 meters. 


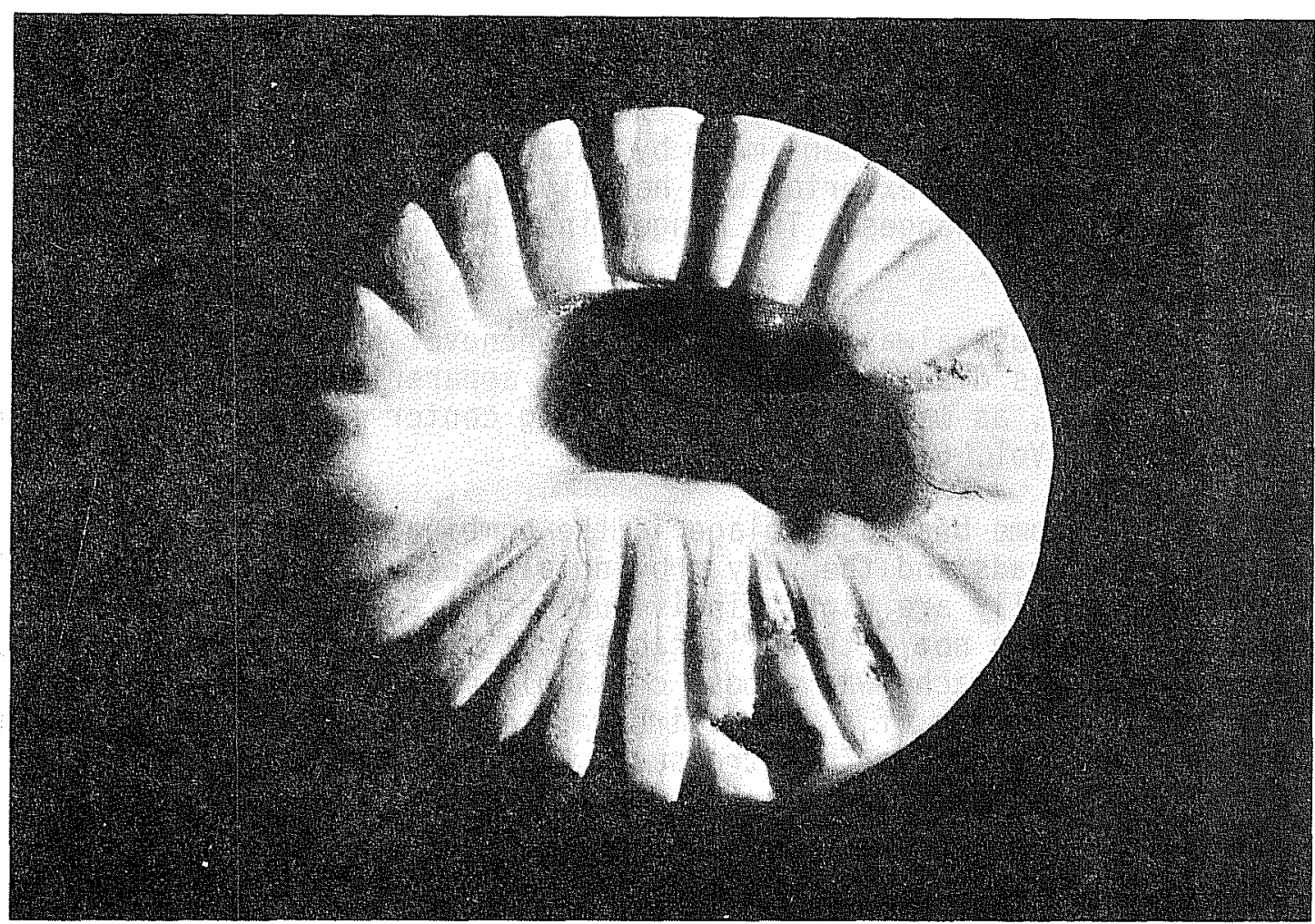

a

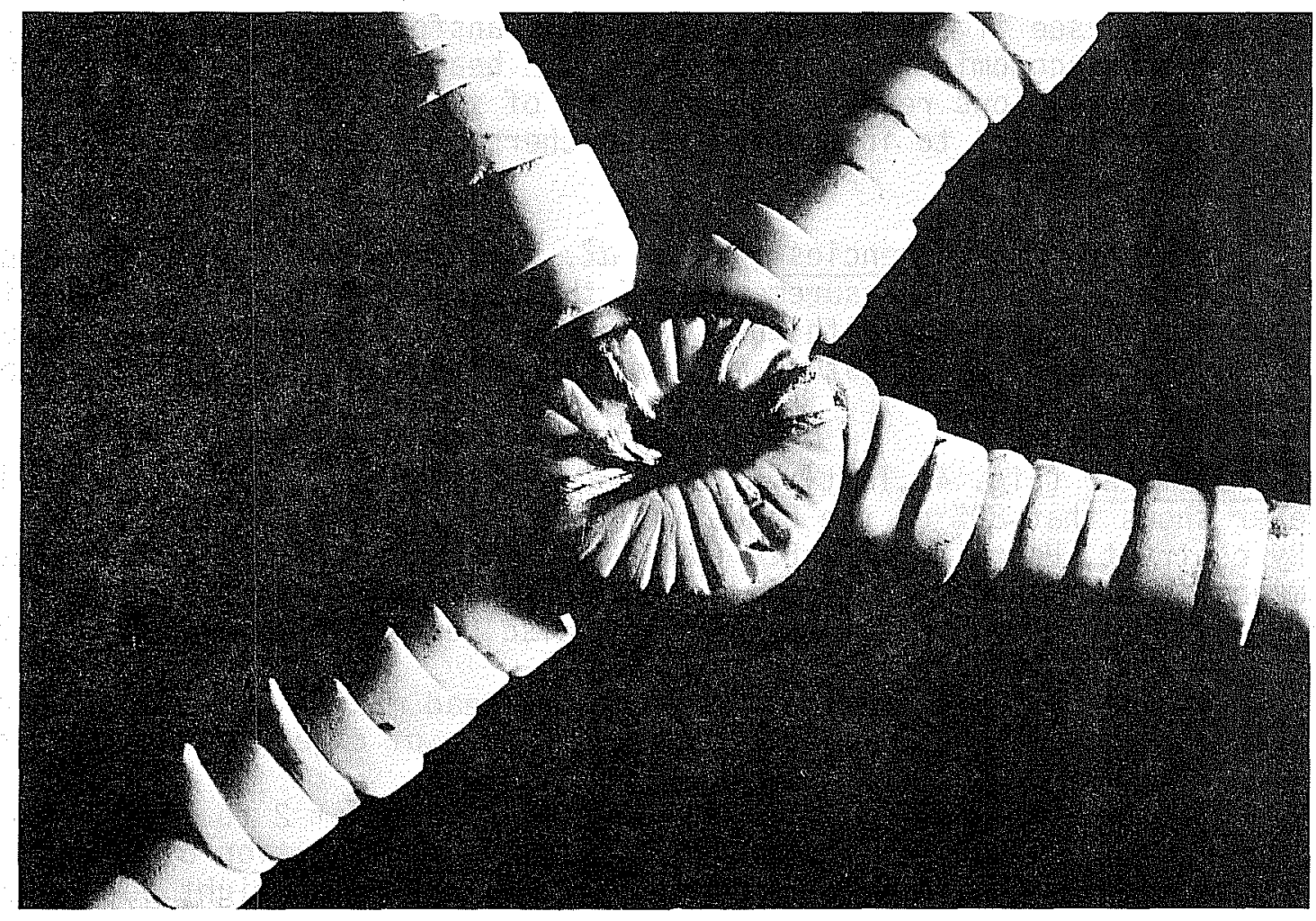

b

Figure 43. Strand Connector from AR095. a, magnified view of strand connector; four grooves show wear polish; $b$, strand connector securing two strands of calcite beads. 
marine pelecypod she11) were made by cutting and grinding around the umbo cavity. Their rough exterior was heavily pock-marked by the action of marine worms and sponges. The hinge lines and teeth were recognized on several specimens.

Casas Grandes must always be considered whenever the distribution of Pacific marine shells is discussed because it was apparently one of the major distribution centers, as well as a manufacturing center for the entire Southwest (DiPeso 1974, Vol. 6:401).

The High Lonesome bead assemblage is the combination of mass-produced, precisionmade calcite beads and the very provincial-looking, crudely-made shell beads that aesthetically are highly individualistic, as are the pendants. I believe the materials are not a trader's cache, but some individual's valued personal belongings. The cache was almost certainly marked with a rock cairn. The most likely function of a rock cairn was to permit a person to find the site again, either to recover his treasure, or for purposes of ceremony or ritual.

\section{Statistical Analysis of the High Lonesome Beads}

The 837 cache beads were measured and data punched on IBM cards. Diameter, thickness (maximum), perforation diameter (minimum), and weight were measured to the closest millimeter or gram. Perforation type (conical, biconical, and cylindrical) and material type were recorded. Several computer programs were explored to see if the raw data could be transformed into aesthetic, technological, or economic information about the bead makers or owners. Some interesting observations resulted that may be of value to future research. The card runs are available to interested researchers at the Center for Archaeological Research.

SPSS Sub-Program Frequencies (Nie et al. 1975:200). This program produced 11 standard statistical measurements and the histograms (Figs. 44,45) which are numbered in accordance with the corresponding paragraphs below. For economy of space, some of the histograms have been attenuated where the data are no longer significant.

1. Diameter (Fig. 44, left). The frequency of beads from 5 to $33 \mathrm{~mm}$ in diameter shows that $80 \%$ of the beads fall between 5 and $10 \mathrm{~mm}$ with a mean of $9.8 \mathrm{~mm}$. By contrast, Haury's (1931:82) Casa Grande bead makers made tiny beads (2 mm mean diameter with very little variation). Casas Grandes bead makers had a mean diameter of $5 \mathrm{~mm}$ for 17,000 stone disc beads (DiPeso 1974, Vol. 7:246).

Observation. A trait of the High Lonesome bead makers was a preference for Targer and less uniform-sized beads than those of other Southwestern people.

2. Thickness (Fig. 44, right). Thickness varies from 2 to $15 \mathrm{~mm}$ with $90 \%$ fal1ing between 3 and $6 \mathrm{~mm}$. Since strand length is a function of numbers of beads times thickness, something of economics and technology might be learned from examining this function closely. Based on maximum thickness the computer gave a predicted length of 3.783 meters for the total length of the High Lonesome 
bead string. It actually measured 3.24 meters because of the nestling of the concavo-convex shel1 beads into each other, and because some of them were wedge-shaped in thickness. If economics (labor and material) entered into the aboriginal scheme of things, there should have been an optimum bead thickness. Using modern drills and sanders on San Antonio River mussel she11, we found in the laboratory that it took over three times as long to make a bead $30 \mathrm{~mm}$ in diameter and $10 \mathrm{~mm}$ thick as it did a bead $8 \mathrm{~mm}$ in diameter and $4 \mathrm{~mm}$ thick (36 minutes vs. 11 minutes). For the two and one-half times gain in thickness we also took 32 times as much material to manufacture the larger bead. (Volume $=\pi \times r^{2} \times t$; for $30 \mathrm{~mm}$ bead: $v=15 \times 15 \times 10 \times 3.1416$ or $7068 \mathrm{cu}$. $\mathrm{mm}$; for $8 \mathrm{~mm}$ bead: $v=4 \times 4 \times 4 \times 3.1416$ or $218 \mathrm{cu} . \mathrm{mm} ; 7068 \div 218=32.4)$.

Assuming that the aboriginal manufacturing time would be at least proportional and that labor and material were valuable, the large and varied sizes of beads represent aesthetic tastes for which the High Lonesome bead owners were willing to pay the price.

An unexpected insight on the technology and reason for manufacture of the shell beads about the umbo cavity of marine pelecypods resulted from this exercise. It is difficult and time-consuming to drill through thick shell even with an electric dril1. With slight grinding of the outside of the shell over the umbo cavity, the aboriginal workman had a shell thickness of only about two mm to perforate. He also had a pre-center-punched surface to drill provided by the numerous marine worm or sponge holes on the shell exterior.

3. Perforation Diameter (Fig. 45). Ninety-eight percent of the beads had perforation diameters from 2 to $3 \mathrm{~mm}$. Only two beads had perforations of $1 \mathrm{~mm}$ diameter, compared with Haury's (1931:85) minimum perforation of .51 and maximum or $1 \mathrm{~mm}$. Both technological and aesthetic differences exist between the two areas.

Assuming that the two $1-\mathrm{mm}$ perforated beads were strung with the rest of the beads, a string of $1 \mathrm{~mm}$ or less in diameter was used to string the High Lonesome beads.

4. Weight (Fig. 45). Weight is a function of diameter and thickness, so the histogram is quite similar to the diameter and thickness histograms. The mean weight is $1.038 \mathrm{gm}$ and the total $(1.038 \times 837)$ is $868.8 \mathrm{gm}$. Our 1-mm diameter string has to support $2.6 \mathrm{gm}$ per $\mathrm{cm}$ in length $(868.8 \div 324$, the total length of the strung beads).

5. Material (histogram not shown). Eighty-eight percent (736) of the beads were of white to cream colored calcite while 12\% (101) were pink-tinged marine she11. The calcite beads appear to be mass or commercially produced. The fact that no other type of stone beads was used would indicate a plentiful supply of calcite, probably in the regional area. Radium Springs and Hatch have been previously mentioned as possible sources. The shell has been identified as marine and probably Pacific in origin.

The individuality and uniqueness of these beads are possibly traits of a previously unidentified group of people of the Jornada area. The finding 
of three other sites in the Radium Springs survey area with identical calcite beads strengthens this possibility.

6. Perforation by Type (Fig. 45). Beads were perforated conically (53\%), biconically (37\%), and cylindrically (10\%). DiPeso (1974, Vol. 6:413) reasons that one man made all the beads in nine caches in one room at Casas Grandes because all were biconically-drilled. If we stretch that assumption, the High Lonesome beads were made by at least three different persons. The calcite vs. shell beads also have different makers implied (mass producers vs. individual manufacture). A correlation test was made by Dr. Joel Gunn to see if the type of perforation was dependent on any of the other variables (SPSS sub-program Multiple Regressions). It seemed logical that the technical problems of perforating thick beads would require biconical drilling. However, no correlations were found.

\section{Conclusions}

There is no evidence that the High Lonesome Cache is either a trader's or a ceremonial cache. Our hypothesis is that the cache was buried and marked with a cairn, and that the owner intended to return. Beads of varying sizes were strung progressively from smallest to largest to smallest (biconically) in contrast to cylindrically strung beads of comparatively constant size reported over most of the Southwest (DiPeso at Casas Grandes 1974, Vols. 6 and 7; Haury at Casa Grande 1931:82; McGregor at Winona Ridge 1965:196).

The apparent unique occurrence of these beads in the Jornada area should be thoroughly investigated in the course of future research. 

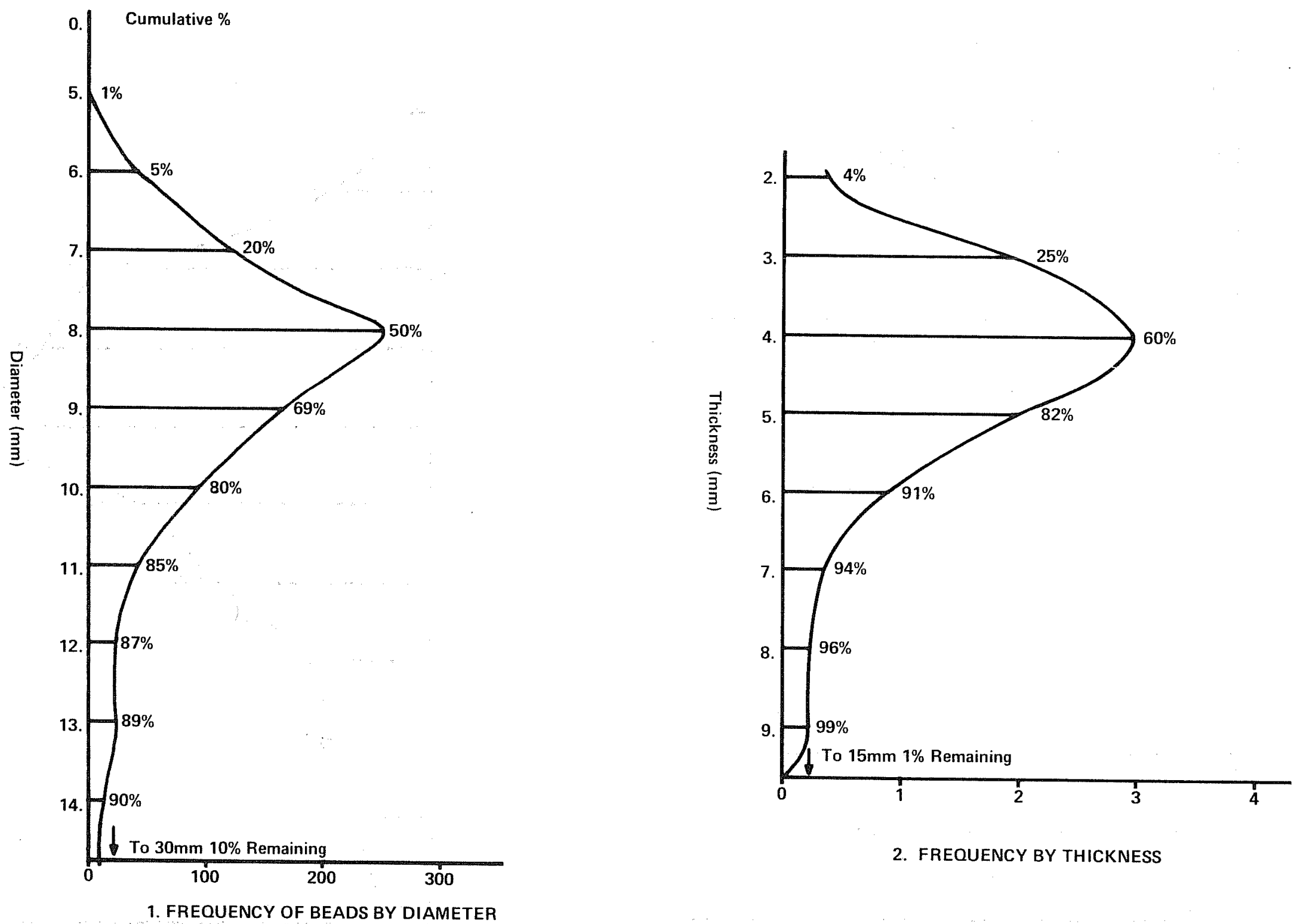

2. FREQUENCY BY THICKNESS

Figure 44. Bead Frequency by Diameter and Thickness. 


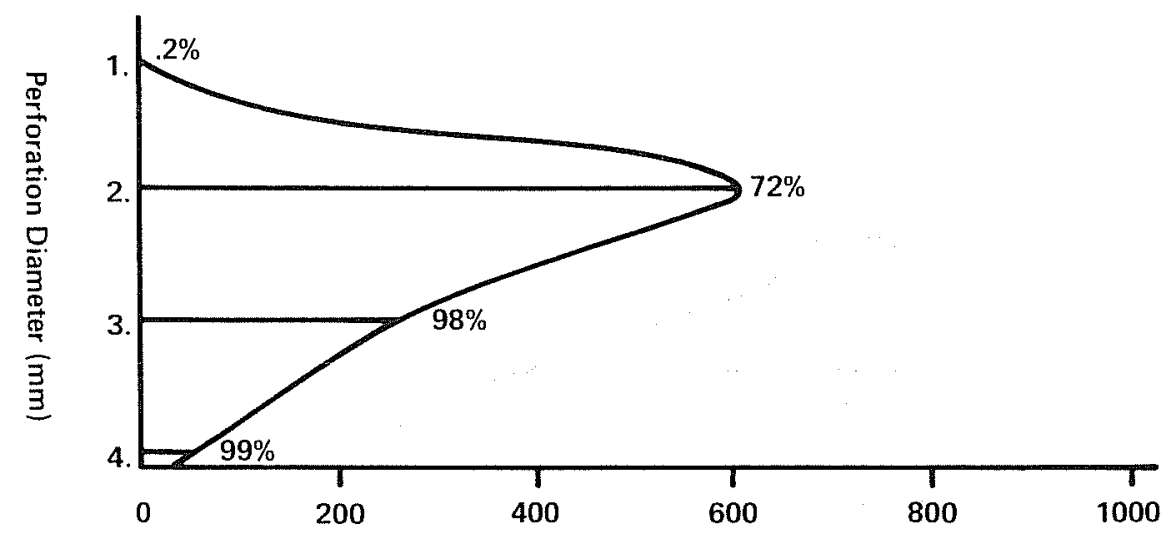

3. FREQUENCY BY PERFORATION DIAMETER

* Scale on horizontal axis indicates the number of beads

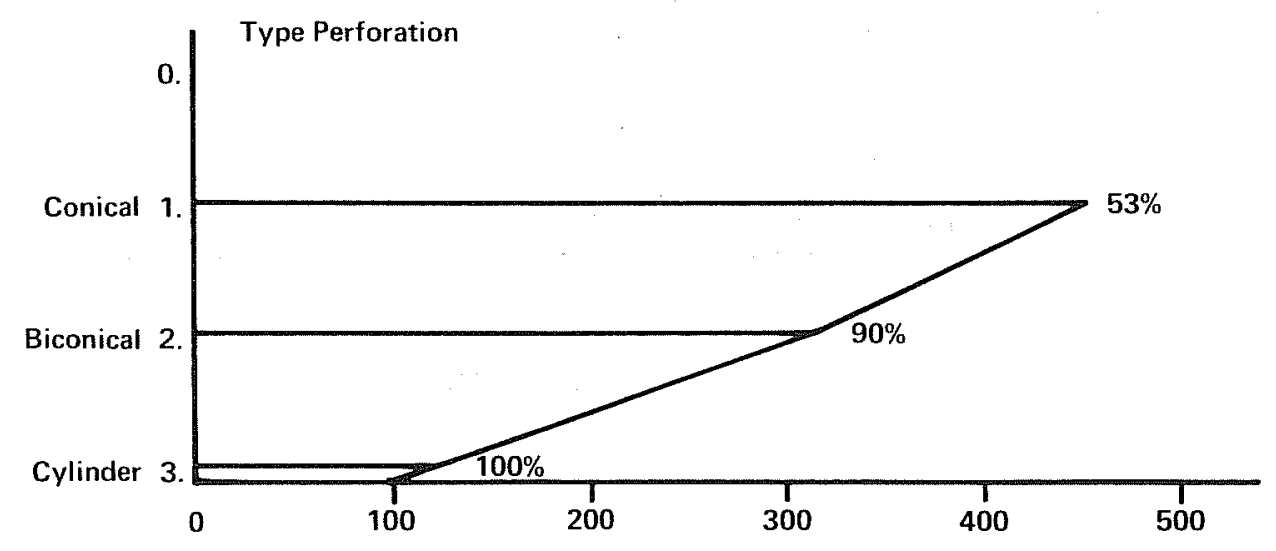

ஜ

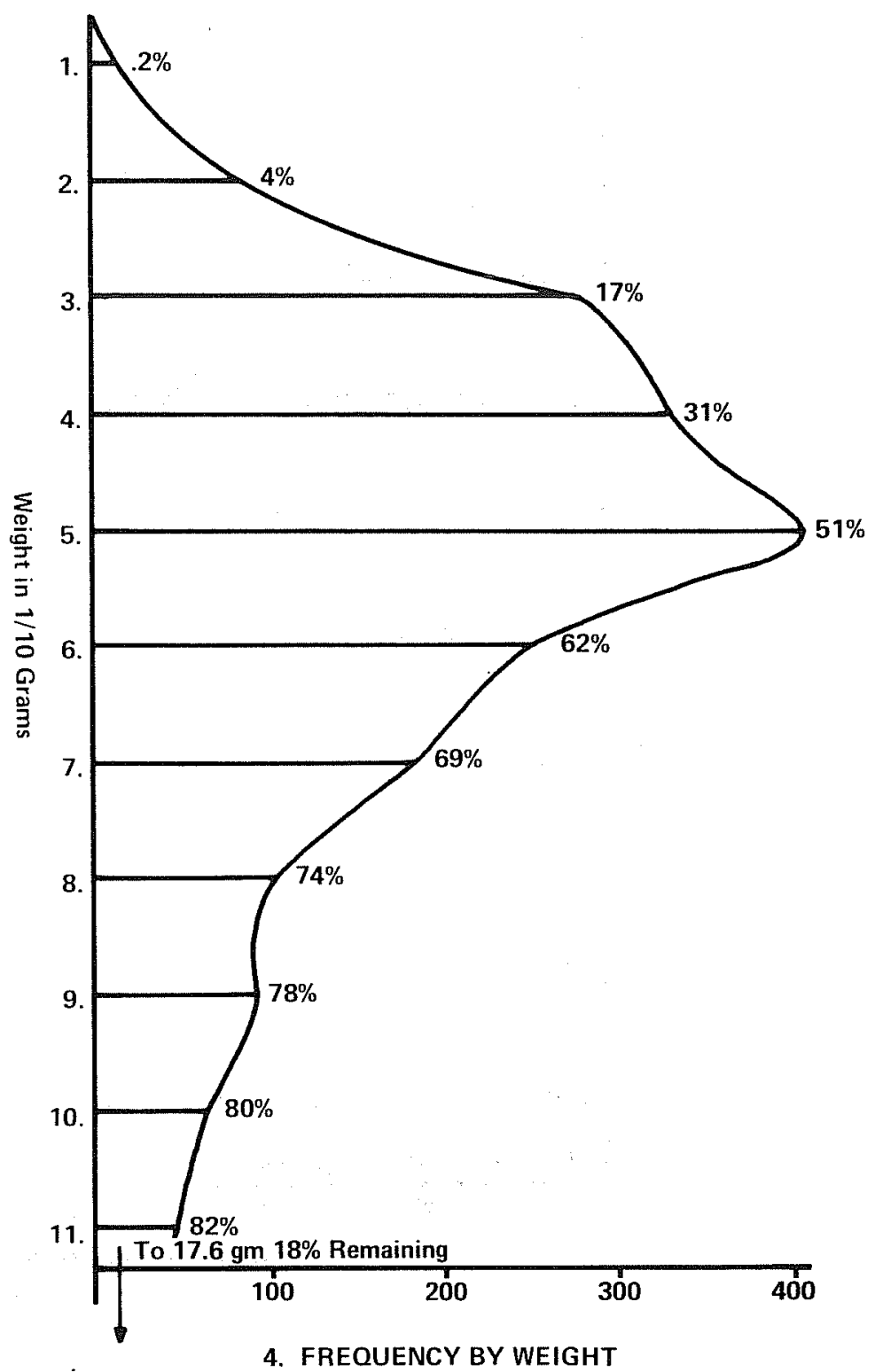

4. FREQUENCY BY WEIGHT

Figure 45. Bead Frequency by Weight, Perforation Diameter, and Type of Perforation. 

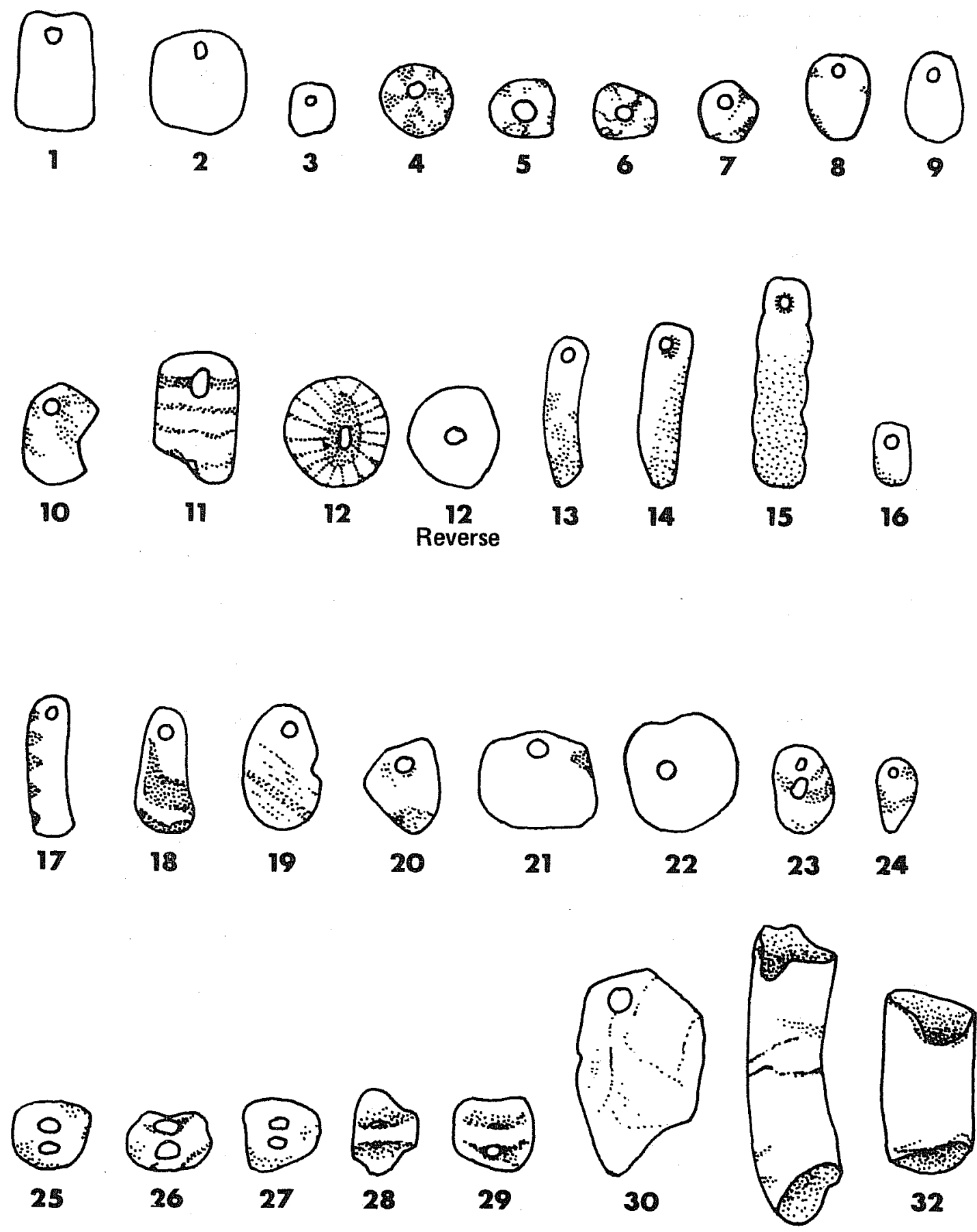

Figure 46. Shell and Stone Pendants from AR095. 1-32, reference Table 16 for descriptive data. 


\begin{tabular}{|c|c|c|c|c|c|c|c|}
\hline No. & $\begin{array}{c}\text { Diameter } \\
\text { or } \\
\text { Length } \\
(\mathrm{mm})\end{array}$ & $\begin{array}{l}\text { Width } \\
(\mathrm{mm})\end{array}$ & $\begin{array}{c}\text { Thickness } \\
(\mathrm{mm})\end{array}$ & $\begin{array}{l}\text { Diameter } \\
\text { of } \\
\text { Perforation } \\
(\mathrm{mm})\end{array}$ & $\begin{array}{c}\text { Weight } \\
(\mathrm{gm})\end{array}$ & Material & $\begin{array}{l}\text { Perforation } \\
\text { Type }\end{array}$ \\
\hline 1 & 17 & 12 & 2 & 2 & .6 & $\begin{array}{l}\text { Iridescent } \\
\text { Fresh Water } \\
\text { Pelecypod }\end{array}$ & Conical \\
\hline 2 & 15 & 14 & 1 & 2 & .5 & $\begin{array}{l}\text { Iridescent } \\
\text { Shè11 }\end{array}$ & Conical \\
\hline 3 & 7 & 6 & 1 & 2 & .1 & $\begin{array}{l}\text { Iridescent } \\
\text { She11 }\end{array}$ & Conical \\
\hline 4 & 11 & - & 5 & 1 & 1.0 & Turquoise & Biconical \\
\hline 5 & 10 & 6 & 4 & 2 & .7 & Turquoise & Biconical \\
\hline 6 & 9 & 6 & 3 & 1 & .3 & Turquoise & Biconical \\
\hline 7 & 9 & 9 & 2 & 2 & .3 & Turquoise & Conical \\
\hline 8 & 12 & 10 & 2 & 1 & .4 & Turquoise & Biconical \\
\hline 9 & 13 & 8 & 3 & 1 & .4 & Turquoise & Conical \\
\hline 10 & 14 & 11 & 2 & 1 & .4 & Turquoise & Biconical \\
\hline 11 & 19 & 14 & 4 & 2 & 1.5 & $\begin{array}{l}\text { Striated } \\
\text { Orange-Yellow } \\
\text { Alabaster }\end{array}$ & Conical \\
\hline 12 & 16 & 14 & 5 & $2 \times 3$ & 1.8 & White She 11 & Cut \\
\hline 13 & 21 & 6 & 4 & 1 & .6 & Marine Shell & Conical \\
\hline 14 & 22 & 7 & 5 & 2 & 1.0 & Marine She11 & Biconical \\
\hline 15 & 30 & 8 & 6 & 1 & 2.0 & Marine She11 & Biconical \\
\hline 16 & 9 & 5 & 4 & 2 & .3 & Marine She11 & Biconical \\
\hline 17 & 21 & 7 & 3 & 2 & .7 & Marine She11 & Conical \\
\hline 18 & 18 & 8 & 5 & 2. & .9 & Marine She 11 & Biconical \\
\hline 19 & 17 & 11 & 4 & 2 & 1.0 & Marine She11 & Biconical \\
\hline 20 & 14 & 11 & 4 & 2 & .7 & $\begin{array}{l}\text { Pink Marine } \\
\text { Shell }\end{array}$ & Biconical \\
\hline 21 & 17 & 16 & 4 & 2 & 1.7 & $\begin{array}{l}\text { Pink Marine } \\
\text { She } 11\end{array}$ & Biconical \\
\hline
\end{tabular}


TABLE 15 (continued)

\begin{tabular}{|c|c|c|c|c|c|c|c|}
\hline No. & $\begin{array}{c}\text { Diameter } \\
\text { or } \\
\text { Length } \\
(\mathrm{mm})\end{array}$ & $\begin{array}{l}\text { Width } \\
(\mathrm{mm})\end{array}$ & $\begin{array}{c}\text { Thickness } \\
(\mathrm{mm})\end{array}$ & $\begin{array}{l}\text { Diameter } \\
\text { of } \\
\text { Perforation } \\
(\mathrm{mm})\end{array}$ & $\begin{array}{c}\text { Weight } \\
(\mathrm{gm})\end{array}$ & Material & $\begin{array}{l}\text { Perforation } \\
\text { Type }\end{array}$ \\
\hline 22 & 18 & - & 6 & 2 & 2.3 & Shell & Biconical \\
\hline 23 & 12 & 8 & 4 & $2-3$ & .6 & $\begin{array}{l}\text { Pink Marine } \\
\text { She11 }\end{array}$ & Biconical \\
\hline 24 & 11 & 6 & 4 & 2 & .3 & She 11 & Biconical \\
\hline 25 & 11 & 10 & 6 & 1 & .8 & $\begin{array}{l}\text { Pink Marine } \\
\text { She11 }\end{array}$ & Cylindrical \\
\hline 26 & 12 & 8 & 5 & 2 & .7 & $\begin{array}{l}\text { Pink Marine } \\
\text { She11 }\end{array}$ & Cylindrical \\
\hline 27 & 11 & 10. & 5 & 2 & .7 & $\begin{array}{l}\text { Buff Marine } \\
\text { She } 11\end{array}$ & Conical \\
\hline 28 & 12 & 10 & 5 & 2 & .5 & $\begin{array}{l}\text { Pink Marine } \\
\text { She11 }\end{array}$ & Conical \\
\hline 29 & 12 & 10 & 6 & 2 & 1.1 & $\begin{array}{l}\text { Pink Marine } \\
\text { Shel } 1\end{array}$ & Biconical \\
\hline 30 & 31 & 18 & 2 & 1 & .8 & $\begin{array}{l}\text { Iridescent } \\
\text { Fresh Water } \\
\text { Mussel }\end{array}$ & Biconical \\
\hline 37 & 43 & 7 & - & 5 & 61.3 & $\begin{array}{l}\text { Dentalium } \\
\text { semipolitum }\end{array}$ & $\begin{array}{l}\text { Natural } \\
\text { Tube }\end{array}$ \\
\hline 32 & 24 & 9 & - & 6 & 37.1 & $\begin{array}{l}\text { Dentalium } \\
\text { semipolitum }\end{array}$ & $\begin{array}{l}\text { Natural } \\
\text { Tube }\end{array}$ \\
\hline
\end{tabular}


TABLE 16

DATA FOR BEAD COLLECTION, AR095

\begin{tabular}{|c|c|c|c|c|c|c|c|c|c|c|c|c|c|c|}
\hline $\begin{array}{l}\text { Diame ter } \\
(\mathrm{mm})\end{array}$ & No. & of Beads & $\begin{array}{l}\text { Range in } \\
\text { Thickness } \\
\text { (mm) }\end{array}$ & $\begin{array}{l}\text { Average } \\
\text { Thickness } \\
\text { (mm) }\end{array}$ & $\begin{array}{c}\text { Range in } \\
\text { Perforation } \\
\text { Diameter } \\
(\mathrm{mm})\end{array}$ & $\begin{array}{c}\text { Average } \\
\text { Perforation } \\
\text { Diameter } \\
\text { (mm) }\end{array}$ & $\begin{array}{l}\text { Range } \\
\text { in } \\
\text { Weight } \\
\text { (gm) }\end{array}$ & $\begin{array}{c}\text { Average } \\
\text { Weight } \\
\text { (gm) }\end{array}$ & $\begin{array}{c}\text { (1) } \\
\text { Material }\end{array}$ & $\begin{array}{c}\text { (1) } \\
\text { Material } \\
\text { Most Commonly } \\
\text { Used }\end{array}$ & $\begin{array}{c}\text { (2) } \\
\text { Type of } \\
\text { Perforation }\end{array}$ & $\begin{array}{l}\quad(2) \\
\text { Most Common } \\
\text { Perforation } \\
\text { Type }\end{array}$ & $\begin{array}{c}\text { (3) } \\
\text { Remarks }\end{array}$ & \\
\hline 5 & & 3 & $2-3$ & 2.7 & 2 & 2 & $.1-.3$ & .2 & 1 & 1 & $2-3$ & 3 & & \\
\hline 6 & & 35 & $2-4$ & 2.8 & $1-2$ & 1.9 & $.2-.3$ & .25 & $1-2$ & 1 & $1-3$ & 1 & 8 beads & $-\# 2$ \\
\hline 7 & & 124 & $2-6$ & 3.5 & 2 & 2 & $.2-.6$ & .35 & $1-2$ & 1 & $I-3$ & 1 & 12 beads & $-\# 2$ \\
\hline 8 & & 249 & $2-6$ & 3.9 & $2-3$ & 2.1 & $.3-.7$ & .47 & $1-3$ & 1 & $1-3$ & 1 & $\begin{array}{r}3 \text { beads } \\
26 \text { beads }\end{array}$ & $\begin{array}{l}-\# 1 \\
-\# 2\end{array}$ \\
\hline 9 & & 167 & $3-7$ & 4.3 & $2-3$ & 2.1 & $.4-.9$ & .56 & $1-3$ & 1 & $1-3$ & 1 & 27 beads & $-\# 2$ \\
\hline 10 & & 88 & $3-8$ & 4.9 & $2-4$ & 2.6 & $.4-1.6$ & .88 & $1-3$ & 1 & $1-3$ & 1 & $\begin{array}{l}9 \text { beads } \\
2 \text { beads }\end{array}$ & $\begin{array}{l}-k_{2} \\
- \text { - } 11\end{array}$ \\
\hline 11 & & 42 & $4-9$ & 5.1 & $2-3$ & 2.7 & $.5-1.8$ & 1.09 & 1 & 1 & $1-3$ & 1 & $\begin{array}{c}1 \text { bead } \\
17 \text { beads }\end{array}$ & $\begin{array}{l}-\# 1 \\
-\# 2\end{array}$ \\
\hline 12 & & 22 & $4-9$ & 5.9 & $2-3$ & 2.7 & $.8-2.2$ & 1.47 & $1-3$ & 1 & $1-2$ & 2 & $\begin{array}{r}2 \text { beads } \\
10 \text { beads }\end{array}$ & $\begin{array}{l}-\# 1 \\
-\# 2\end{array}$ \\
\hline 13 & & 16 & $4-7$ & 5.3 & $2-3$ & 2.8 & $.9-2.2$ & 1.48 & $1-3$ & 1 & $1-3$ & 2 & $\begin{array}{c}1 \text { bead } \\
10 \text { beads }\end{array}$ & $\begin{array}{l}-\# 1 \\
-\# 2\end{array}$ \\
\hline 14 & & 10 & $5-8$ & 6.1 & 3 & 3 & $1.5-2.7$ & 2.0 & $1 \& 3$ & 1 & $1-2$ & 2 & $\begin{array}{l}2 \text { beads } \\
5 \text { beads }\end{array}$ & $\begin{array}{l}-\# 1 \\
-\# 2\end{array}$ \\
\hline 15 & & 8 & $4-7$ & 5.3 & $2-3$ & 2.9 & $1.8-2.9$ & 2.25 & $1 \& 3$ & 1 & $1-2$ & 2 & 2 beads & $-\# 2$ \\
\hline 16 & & 8 & $4-8$ & 5.5 & $2-3$ & 2.9 & $1.5-2.8$ & 1.95 & $2-3$ & $2-3$ & $1-2$ & $1-2$ & $\begin{array}{l}1 \text { bead } \\
2 \text { beads } \\
6 \text { beads }\end{array}$ & $\begin{array}{l}-\# 1 \\
-\# 2 \\
-\# 4\end{array}$ \\
\hline 17 & & 4 & $6-9$ & 7 & 3 & 3 & $2.1-3.5$ & 2.93 & $2-3$ & $2-3$ & $1-2$ & $1-2$ & $\begin{array}{l}1 \text { bead } \\
1 \text { bead } \\
2 \text { beads }\end{array}$ & $\begin{array}{l}-\# 1 \\
-\# 2 \\
-\# 4\end{array}$ \\
\hline
\end{tabular}




\begin{tabular}{|c|c|c|c|c|c|c|c|c|c|c|c|c|}
\hline $\begin{array}{l}\text { Diame ter } \\
\quad(\mathrm{mm})\end{array}$ & No. of Beads & $\begin{array}{l}\text { Range in } \\
\text { Thickness } \\
\text { (mm) }\end{array}$ & $\begin{array}{l}\text { Average } \\
\text { Thi.ckness } \\
\text { (mm) }\end{array}$ & $\begin{array}{l}\text { Range in } \\
\text { Perforation } \\
\text { Diameter } \\
\text { (mm) }\end{array}$ & $\begin{array}{l}\text { Average } \\
\text { Perforation } \\
\text { Diameter } \\
\text { (mm) }\end{array}$ & $\begin{array}{l}\text { Range } \\
\text { in } \\
\text { Weight } \\
\text { to (gmi) }\end{array}$ & $\begin{array}{l}\text { Average } \\
\text { Weight } \\
\text { to }(\mathrm{gm})\end{array}$ & $\begin{array}{l}(1) \\
\text { Material }\end{array}$ & $\begin{array}{c}\text { (1) } \\
\text { Material } \\
\text { Most Commonly } \\
\text { Used }\end{array}$ & $\begin{array}{c}\text { (2) } \\
\text { Type of } \\
\text { Perforation }\end{array}$ & $\begin{array}{l}\text { (2) } \\
\text { Most Common } \\
\text { Perforation } \\
\text { Type }\end{array}$ & $\begin{array}{c}\text { (3) } \\
\text { Remarks }\end{array}$ \\
\hline 18 & 7 & $4-8$ & 6.6 & 3 & 3 & $1.6-4.6$ & 2.86 & $1-3$ & 3 & $1-2$ & 2 & 2 beads $-\# 1$ \\
\hline 19 & 7 & $6-9$ & 7.9 & 3 & 3 & $2.2-6.2$ & 4.17 & $1-3$ & $1 \& 3$ & $I-2$ & 2 & $\begin{array}{l}1 \text { bead }-\# 11 \\
4 \text { beads }-\$ 12 \\
3 \text { beads }-\# 4\end{array}$ \\
\hline 20 & 4 & $6-9$ & 7 & $1-3$ & 3 & $2.3-4.0$ & 3.25 & $2-3$ & $2-3$ & $1-3$ & 2 & $\begin{array}{l}4 \text { beads }-\# 44 \\
1 \text { bead }-\# 66\end{array}$ \\
\hline 21 & 10 & $6-9$ & 7.1 & $1-4$ & 3 & $2.1-5.6$ & 3.7 & $2-3$ & 3 & $1-3$ & 2 & $\begin{array}{l}2 \text { beads }-\# 2 \\
8 \text { beads - } \# 4 \\
1 \text { bead - } \# 5 \\
1 \text { bead - } \$ 6\end{array}$ \\
\hline 22 & 3 & $7-11$ & 9 & $3-4$ & 3.3 & $3.7-7.3$ & 5.83 & $2-3$ & 2 & $2-4$ & 2 & $\begin{array}{l}3 \text { beads }-\# 44 \\
1 \text { bead }-\$ 16\end{array}$ \\
\hline 23 & 7 & $6-12$ & 8 & $2-3$ & 2.4 & $3.9-8.0$ & 5.61 & $2-3$ & 3 & $1-2$ & 2 & $\begin{array}{l}2 \text { beads }-\$ 22 \\
5 \text { beads }-\$ 44 \\
1 \text { bead }-\$ 6\end{array}$ \\
\hline 24 & 4 & $7-10$ & 8.5 & 3 & 3 & $5.3-7.8$ & 6.78 & $2-3$ & $2-3$ & $1-2$ & 2 & $\begin{array}{l}2 \text { beads }-\# 2 \text { - } 2 \text { beads }-\# 4\end{array}$ \\
\hline 25 & 5 & $7-10$ & 8.8 & 3 & 3 & $4.0-8.4$ & 6.38 & $2-3$ & 3 & $1-2$ & 2 & $\begin{array}{l}1 \text { bead }-\# 2 \text { beads }-\# 44 \\
4 \text { b }\end{array}$ \\
\hline 26 & 1 & 11 & 11 & 3 & 3 & 8.9 & 8.9 & 3 & 3 & 3 & 3 & 1 bead $-\# / 4$ \\
\hline 27 & 5 & $9-12$ & 9.8 & $3-4$ & 3.4 & $5.3-9.9$ & 7.76 & $2-3$ & 2 & $1-3$ & 2 & 5 beads $-\# 4$ \\
\hline 28 & 2 & $8-9$ & 8.5 & 4 & 4 & $9.1-9.4$ & 9.25 & 2 & 2 & $1-2$ & $1-2$ & 2 beads $-\not k 4$ \\
\hline 29 & 2 & $9-11$ & 10 & 4 & 4 & $9.2-10.4$ & 9.8 & $2-3$ & $2-3$ & $1-2$ & $1-2$ & 2 beads $-\not 14$ \\
\hline 30 & 1 & 9 & 9 & 4 & 4 & 11.3 & 11.3 & 3 & 3 & 2 & 2 & 1 bead $-\not \mid 4$ \\
\hline 31 & 1. & 13 & 13 & 2 & 2 & 13.2 & 13.2 & 3 & 3 & 3 & 3 & 1 bead $-\# 4$ \\
\hline 33 & 2 & $12-15$ & 13.5 & 3 & 3 & $15.7-17.6$ & 16.5 & 3 & 3 & 3 & 3 & 2 beads $-\not \mid ⿰ 4$ \\
\hline
\end{tabular}
837

KEY: (1) Material: 1. Calcite; 2. Marine Shel1; 3. Musse1 She11 (2) Perforation Type: 1. Conical; 2. Biconical; 3. Cylindrical 1. Out of round; 2. Non-uniform thickness; 3. Tubular; 4. Concavo-conver; 5. Perforation off-center; 6. Double Perforation; 7. Incised 



\section{APPENDIX III \\ TRACE ELEMENT ANALYSIS OF OBSIDIAN ARTIFACTS \\ FROM THE RADIUM SPRINGS AREA}

Thomas R. Hester

In the past 15 years, there has been extensive research in the area of geologic trace analysis of archaeological obsidian. The value of such research lies in the potential for sound archaeological inferences regarding trade and other forms of intercultural contact. The application of this research technique is reflected in dozens of publications, and it has been used with particular success in the Mesoamerican area (cf. Stross et al. 1976). Simply stated, nuclear chemistry is employed (neutron activation analysis and $x$-ray fluorescence are the two primary techniques utilized) to determine the specific trace element composition of artifact and geologic source samples. Most geologic sources (and the artifacts made of obsidian derived from them) have their own peculiar pattern of trace elements (often described as "fingerprints" by some researchers), enabling an obsidian artifact to be traced back to the source.

Several pieces of obsidian were found at archaeological sites within the Radium Springs project area. Because of previous work I had done with obsidian sources in New Mexico (Hester and Mitche11 1974) and with the use of available (but largely unpublished) geologic source data (R. N. Jack, personal communication), it was felt that non-destructive trace element studies should be carried out. This would permit us the opportunity to determine the source of these obsidian artifacts, and to perhaps provide some discussion of trade relationships or contacts which could be tested through more extensive analysis in future investigations in the region.

At the time this final report was being written, the results of the trace element studies were not available. The research is being directed by Dr. Frank Asaro of the Lawrence Berkeley Laboratory, University of California, Berkeley. Because of equipment problems (primarily the installation of the new x-ray fluorescence facilities) and sample backlog at the Berkeley laboratory, it will be sometime in August, 1977, before the results are available (Frank Asaro, letter to T. R. Hester of February 8, 1977).

When the results and interpretations are available, these data will be published separately and provided to the Bureau of Land Management. 



\section{REFERENCES}

The bulk of the publications listed here are cited in the text. However, we have included in this compilation a series of additional references which we feel may be of value to archaeologists doing further work in the Radium Springs vicinity. These "resource" items are indicated with an asterisk (*).

Alexander, H. L.

1963 The Levi Site: A Paleo-Indian Campsite in Central Texas. American Antiquity 28(4):510-528.

Anonymous

* 1971 Unit Resource Analysis, Las Cruces Resource Area, Caba110 Planning Unit 3-06. Unpublished Bureau of Land Management document.

Ares, F. N.

1974 Jornada Experimental Range. Range Monograph 1. Society for Range Management, Denver.

Aten, L. E.

* 1972 Evaluation of the Cultural Resources of the Northgate Site E1 Paso County, Texas. Texas Archeological Salvage Project Research Report 5.

Bailey, V.

1913 Life Zones and Crop Zones of New Mexico. U.S. Department of Agriculture, Washington.

Basehart, H. W.

1973a Selections from: Chiricahua Apache Land Claims Project, Janos, Jacomes, Mansos and Sumas. Human Systems Research, Technical Manua 1, 1973:121-123.

1973b Mescalero Apache Subsistence Patterns. Human Systems Research, Technical Manual, 1973:145-181.

* 1974 Mescalero Apache Subsistence Patterns and Sociopolitical Organization. Apache Indians XII. New York, Garland Publishing Company.

Beck, W. A. and Y. D. Haase

* 1969 Historical Atlas of New Mexico. University of Oklahoma Press, Norman. 
Beckes, M. R. et al.

1977 The Cultural Resource Inventory and Assessment of McGregor Guided Missile Range, Otero County, New Mexico. Texas Archeological Survey, Research Report 65, Parts 1, 2, and 3.

Beckett, P. H.

1976 An Archaeological Survey of an Exxon Company U.S.A. Access Road in Southern Sierra County, New Mexico. Cultural Resources Management Division Repart 57.

Bennet, M. A.

* 1974 Basic Ceramic Analysis. Contributions in Anthropology 6(1). Eastern New Mexico University.

Betancourt, J.

1977 Preliminary Reconnaissance of Archaeological Resources in the Lower Hueco Mountains: A Natural Areas Survey. Manuscript.

Bilbo, M. J.

* 1972 The Castner Annex Range Dam Site EPAS-10 Preliminary Report. The Artifact 10(2):59-81.

Blalock, H. M., Jr.

1972 Social Statistics. McGraw-Hi11 Book Company, New York. Bogusch, E. R.

1952 Brush Invasion in the Rio Grande Plain of Texas. Texas Journal of Science 3(1):85-91.

Bradfield, $W$.

1929 Cameron Creek Village. The School of American Research. El Palacio Press, Santa Fe.

Breternitz, D. A.

1966 An Appraisal of Tree-Ring Dated Pottery in the Southwest. Anthropological Papers of the University of Arizona 10.

Brook, V. R.

* 1966 The McGregor Site. The Artifact 4(4):1-22. 
Brook, V. R. (continued)

* 1970 Four Archaeo-Magnetic Dates from the Hot Wel1 Site (EPAS-3). The Artifact 8(1):1-15.

1971 Some Hypotheses About Prehistoric Settlement in the TularosaHueco Bolson Between A.D. 1250-1350. Transactions of the Sixth Regional Archaeological Symposium for Southeastern New Mexico and Western Texas:63-82.

1972 The Temporal Point: A New Diagnostic Type. Transactions of the Seventh Regional Archeological Symposium for Southeastern New Mexico and western Texas:83-88.

* 1975 Development of Prehistoric House Types in the Jornada Branch. Awanyu 3(4):16-31.

* 1976 Negative Evidence from Southern Jornada Sites after the Archaic. Transactions of the Eleventh Regional Archaeological Symposium for Southeastern New Mexico and Western Texas:21-32.

Buffington, L. C. and C. H. Herbel

1965 Vegetational Changes on a Semidesert Grassland Range from 1858 to 1963. Ecological Monograph 35(2):139-164.

Bussey, S., R. Ke11y, and J. Southward

* 1976 LA 4921, Three Rivers, Otero County, New Mexico. Cultural Resources Management Division, New Mexico State University, Report 69.

Butzer, K.W.

1971 Environment and Archaeology. 2nd Edition. Aldine Publishing Company, Chicago.

Campbe11, K. M.

* 1926 An Archaeological Site in the Jornada del Muerto. El Palacio 20(6).

Campbe11, R. S. and I. F. Campbe11

* 1938 Vegetation on Gypsum Soils of the Jornada Plain. Ecology 19:572-577.

Collins, M. B.

* 1968 The Andrews Lake Locality: New Archaeological Data from the Southern Llano Estacado, Texas. MA thesis on file at the University of Texas at Austin. 
Colton, H. S.

* 1953 Potsherds, An Introduction to the Study of Prehistoric Southwestern Ceramics and Their Use in Historic Reconstruction. Museum of Northern Arizona. Bulletin 25.

Cosgrove, C. B.

1947 Caves of the Upper Gila and Hueco Areas in New Mexico and Texas. Papers of the Peabody Museum of American Archaeology and Ethnology 24(2).

Cosgrove, H. S. and C. B. Cosgrove

* 1932 The Swarts Ruin: A Typical Mimbres Site in Southwestern New Mexico. Papers of the Peabody Museum of American Archaeology 15(1).

Cremony, J. C.

1969 Life Among the Apaches. Rio Grande Press, GTorietta, New Mexico.

Davis, J. V.

1976 Let's Get Serious About Rock Art. Transactions of the Eleventh Regional Archaeological Symposium for Southeastern New Mexico and Western Texas:1-19.

Davis, J. V. and K. S. Torress

* 1974 A Rock Art Inventory of Hueco Tanks State Park, Texas. El Paso Archaealogical Society, Special Repart 12.

Davis, L.

* 1968 Recent Excavations at Hot Well Site. Transactions of the Third Regional Archaeological Symposium for Southeastern New Mexico and Western Texas:23-32.

1969 Bishop Cap Cave. Transactions of the Fifth Regional Archaeological Symposium for Southeastern New Mexico and Western Texas:35-43.

Dick, H.

1965 Bat Cave. School of American Research Monograph 27.

DiPeso, C. C., J. B. Rinaldo, and G. J. Fenner

1974 Casas Grandes: A Fallen Trading Center of the Gran Chichimeca. Volume 6: Ceramics and She11; Volume 7: Stone and Metal. 
Doreian, P.

1972 Multivariate Analys is and Categorized Data. Quality and Quantity 1(2):253-272. Bologna, Italy.

Fitting, J. E.

* 1971 Burris Ranch Site, Dona Ana County. Southwestern New Mexico Research Report 1. Department of Anthropology, Case Western Reserve University, Cleveland.

1972 Chipped Stone from the 1967 Mimbres Area Survey. Parts I and II. Southwestern New Mexico Research Reports 8. Department of Anthropology, Case Western Reserve University, Cleveland.

Fuller, S. L., A. E. Rogge, and L. M. Gregonis

1976 Orme Alternatives: The Archaeological Resources of Roosevelt Lake and Horseshoe Reservoir. Arizona State Museum, University of Arizona, Tucson.

Gardner, J. L.

* 1951 Vegetation of the Creosote Bush Area of the Rio Grande Valley in New Mexico. Ecological Monograph 21:379-403.

GiTe, L. H.

1977 Holocene Soils and Soil-Geomorphic Relations in a Semi-Arid Region of Southern New Mexico. Quaternary Research 7(1):112-132.

Gladwin, H. S.

* 1931 Some Southwestern Pottery Types, Series II. Medallion Papers X. Gila Pueblo, Giobe.

Gladwin, H. S. and W. Gladwin

* 1933 Some Southwestern Pottery Types, Series III. Medallion Papers XIII. Gila Pueblo, Globe.

Green, J.W.

* 1967 Fusselman Canyon Petroglyph Site EPAS-44. The Artifact $5(1): 1-19$.

* 1968 A Preliminary Report of the Salvage of an El Paso Phase House Ruin: Transactions of the Fourth Regional Archaeological Symposium for Southeastern New Mexico and Western Texas: 73-77.

* 1969 Preliminary Report on Site EPAS-60: An El Paso Phase House Ruin. Transactions of the Fifth Regional Archaeological Symposium for Southeastern New Mexico and Western Texas: 1-12. 
Hammack, L. C.

1962 LA 5599, A Pithouse Village Near Rincon, New Mexico. Unpublished manuscript, Museum of New Mexico.

Hammersen, M. M.

* 1972 The Prehistoric Mogollon Culture and Its Regional Aspects in the El Paso Area. The Artifact 10(1):1-57.

Harris, D. R.

1966 Recent Plant Invasions in the Arid and Semiarid Southwest of the United States. Annals; Association of America Geographers $56: 408-422$.

Haury, E. W.

1931 Minute Beads from Prehistoric Pueblos. American Anthropologist $33: 80-87$.

* 1936 Some Southwestern Pottery Types, Series IV. Medallion Papers XIX. Gila Pueblo, Globe.

Hawley, F. M.

1950 Field Manual of Prehistoric Southwestern Pottery Types. The University of New Mexico Bulletin 291, University of New Mexico.

Hester, J. J.

1975 Paleoarchaeology of the Llano Estacado. In: Late Pleistocene Environments of the Southern High Plains ( $F$. Wendorf and J. J. Hester, eds.). Publications of the Fort Burgwin Research Center $9: 247-256$.

Hester, T. R. and R. F. Heizer

1972 Problems in Functional Interpretations: The Scraper-PTanes of Mitla, Oaxaca, Mexico. University of California Archaeological Research Facility, Contributions 14:107-123.

1973 Bibliography of Archaeology I: Experiments in Archaeology, Lithic Technology and Petrography. Addison-Wesley Module in Anthropology 29.

Hester, T. R. and J. L. Mitchel1

1974 Source Analysis of Obsidian Artifacts from McMullen County, Texas. Bulletin of the Lower Plains Archeological Society 4:25-32. 
$\mathrm{Hi} 11, \mathrm{M}$.

1971 Preliminary Report of an El Paso Brownware Site, El Paso County, Texas. Transactions of the Sixth Regional Archaeological

Symposium for Southeastern New Mexico and Western Texas:91-100.

Houghton, F. E.

* 1973 The Climate of Otero County, New Mexico. In: Human Systems Research, Technical Manual 1973:192-196.

Human Systems Research, Inc.

1973 Technical Manual, 1973. Survey of the Tularosa Basin, Three Rivers, New Mexico.

* 1975 Archaeological Survey of the Three Rivers Drainage in the

Tularosa Basin, Southern New Mexico. Technical Report I:

Environmental Parameters.

1977 Survey of the Three Rivers Drainage (manuscript in preparation).

Irwin-Williams, C.

1967 Picosa: The Elementary Southwestern Culture. American Antiquity $32(4): 441-457$.

Jelinek, A. J.

1967 A Prehistoric Sequence in the Middle Pecos Valley, New Mexico. Anthropology Papers 31, Museum of Anthropology, University of Michigan.

Judge, W. J.

1973 Paleo-Indian Occupation of the Central Rio Grande Valley in New Mexico. University of New Mexico Press, Albuquerque.

Katz, P. R.

1976 A Technological Analysis of the Kansas City Hopewell Chipped Stone Industry. Ph.D. dissertation, University of Kansas.

Keen, A. M.

1958 Sea Shells of Tropical West America. Stanford University Press, Stanford.

Kelley, J. H.

1966 The Archaeology of the Sierra Blanco Region of Southeastern

New Mexico. Ph.D. dissertation, Harvard University. 
Kelly, T. C. and T. R. Hester

1975 Archaeological Investigations at Four Sites in the Dry Coma1 Watershed, Comal County, South Central Texas. Center for Archaeological Research. The University of Texas at San Antonio, Archaeological Survey Report 15.

Kelly, V. C. and C. Silver

* 1952 Geology of Cabal10 Mountains. University of New Mexico, Geological Series 4.

Keyes, C. R.

* 1905 Geology and Underground Water Conditions of the Jornada de 1

Muerto, New Mexico. U.S. Geological Survey Water Supply Paper 123.

KTinger, T. C. and S. Lekson

1973 A Bead Cache from Saige-McFarland, A Mimbres Site in Southwestern New Mexico. The Artifact 11(4):66-89.

Kottlowski, F. W., R. H. Flower, M. L. Thompson, and R. W. Foster

1956 Stratigraphic Studies of the San Andres Mountains, New Mexico. Memoir I, State Bureau of Mines and Mineral Resources. New Mexico Institute of Mining and Technology, Socorro.

Krone, M. F.

* 1974 Little Peaks Site Report. The Artifact 12(3):1-19.

1975 Report on Folsom Points Found in the El Paso Area. The Artifact $13(4): 1-19$.

Laumbach, K. W.

* 1976 An Ex Post Facto Archaeological Reconnaissance of a Mountain Bel1 Telephone Distribution Line from Hatch, New Mexico to the Las Uvas Farms. Department of Sociology and Anthropology, New Mexico State University, Las Cruces.

Lehmer, D. J.

1948 The Jornada Branch of the Mogol1on. University of Arizona Social Science Bulletin 17. 
Levine, F. and C. M. Mobley

1976 Archaeological Resources at Los Esteros Lake, New Mexico. Southern Methodist University Contribution in Anthropology 17.

Little, E. L. and R. S. Campbel1

1943 Flora of Jornada Experimental Range, New Mexico. American Midland Naturalist 30(3):626-670.

Lynn, W. M.

* 1976 Archaeological Testing at the Northeast Sewage Treatment Plant, El Paso County, Texas. Texas Historical Commission, Archaeological Survey Report 15.

Lynn, W. M., B. J. Baskin, and W. R. Hudson, Jr.

* 1975 A Preliminary Archaeological Reconnaissance of Selected Public Free School Lands in E1 Paso County, Texas. General Land Office and Texas Historical Cammission Archaeological Survey Report 13.

Marsha11, M. P.

1973 Backqround Information on the Jornada Cultural Area. Human Systems Research, Technical Manual, 1973:49-120.

Martin, P. S. and F. Plog

1973 The Archaeology of Arizona: A Study of the Southwest Region. Doubleday/Natural History Press, New York.

Martin, P. S., J. B. Rinaldo, E. Bluhm, and R. Grange, Jr.

1952 Mogolion Cultural Continuity and Change: The Stratigraphic Analys is of Tularosa and Cordova Caves. Field Museum of Natural History, Publications, Anthropological Series 40.

Martin, P. S. and H. E. Wright

* 1967 Pleistocene Extinctions: The Search for a Cause. Yale University Press.

McCluney, E. B.

1962 A New Name and Revised Description for a Mogollon Pottery Type from Southern New Mexico. Southwestern Lore 27(4):49-55.

McGregor, J. C.

1965 Southwestern Archaeology. 2nd edition. University of Il linois Press, Urbana. 
Mera, H. P.

1935 Ceramic Clues to the Prehistory of North Central New Mexico. Laboratory of Anthropology, Technical Series, Bulletin 8.

* 1943 An Outline of Ceramic Developments in Southern and Southeastern New Mexico. Laboratory of Anthropology. Technical Series, Bulletin 11 .

Moorhead, M. L.

* 1958 New Mexico's Royal Road: Trade and Travel on the Chihuahua Trail. University of Oklahoma Press, Norman.

Mueller, J.W.

1974 The Use of Sampling in Archaeological Survey. Memoirs of the Society for American Archaeology 28.

Nesbitt, P. H.

* 1931 The Ancient Mimbrenos. Based on Investigation at Mattocks Ruin, Mimbres Valley, New Mexico. Logan Museum Bulletin 4. Publications in Anthropology, Beloit College.

* 1938 Starkweather Ruin. A Mogollon-Pueblo Site in the Upper Gila Area of New Mexico and Other Aspects of the Mogollon Culture. Logan Museum Bulletin 6. Publications in Anthropology, Beloit College.

Nie, N. H., C. H. Hul1, J. G. Jenkins, K. Steinbrenner, and D. H. Bent

1975 Statistical Package for the Social Sciences. McGraw-Hi11, New York.

Opler, M. E. and H. Opler

1950 Mescalero Apache History in the Southwest. New Mexico Historical Review 25(1):1-36.

Oppe1t, N. T.

* 1976 Southwestern Pottery: An Annotated Bibliography and List of Types and Wares. Occasional Publications in Anthropology, Archaeology Series No. 7, University of Northern Colorado.

Pheips, A.

1967 Six Stone Bal1s-A Cache. The Artifact 5(1):21-31.

* 1974 An Analysis of the Ceramics of the Guadalupe Mountains National Park. Bulletin of the Texas Archeological Society 45:121-150. 
Quimby, B. and V. R. Brook

* 1967 A Folsom Site Near El Paso, Texas. The Artifact 5(4):31-47.

Redman, C. L.

1973 Research and Theory in Current Archaeology: An Introduction. In: Research and Theory in Current Archaeology (C. L. Redman, ed. ) :5-20.

Reeves, H. C.

1973 Fire in the Management of Vegetation. The Journal of Geography $72(2): 37-37$.

Rinaldo, J. B. and E. A. B Tuhm

* 1956 Late Mogolion Pottery Types of the Reserve Area. Fieldiana: Anthropology 36(7).

Rose, $M$.

* 1970 Deming Ranchette Site Survey. The Artifact 8(4):4-28.

Rumme1, R. J.

1970 Applied Factor Analysis. Northwestern University Press, Evanston.

Runyan, J. W. and J. A. Hedrick

1973 Pottery Types of the SWFAS Area. Transactions of the Eighth Regional Archaeological Symposium for Southeastern New Mexico and Western Texas:19-45.

Russe11, P., Jr.

* 1968 Folsom Complex Near Orogrande, New Mexico. The Artifact 6(2):11-17.

Sayles, E. B.

* 1936 Some Southwestern Pottery Types, Series V. Medallion Papers XXI. Gila Pueblo, Globe.

Sayles, E. B. and E. Antevs

1941 The Cochise Culture. Medallion Papers XXIX. Gila Pueblo, Globe. Schaafsma, C.

1974 The Hatch Site: Archaeological Salvage Excavations on Interstate Highway 25, Dona Ana County, New Mexico. Unpublished manuscript. 
Schaafsma, P.

1972 Rock Art in New Mexico. State Planning Office, Santa Fe. Schroeder, A. H.

1973 The Mescalero Apaches. In: Human Systems Research, Technical Manual 1973: 124-144.

Shepard, A. 0.

* 1965 Ceramics for the Archaeologist. Carnegie Institution of Washington, Washington, D.C.

Shumard, G. G.

* 1859 The Geological Structure of the "Jornada del Muerto," New Mexico. Academy of Science, St. Louis, Transaction 1:341-355.

Skinner, S. A., P. P. Steed, Jr., and S. E. Bearden

1973 Prehistory at Milehigh. Archaeology Research Program, Southern Methodist University, Dallas.

Smiley, T. L. and B. Bannister

* 1953 A Foundation for the Dating of Some Late Archaeological Sites in the Rio Grande Area, New Mexico. Based on Studies in Tree-Ring Methods and Pottery Analysis. University of Arizona Bulletin 24(3), Tucson.

Soil Conservation Service

* 1963 Standard Soil Survey of Jornada Experimental Range, New Mexico. Unpublished.

Sokal, R. R. and F. J. Rohif

1969 Biometry. W. H. Freeman and Company, San Francisco.

Sollberger, J. B. and T. R. Hester

1972 The Strohacker Site: A Review of Pre-Archaic Manifestations in Texas. Plains Anthropologist 17(58), Pt. 1:326-344.

Sommer, A.

* 19741973 SWFAS Early Man Conference. Transactions of the Ninth Regional Archaeological Symposium for Southeastern New Mexico and Western Texas: 109-141.

Sonnichsen, C. L.

1958 The Mescalero Apaches. University of 0k1ahoma Press, Norman. 
Stevenson, M. C.

1904 The Zuni Indians: Their Mythology, Esoteric Fraternities and Ceremonies. Bureau of American Ethnology, Annual Report 1901-02:13-608.

Stross, F. H., T. R. Hester, R. F. Heizer and R. N. Jack

1976 Chemical and Archaeological Studies of Mesoamerican Obsidians. In: Advances in Obsidian Glass Studies: Archaeological and Geochemical Perspectives (R. E. Taylor, ed.): 240-258.

Sudar-Murphy, T. and K. Laumbach

* 1976 A Preliminary Report of an Archaeological Reconnaissance in West Dona Ana County: The North-South Transect. Petty Ray Line No. 1. Cyktural Resources Management Division, Report 41.

Suhm, D. A. and E. B. Jelks

1962 Handbook of Texas Archeology: Type Descriptions. Texas Archeological Society, Special Publication 1 and Texas Memorial Museum. Bulletin 4.

Suhm, D. A., A. D. Krieger, and E. B. Jelks

1954 A Handbook of Texas Archeology. Bulletin of the Texas Archeological Society 25 (whole volume).

Trost, M. W.

1970 An El Paso Polychrome Bow Used as a Mortuary Vesse1. The Artifact 8(3):1-19.

Ungrade, H. E.

* 1972 Guide to the New Mexico Mountains. University of New Mexico Press, Aibuquerque.

Warren, A. H.

* 1970 Notes on Manufacture and Trade of Rio Grande G7azes. The Artifact 8(4): 1-7.

Way, K. L.

n.d. Franklin Mountains Archaeological Reconnaissance Project, 1976. Manuscript at El Paso Centennial Museum; to appear in a volume published by the Natural Areas Survey, Austin. 
We11s, P. V.

1970 Historical Factors Controlling Vegetation Patterns and Floristic Distributions in the Central Plains Region of North America. In: Pleistocene and Recent Environments of the Central Great Plains. Department of Geology, University of Kansas, Special Publication 3:211-221.

Wendorf F. and J. J. Hester (eds.)

1975 Late Pleistocene Environments of the Southern High Plains. Publication of the Fort Burgwin Research Center 9.

Whaten, M. E.

1977 Settlement Patterns of the Eastern Hueco Bolson. Anthropological Paper 4. Centennial Museum, University of Texas at El Paso.

White, L. A.

1962 The Pueblo of Sia, New Mexico. Bureau of American Ethnology, Bulletin 184.

Wilson, J. P. and H. Warren

1973 New Pottery Type Described-Seco Corrugated. Awanyu 1(1):12-13.

Wimberly, M. L. and P. L. Eidenbach

1972 Tularosa Valley Project 1972, Excavations at Fresnal Shelter. Training Bulletin, Human Systems Research, Inc.

Wiseman, R. N.

* 1970 BM III?; P II?. The Artifact 8(3):21-28.

Wormington, H.M.

* 1947 Prehistoric Indians of the Southwest. The Denver Museum of Natural History Popular Series No. 7, Denver.

York, J. C. and W. A. Dick-Peddie

1969 Vegetation Changes in Southern New Mexico During the Past Hundred Years. Arid Lands in Perspective (W. G. McGinnies, ed.): 157-166. University of Arizona Press, Tucson. 